Investigação de métodos de desambiguação lexical de sentidos de verbos do português do Brasil 

Assinatura:

\title{
Marco Antonio Sobrevilla Cabezudo
}

\section{Investigação de métodos de desambiguação lexical de sentidos de verbos do português do Brasil}

\author{
Dissertação apresentada ao Instituto de Ciências \\ Matemáticas e de Computação - ICMC-USP, como \\ parte dos requisitos para obtenção do título de \\ Mestre em Ciências - Ciências de Computação e \\ Matemática Computacional. VERSÃO REVISADA \\ Área de Concentração: Ciências de Computação e \\ Matemática Computacional \\ Orientador: Prof. Dr. Thiago Alexandre Salgueiro \\ Pardo
}


Ficha catalográfica elaborada pela Biblioteca Prof. Achille Bassi e Seção Técnica de Informática, ICMC/USP, com os dados fornecidos pelo(a) autor(a)

\begin{tabular}{|c|c|}
\hline \multirow[t]{3}{*}{ S677i } & $\begin{array}{l}\text { Sobrevilla Cabezudo, Marco Antonio } \\
\text { Investigação de métodos de desambiguação lexical } \\
\text { de sentidos de verbos do português do Brasil / } \\
\text { Marco Antonio Sobrevilla Cabezudo; orientador } \\
\text { Thiago Alexandre Salgueiro Pardo. -- São Carlos, } \\
2015 . \\
134 \text { p. }\end{array}$ \\
\hline & $\begin{array}{l}\text { Dissertação (Mestrado - Programa de Pós-Graduação } \\
\text { em Ciências de Computação e Matemática } \\
\text { Computacional) -- Instituto de Ciências Matemáticas } \\
\text { e de Computação, Universidade de São Paulo, } 2015 .\end{array}$ \\
\hline & $\begin{array}{l}\text { 1. Investigação de Métodos de Desambiguação } \\
\text { Lexical de Sentidos de Verbos do Português do } \\
\text { Brasil. 2. Processamento da Língua Natural. I. } \\
\text { Salgueiro Pardo, Thiago Alexandre, orient. II. }\end{array}$ \\
\hline
\end{tabular}


Marco Antonio Sobrevilla Cabezudo

\title{
Research of word sense disambiguation methods for verbs in brazilian portuguese
}

\begin{abstract}
Master dissertation submitted to the Instituto de Ciências Matemáticas e de Computação - ICMCUSP, in partial fulfillment of the requirements for the degree of the Master Program in Computer Science and Computational Mathematics. FINAL VERSION

Concentration Area: Computer Science and Computational Mathematics

Advisor: Prof. Dr. Thiago Alexandre Salgueiro Pardo
\end{abstract}



Tudo o que fizerem, façam de todo o coração, como para o Senhor, e não para os homens, sabendo que receberão do Senhor a recompensa da herança. É a Cristo, o Senhor, que vocês estão servindo.

Colosenses 3:23-24 



\section{Agradecimentos}

Agradeço, primeiramente, a Deus, porque Ele cuidou de mim e permitiu que aprendesse muito, conhecesse muitas pessoas maravilhosas e atingir esta meta. Hoje eu posso dizer "Até aqui o Senhor nos ajudou".

À minha família, por sua paciência, seu apoio incondicional, suas orações e por ter me abraçado com seu amor em todo este tempo. Especialmente, a minha mãe Angela Isabel, minha irmã Mayra e minha avó Victoria. "Gordas, esto va para ustedes, las amo!".

Ao meu orientador, Prof. Thiago Pardo, pela confiança, apoio e ensino ao longo deste projeto. Por ter me provocado para eu conseguir chegar mais longe do que eu pensei que poderia.

A minha noiva Katherine, por ter compartilhado comigo este caminhar, não de maneira física, mas sim no pensamento, nas orações e no ânimo. Obrigado por teu amor incondicional neste tempo cachetona.

Aos meus colegas e amigos do NILC, pelo tempo de aprendizado juntos (e aprendi muito), de descontração e pela amizade mostrada.

Aos meus amigos da Igreja Metodista em São Carlos, por sua amizade, suas orações, por ter me dado mais do que eu tivesse esperado. Especialmente ao Pr. Levi Fernandes, Epaphras, Marcela, Valdemar, Elard, José e Rosalia. Obrigado família!

Aos meus amigos peruanos no Brasil, que com suas piadas, momentos de discussão e compartilhar fizeram minha estância no Brasil mais fácil.

À SAMSUNG Eletrônica da Amazônia LTDA e a CAPES, pelo apoio financeiro prestado ao meu mestrado. 



\section{Resumo}

A Desambiguação Lexical de Sentido (DLS) consiste em determinar o sentido mais apropriado da palavra em um contexto determinado, utilizando-se um repositório de sentidos préespecificado. Esta tarefa é importante para outras aplicações, por exemplo, a tradução automática. Para o inglês, a DLS tem sido amplamente explorada, utilizando diferentes abordagens e técnicas, contudo, esta tarefa ainda é um desafio para os pesquisadores em semântica. Analisando os resultados dos métodos por classes gramaticais, nota-se que todas as classes não apresentam os mesmos resultados, sendo que os verbos são os que apresentam os piores resultados. Estudos ressaltam que os métodos de DLS usam informações superficiais e os verbos precisam de informação mais profunda para sua desambiguação, como frames sintáticos ou restrições seletivas. Para o português, existem poucos trabalhos nesta área e só recentemente tem-se investigado métodos de uso geral. Além disso, salienta-se que, nos últimos anos, têm sido desenvolvidos recursos lexicais focados nos verbos. Nesse contexto, neste trabalho de mestrado, visou-se investigar métodos de DLS de verbos em textos escritos em português do Brasil. Em particular, foram explorados alguns métodos tradicionais da área e, posteriormente, foi incorporado conhecimento linguístico proveniente da Verbnet.Br. Para subsidiar esta investigação, o córpus CSTNews foi anotado com sentidos de verbos usando a WordNet-Pr como repositório de sentidos. Os resultados obtidos mostraram que os métodos de DLS investigados não conseguiram superar o baseline mais forte e que a incorporação de conhecimento da VerbNet.Br produziu melhorias nos métodos, porém, estas melhorias não foram estatisticamente significantes. Algumas contribuições deste trabalho de mestrado foram um córpus anotado com sentidos de verbos, a criação de uma ferramenta que auxilie a anotação de sentidos, a investigação de métodos de DLS e o uso de informações especificas de verbos (provenientes da VerbNet.Br) na DLS de verbos.

Palavras-chave: Desambiguação Lexical de Sentido, Processamento da Linguagem Natural, Linguística Computacional. 


\begin{abstract}
Word Sense Disambiguation (WSD) aims at identifying the appropriate sense of a word in a given context, using a pre-specified sense-repository. This task is important to other applications as Machine Translation. For English, WSD has been widely studied, using different approaches and techniques, however, this task is still a challenge for researchers in Semantics. Analyzing the performance of different methods by the morphosyntactic class, note that not all classes have the same results, and the worst results are obtained for Verbs. Studies highlight that WSD methods use shallow information and Verbs need deeper information for its disambiguation, like syntactic frames or selectional restrictions. For Portuguese, there are few works in WSD and, recently, some works for general purpose. In addition, it is noted that, recently, have been developed lexical resources focused on Verbs. In this context, this master work aimed at researching WSD methods for verbs in texts written in Brazilian Portuguese. In particular, traditional WSD methods were explored and, subsequently, linguistic knowledge of VerbNet.Br was incorporated in these methods. To support this research, CSTNews corpus was annotated with verb senses using the WordNet-Pr as a sense-repository. The results showed that explored WSD methods did not outperform the hard baseline and the incorporation of VerbNet.Br knowledge yielded improvements in the methods, however, these improvements were not statistically significant. Some contributions of this work were the sense-annotated corpus, the creation of a tool for support the sense-annotation, the research of WSD methods for verbs and the use of specific information of verbs (from VerbNet.Br) in the WSD of verbs.
\end{abstract}

Keywords: Word Sense Disambiguation, Natural Language Processing, Computional Linguistics. 


\section{Publicações}

Como resultado da pesquisa feita neste trabalho de mestrado, até o momento foram publicados os seguintes artigos e relatórios técnicos:

- Marco Sobrevilla-Cabezudo, Erick Maziero, Jackson Souza, Márcio Dias, Paula Cardoso, Pedro Balage, Verónica Agostini, Fernando Nóbrega, Cláudia Dias De Barros, Ariani Di Felippo, and Thiago Pardo. (2014). Anotação de Sentidos de Verbos em Notícias Jornalísticas em Português do Brasil. In the Proceedings of the XII Encontro de Linguística de Corpus - ELC. Uberlândia-MG/Brazil. Sobrevilla-Cabezudo

- Marco Sobrevilla-Cabezudo, Erick Maziero, Jackson Souza, Márcio Dias, Paula Cardoso, Pedro Balage, Verónica Agostini, Fernando Nóbrega, Cláudia Dias De Barros, Ariani Di Felippo, and Thiago Pardo. (2014). Anotação de Sentidos de Verbos em Notícias Jornalísticos em Português do Brasil. Série de Relatórios Técnicos do Instituto de Ciências Matemáticas e de Computação, Universidade de São Paulo. NILC - TR - 14 - 05. São Carlos, SP.

- Roque López, Lucas Avanço, Pedro Balage, Alessandro Bokan, Paula Cardoso, Márcio Dias, Fernando Nóbrega, Marco Sobrevilla-Cabezudo, Jackson Souza, Andressa Zacarias, Ariani Di Felippo, Eloize Seno e Thiago Pardo. A Qualitative Analysis of a Corpus of Opinion Summaries based on Aspects. In the Proceedings of the IX Linguistic Annotation Workshop (LAW-2015). Colorado, USA.

- Márcio Dias, Alessandro Bokan, Carla Chuman, Cláudia Barros, Erick Maziero, Fernando Nobrega, Jackson Souza, Marco Sobrevilla, Marina Delege, Lucía Castro, Naira Silva, Paula Cardoso, Pedro Balage, Roque López, Vanessa Marcasso, Ariani Felippo, Maria Graças e Thiago Pardo. Enriquecendo o Corpus CSTNews - a Criação de Novos Sumários Multidocumento. In the Proceedings of the I Workshop on Tools and Resources for Automatically Processing Portuguese and Spanish (ToRPorEsp-2014). São Carlos, Brazil.

- Marco Sobrevilla e Thiago Pardo. (2015). Exploratory Study of Word Sense Disambiguation Methods for Verbs in Brazilian Portuguese. 16th International Conference on Intelligent Text Processing and Computational Linguistics - CICLing 2015. Egypt. (to appear) 


\section{Sumário}

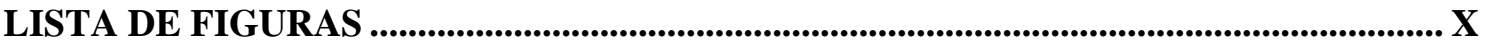

LISTA DE TABELAS........................................................................................................................ XII

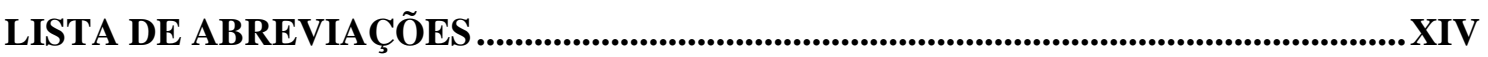

1. INTRODUÇÃ

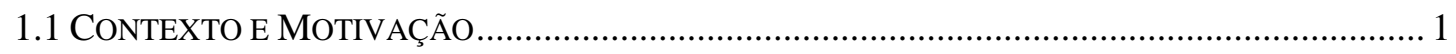

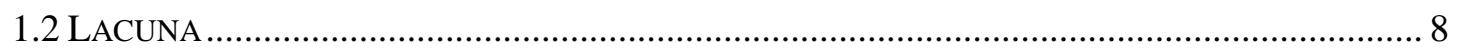

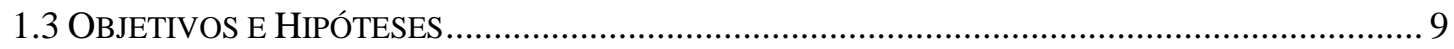

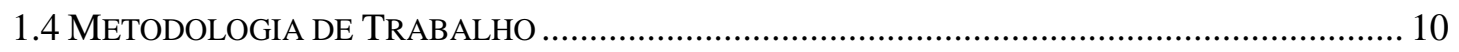

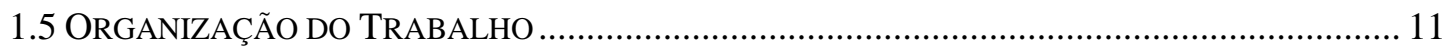

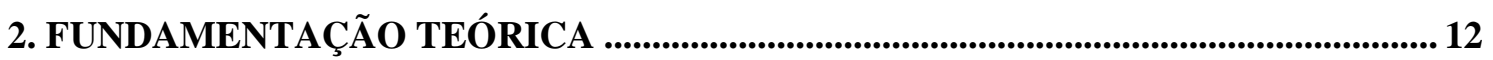

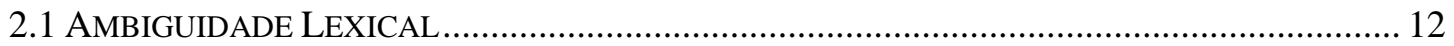

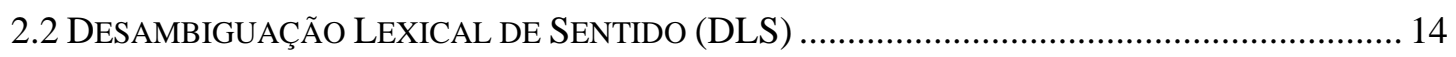

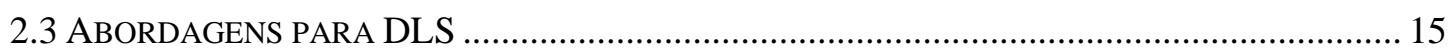

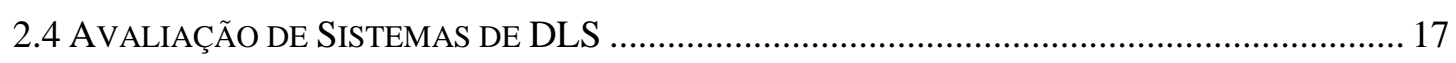

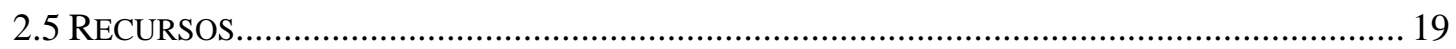

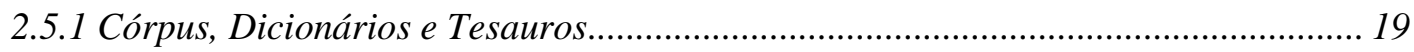

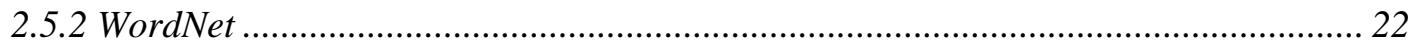

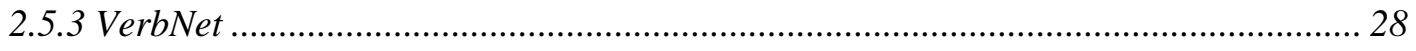

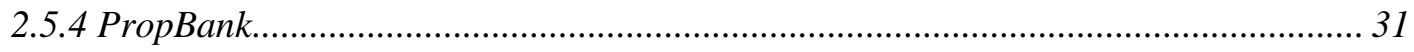

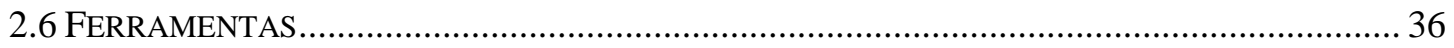

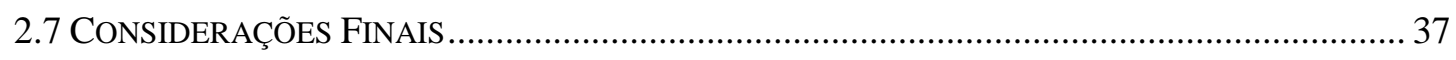

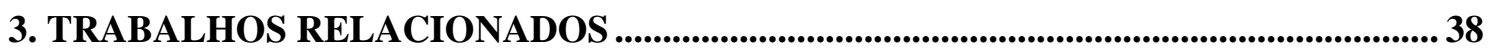

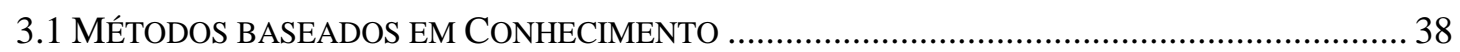

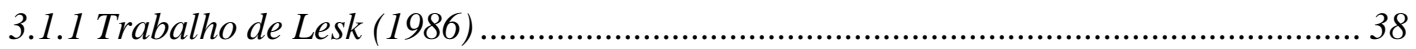

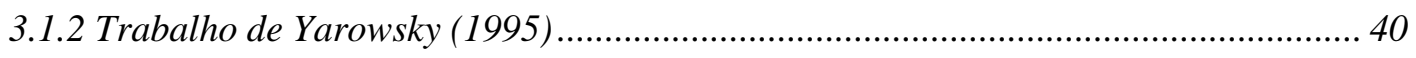

3.1.3 Trabalho de Killgarriff et al. (2000) .......................................................................... 40

3.1.4 Trabalho de Banerjee e Pedersen (2002)................................................................ 41 


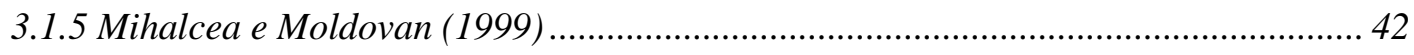

3.1.6 Trabalho de Sinha e Mihalcea (2007)......................................................................... 44

3.1.7 Trabalho de Roberts e Kordoni (2012) ................................................................... 47

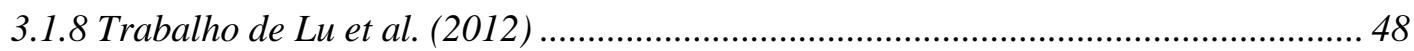

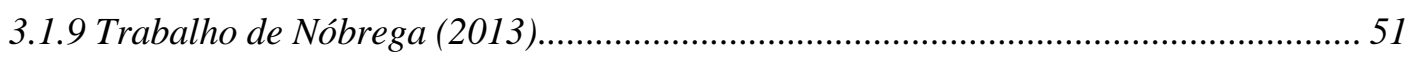

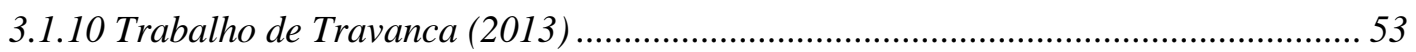

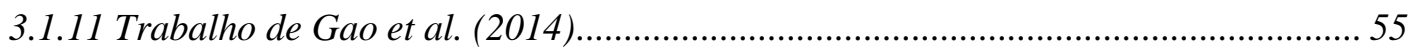

3.1.12 Trabalho de Agirre et al. (2014) e Agirre e Soroa (2009) ...................................... 56

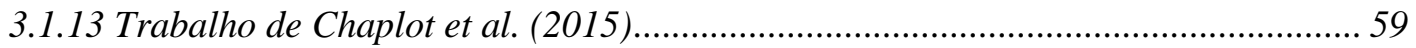

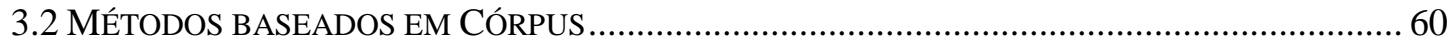

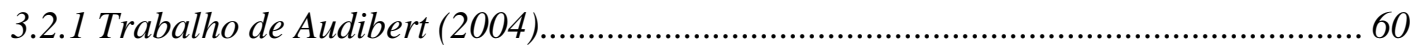

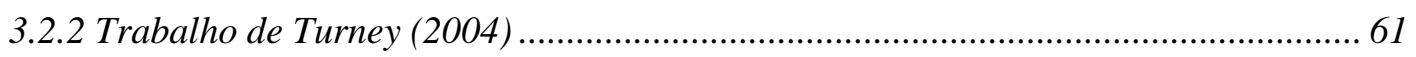

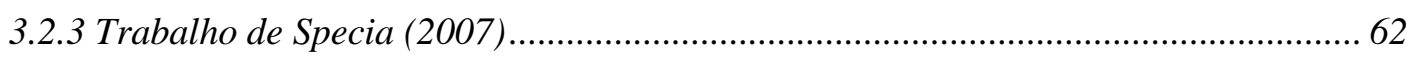

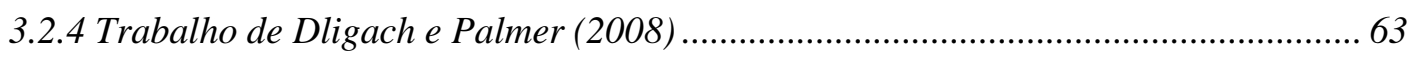

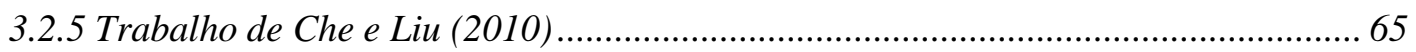

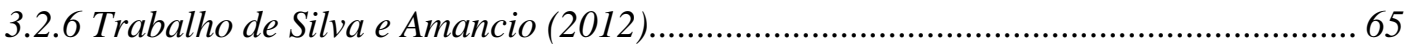

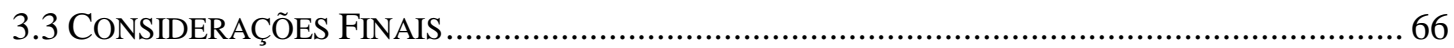

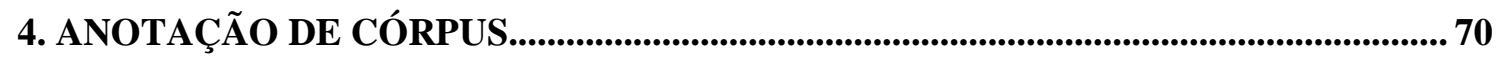

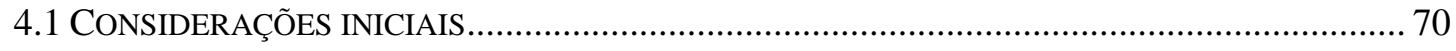

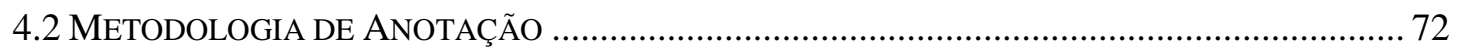

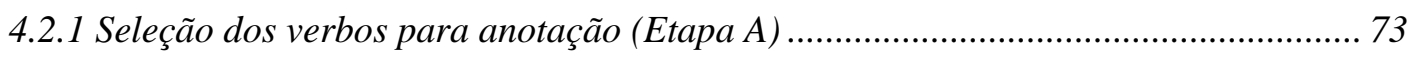

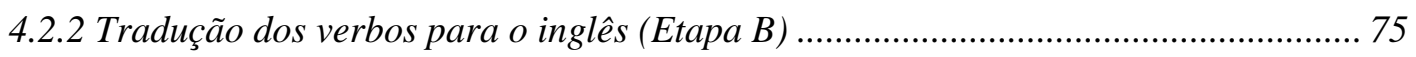

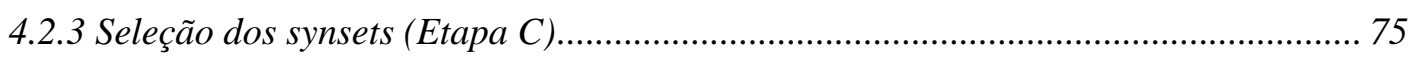

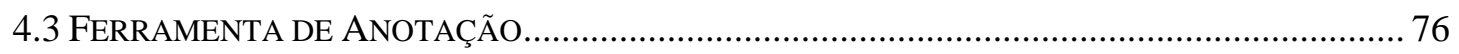

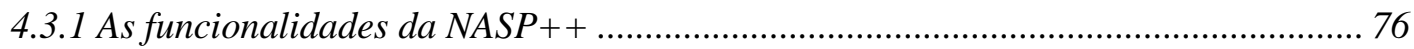

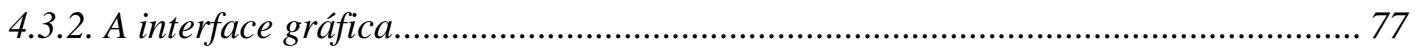

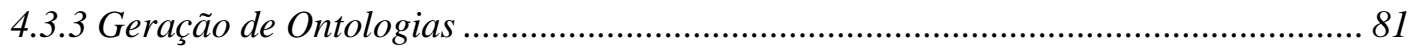

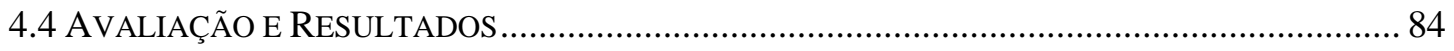

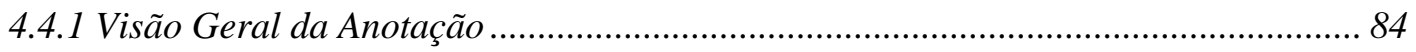

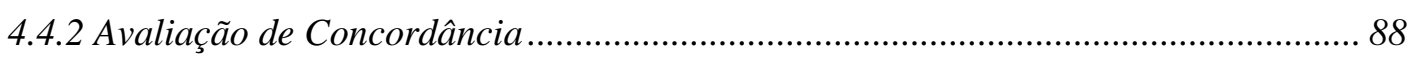

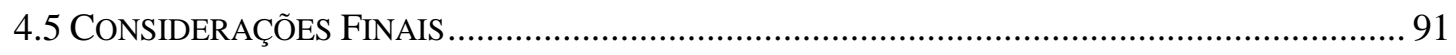

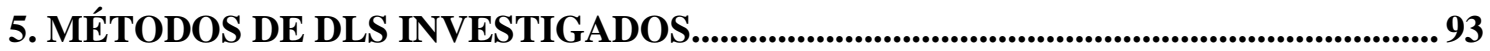

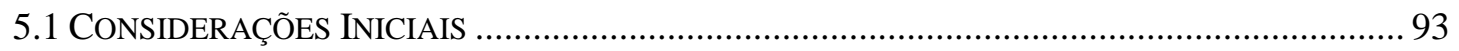

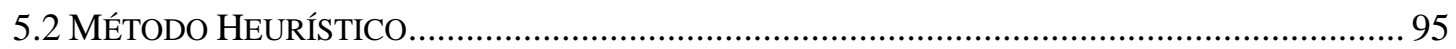

5.3 MÉTOdo BASEAdO EM SOBREPOSIÇÃO DE PALAVRAS ………………………………...... 95

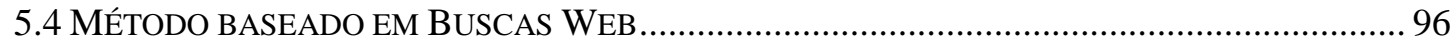

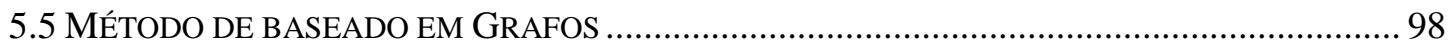




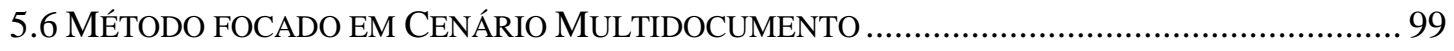

5.7 INCORPORAÇÃO DE CONHECIMENTO DA VERBNET.BR ….............................................. 101

5.7.1 Agrupamento de verbos segundo Classes da VerbNet.Br ........................................ 101

5.7.2 Refinamento do agrupamento de verbos usando informações sintáticas.................. 102

5.7.3 Enriquecimento de Contextos nos métodos de DLS explorados .............................. 104

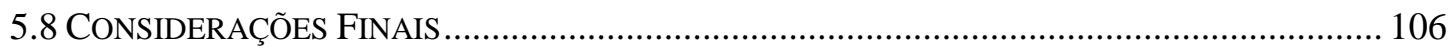

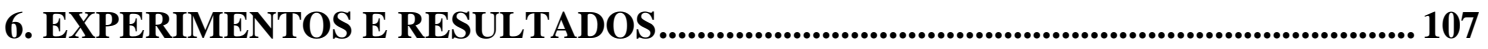

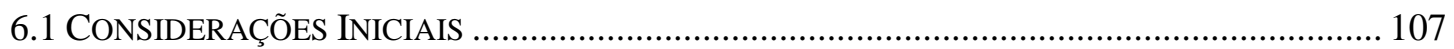

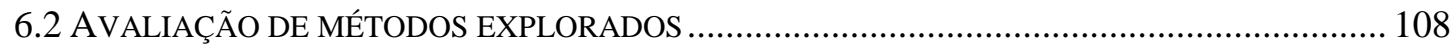

6.3 AVALIAÇÃO DE INCORPORAÇÃO DE CONHECIMENTO DA VERBNET.BR ............................ 114

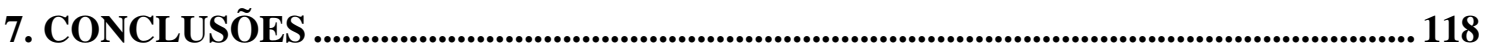

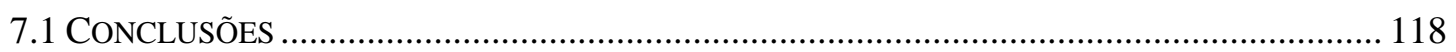

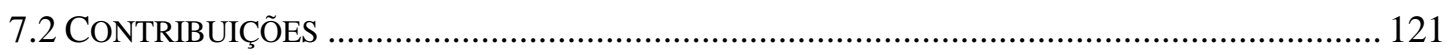

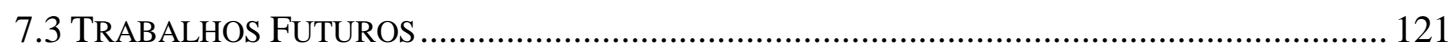

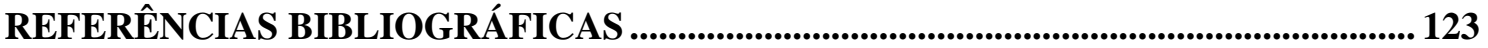




\section{Lista de Figuras}

FIGURA 1.1: ABSTRAÇÃO E COMPLEXIDADE DOS NÍVEIS DE CONHECIMENTO LINGUÍSTICO. ....... 2

FIGURA 2.1: ESQUEMA DOS ALGORITMOS DE DESAMBIGUAÇÃO LEXICAL DO SENTIDO. 14

FIGURA 2.2: EXEMPLO DO CLUSTER FORMADO PELOS ANTÔNIMOS “WET” E “DRY” NA

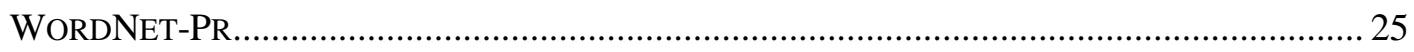

FIGURA 2.3: HIERARQUIA DE CLASSES NA VERBNET PARA A CLASSE THROW-17.1 .................... 29

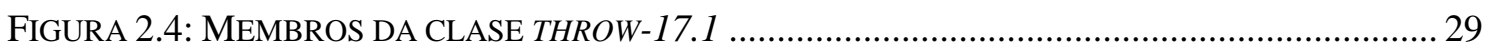

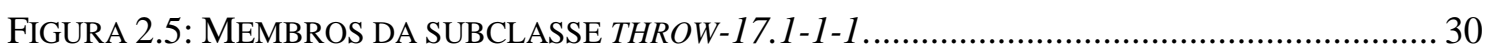

FigURA 2.6: PAPÉIS SEMÂNTICOS E RESTRIÇÕES DE SELEÇÃO DA CLASSE THROW-17.1 .............. 30

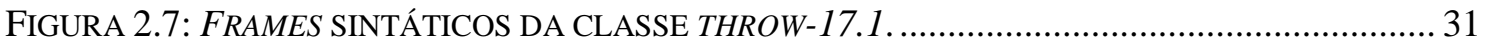

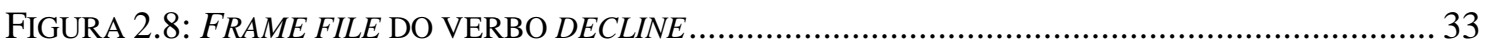

FIGURA 2.9: EXEMPLO DE FRAME FILE DO VERBO GANHAR. ................................................. 35

FIGURA 3.1: GRAFO DE RELAÇÕES GERADO PARA A SENTENÇA “THE FIGHTER BROKE HIS ARM"

FIGURA 3.2: GRAFO DE CO-OCORRÊNCIA DA PALAVRA “AVIÃO”. EXTRAÍDO DE NÓBREGA (2013)

FigURA 3.3: LINHA DO TEMPO DE TRABALHOS RELACIONADOS À DESAMBIGUAÇÃO LEXICAL

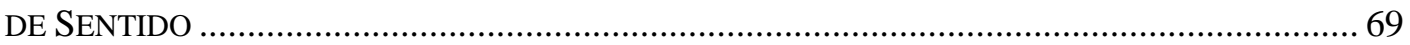

FIGURA 4.1: PERCENTUAL DE OCORRÊNCIA NO CÓRPUS POR CLASSE MORFOSSINTÁTICA. ......... 71

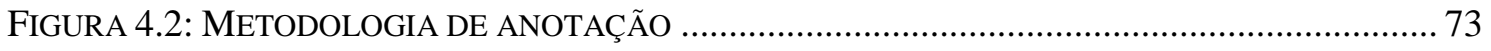

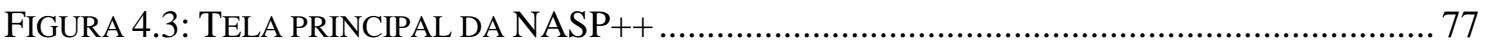

FIGURA 4.4: EXEMPLO DE ANOTAÇÃO DO VERBO “MORRER” NA NASP++ ................................. 78

FIGURA 4.5: VISUALIZADOR DE TEXTOS COM O VERBO “MORRER” PREVIAMENTE ANOTADO ... 79

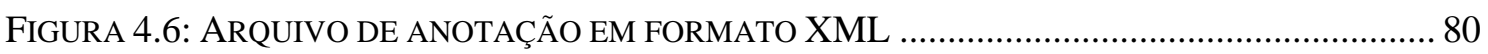

FIGURA 4.7: HIERARQUIAS CONCEITUAIS DAS COLEÇÕES C1 E C2 ….......................................... 82

FIGURA 4.8: HIERARQUIA GERADA PARA UM SYNSET DO VERBO “MORRER” "................................ 83

FIGURA 4.9: HIERARQUIA GERADA PARA UM SYNSET DO VERBO “MATAR” .................................. 83

FIGURA 4.10: EXEMPLO DE UNIFICAÇÃO DE HIERARQUIAS PARCIAIS ......................................... 83

FIGURA 4.11: DISTRIBUIÇÃO DE SYNSETS POR VERBO DIFERENTE NO CÓRPUS.............................. 85 
FIGURA 4.12: DISTRIBUIÇÃO DE SYNSETS POR VERBO DIFERENTE NAS COLEÇÕES DO CÓRPUS... 86

FIGURA 4.13: DISTRIBUIÇÃO DO NÚMERO DE VERBOS DIFERENTES POR NÚMERO DE POSSÍVEIS SYNSETS

FiguRA 5.1: MÉTODO DE OBTENÇÃO DOS SYNSETS DA WORDNET-PR PARA O VERBO “REUNIR”94

FIGURA 5.2: REPRESENTAÇÃO DE UMA PARTE DO PARÁGRAFO PARA A DESAMBIGUAÇÃO DA PALAVRA "REUNIR"

FIGURA 5.3: GRAFO GERADO A PARTIR DA SEQUÊNCIA “QUINTA-FEIRA”, “REUNIR”, “HORA”, "DECIDIR", E “ACEITAR" 100

FIGURA 5.4: GRAFO DE CO-OCORRÊNCIA GERADO PARA O VERBO “REUNIR" 101

FiguRA 5.5: Classes DA VERBNET.BR POSSÍVEIS PARA CADA VERBO 102

FiguRA 5.6: ESTRUTURA ARGUMENTAL DA SENTENÇA DE EXEMPLO PARA O VERBO “REUNIR"

FIGURA 5.7: MAPEAMENTO ENTRE A SAÍDA DO ANOTADOR DE PAPÉIS SEMÂNTICOS E A ESTRUTURA SINTÁTICA APRESENTADA NO PARSER PALAVRAS 104

FIGURA 5.8: GRAFO DE CO-OCORRÊNCIA GERADO JUNTANDO TODOS OS VERBOS INCLUÍDOS EM UMA MESMA CLASSE DA VERBNET.BR 106 


\section{Lista de Tabelas}

TABELA 1.1: LISTA DE 2 SENTIDOS ADVINDOS DA WORDNET-BR PARA O VERBO “CORRER”. ..... 4

TABela 1.2: ACURÁCIAS obTidas nos trabalhos de BANERJeE E PEDERSEN (2002) E

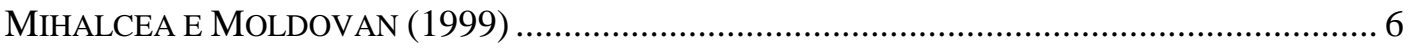

TABELA 2.1: LISTA DE UNIQUE BEGINNERS DE SUBSTANTIVOS DA WORDNET-PR....................... 24

TABELA 2.2: LISTA DE DOMÍNIOS SEMÂNTICOS DE VERBOS DA WORDNET-PR............................ 26

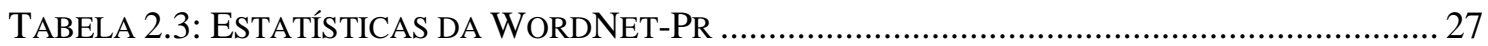

TABELA 2.4: MÉDIA DE SENTIDOS POR PALAVRA SEGUNDO CLASSES GRAMATICAIS NA

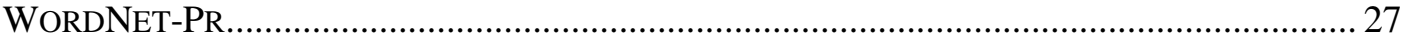

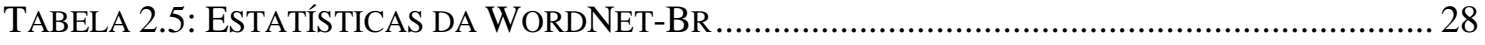

TABELA 2.6: MÉDIA DE SENTIDOS POR PALAVRA SEGUNDO CLASSES GRAMATICAIS NA

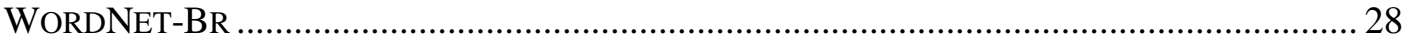

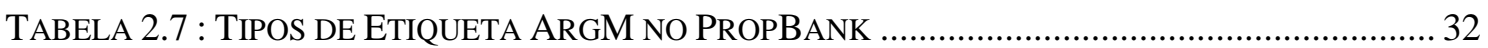

TABELA 2.8: ESTADO ATUAL DA ANOTAÇÃO DO PROPBANK ……................................................. 34

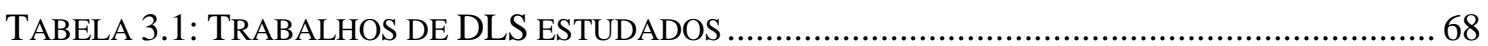

TABELA 4.1: ESTATÍSTICAS DA ANOTAÇÃO DE VERBOS DO CÓRPUS CSTNEWS .......................... 84

TABELA 4.2: VARIAÇÃO DE NÚMERO DE SYNSETS PARA SUBSTANTIVOS E VERBOS ...................... 86

TABELA 4.3: COMPARAÇÃO DA DISTRIBUIÇÃO DE POSSÍVEIS SYNSETS POR SUBSTANTIVOS E

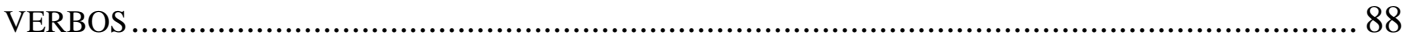

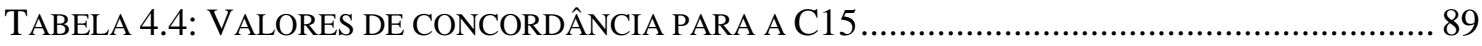

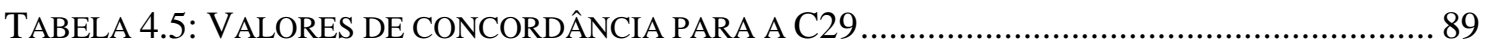

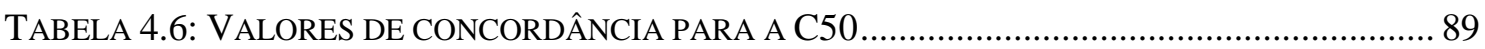

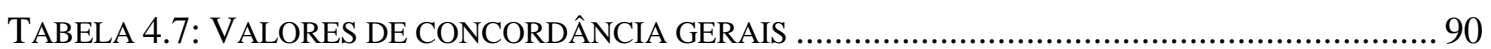

TABELA 4.8: VALORES DE CONCORDÂNCIA DA ANOTAÇÃO FEITA POR NÓBREGA (2013) .......... 90

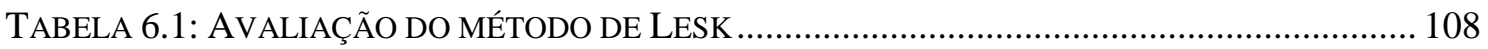

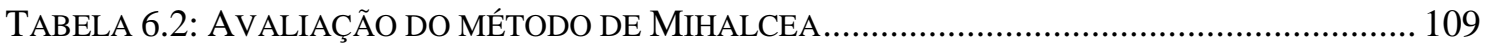

TABELA 6.3: AVALIAÇÃO DO MÉTODO DE AGIRRE E SOROA..................................................... 110

TABELA 6.4: AVALIAÇÃO DO MÉTODO DE NÓBREGA ………...................................................... 110 
TABELA 6.5: RESULTADOS GERAIS PARA A TAREFA ALL-WORDS. 111

TABELA 6.6: AVALIAÇÃO DA TAREFA LEXICAL SAMPLE. 113

TABELA 6.7: RESULTADOS DA TAREFA ALL-WORDS PARA OS SUBSTANTIVOS. 113

TABELA 6.8: RESULTADOS OBTIDOS NAS VARIAÇÕES DO MÉTODO DE LESK 115

TABELA 6.9: RESULTADOS OBTIDOS NAS VARIAÇÕES DO MÉTODO DE NÓBREGA.. 116 


\section{Lista de Abreviações}

DLS

PLN

AM

NASP

IDC

WSD

$\mathbf{L}^{2} \mathbf{F}$

Desambiguação Lexical de Sentido

Processamento de Linguagem Natural

Aprendizado de Má quina

Nilc Anotador de Sentidos para o Português

International Data Consortium

Word Sense Disambiguation

Laboratório de sistemas de Língua Falada 


\section{Introdução}

\subsection{Contexto e Motivação}

Atualmente, a quantidade de informações produzidas na Web, principalmente as não estruturadas, têm crescido aceleradamente. Um estudo realizado por Turner et al. (2014) no artigo publicado pela IDC (International Data Corporation) mostra que, até finais do 2013, foram criados e replicados $4.4 \mathrm{ZB}$ de dados. Este crescimento tem ocorrido como produto da evolução das tecnologias da informação e a chegada da Web 2.0, que fomenta a participação dos usuários de internet na criação de conteúdo.

A área de Processamento da Linguagem Natural (PLN) é a área que lida com o processamento computacional de informação expressada em língua natural, com o fim de habilitar os computadores com a capacidade de compreender textos escritos por humanos e produzir textos em uma linguagem familiar para os humanos.

Aplicações de PLN podem empregar diversos níveis de conhecimento linguístico, como fonética/fonologia, morfologia, sintaxe, semântica, discurso e pragmática (Jurafsky e Martin, 2009) para o tratamento dessas informações. Na Figura 1.1, apresenta-se a ordem dos níveis de conhecimento linguístico, segundo a complexidade de tratamento e a abstração das informações que possuem. Os conhecimentos em níveis superiores têm uma complexidade e um nível de abstração maior É por isso que aplicações que usam conhecimentos desses níveis são consideradas como aplicações de abordagens profundas e as que usam conhecimentos em níveis inferiores são consideradas como aplicações de abordagens superficiais. 


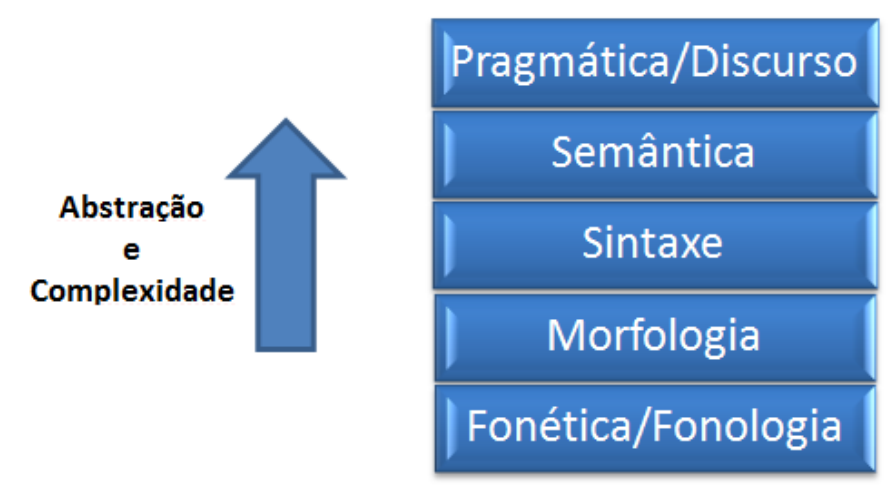

Figura 1.1: Abstração e complexidade dos níveis de conhecimento linguístico. Extraído e adaptado de Nóbrega (2013)

No atual cenário, com a quantidade crescente de informação e a necessidade de formas mais inteligentes de aprender e processar tanta informação, a semântica, que lida com o significado em seus vários níveis, está na vanguarda dos interesses de pesquisa da comunidade de PLN, sendo importante para a melhor interpretação do conteúdo textual, com a finalidade de produzir ferramentas e sistemas computacionais com melhor desempenho. Dentre os problemas associados ao nível semântico, a ambiguidade lexical é um dos mais importantes a resolver, pois algumas palavras podem ter duas ou mais interpretações segundo a sentença de contexto onde estão localizadas. Por exemplo, veja as sentenças a seguir:

1. "O homem contou os fatos acontecidos."

2. "Ele bateu a bola com pouca força".

3. "Ele bateu as botas."

4. "O banco quebrou na semana passada"

Na sentença 1, do ponto de vista humano, a identificação do sentido do verbo "contar" não apresenta dúvida. Já do ponto de vista computacional, apresenta ambiguidade, já que o computador teria que identificar se é o sentido de "narrar" ou de "enumerar". Da mesma forma, do ponto de vista do humano, a sentença 2 não apresenta dúvida na identificação do sentido do verbo "bater" (que seria “dar pancada") . Já na sentença 3, se consideramos só o verbo "bater", se poderia inferir que apresenta o sentido de "sacudir", mas se consideramos a expressão "bater as botas", teria o sentido de "morrer". Do ponto de vista computacional, o verbo "bater" é difícil de desambiguar nas duas sentenças. Por fim, na última sentença, tanto para o humano quanto para o computador, não se poderia determinar o sentido da palavra "quebrar", que poderia ser "falir financeiramente" ou "fazer-se em pedaços", já que é necessário conhecer melhor o contexto. Como se tem visto, em alguns casos, determinar o sentido correto de uma palavra pode ser relativamente fácil, mas, por exemplo, nas últimas 2 sentenças, precisa-se de 
um contexto maior para poder determinar o sentido correto. Isto nos faz pensar que se, para um humano a tarefa pode tornar-se difícil, para um computador é ainda mais difícil.

A tarefa cujo objetivo é tratar a ambiguidade lexical e escolher o sentido mais adequado para uma palavra dentro de um contexto (sentença, usualmente) é chamada Desambiguação Lexical de Sentido (DLS). Na forma mais básica, os métodos de DLS recebem como entrada uma palavra (chamada "palavra alvo"), um contexto onde está incluída esta palavra (limitado por uma sentença ou uma porção de texto maior) e um conjunto fixo de potenciais sentidos, chamado repositório de sentidos (RS); e devem retornar o sentido correto que corresponde à palavra alvo (Jurafsky e Martin, 2009). Como exemplo, considere a primeira sentença mencionada no parágrafo anterior "o homem contou os fatos acontecidos.", na qual a DLS indicaria que a palavra "contou" refere-se ao sentido de "narrar" (e não "enumerar"). Em geral, utiliza-se um repositório de sentidos que forneça todas as opções de sentidos possíveis para cada palavra, e o método de DLS empregado elege o sentido mais adequado dentre os disponíveis.

Os repositórios de sentidos são estruturas computacionalmente tratáveis, compostos minimamente por pares de palavras e seus respectivos sentidos. Exemplos desses repositórios são os dicionários, os tesauros e as wordnets, entre outros, sendo as wordnets usadas com maior frequência. As wordnets estão organizadas por conjuntos de sinônimos, denominados synsets, que representam os sentidos das palavras e estão compostos por conjuntos de palavras sinônimas; uma glosa, que é uma descrição do synset; exemplos (nem sempre), compostos por sentenças que empregam as palavras do conjunto de sinônimos; e relações semânticas com outros synsets. A wordnet mais usada na literatura, e a primeira, é a WordNet de Princeton (WordNet-Pr ${ }^{1}$ ) (Fellbaum, 1998), que foi construída para o idioma inglês. Para o português brasileiro, foi construída a WordNet-Br (Dias Da Silva, 2005). A WordNet-Br está alinhada com a WordNet-Pr por meio dos identificadores dos synsets. Na Tabela 1.1, apresentam-se dois sentidos da palavra "correr" (só apresentando 2 exemplos para cada sentido), advindos da WordNet-Br. O primeiro sentido faz referência a mover-se rapidamente e, o segundo, a moverse adiante.

\footnotetext{
${ }^{1}$ Disponível em http://wordnet.princeton.edu/
} 


\begin{tabular}{|c|c|}
\hline Sentido 1 & \\
\hline Synset: & Correr, disparar, voar \\
\hline Glosa: & Mover-se rapidamente ou repentinamente \\
\hline Exemplos: & $\begin{array}{l}\text { - Ele era todo felicidade e logo correu ao seu encontro, mas ao se } \\
\text { aproximar, percebeu que algo havia acontecido...ela estava diferente., -- } \\
\text { (Fonte: Corpus NILC) } \\
\text { - Logo, a turma correu para o ônibus, que disparou em direção à nova } \\
\text { morada do nosso futebol, auspiciosamente denominada de Villa Felice., -- } \\
\text { (Fonte: Corpus NILC) }\end{array}$ \\
\hline
\end{tabular}

\begin{tabular}{|c|c|}
\hline Sentido 2 & \\
\hline Synset: & Correr, defluir, desenrolar-se, deslizar, escorrer, ir, passar \\
\hline Glosa: & Mover-se para diante \\
\hline Exemplos: & $\begin{array}{l}\text { - O rio Paraíba corria bem próximo ao cercado., -- (Fonte: Internet) } \\
\text { - As várias usinas hidroelétricas são representadas de forma agregada em } \\
\text { um único reservatório equivalente, ao qual aflui e do qual deflui energia } \\
\text { ao invés de água., -- (Fonte: Internet) }\end{array}$ \\
\hline
\end{tabular}

Tabela 1.1: Lista de 2 sentidos advindos da WordNet-Br para o verbo "correr". Extraído da WordNet-Br

A DLS é uma tarefa necessária e importante para outras análises nas tarefas de PLN, tais como a análise sintática e a análise semântica, e também para o desenvolvimento de aplicações finais, como descrito no trabalho de Ide e Verónis (1998). Algumas das aplicações mencionadas são as seguintes: a classificação de textos, na qual se poderia analisar melhor o conteúdo e gerar melhores atributos a usar em classificadores de textos; a tradução automática, já que, dependendo do contexto, palavras podem ter traduções completamente diferentes, por exemplo, "dedo do pé" seria traduzido no inglês como "toe" e "dedo da mão" seria traduzido como "finger", então a desambiguação poderia ajudar a escolher melhores candidatos de traduções; e a recuperação de informação, na qual a desambiguação de documentos base junto com uma possível desambiguação das palavras de consulta permitiria eliminar documentos que contivessem as mesmas palavras com diferentes significados e recuperar documentos expressando o mesmo significado com diferentes palavras. Outra aplicação que poderia beneficiar-se da DLS é a análise de sentimento (Akkaya et al., 2009), já que, conhecendo o sentido correto de uma palavra em um contexto, poderíamos inferir se faz referência a uma opinião negativa ou positiva, ou também se poderia inferir se os textos escritos são opiniões ou não. 
Os métodos de DLS, segundo a abordagem que seguem, podem ser classificados em métodos baseados em conhecimento, métodos baseados em córpus e métodos híbridos. Os métodos baseados em conhecimento são caracterizados por usar fontes de conhecimento, tais como dicionários, tesauros, ontologias e bases de dados lexicais, como bases de conhecimento para a desambiguação e medidas de similaridade para encontrar atribuir os sentidos. Os métodos baseados em córpus fazem uso de córpus e técnicas de aprendizado de máquina para gerar modelos que depois possam ser usados na desambiguação de sentidos. Por fim, métodos híbridos combinam características das duas abordagens anteriores.

Para a língua inglesa, existem muitos trabalhos em DLS (veja, por exemplo, o survey realizado por Navigli (2009)), utilizando-se diferentes abordagens e paradigmas. Segundo Gao et al. (2014), só recentemente, métodos de DLS que seguem uma abordagem baseada em conhecimento têm se tornados populares. Apesar dos autores não mencionarem razões para isso, podem-se inferir algumas razões, por exemplo: o aumento da necessidade de métodos capazes de integrar-se em outras ferramentas ou aplicações (de uso geral), e a disponibilidade dos recursos, tais como repositórios de sentidos, que permitem ajudar na melhora dos métodos atuais.

Apesar dos métodos de DLS baseados em conhecimento terem-se tornado populares e avançado, os resultados não são os suficientemente satisfatórios, mostrando que é a DLS é ainda uma tarefa difícil de resolver. Analisando os resultados dos diversos métodos segundo a classe gramatical, salienta-se que os métodos tradicionais de DLS não obtêm os mesmos níveis de acurácia em todas as classes gramaticais. A maioria deles apresenta resultados pouco satisfatórios, principalmente, na classe gramatical do verbo. Por exemplo, veja na Tabela 1.2 os resultados do trabalho de Banerjee e Pedersen (2002) e Mihalcea e Moldovan (1999). Como pode ser visto, a tarefa de DLS nos verbos apresenta os piores resultados $(24.9 \%$ e $60 \%$ em acurácia), comparados com outras classes gramaticais, por exemplo, os substantivos $(32.2 \%$ e $76 \%$ em acurácia). Uma estratégica comum para a desambiguação de substantivos consiste da análise das palavras em um contexto do substantivo ambíguo. Porém, os verbos requerem outras fontes de conhecimento mais específicas e, em geral, mais elaboradas que simples atributos contextuais. Estudos realizados mostram que informações sintáticas e semânticas têm uma grande utilidade na melhoria do desempenho de DLS dos verbos (Miller et. al. (1990), Dang e Palmer (2005) e Hanks (1996)). 


\begin{tabular}{c|cc}
\hline POS & Banerjee e Pedersen (2002) & Mihalcea e Moldovan (1999) \\
\hline Substantivo & $32.2 \%$ & $76 \%$ \\
Verbo & $24.9 \%$ & $60 \%$ \\
Adjetivo & $46.9 \%$ & $79.8 \%$ \\
Advérbio & - & $87 \%$ \\
\hline
\end{tabular}

Tabela 1.2: Acurácias obtidas nos trabalhos de Banerjee e Pedersen (2002) e Mihalcea e Moldovan (1999)

O verbo é uma classe gramatical de grande relevância. As palavras classificadas como verbos possuem uma grande carga de informação sintática e semântica. A partir destas informações, é possível saber como pode ser construída uma sentença (Fillmore, 1968). Uma característica a considerar é que, dentre todas as classes gramaticais, os verbos possuem um maior grau de polissemia, por exemplo, na WordNet- $\operatorname{Pr}^{2}$, os verbos em média (excluindo as palavras monossêmicas) possuem 4 sentidos, diferentemente dos substantivos, dos adjetivos e dos advérbios, que apresentam 3 sentidos. A alta polissemia dos verbos sugere que os significados dos verbos são mais flexíveis do que dos substantivos. Verbos podem mudar seu significado dependendo do tipo de argumentos com os quais co-ocorrem, em quanto os significados dos substantivos tendem a ser mais estáveis na presença de diferentes verbos (Miller et al., 1990). Por exemplo, na sentença "Eu tenho um carro", o verbo "ter" tem o sentido de "possuir". Já na sentença "Eu tenho dor de cabeça", o verbo "ter" tem o sentido de "estar sofrendo". Podemos ver que os argumentos "carro" e "dor de cabeça" têm influência na definição do sentido de "ter". Além disso, verbos tendem a apresentar um sentido diferente segundo os frames $\operatorname{sintáticos}^{3}$ nos quais eles são apresentados. Por exemplo, o verbo "jogar" pode apresentar os seguintes frames sintáticos ${ }^{45}$ para os sentidos de "balançar" e "lançar ou arremessar" (cada um com seus respectivos exemplos):

- NP_V (Quem estava dentro do barco sentia-se como uma meia dentro de uma máquina de levar de tanto que $\left.[\text { o barco }]_{\mathrm{NP}}[\text { jogava }]_{\mathrm{V}}\right)$;

- $\quad$ NP_V_NP $\left([0 \text { menino }]_{\mathrm{NP}}[\mathbf{j o g o u}]_{\mathrm{V}}[\text { a bola }]_{\mathrm{NP}}\right.$.);

- NP_V_NP_PP[de] $\left([0 \text { menino }]_{N P}[\mathbf{j o g o u}]_{\mathrm{V}}[\text { a bola }]_{\mathrm{NP}}[\text { da sacada }]_{\mathrm{PP} .}\right)$.

\footnotetext{
${ }^{2}$ Disponível em http://wordnet.princeton.edu/wordnet/man/wnstats.7WN.html

${ }^{3}$ Os frames sintáticos descrevem, no nível da sintaxe, as diferentes combinações de argumentos que cada verbo pode apresentar.

${ }^{4}$ Nos frames sintáticos apresentados, NP representa o sintagma nominal (em inglês, Noun Phrase), V representa o verbo, e PP representa o sintagma preposicional (em inglês, Prepositional Phrase).

${ }^{5}$ A notação usada na VerbNet.Br está composta dos sintagmas unidos pelo caractere “_”. Além disso, os sintagmas preposicionais contêm a preposição do sintagma entre colchetes.
} 
Analisando os frames sintáticos e seus exemplos, podemos ver que só o primeiro frame sintático está associado ao sentido de "balançar", e os outros 4 ao sentido de "lançar ou arremessar".

A DLS dos verbos é muito importante para ferramentas e aplicações. Dentro das ferramentas que salientam a importância do sentido dos verbos, destaca-se o anotador automático de papéis semânticos (Yi e Palmer (2004), Palmer et al. (2010)). Os autores mencionam que existe uma ligação entre a identificação de sentido dos verbos e a identificação dos papéis semânticos relacionados ao mesmo. Ao ser a anotação de papéis semânticos uma tarefa intermediaria a outras aplicações (por exemplo, sistemas de perguntas e respostas), uma melhora na DLS de verbos traria benefícios no desempenho das aplicações que são beneficiadas pela anotação de papéis semânticos também. Dentre as aplicações que se beneficiam da identificação do sentido do verbo, destaca-se a tradução automática, já que uma tradução inadequada pode modificar completamente o sentido da sentença e ainda influenciar negativamente na tradução de outras palavras, principalmente dos seus argumentos (Specia, 2007).

No caso do português, no Brasil há poucos trabalhos em DLS e alguns são de aplicação restrita. Por exemplo, Specia (2007) investiga métodos de desambiguação para a tradução automática inglês-português, focando em 10 verbos altamente ambíguos do inglês. Machado et al. (2011) focam em desambiguar expressões relacionadas a localizações geográficas. Nóbrega e Pardo (2013) realizam o primeiro estudo de métodos de DLS de propósito geral (não restrito a um domínio) conhecido para o português do Brasil usando a WordNet-Pr. Eles exploram métodos de desambiguação de substantivos apenas. Em Portugal, Travanca (2013) apresenta o primeiro trabalho de propósito geral de desambiguação de verbos usando duas abordagens, uma baseada em regras e outra usando aprendizado de máquina.

Em geral, pode-se afirmar que só recentemente a semântica tem sido mais investigada de uma maneira mais sistemática na comunidade de PLN no Brasil e os primeiros recursos e ferramentas mais robustas têm surgido. Além dos trabalhos em DLS, pode-se citar, por exemplo, as iniciativas para construção das ontologias linguísticas Wordnet-Br (Dias da Silva et al. (2008), OpenWordNet-Pt (De Paiva et al., 2012), Scarton e Aluisio (2009)) e Onto.PT (Gonçalo Oliveira et al., 2012) e os repositórios semânticos VerbNet.Br (Scarton, 2011), PropBank-Br (Duran e Aluísio, 2012), Verbo-Brasil (Duran et al., 2013a), FrameNet Brasil (Salomão, 2009) e FrameCorp (Bertoldi e Chishman, 2009). Quanto às ontologias mencionadas, estas organizam conceitualmente os termos gerais da língua; os repositórios citados propõem principalmente a classificação e sistematização dos verbos do português. A VerbNet.Br, por exemplo, classifica os verbos organizando-os em classes verbais (segundo Levin (1993)), identificando seus argumentos e papéis semânticos correspondentes esperados, e explicitando a correlação entre esses argumentos e os componentes sintáticos esperados nas sentenças em que 
eles ocorrem. As classes verbais incluem um conjunto de sentidos de verbos que possuem características sintáticas e semânticas similares. Por exemplo, o verbo "limpar" possui um sentido que é classificado como sendo da classe "clear" (que também inclui os verbos "abrir", “descarregar", "refluir" e "vazar"), possuindo argumentos com os papéis semânticos 6 "agente" (com a restrição seletiva ${ }^{7}$ de ser um "ser que possua controle"), "lugar" (como a restrição seletiva de "lugar") e "tema" (com a restrição seletiva de "concreto"), que seriam realizados sintaticamente da seguinte forma:

- $\quad \mathrm{NP}_{-} \mathrm{V}$

- NP_V_NP

- NP_V_NP_PP

$\mathrm{Na}$ sentença "João limpou os pratos da mesa.", pode-se ver uma das estruturas sintáticas mencionadas: $[\text { João }]_{\mathrm{NP}}[\text { limpou }]_{\mathrm{V}}[\text { os pratos }]_{\mathrm{NP}}[\text { da mesa }]_{\mathrm{PP}}$. Além disso, nota-se que, nessa sentença, "João" é o "agente", "pratos" é o "tema" e "mesa" é o "lugar".

O PropBank-Br é um córpus que inclui sentenças anotadas com papéis semânticos, vistos como argumentos ou adjuntos. Esse córpus é usado amplamente para o treinamento de anotadores de papéis semânticos. Contém também um léxico de verbos, chamado Verbo-Brasil, o qual inclui uma lista de verbos diferenciados por seus sentidos, que fornecem informações sobre os argumentos e os frames sintáticos que podem apresentar cada um desses sentidos.

Estes recursos podem ajudar no processo de desambiguação do sentido das palavras, especialmente dos verbos, já que, como foi mencionado, estudos realizados mostram que informações sintáticas e semânticas são muito importantes para a determinação do sentido dos verbos.

Finalmente, destaca-se que o presente trabalho de mestrado se desenvolve no contexto descrito em parágrafos anteriores.

\subsection{Lacuna}

Seguindo a hierarquia dos níveis do conhecimento linguístico proposta por Jurafsky e Martin (2009), aplicações ou métodos que usam conhecimento de níveis superiores são de abordagens mais profundas e, portanto, podem apresentar melhores resultados. Hanks (1996) ressalta que a distinção de sentido do verbo depende frequentemente da distinção na semântica do mesmo.

\footnotetext{
${ }^{6}$ Descrevem a relação semântica entre um verbo e seus argumentos (Kipper, 2005).

${ }^{7}$ Uma restrição seletiva ou traço semântico determina a semântica permitida nos papéis semânticos (Kipper, 2005).
} 
Dang e Palmer (2005) sugerem que a anotação de papéis semânticos e os frames sintáticos podem ser uma fonte de recursos muito úteis na tarefa de DLS dos verbos.

O principal problema é que, atualmente, os métodos tradicionais de DLS consideram atributos simples, tais como janelas de palavras e medidas de similaridade, e não consideram conhecimentos dos níveis sintático e semântico (que são mais profundos e necessários para os verbos) na tarefa de desambiguação de verbos. Consequentemente, não conseguem atingir bons resultados. Isto também tem um impacto negativo sobre as aplicações que fazem uso desta tarefa. Além disso, como tem sido descrito, existem poucos trabalhos de DLS para o português, e alguns deles focados em problemas específicos como tradução automática ou desambiguação geográfica.

\subsection{Objetivos e Hipóteses}

Neste trabalho de mestrado, objetiva-se:

- Explorar e adaptar métodos tradicionais da área de Desambiguação Lexical de Sentido (DLS) e avaliar os mesmos na desambiguação dos verbos do português brasileiro.

- Incorporar o conhecimento linguístico proveniente de repositórios semânticos para a língua portuguesa, especificamente, a Verbnet.Br, e avaliar o impacto que este conhecimento produz sobre os métodos tradicionais.

Uma etapa necessária que surge para a correta execução dos dois objetivos mencionados é a anotação de sentidos de verbos em um córpus. A tarefa de anotação é muito importante porque com ela se podem fazer avaliações, analisar os fenômenos semânticos que podem acontecer, e também, prover um recurso útil, isto é, um córpus, para futuras pesquisas em Desambiguação Lexical de Sentido.

Tanto para a anotação de córpus quanto para a adaptação dos métodos de DLS, faz-se necessário o uso de um repositório de sentidos (RS). Nesse projeto, usa-se a WordNet-Pr como RS. Os motivos para essa escolha são os seguintes: (1) a WordNet-Pr é a mais utilizada e completa na literatura; mesmo que tenha sido desenvolvida para outra língua, podem ser usados dicionários bilíngues que facilitem as tarefas de anotação e de desenvolvimento; (2) a WordNet$\mathrm{Br}$, atualmente, mesmo que agora esteja completa para os verbos, ainda precisava de uma fase de validação no momento em que esse mestrado se definiu; e (3) a WordNet-Br possui mapeamentos para a WordNet-Pr, isto é, quando acabar a fase de validação, os synsets da WordNet-Pr poderão ser mapeados para a WordNet-Br. 
Atualmente, tem-se disponibilizado repositórios para os verbos que contêm informações sintáticas e/ou semânticas (classes verbais, frames sintáticos, papéis semânticos e restrições seletivas, entre outros) sobre os mesmos. Estas informações nos fornecem a possibilidade de entender o comportamento e os sentidos dos verbos, por isso, tem-se como hipótese que o uso de informações linguísticas advindas de repositórios semânticos, especificamente, a Verbnet.Br, melhoram o desempenho dos métodos tradicionais de DLS para os verbos.

De acordo com os objetivos deste projeto de pesquisa, tem-se como outra hipótese que o uso de métodos tradicionais de DLS aplicados nos verbos produz resultados pouco satisfatórios comparados com os métodos de DLS aplicados em outras classes gramaticais (especificamente nos substantivos). (Nóbrega e Pardo, 2014).

Dado o uso da WordNet-Pr como RS, outra hipótese que surge é que a WordNet-Pr é suficiente para o desenvolvimento de métodos de DLS para os verbos do português brasileiro, mesmo tendo algumas lacunas lexicais, advindas de palavras próprias do português que não têm sentido apropriado descrito na WordNet-Pr.

O uso da WordNet-Pr como RS origina a necessidade do uso de dicionários bilíngues para poder encontrar os synsets em inglês provenientes das palavras em português. Portanto, a hipótese que surge é que o uso dicionários bilíngues poderá ajudar no desenvolvimento de métodos de DLS dos verbos para o português do Brasil, mesmo se algumas palavras não tiverem uma tradução direta.

\subsection{Metodologia de Trabalho}

Com o fim de atingir os objetivos definidos neste trabalho de mestrado, propôs-se uma metodologia de trabalho que consistiu em 3 etapas:

- Anotar manualmente os sentidos dos verbos em um córpus. A finalidade de esta etapa foi criar um recurso que possa servir para a avaliação de métodos de DLS. Nesta etapa, escolheu-se um córpus que abranja diferentes de domínios com o fim de satisfazer as necessidades desta pesquisa.

- Investigação de métodos tradicionais de DLS. Nesta etapa, se pesquisou sobre métodos tradicionais de DLS, tanto baseados em conhecimento quanto baseados em córpus, dando ênfase nos métodos baseados em conhecimento, visando cumprir a características dos métodos selecionáveis, que foi que não sejam restritos a um domínio especifico. Finalmente, escolheram-se alguns métodos para serem investigados a profundidade e testados no córpus. 
- Incorporação de conhecimento da VerbNet.Br. Nesta etapa, analisou-se quais características da VerbNet.Br poderiam melhorar o desempenho da DLS de verbos para, depois, incorporálas nos métodos selecionados.

Salienta-se que em cada etapa desta metodologia foi realizada uma avaliação da mesma.

\subsection{Organização do Trabalho}

O presente trabalho de mestrado descreve-se em 6 capítulos. No Capítulo 2, é apresentada a fundamentação teórica sobre a ambiguidade lexical e a área de DLS, as abordagens que existem na área de DLS, métodos de avaliação e também os recursos utilizados na literatura. No Capítulo 3, são apresentados os trabalhos relacionados à DLS encontrados na literatura nas diferentes abordagens existentes. No Capítulo 4, é apresentado o processo de anotação de córpus realizado neste mestrado, visando a fornecer um recurso para o desenvolvimento e a avaliação dos métodos de DLS. No Capítulo 5, são apresentados alguns métodos baseados em conhecimento selecionados para este pesquisa e a incorporação de conhecimento proveniente da VerbNet.Br. No Capítulo 6, é apresentada a avaliação dos métodos investigados e a incorporação do conhecimento proposto no Capítulo anterior. Finalmente, no Capítulo 7 são apresentadas as conclusões, contribuições e trabalhos futuros de este projeto de mestrado. 


\section{Capítulo}

\section{Fundamentação Teórica}

Neste capítulo, serão descritos alguns conceitos pertinentes para esta pesquisa. Na Seção 2.1, trataremos sobre a ambiguidade lexical, as origens da mesma e outros tipos de ambiguidade linguística; nas Seções 2.2, 2.3, 2.4, tratar-se-ão conceitos de Desambiguação Lexical de Sentido (DLS), abordagens a considerar e avaliações de sistemas de DLS, respectivamente; na Seção 2.5, descreveremos os recursos mais utilizados por métodos de DLS; na Seção 2.6, descreveremos algumas ferramentas usadas na tarefa de DLS e as ferramentas que serão usadas neste trabalho de mestrado; e, finalmente, na Seção 2.7, serão apresentadas algumas considerações do capítulo.

\subsection{Ambiguidade Lexical}

A ambiguidade linguística acontece quando uma palavra, expressão ou sentença é suscetível de ter dois ou mais significados ou interpretações. A ambiguidade pode se apresentar em diversos níveis de análise. Piruzelli e Dias da Silva (2010) apresentam a seguinte tipologia de ambiguidades: lexical, relacionada ao nível lexical; estrutural, relacionada ao nível sintático; anafórica ou referencial, relacionada ao contexto; e temática, que está relacionada à semântica.

A ambiguidade lexical pode ser classificada em quatro tipos: polissemia, homonímia, categorial e de transferência, sendo as principais as duas primeiras. Isto se deve ao fato de serem as mais frequentes. A polissemia ocorre quando os possíveis sentidos de uma palavra ambígua têm alguma relação semântica entre si. Por exemplo, a palavra "rede" tem os seguintes sentidos: (1) rede elétrica ou (2) rede de computadores (para este exemplo usaremos estes dois sentidos apenas, podendo haver mais). Como se pode observar, todos estes significados têm uma relação semântica, que, neste caso, seria a representação de um conjunto de objetos interconectados. Já a homonímia ocorre quando uma palavra apresenta sentidos que não tem nenhuma relação entre si. Um exemplo deste fenômeno é a palavra "manga", que poderia apresentar os significados de 
(1) fruto da mangueira ou (2) parte do vestuário que cobre o braço (para este exemplo usaremos estes dois sentidos apenas, podendo havendo mais), sendo que estes significados não guardam nenhuma relação semântica entre si $^{8}$. Contudo, embora existam palavras cujas diferenças sejam visíveis, existem outras para as quais é mais difícil distinguir entre polissemia ou homonímia. A ambiguidade categorial é aquela na qual uma palavra tem significados que pertencem a classes gramaticais múltiplas, variando de acordo com o texto de uso. Por exemplo, a palavra "canto" na sentença "eu canto salsa", é um verbo que faz referência à ação de cantar, mas a sentença "o canto da oficina" faz referência a uma localização da oficina e pertence à classe gramatical dos substantivos. A ambiguidade por transferência é ocasionada em um contexto bilíngue, quando uma palavra em uma língua fonte pode ter muitas traduções na língua destino, por exemplo, a palavra "dedo" em português poderia ser traduzida como "finger" ou como "toe" em inglês, dependendo se for o dedo da mão ou o dedo do pé, respectivamente.

A ambiguidade estrutural é dada no nível sintático, pois, em uma sentença há diferentes possibilidades de agrupamento e de fixação (hierarquização) dos constituintes oracionais. As diferentes alternativas podem resultar em orações ou segmentos de sentenças ambíguas. A combinação ambígua de itens lexicais, constituintes e fragmentos oracionais é frequentemente apontada como a principal causa das ambiguidades estruturais. Como exemplo, podemos citar a sentença "o homem olhou a mulher com binóculo": nesta sentença, podem-se ter duas interpretações que são refletidas na sintaxe: (1) que o homem está olhando para uma mulher que tem um binóculo, caso o sintagma preposicional "com binóculo" esteja relacionado ao sintagma nominal "a mulher"; ou (2) que o homem tem um binóculo com o qual olha para uma mulher, caso o sintagma preposicional "com binóculo" esteja relacionado ao verbo "olhar".

A ambiguidade temática ocorre quando há diferentes opções de marcação de papéis semânticos para um sintagma dentro de uma sentença. Por exemplo, na sentença "Eu gosto da foto de Joana." O sintagma preposicional "de Joana" pode introduzir como papel semântico um tema, caso Joana aparecesse dentro da foto; ou um possuidor, caso Joana seja a proprietária da foto.

A ambiguidade anafórica ou referencial ocorre quando uma palavra ou expressão pode potencialmente ligar-se a mais de um antecedente em uma sentença, por exemplo, na sentença "O professor vai dizer ao aluno até onde ele poderá chegar.", não se pode determinar com precisão qual dos dois (professor ou aluno) é o referente, incluindo que se poderia considerar que o pronome "ele" faz referência a uma terceira pessoa diferente do professor ou do aluno.

\footnotetext{
${ }^{8}$ Contudo, isto não é completamente verdadeiro, já que muitos desses significados podem ter alguma relação semântica se analisarmos desde a origem das palavras.
} 
Todas estas ambiguidades podem ser encontradas na escrita. Contudo, o foco deste trabalho é a ambiguidade lexical e, dentro dela, as ambiguidades que advêm da homonímia e da polissemia. Outro ponto a ressaltar é que, neste trabalho não se fará distinção entre homonímia e polissemia, apesar de existirem diferenças de origem entre elas, sendo polissemia usada para descrever estes dois tipos de ambiguidades.

\subsection{Desambiguação Lexical de Sentido (DLS)}

Segundo Jurafsky e Martin (2009), a Desambiguação Lexical de Sentido (DLS) consiste na tarefa de selecionar o sentido correto para uma palavra. Os algoritmos de DLS são representados, da forma mais básica, como se mostra na Figura 2.1: possuem como entrada uma palavra em um contexto, juntamente com um inventário de sentidos potenciais para a palavra; e, na saída, o resultado da desambiguação, que é o sentido correto da palavra.

- Sentença de Contexto

- Palavra alvo

- Lista de possíveis sentidos da palavra alvo

\section{Método de}

Desambiguação

Lexical do Sentido

Figura 2.1: Esquema dos algoritmos de Desambiguação Lexical do Sentido

O problema que resolve a DLS é considerado como intermediário a outras aplicações, isto é, ao executar uma aplicação, por exemplo, uma aplicação tradução automática, esta terá à DLS como uma etapa de sua execução. Além disso, considera-se também a tarefa de DLS como uma tarefa completa da Inteligência Artificial (Ide e Veronis, 1998), ou seja, a resolução da tarefa de DLS é tão difícil quanto a resolução dos problemas mais difíceis da Inteligência Artificial, por exemplo, a aquisição do conhecimento. Isto acontece devido às quantidades de palavras existentes no vocabulário humano e às modificações que sofrem ao longo do tempo, já que novas palavras são criadas ou sofrem variações no significado, provocando que a representação do conhecimento seja também uma tarefa difícil de ser resolvida. Tudo isso atinge os recursos desenvolvidos como fonte de conhecimento e, em consequência, também a tarefa de DLS.

Sendo a DLS uma tarefa intermediária, ela pode fornecer melhorias no desempenho de outras aplicações. Como exemplos, pode-se citar a tradução automática, já que as pesquisas em DLS surgiram motivadas pelos problemas encontrados nesta aplicação; a recuperação de informação, dado que algumas queries podem apresentar ambiguidades, por exemplo, ao buscar a palavra "serra", pode se encontrar resultados relacionados à ferramenta "serra" e não à "montanha" ou vice-versa; mineração de textos, porque, na análise dos textos, poderia existir confusão em palavras que tivessem muitos sentidos; entre outras aplicações. 
Devido ao uso de diversos recursos e técnicas na tarefa de DLS, pode-se considerar duas variantes da mesma (Jurafsky e Martin, 2009):

- Desambiguação de uma amostra de palavras ou Lexical sample: nessa tarefa, define-se um conjunto limitado de palavras a desambiguar em um texto;

- Desambiguação de todas as palavras ou All-words: nessa tarefa, fornece-se um texto, e se pretende desambiguar todas as palavras de conteúdo do texto.

Geralmente, os métodos de DLS possuem uma alta complexidade (Agirre e Edmonds, 2006). Visando à diminuição da complexidade destes métodos, podem-se aplicar algumas heurísticas, como as apresentadas no trabalho de Mihalcea (2006):

- Sentido mais frequente: usa-se o sentido que ocorre com maior frequência em um córpus anotado ou em um repositório de sentidos. Algumas das dificuldades que se podem encontrar são (1) a dependência do domínio (representado pelo córpus) e (2) que nem sempre tem-se disponibilidade de estatísticas da frequência dos sentidos das palavras.

- Um sentido por colocação: palavras que, frequentemente, co-ocorrem com a palavra a desambiguar (formando uma colocação) fornecem uma forte e consistente pista do sentido correto. Por exemplo, se a palavra "jogar" tem o sentido de "brincar" e tem a palavra "bola" próxima dela, então, para cada ocorrência da palavra "jogar" próxima de "bola", atribuir-se-á o sentido de "brincar". A dificuldade que apresenta esta heurística é que uma colocação deve ser predefinida e desambiguada para poder depois ser aplicada às outras.

Um sentido por discurso: o sentido de uma palavra dentro de um componente discursivo (uma sentença, um parágrafo ou um texto) é o mesmo em todas as ocorrências. A dificuldade que apresenta esta heurística é que ainda tem que ser desambiguada uma instância de cada palavra no componente discursivo para que as outras instâncias dessa mesma palavra tenham o mesmo sentido.

\subsection{Abordagens para DLS}

Existem muitas maneiras de tratar a DLS, as quais estão agrupadas em três abordagens: métodos baseados em conhecimento, métodos baseados em córpus e métodos híbridos (Agirre e Edmonds, 2006). Os métodos baseados em conhecimento fazem uso de fontes de conhecimento, tais como dicionários, tesauros, ontologias e bases de dados lexicais, como bases de conhecimento para a desambiguação. As principais técnicas usadas são as restrições seletivas, as sobreposições de definições e as medidas de similaridade semântica. 
As restrições seletivas são atributos específicos que definem a semântica permitida de determinados argumentos (Kipper, 2005). A seguir, são apresentadas duas sentenças:

- "O menino corre todos os dias."

- "As horas correm muito rápido."

Na primeira sentença, tem-se que o verbo "correr" faz referência a "mover-se com velocidade" e tem como sujeito "o menino", onde o núcleo deste sujeito ("menino") tem como característica "ser animado". Na segunda sentença, o verbo "correr" faz referência a "passar ou decorrer" e tem como sujeito "as horas", onde o núcleo ("horas") tem como característica "tempo". Com isto, podemos determinar que, quando o núcleo do sujeito (primeiro argumento) tem como característica "ser animado", o sentido de "correr" será "mover-se com velocidade"; e, quando tiver como característica "tempo", o sentido será "passar ou decorrer".

A sobreposição de definições é uma técnica que conta o número de palavras que compartilham as definições de duas ou mais palavras. Por exemplo, na sentença "sentar no banco", obter-seão todas as definições de "sentar" e de "banco" e se fará o cálculo da quantidade de palavras compartilhadas para cada combinação entre as definições. As definições que possuam maior quantidade de palavras compartilhadas representarão o sentido correto da palavra (veja, por exemplo, o algoritmo de Lesk (1986) que será descrito no Capítulo 3).

As medidas de similaridade semântica analisam quão relacionados são dois ou mais sentidos de palavras mediante técnicas de análise de grafos de conhecimento que advêm de algum repositório lexical de sentidos (como exemplo, tem-se o trabalho de Sinha e Mihalcea (2007)).

Estes métodos ainda são motivos de pesquisa por serem mais abrangentes, ou seja, são capazes de desambiguar um maior número de palavras. Além disso, métodos baseados em conhecimento têm potencial cross-linguístico, o que os torna fáceis de reproduzir em outras línguas. A maior dificuldade que estes métodos apresentam é o desempenho em comparação com outras abordagens que possuem resultados superiores a estes.

Os métodos baseados em córpus fazem uso de um córpus e técnicas de aprendizado de máquina. Estes métodos têm um melhor desempenho em comparação com os métodos baseados em conhecimento, mas têm como dificuldades o tempo de desenvolvimento das técnicas e também a pouca abrangência, já que, ao desambiguar mais palavras, precisa-se de um tempo maior de desenvolvimento e execução. É por este motivo que este tipo de método é utilizado principalmente na tarefa Lexical sample. Estes métodos podem ser classificados em métodos supervisionados e não supervisionados. Os métodos supervisionados fazem uso de córpus 
anotado para treinamento, ou um conjunto de dados iniciais em um processo de bootstrapping ${ }^{9}$. Quase todos os enfoques de aprendizado supervisionado têm sido aplicados a DLS, incluindo algoritmos discriminativos que utilizam listas de decisão ou árvores de decisão, onde se utilizam regras associadas a cada um dos diferentes sentidos de uma palavra e, técnicas associativas como seleção de atributos e otimização de parâmetros.

Os métodos não supervisionados evitam quase completamente informação externa e trabalham diretamente com um córpus não anotado. São incluídos nesta categoria métodos que usam córpus alinhados por palavras para reunir evidência cross-linguística para discriminação de sentido. Métodos de aprendizado não supervisionado têm o potencial de superar o problema de aquisição de novo conhecimento (etiquetagem manual do sentido) e conseguem bons resultados. Estes métodos são capazes de induzir sentidos de palavras de um texto de treinamento através do agrupamento de ocorrência de palavras e depois classificar novas ocorrências dentro do grupo de sentidos induzido.

Por fim, abordagens híbridas agrupam características das duas abordagens anteriormente mencionadas.

\subsection{Avaliação de Sistemas de DLS}

Uma das etapas mais importantes e complicadas no desenvolvimento de métodos ou sistemas é a avaliação dos mesmos. A complexidade da avalição ocorre devido ao fato de que, para comparar métodos, é preciso considerar que estejam usando recursos comuns a todos. Jurafsky e Martin (2009) propõem duas formas de avaliar sistemas de DLS: a avaliação extrínseca e a intrínseca. A avaliação extrínseca tem obtido maior interesse pela comunidade de pesquisa, mas é menos comum. Com esta avaliação, pode-se determinar se a DLS está sendo útil para a melhora do desempenho de outras aplicações. Contudo, estas avaliações tendem a ser muito custosas em termos de implementação. Além disso, estão restritas a contextos específicos, por exemplo, a DLS ter melhorado o desempenho na tarefa de recuperação de informação não garante que aconteça o mesmo com uma aplicação de tradução automática. A avaliação intrínseca é mais usada e foca em avaliar o método como um sistema independente de qualquer aplicação.

\footnotetext{
${ }^{9}$ Bootstrapping (Abney, 2002) é uma técnica geral que treina um classificador (iterativamente) com um conjunto pequeno de dados anotados e executa o classificador sobre o um conjunto de dados não anotados com o fim de aumentar o conjunto de treinamento e, posteriormente, melhorar o desempenho do classificador.
} 
As métricas de avaliação mais usadas para avaliar tarefas que envolvem DLS (Edmonds, 2002), assim como as propostas por Jurafsky e Martin (2009), são as seguintes (considerando: $n C$ é o número de palavras corretamente desambiguadas; $n T$ é o número total de palavras a serem desambiguadas e $n D$ é o número de palavras que foram desambiguadas):

- Precisão: percentual de palavras corretamente desambiguadas em relação à quantidade de palavras do conjunto de teste que foram desambiguadas pelo sistema, independentemente se for correto ou não.

$$
P=\frac{n C}{n D}
$$

- Cobertura: percentual de palavras corretamente desambiguadas em relação a todas as palavras do conjunto de teste que deveriam ser desambiguadas.

$$
C=\frac{n C}{n T}
$$

- Abrangência: percentual das palavras que foram desambiguadas, independente da desambiguação ser correta ou não, em relação ao total de palavras que deveriam ser desambiguadas.

$$
A=\frac{n D}{n T}
$$

Specia (2007) propõe, além das métricas mencionadas no parágrafo anterior, uma variação na medida de acurácia, calculando-a por meio do percentual de palavras corretamente desambiguadas pelo sistema em relação ao total de palavras que deveriam ser desambiguadas, usando o sentido mais frequente nos casos em que o sistema não consiga desambiguar uma palavra.

Além destas métricas usadas para avaliar, são usadas também medidas de referência, denominadas topline e baseline. $\mathrm{O}$ topline nos diz o desempenho limite que pode atingir um método. O topline geralmente usado é o desempenho humano na tarefa. O baseline nos diz como um método se desempenha em comparação com outro método relativamente simples. $\mathrm{O}$ método mais usado como baseline é o método do sentido mais frequente para cada palavra. Este método precisa de um repositório ou córpus no qual os sentidos incluídos para cada palavra possam ser ordenados segundo o número de ocorrências No caso da WordNet-Pr (Fellbaum, 1998) (base de dados lexical apresentada na subseção seguinte) e suas derivações, corresponde ao primeiro sentido que aparece para uma palavra, devido ao fato de que, na WordNet-Pr, os sentidos de uma palavra são ordenados pela frequência de ocorrência de forma decrescente. Salienta-se também que o método do sentido mais frequente é muito difícil de ser superado por métodos de DLS baseados em conhecimento, tornando-se um grande desafio para a área. Outro 
método usado também como baseline é o algoritmo de Lesk (1986), que será detalhado no Capítulo seguinte.

Um ponto importante na avalição de sistemas de DLS é a comparação entre sistemas. Geralmente, as comparações entre métodos de DLS são difíceis de fazer, devido à necessidade de configurações similares em todos os métodos, isto é, o mesmo repositório de sentidos, o mesmo córpus de treinamento e de avaliação, entre outros. O Senseval ${ }^{10}$ nasceu como uma iniciativa para comparar os diversos sistemas de DLS. O objetivo da competição é a realização de uma avaliação comparativa dos sistemas de DLS em vários tipos de tarefas (All-words e Lexical sample) para diferentes idiomas. Desde o ano 2007, o evento trocou do nome para SemEval (SemEval-2007 ${ }^{11}$ ), avaliando novas tarefas semânticas, tais como a anotação de papéis semânticos, análise de sentimentos e a substituição lexical, entre outras. A tarefa de DLS é considerada dentre essas tarefas para avaliar o impacto sobre as mesmas.

Atualmente, o SemEval encontra-se na edição 2014 (SemEval-2014 ${ }^{12}$ ). Alguns dos temas tratados são: análise de sentimentos baseado em aspectos, análise de sentimentos em Twitter, parsers semânticos, e similaridade semântica, entre outros.

\subsection{Recursos}

Nesta seção, serão apresentados os recursos mais utilizados em sistemas de DLS e também recursos específicos focados em verbos, tais como a VerbNet, a VerbNet.Br, o PropBank e o PropBank-Br.

\subsubsection{Córpus, Dicionários e Tesauros}

O córpus, segundo Sanchez (1995), é definido como um conjunto de dados linguísticos (pertencentes ao uso oral ou escrito da língua, ou aos dois), sistematizados segundo determinados critérios, suficientemente extensos em amplitude e profundidade, de maneira que sejam representativos da totalidade do uso linguístico ou de algum de seus âmbitos, dispostos de tal modo que possam ser processados por computador, com a finalidade de propiciar resultados vários e úteis para a descrição e análise.

Algumas das características importantes de um córpus é a possibilidade de anotação, que se trata de uma maneira de explicitar diferentes níveis de conhecimento ao rotular elementos do córpus. A anotação permite fazer diversos estudos para analisar fenômenos que ocorrem em um

\footnotetext{
${ }^{10}$ Disponível em http://www.senseval.org

${ }^{11}$ Disponível em http://nlp.cs.swarthmore.edu/semeval/

${ }^{12}$ Disponível em http://alt.qcri.org/semeval2014/
} 
córpus. Também permite o desenvolvimento, a aplicação e a avaliação de métodos sobre estes. Dentre os recursos disponíveis na literatura, podem se citar o SemCor (Mihalcea, 1998) e o OntoNotes (Hovy et al., 2006) para a língua inglesa; e o CSTNews (Aleixo e Pardo (2008); Cardoso et al. (2011)) para a língua portuguesa.

O SemCor é o córpus anotado com sentidos mais usado. Foi criado pela Universidade de Princeton e inclui 352 textos extraídos do córpus Brown (Kucera e Francis, 1967). Possui anotações da classe gramatical, lema, e synsets da WordNet-Pr. Atualmente se encontra na versão 3.0, com mais de 200 mil palavras anotadas (Melli's, 2011).

O OntoNotes é um projeto desenvolvido entre Raytheon BBN Technologies, a University of Colorado, a University of Pennsylvania e a University of Southern California. O objetivo foi a criação de um grande córpus anotado semanticamente em vários idiomas. Este córpus abrange vários gêneros textuais (notícias, conversações telefônicas, weblogs e entrevistas, entre outros) escritos em inglês, chinês e árabe.

O CSTNews é um córpus multidocumento composto por 50 coleções ou grupos de textos, sendo que cada coleção fala sobre um mesmo tópico. Os textos incluídos em cada coleção pertencem a notícias de portais jornalísticos brasileiros. O CSTNews é anotado com duas teorias discursivas: a Rhetorical Structure Theory (RST) (Mann e Thompson, 1987) e a Cross-Document Structure Theory (CST) (Radev, 2000); além disso, conta com segmentação topical, sumários mono e multidocumento (Aleixo e Pardo, 2008), alinhamento sentencial entre textos fonte e sumários (Agostini et al., 2012) e a anotação de sentidos de substantivos (Nóbrega, 2013), dentre outras anotações.

A respeito da anotação desenvolvida por Nóbrega (2013), pode-se mencionar que foram anotados só substantivos comuns. A anotação dessa classe gramatical foi motivada pelos estudos sobre o impacto positivo que tem a desambiguação de substantivos na sumarização automática (Plaza e Diaz, 2011). No começo, visou-se a anotação de todos os substantivos, mas durante o treinamento dos anotadores, se obteve que o tempo da anotação de um texto dentro de uma coleção foi de 3 sessões. Assim, a anotação limitou-se a 10\% (2192) dos substantivos comuns, devido a que nos experimentos se observou que palavras abaixo desse limiar ocorriam muito pouco nos textos, e, por isso, foram consideradas pouco representativas para a tarefa de anotação. Para a anotação, foi usado como repositório de sentidos a WordNet-Pr 3.0 (Fellbaum, 1998). Dado que a WordNet-Pr está em língua inglesa, usou-se a WordReference ${ }^{13}{ }^{13}$ como dicionário bilíngue para poder encontrar as traduções para o português. Esses dois recursos

\footnotetext{
${ }^{13}$ Disponível em http://www.wordreference.com
} 
foram integrados na ferramenta $\mathrm{NASP}^{14}$, que é uma ferramenta desenvolvida por este mesmo autor, que serve de auxilio a anotação de sentidos de substantivos.

Os dicionários foram recursos utilizados nos primeiros trabalhos de DLS (Lesk, 1986). São compostos por um conjunto de palavras e suas respectivas definições. Estes dicionários, em relação a sistemas de software, podem ser classificados em: dicionários legíveis por máquina ou Machine Readable Dictionary (MRD) e manipuláveis por máquina ou Machine Tractable Dictionary (MTD) (Wilks et al., 1988). Os MRDs são dicionários feitos por lexicógrafos e concebidos para uso humano. São geralmente dicionários que, ou foram inicialmente construídos em formato digital, ou foram criados no formato de papel e posteriormente transferidos para formato digital. Os MTDs são MRDs transformados, apresentados em um formato que os torne aptos a serem usados em sistemas de PLN.

Um tesauro é um recurso onde se listam as palavras agrupadas segundo a similaridade de significado (contendo sinônimos e, algumas vezes, antônimos), em contraste com um dicionário, que fornece definições para as palavras, e, geralmente, apresenta-as em ordem alfabética (Kilgarriff e Yallop, 2000). Normalmente, esses recursos possuem estruturas para organizar as palavras pela classe gramatical e também relacioná-las com seus respectivos antônimos. Assim, torna-se possível a busca de palavras semanticamente relacionadas, seja por sinonímia ou antonímia. O tesauro mais amplamente usado na área de desambiguação lexical do sentido é o Roget's International Thesaurus (Roget, 1911). Para o português brasileiro, podemos citar como exemplo o Tep2.0 $0^{15}$ (Maziero et al., 2008), composto por 44678 itens lexicais distribuídos em 19888 conjuntos de sinônimos e com 4276 relações de antonímia. Para mostrar um exemplo, apresenta-se o resultado da busca no Tep 2.0 para o verbo "bancar":

1. bancar, afetar, amostrar, aparentar, disfarçar, dissimular, encenar, fazer, fingir, posar, simular

2. bancar, custear, financiar

Vemos que as palavras mostradas são agrupadas pela similaridade de significados, tendo dois: o primeiro deles agrupa todos os verbos que possuam o sentido de "aparentar", e o segundo, agrupa os verbos que possuam o sentido de "financiar".

\footnotetext{
${ }^{14}$ Disponível em http://www.icmc.usp.br/ taspardo/sucinto/files/NASP.zip

${ }^{15}$ Disponível em http://www.nilc.icmc.usp.br/tep2/index.htm
} 


\subsubsection{WordNet}

A WordNet-Pr (Fellbaum, 1998) é uma base de dados lexical que foi desenvolvida inicialmente para o inglês pela Universidade de Princeton (WordNet-Pr). Contém substantivos, verbos, adjetivos e advérbios, que são organizados em um conjunto de sinônimos que representam o sentido de uma palavra. Este conjunto de sinônimos é chamado synset. Um synset, além de conter o conjunto de sinônimos, tem uma glosa, que é a descrição informal do sentido do synset e, em muitos casos, possui uma sentença de exemplo.

A WordNet está organizada em relações semânticas que podem dar-se entre palavras ou entre sentidos de palavras (synsets), sendo que as principais relações semânticas são as seguintes:

- Sinonímia: a principal relação semântica simétrica na WordNet se dá entre palavras. Segundo a definição da WordNet (Miller et al., 1990), duas palavras são sinônimas em um contexto linguístico $C$, se a substituição de uma pela outra em $C$ não altera o valor de verdade da sentença. Por exemplo, as palavras "play" e "act" são sinônimas na seguinte sentença: "Gielgud played Hamlet" ("Gielgud atuou de Hamlet"), que está no contexto da atuação. Já na sentença "He plays football" (“Ele joga futebol”), no contexto dos esportes, as duas palavras não são sinônimas.

- Antonímia: relação semântica simétrica entre palavras, tem o sentido inverso da sinonímia, ligando palavras com significados opostos, por exemplo, "old" ("velho") e "young" ("novo") ou "rapidly" ("rapidamente") e "slowly" ("lentamente"). A antonímia tem um papel importante na organização dos adjetivos e advérbios na WordNet.

- Hiperonímia/Hiponímia: relação semântica transitiva e assimétrica entre synsets (especificamente para os substantivos). Um synset A é hipônimo de outro synset B se A pode ser descrito como um tipo de B, sendo que B é o hiperônimo. Podemos colocar como exemplo o synset \{victim\} (synset de "vítima"), que é o hipônimo do synset \{unfortunate, unfortunate person\} (synset de "pessoa desafortunada"). Este tipo de relação permite estabelecer uma hierarquia de conceitos.

- Meronímia/Holonímia: relação semântica transitiva e assimétrica de parte-todo entre synsets, especificamente para os substantivos. Um synset A é merônimo de outro synset B se A é parte de B, por exemplo, "brim" ("aba") e "hat" ("chapéu”).

- Troponímia: relação entre verbos que denota uma maneira particular de fazer alguma coisa. É, para os verbos, o mesmo que a hiponímia é para os substantivos. Por exemplo, temos que $\{$ state, say, tell $\}$ seria o tropônimo de $\{$ express, verbalize, verbalise, utter, give tongue to $\}$.

- Implicação ou Acarretamento: relação entre os verbos, que tem a mesma definição que em lógica, isto é, para que o antecedente seja verdadeiro, então o consequente também deve ser verdadeiro, por exemplo, os verbos "snore" ("roncar") e "sleep" (“dormir"). 
As classes gramaticais na WordNet estão organizadas segundo as relações semânticas mencionadas no parágrafo anterior. Os substantivos estão organizados mediante as relações de hiperonímia e hiponímia entre os synsets. A estrutura de substantivos está divida em 25 hierarquias (separadas em arquivos diferentes), sendo que cada uma destas corresponde a características semânticas relativamente distintas, não são mutuamente exclusivas e possuem um componente primitivo semântico chamado unique beginner (UB), que é o conceito mais geral na hierarquia, do qual todos os hipônimos herdam características semânticas.

Na Tabela 2.1, apresenta-se a lista de UB definidos na WordNet-Pr. Como foi descrito, cada um destes tem características semânticas diferentes. Porém, embora apresentem estas diferenças, faz-se necessário um agrupamento entre si. Por exemplo, os UB $\{$ animal $\},\{$ plant $\}$ e $\{$ person $\}$ são seres vivos $\{$ organism, being $\}$, diferentemente dos UB $\{$ object $\}$, $\{$ artifact $\}$ e $\{$ food $\}$, que podem ser objetos físicos simplesmente (\{physical object $\})$. É por isso que são agrupados até chegar ao synset \{entity\} (synset raiz). Para agrupar todos estes synsets que não pertencem a nenhum unique beginner da lista, foi criado um arquivo adicional com o nome de tops. Contudo, a maioria dos substantivos está contida nos 25 componentes iniciais. 


\begin{tabular}{|c|c|}
\hline Unique Beginner & Descrição \\
\hline Act & Atos ou ações \\
\hline Animal & Animais \\
\hline Artifact & Objetos feitos pelo homem \\
\hline Atribute & Atributos de pessoas e objetos \\
\hline Body & Partes do corpo \\
\hline Cognition & Conteúdos e processos cognitivos \\
\hline Comunnication & Conteúdos e processos comunicativos \\
\hline Event & Eventos naturais \\
\hline Feeling & Emoções e sentimentos \\
\hline Food & Alimentos e bebidas \\
\hline Group & Grupos de pessoas e objetos \\
\hline Location & Posição espacial \\
\hline Motive & Objetivos \\
\hline Object & Objetos naturais, não feitos pelo homem \\
\hline Person & Pessoas \\
\hline Phenomenon & Fenômenos naturais \\
\hline Plant & Plantas \\
\hline Possession & Possessão e transferência de possessão \\
\hline Process & Processos naturais \\
\hline Quantity & Quantidades e unidades de medida \\
\hline Relation & Relações entre pessoas, coisas ou ideias \\
\hline Shape & Formas em duas ou três dimensões \\
\hline State & Estado de situações estáveis \\
\hline Substance & Substâncias \\
\hline Time & Tempo e relações temporais \\
\hline
\end{tabular}

Tabela 2.1: Lista de Unique Beginners de substantivos da WordNet-Pr

Os adjetivos estão organizados em clusters. Cada cluster está composto de um par de antônimos, por exemplo, wet-dry ("molhado"-"seco"), chamados synsets núcleo. Cada synset núcleo (pertencente ao par de antônimos) é associado a adjetivos semanticamente similares (chamados synsets satélites). Esses synsets satélites são chamados antônimos indiretos do adjetivo pertencente ao núcleo do cluster. Na Figura 2.2, apresenta-se um exemplo da organização de adjetivos: tem-se a existência do par de antônimos diretos wet e dry (synsets $\{$ wet $\}$ e $\{$ dry\}, respectivamente); os synsets $\{$ dripping\} $e$ \{air, waterless $\}$ são synsets satélites dos synset $\{$ wet $\}$ e $\{d r y\}$, respectivamente; e, finalmente, $\{$ air, waterless $\}$ é um antônimo indireto do "wet" (synset \{wet\}) e \{dripping\} é antônimo indireto do "dry" (synset \{dry\}). 


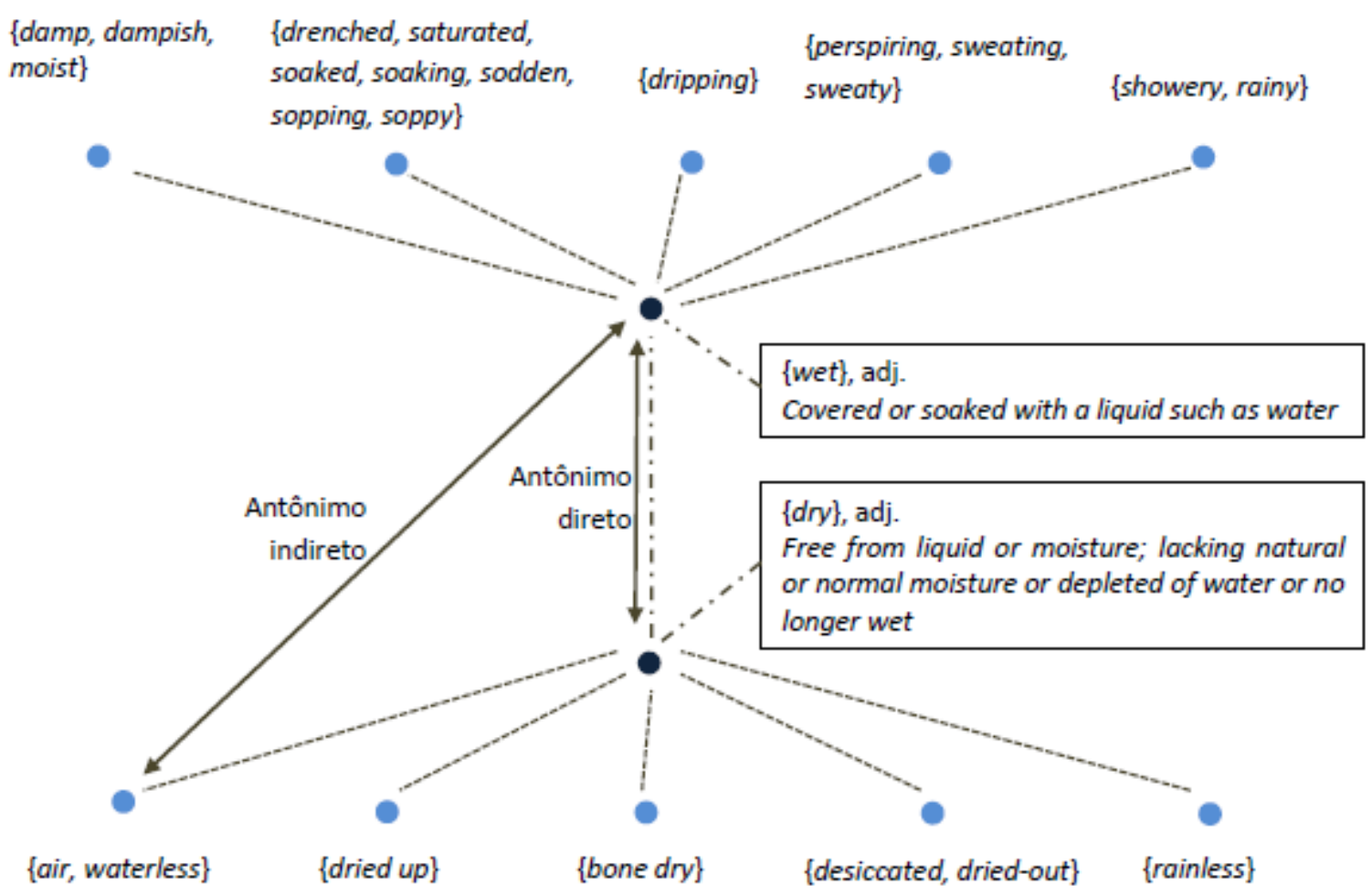

Figura 2.2: Exemplo do cluster formado pelos antônimos "wet" e "dry” na WordNet-Pr

Para o caso dos verbos, eles seguem a mesma estrutura hierárquica dos substantivos, mas mudando a relação de hiponímia pela troponímia. Para os verbos, a WordNet-Pr está baseada em 15 arquivos diferentes, sendo que cada um deles cobre um domínio semântico diferente (na Tabela 2.2, eles são apresentados). Cada um destes arquivos contém um conjunto de unique beginners, que correspondem aos verbos no nível mais alto na hierarquia e denotam os conceitos mais básicos na árvore, que é especializada mediante os verbos restantes na árvore.

Todos os verbos incluídos nos arquivos (excetuando o arquivo stative) denotam eventos ou ações. Por exemplo, o arquivo change (apresentado na Tabela 2.2) contém verbos que fazem referência a mudança. Nesse arquivo estão incluídos os synsets \{convert\} (cuja glosa é "mudar a natureza, propósito ou função de algo") e \{coarsen\} (cuja glosa é "fazer menos sutil ou refinado"). Já o arquivo cognition contém verbos que fazem referência a verbos que contenham processos cognitivos, tais como os synsets $\{$ think $\}$ (cuja glosa é “julgar ou considerar") e $\{$ feel $\}$ (cuja glosa é "ter um sentimento ou percepção sobre si mesmo em reação ao comportamento ou atitude de alguém").

$\mathrm{O}$ arquivo stative contém verbos que denotam estados, por exemplo, satisfazer, pertencer e assemelhar. Esses verbos não constituem um domínio semântico e não compartilham propriedades semânticas entre si, com exceção do fato de eles se referirem a estados. 


\begin{tabular}{c|c}
\hline Nome de Arquivo & Descrição \\
\hline Body & Aparência, vestir-se e cuidado com o corpo \\
Change & Mudança de temperatura, tamanho, intensidade \\
Cognition & Pensar, julgar, analisar, duvidar \\
Communication & Falar, perguntar, ordenar, cantar \\
Competition & Lutar, atividades atléticas \\
Consumption & Comer e beber \\
Contact & Tocar, bater, amarrar, cavar \\
Creation & Costura, panificação, pintura, desempenho \\
Emotion & Emoções e sentimentos \\
Motion & Caminhar, voar, nadar \\
Perception & Ver, escutar, sentir \\
Possession & Comprar, vender, possuir \\
Social & Atividades e eventos sociais e políticos \\
Stative & Ser, ter, relações espaciais \\
Weather & Chover, nevar, trovejar \\
\hline
\end{tabular}

Tabela 2.2: Lista de domínios semânticos de verbos da WordNet-Pr

Uma limitação que se pode encontrar na WordNet-Pr é que, por ser a WordNet-Pr um recurso lexical, não contém informações sintáticas ou semânticas (no caso dos verbos). Porém, para cobrir, pelo menos, os aspectos sintáticos mais importantes dos verbos, a WordNet-Pr inclui para cada synset de verbo um ou vários frames de sentenças, incluindo características de subcategorização dos verbos no synset e indicando o tipo de sentença em que eles podem ocorrer. Por exemplo, o synset \{eat\} (cuja glosa é "ingerir comida sólida") possui o seguinte frame de sentença:

\section{Somebody ----s something}

no qual indica que o synset $\{e a t\}$ pode ocorrer em sentenças do tipo mostrado. No frame, o antecedente do verbo deve ser alguém (um ser vivo, representado por somebody) e depois disso deve ter uma coisa (representado por something).

Outras limitações, além da mencionada, é que a WordNet-Pr não considera as relações sintagmáticas, por exemplo, os papéis temáticos dos substantivos que funcionam como argumentos dos verbos não estão codificados como em outros repositórios, por exemplo, a FrameNet (Baker et al., 1998) ou o PropBank (Palmer et al., 2005).

Atualmente a WordNet-Pr está na versão 3.1, possuindo as cifras mostradas na Tabela 2.3: 


\begin{tabular}{c|ccc}
\hline Classe Gramatical & \# Palavras & $\begin{array}{c}\text { \# Palavras } \\
\text { polissêmicas }\end{array}$ & \# Synsets \\
\hline Substantivo & 117798 & 15935 & 82115 \\
Verbo & 11529 & 5252 & 13767 \\
Adjetivo & 21479 & 4976 & 18156 \\
Advérbio & 4481 & 733 & 3621 \\
Total & 155287 & 26896 & 117659 \\
\hline
\end{tabular}

Tabela 2.3: Estatísticas da WordNet-Pr

Como se pode ver na Tabela 2.3, o número de palavras polissêmicas para os verbos representa 45.55\% (5252 de 11529) do total de verbos, diferentemente dos substantivos, adjetivos e advérbios, cuja porcentagem de palavras polissêmicas é bem menor $(13.53 \%, 23.17 \%$ e $16.36 \%$, respectivamente). Isto mostra que os verbos tendem a ser mais polissêmicos que outras classes gramaticais.

Na Tabela 2.4, apresenta-se a média de sentidos por palavra para cada classe gramatical. Estes dados foram extraídos ao analisar a Tabela 2.3. Podemos ver que os verbos possuem também o maior grau de polissemia de todas as classes gramaticais (2.17 sentidos por palavra quando são incluídas palavras monossêmicas e 3.57 sentidos por palavra quando são excluídas as palavras monossêmicas).

\begin{tabular}{c|cc}
\hline Classe Gramatical & $\begin{array}{c}\text { \# sentidos por palavra } \\
\text { (incluindo palavras } \\
\text { monossêmicas) }\end{array}$ & $\begin{array}{c}\text { \# sentidos por palavra } \\
\text { (excluindo palavras } \\
\text { monossêmicas) }\end{array}$ \\
\hline Substantivo & 1.24 & 2.79 \\
Verbo & 2.17 & 3.57 \\
Adjetivo & 1.40 & 2.71 \\
Advérbio & 1.25 & 2.50 \\
\hline
\end{tabular}

Tabela 2.4: Média de sentidos por palavra segundo classes gramaticais na WordNet-Pr

A WordNet-Br (Dias Da Silva (2005); Dias da Silva et al. (2008)) é a WordNet desenvolvida para o português brasileiro. Está alinhada com a WordNet-Pr versão 2.0. Atualmente, a WordNet.Br está completa para os verbos (contando com 7696 verbos em 3713 synsets) e disponível por meio de uma interface web, faltando apenas a validação dos synsets e dos alinhamentos. No trabalho de Scarton e Aluisio (2009), foram herdadas automaticamente as relações de hiperonímia da WordNet para a WordNet.Br, baseando-se nos alinhamentos das bases de verbos das duas wordnets. No trabalho de Scarton (2013), completaram-se as relações 
de troponímia e termos coordenados ${ }^{16}$. As informações básicas extraídas da WordNet-Br são apresentadas na Tabela 2.5 e 2.6 :

\begin{tabular}{c|ccc}
\hline Classe Gramatical & \# Palavras & $\begin{array}{c}\text { \# Palavras } \\
\text { polissêmicas }\end{array}$ & \# Synsets \\
\hline Substantivo & 17272 & 5886 & 8526 \\
Verbo & 7696 & 3440 & 3713 \\
Adjetivo & 15001 & 3815 & 6647 \\
Advérbio & 1146 & 244 & 566 \\
Total & 41115 & 13385 & 19452 \\
\hline
\end{tabular}

Tabela 2.5: Estatísticas da WordNet-Br

$\mathrm{Na}$ Tabela 2.5, pode ser visto que a quantidade de palavras polissêmicas para os verbos representa $44.70 \%$ (3440 de 7696) do total de verbos, sendo a maior de todas as classes gramaticais $(34.08 \%$ para os substantivos, $25.43 \%$ para os adjetivos e $21.29 \%$ para os advérbios). Outro ponto a salientar é que o tamanho da WordNet-Br é bem menor do que o tamanho da WordNet-Pr.

A média de sentidos por palavra para cada classe gramatical é apresentada na Tabela 2.6. Podemos ver novamente que os verbos possuem o maior grau de polissemia de todas as classes gramaticais (2.02 sentidos por palavra quando são incluídas palavras monossêmicas e 3.28 sentidos por palavra quando são excluídas as palavras monossêmicas).

\begin{tabular}{c|cc}
\hline Classe Gramatical & $\begin{array}{c}\text { \# sentidos por palavra } \\
\text { (incluindo palavras } \\
\text { monossêmicas) }\end{array}$ & $\begin{array}{c}\text { \# sentidos por palavra } \\
\text { (excluindo palavras } \\
\text { monossêmicas) }\end{array}$ \\
\hline Substantivo & 1.72 & 3.11 \\
Verbo & 2.02 & 3.28 \\
Adjetivo & 1.45 & 2.79 \\
Advérbio & 1.32 & 2.48 \\
\hline
\end{tabular}

Tabela 2.6: Média de sentidos por palavra segundo classes gramaticais na WordNet-Br

\subsubsection{VerbNet}

A VerbNet (Kipper, 2005) é um léxico de verbos on-line disponível para o inglês que contém informações sintáticas e semânticas dos verbos com base nas classes de Levin (1993), possuindo mapeamentos para a WordNet-Pr, Xtag (XTAG Research Group, 2001) e FrameNet

\footnotetext{
${ }^{16}$ Termos coordenados são verbos que possuem um hiperônimo em comum.
} 
(Baker et al., 1998). As classes de Levin são um conjunto de classes que agrupam verbos que compartilham características sintáticas e aspectos semânticos.

A VerbNet baseou-se na proposta de Levin (com 191 classes verbais), mas, depois, estendeu-se por meio do refinamento e da adição de subclasses para atingir a coerência sintática e semântica entre os membros de uma classe. A seguir, apresenta-se a descrição de uma classe verbal na VerbNet. Para esse exemplo, mostraremos a classe verbal throw-17.1:

- Hierarquia de Classes: contém uma estrutura de árvore que inclui uma classe base e também subclasses que herdam desta os comportamentos sintático e semântico, mas sendo mais específicos. Na Figura 2.3, pode-se ver a classe throw-17.1 e as subclasses derivadas dela. Cada uma delas incluirá seus próprios verbos membros e suas próprias características, herdando também o comportamento da classe pai.

\section{Class Hierarchy \\ throw-17.1 \\ throw-17.1-1 \\ throw-17.1-1-1}

Figura 2.3: Hierarquia de classes na VerbNet para a classe throw-17.1. Extraído da VerbNet ${ }^{17}$

- Membros: lista de verbos que são contidos em uma classe ou subclasse; estes verbos contêm mapeamentos para a WordNet, a FrameNet e a OntoNotes Groupings (Hovy et al., 2006). Na Figura 2.4, tem-se, por exemplo, o membro "cast" ( $f n 1 ; w n 1,4 ; g$ ); isto significa que "cast" é membro da classe throw-17.1 e que o sentido de "cast" na FrameNet é o número 1, os sentidos na WordNet-Pr são os número 1 e 4 e, na OntoNotes Groupings, o sentido 1 é aquele que representa a palavra "cast".

\section{Members \\ cast (fn: 1 ; wn: 1,$4 ; \mathrm{g}: 1$ ) \\ discard (fn: $1 ;$ wn:1; g:1)}

Figura 2.4: Membros da clase throw-17.1 Extraído da VerbNet ${ }^{18}$

Na Figura 2.5, apresentam-se os membros da subclasse throw-17.1-1-1. Esses membros herdarão as características das classes superiores a eles na hierarquia e pertencem também a essas classes superiores.

\footnotetext{
${ }^{17}$ Disponível em http://verbs.colorado.edu/verb-index/vn/throw-17.1.php

${ }^{18}$ Disponível em http://verbs.colorado.edu/verb-index/vn/throw-17.1.php
} 


\section{Members}

catapult (fn: $1 ;$ wn: 1, 2)

kick (fn: 1 ; wn: $1 ; \mathrm{g}: 1$ )

launch (fn: 1, 2; wn: 2, 5; g: 1, 2)

throw (fn: 1, 2, 3; wn: 1, 2, 4, 8; g: 1, 3)

tip (g: 1, 7)

toss (fn: 1 ; wn: $1,2,3 ; \mathrm{g}: 1,4$ )

Figura 2.5: Membros da subclasse throw-17.1-1-1. Extraído da VerbNet ${ }^{10}$

- Papéis semânticos e restrições de seleção: os papéis semânticos fazem referência à relação entre um predicado e seus argumentos (são propostos, no total, $23^{19}$ ), por exemplo, para um membro da classe throw-17.1 ("toss", pertencente à subclasse throw-17.1-1-1) na sentença "Steve tossed the ball." (apresentada na Figura 2.7), podemos ver que "Steve" é o Agente (Agent, na Figura 2.6) e "the ball" é o Tema (Theme, na Figura 2.6) do verbo central que é "toss". As restrições de seleção fornecem características que devem cumprir os papéis semânticos, por exemplo, na Figura 2.7, o papel Tema (Theme) tem que ser concreto (+concrete). Na sentença anterior, "the ball" cumpria o papel de Tema, e esse é um objeto concreto (físico).

$\begin{array}{ll}\text { Roles } & \text { Destination [+animation] [+location \& } \\ \text { Agent [+int_control] } & \text {-region] } \\ \text { Result }\end{array}$

Figura 2.6: Papéis semânticos e restrições de seleção da classe throw-17.1. Extraído da

$$
\text { VerbNet }{ }^{10}
$$

- Frames Sintáticos: fornecem uma descrição das diferentes realizações permitidas para os membros da classe; consistem em construções sintáticas, exemplos e papéis semânticos mapeados aos argumentos sintáticos; também inclui predicados semânticos mostrando como os participantes estão envolvidos no evento. Por exemplo, na Figura 2.7, apresentamse dois frames da classe throw-17.1, ou seja, os verbos pertencentes a essa classe podem apresentar essas duas realizações sintáticas.

\footnotetext{
${ }^{19}$ Disponível em http://verbs.colorado.edu/ mpalmer/projects/verbnet.html
} 


Frames
NP V NP
$\begin{array}{ll}\text { Example } & \text { "Steve tossed the ball" } \\ \text { Syntax } & \text { Agent V Theme } \\ \text { Semantics } & \text { motion (during(E1), Theme) exert_force (during(EO), Agent, Theme) contact } \\ & \text { (end(E0), Agent, Theme) not (contact (during(E1), Agent, Theme)) cause } \\ & \text { (Agent, E1) meets (E0, E1) }\end{array}$

\begin{tabular}{|c|c|}
\hline \multicolumn{2}{|c|}{ NP V NP PP.initial_location PP.destination } \\
\hline Example & "Steve tossed the ball from the corner to the garden" \\
\hline Syntax & Agent V Theme $\{\{s r c\}\}$ Initial_Location $\{\{+$ dest_dir $\}\}$ Destination \\
\hline Semantics & $\begin{array}{l}\text { exert_force (during(EO), Agent, Theme) ) contact (end(EO), Agent, Theme) } \\
\text { motion (during(E1), Theme) not (contact (during(E1), Agent, Theme)) } \\
\text { location (start(E1), Theme, Initial_Location) location (end(E1), Theme, } \\
\text { Destination) cause (Agent, E1) meets (E0, E1) }\end{array}$ \\
\hline
\end{tabular}

Figura 2.7: Frames sintáticos da classe throw-17.1. Extraído da VerbNet ${ }^{20}$

Atualmente, a VerbNet possui 274 classes, 3769 lemas de verbos e 5257 sentidos de verbos.

Para o português, construiu-se a VerbNet.Br (Scarton (2011), Scarton, (2013)), que está baseada na VerbNet do inglês. Ela contém informações sobre a interface sintático-semântica dos verbos do português do Brasil. A VerbNet.Br foi construída semiautomaticamente, considerando o potencial cross-linguístico das classes de Levin, a partir dos mapeamentos entre a VerbNet e a WordNet-Pr e dos alinhamentos entre a WordNet-Pr e a WordNet.Br (Wordnet do português do Brasil). A VerbNet.Br 1.0 contém 202 classes (alinhadas com a VerbNet), 1766 lemas de verbos e 4333 sentidos de verbos. Componentes como os papéis semânticos, as restrições de seleção e os predicados semânticos são diretamente herdados da VerbNet. Atualmente, a tarefa de desenvolvimento está concluída. Contudo, embora o método usado tenha um potencial crosslinguístico, a validação por parte de linguistas deve ser considerada.

\subsubsection{PropBank}

O PropBank (Palmer et al., 2005) foi um projeto desenvolvido para a língua inglesa. Este adiciona informação sobre papéis semânticos ${ }^{21}$, vistos como $\operatorname{argumentos}^{22}$ e $\operatorname{adjuntos}^{23}$, às estruturas sintáticas do Penn Treebank (Marcus et al., 1993), anotando cada instância dos verbos no Penn Treebank. Este projeto visa a prover um córpus de ampla cobertura para permitir o melhor treinamento de sistemas de aprendizado de máquina para a tarefa de anotação de papéis

\footnotetext{
${ }^{20}$ Disponível em http://verbs.colorado.edu/verb-index/vn/throw-17.1.php

${ }^{21}$ Os papéis semânticos descrevem as relações semânticas entre o verbo e seus argumentos em uma sentença.

${ }^{22}$ Um argumento é um constituinte obrigatoriamente requerido por um verbo.

${ }^{23}$ Um adjunto é aquele que não tem presença obrigatória na sentença; sem ele, o sentido da sentença não se perde.
} 
semânticos e o estudo quantitativo de quanto e por quê as variações sintáticas dos verbos ocorrem.

Dada a dificuldade de definir um conjunto geral de papéis semânticos que abranja todos os tipos de predicados, o PropBank define papéis semânticos para cada verbo. Os argumentos semânticos de um verbo em particular estão numerados, variando de zero até cinco ( $\operatorname{ArgN})$. Além destes papéis numerados específicos para cada verbo, o PropBank define vários outros papéis (são, na maioria, adjuntos, com exceção de NEG e MOD) que são mais gerais e que podem ser aplicados para qualquer verbo, chamados ARGMs. A lista completa é apresentada na Tabela 2.7.

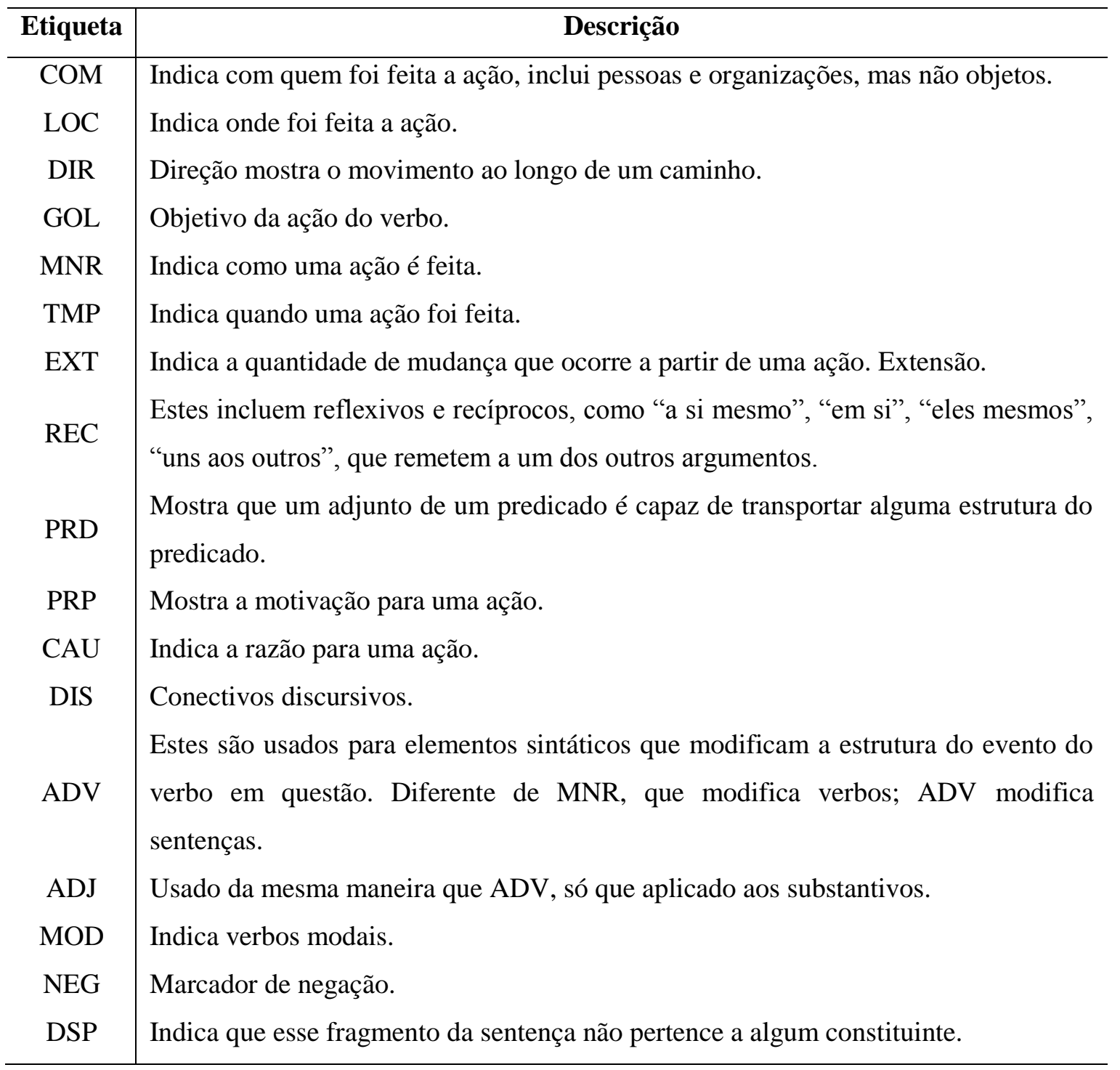

Tabela 2.7 : Tipos de Etiqueta ArgM no PropBank

Da Tabela 2.7, pode-se mencionar alguns exemplos de uso das etiquetas ArgM. Por exemplo, na sentença "Eu cantei uma canção com minha irmã." o adjunto "com minha irmã" é representado 
pela etiqueta "ArgM-COM". Já na sentença "Ela disse “?"”, "?” não é reconhecido como um constituinte e recebe a etiqueta ArgM-DSP.

O PropBank, além de fornecer um córpus anotado com proposições semânticas, fornece um léxico de verbos que contém informações sobre os papéis semânticos e estruturas predicadoargumento pertencentes a cada verbo. A Figura 2.8 descreve como as entradas de um verbo pertencente ao léxico do PropBank estão compostas:

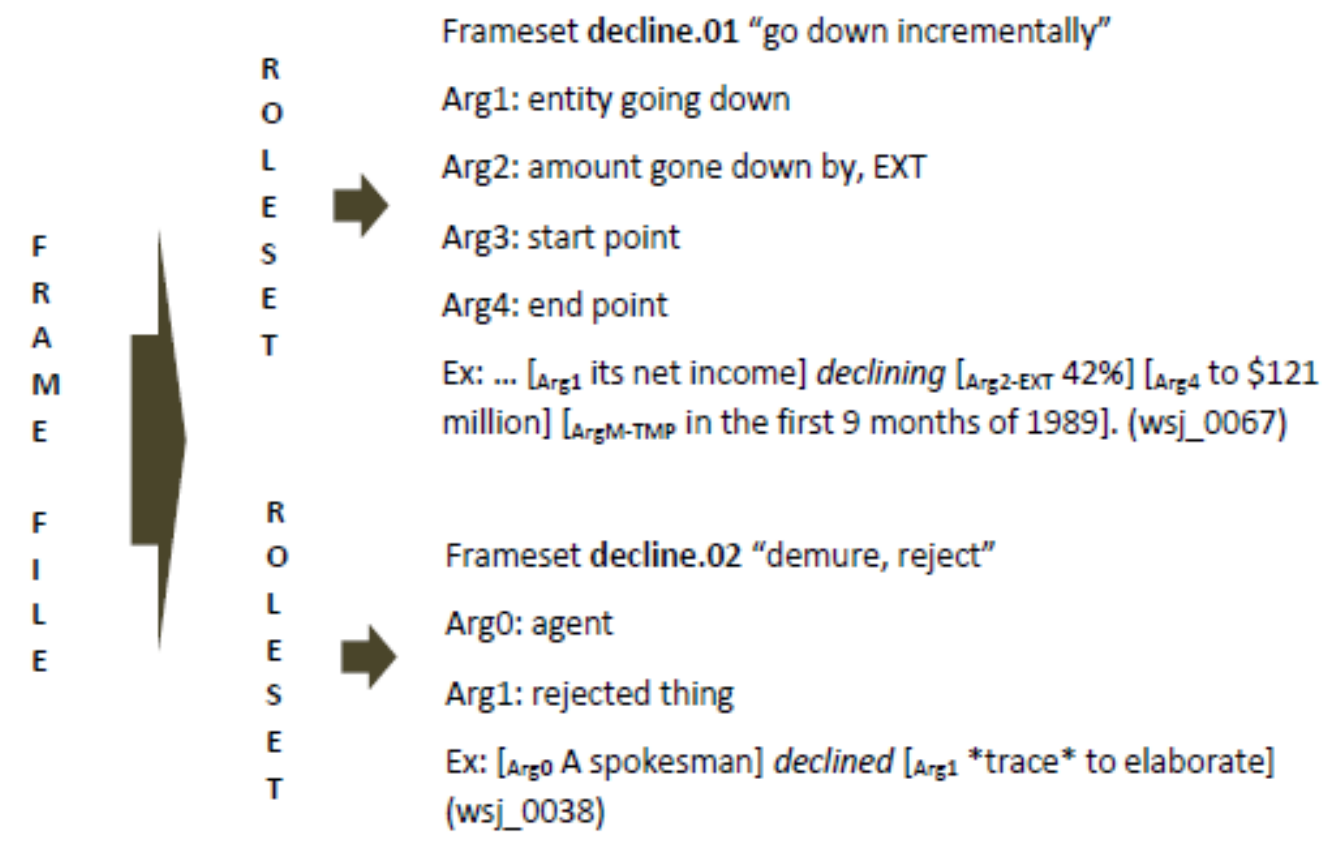

Figura 2.8: Frame file do verbo decline

Vê-se que:

- Roleset: conjunto de papéis semânticos (vistos como argumentos e adjuntos) que podem ser usados em um frameset; na Figura 2.8, estas vêm representadas pelos argumentos Arg0, Arg1, Arg2, Arg3 e Arg4 no frameset decline.01 e por Arg0 e Arg1 no frameset decline.02.

- Frameset: compreende um roleset mais os frames sintáticos de que um verbo participa. Representa o sentido de um verbo. Na Figura 2.8, os framesets são decline.01 e decline.02, incluindo os seus respectivos rolesets e os frames sintáticos.

- Frame file: é uma coleção de framesets para um verbo; estes múltiplos framesets são gerados devido à polissemia de alguns verbos, já que pode haver mais de um frameset quando as diferenças de sentido são suficientemente grandes para requerer um conjunto diferente de papéis. Para o exemplo mostrado, o frame file do verbo decline estaria composto pelos dois framesets mostrados (Figura 2.8), cada um deles representando um sentido diferente. 
Atualmente, o Projeto PropBank tem os mapeamentos para a VerbNet, a WordNet-Pr e a FrameNet, como parte do projeto SemLink (Loper et al., 2007) ${ }^{24}$ que visa relacionar diferentes recursos lexicais por meio de um conjunto de mapeamentos. Estes mapeamentos farão possível a combinação de diferentes informações advindas de diferentes recursos lexicais, para tarefas que envolvam inferência. Isto ajudará no enriquecimento da cobertura dos recursos disponíveis.

Inicialmente, o PropBank estava focado só na anotação de papéis semânticos dos verbos. Agora também possui anotações para os substantivos e adjetivos. O estado atual da anotação pode ser visto na Tabela $2.8^{25}$.

\begin{tabular}{c|ccc}
\hline Classe Gramatical & Frame Files & Predicados & Framesets \\
\hline Substantivo & 2535 & 2655 & 3129 \\
Verbo & 5940 & 6742 & 8121 \\
Adjetivo & 1880 & 1897 & 2210 \\
\hline
\end{tabular}

Tabela 2.8: Estado atual da anotação do PropBank

Para o português do Brasil, foi desenvolvido o projeto PropBank.Br (Duran e Aluísio, 2012), que visa a anotação de um Treebank ${ }^{26}$ de português do Brasil com papéis semânticos, seguindo as diretrizes do projeto PropBank. O córpus sobre o qual se fez a anotação foi o córpus Bosque da Floresta Sintá (c) tica ${ }^{27}$ (Afonso et al., 2002), anotado pelo parser Palavras (Bick, 2000) e revisado manualmente por linguistas.

Inicialmente, o PropBank.Br possuía 1068 verbos (frame files) e 6142 instâncias anotadas, o que é menos de $10 \%$ do tamanho do Propbank do inglês, portanto, o seguinte objetivo foi aumentar o tamanho do córpus. Para isto, primeiro foi necessária a criação de um recurso lexical que sirva como base para anotação de um córpus maior. Foi assim que surgiu o Verbo-Brasil (Duran et al., 2013a). As instâncias anotadas do PropBank.Br foram usadas para a criação do Verbo-Brasil, adicionando nas mesmas os seguintes atributos:

- PB-roleset: sentido do verbo no repositório do PropBank do inglês, equivalente ao sentido anotado em português;

- nota: campo utilizado quando é necessário fazer alguma observação sobre o sentido do verbo para os anotadores;

\footnotetext{
${ }^{24}$ Disponível em http://verbs.colorado.edu/semlink/

${ }^{25}$ Disponível em http://verbs.colorado.edu/propbank/propbank-status-en.html. Acessado em Dezembro de 2013

${ }^{26}$ Um treebank é um corpus de texto que possui anotação sintática ou semântica.

${ }^{27}$ Disponível em http://www.linguateca.pt/Floresta/
} 
- nota do exemplo: esse campo é utilizado só para chamar a atenção dos anotadores para algum aspecto do exemplo;

- predicate lemma: campo obrigatório na primeira ocorrência de um sentido, é onde se coloca o nome do predicado, incluindo predicados complexos (idiomáticos ou não), como por exemplo, "abrir_mão";

- sentido: identificação do sentido do verbo em uma sentença;

- e, t-glosa: campo obrigatório na primeira ocorrência de um sentido; é onde se coloca uma definição informal do sentido do verbo que permitirá ao anotador distinguir um sentido de outro.

Como foi mencionado, o Verbo-Brasil é um léxico de sentidos de verbos que serve como suporte para a tarefa de anotação de papeis semânticos. A estrutura da mesma é similar à do PropBank, herdando características da mesma, como a classe da VerbNet. Na Figura 2.9 é apresentado um exemplo de frame file do verbo "ganhar".

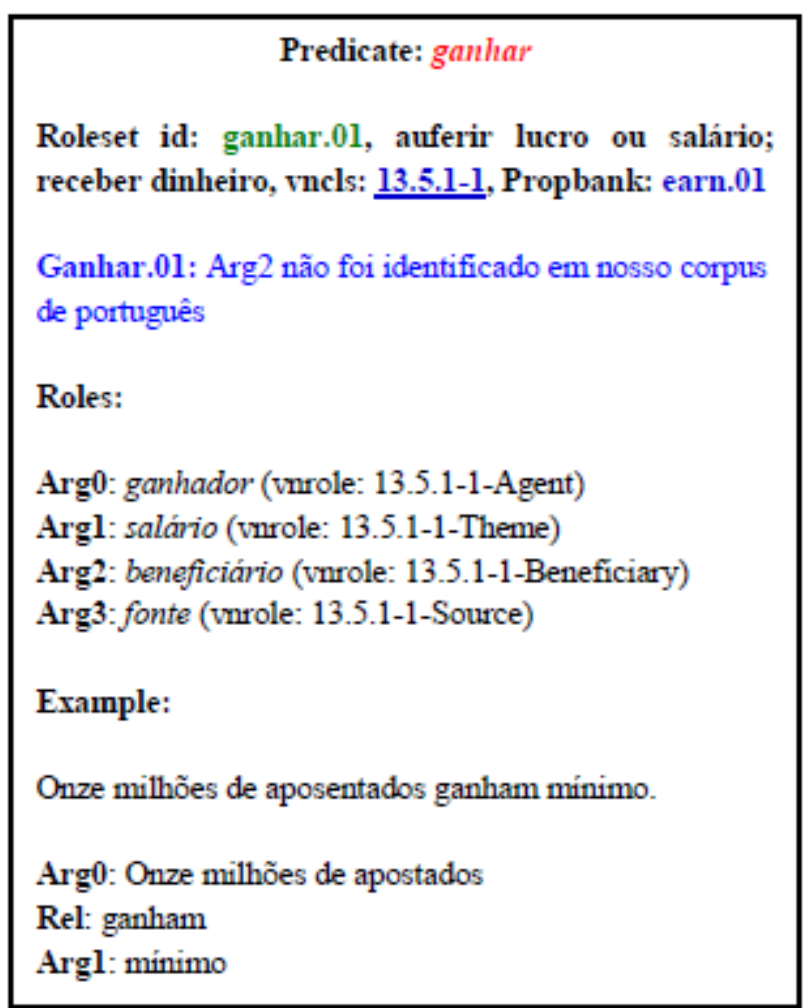

Figura 2.9: Exemplo de Frame File do verbo ganhar. Extraído do Verbo-Brasil

Na Figura 2.9, pode-se ver um sentido do mesmo, representado pelo identificador "ganhar.01" e que faz referência a receber dinheiro, a associação com a classe "13.5.1-1" da VerbNet e o roleset "earn.01" do PropBank, os argumentos do roleset "ganhar.01" e os exemplos de uso desse sentido (roleset "ganhar.01"). 
Atualmente, o Verbo-Brasil possui 8345 instâncias anotadas, 2598 verbos (frame files) e 2.992 sentidos (rolesets) (Duran e Aluísio, 2015). Do número de verbos incluídos, salienta-se que 541 verbos foram usados para a avaliação de concordância, na qual teve por objetivo a correta distinção do sentido dos verbos. O resultado desta avaliação foi um valor Kappa de 0.93 .

\subsection{Ferramentas}

Uma das ferramentas necessárias para o pré-processamento e posterior desenvolvimento de métodos de DLS é o anotador morfossintático ou POS-tagger. Este permite identificar a classe gramatical das diferentes palavras em uma sentença ou texto. Por exemplo, na sentença " $O$ menino comeu muito", o POS-tagger identificaria as classes gramaticais de artigo (" $O$ "), substantivo ("menino"), verbo (“comeu”) e advérbio ("muito"), respectivamente.

Neste trabalho de mestrado tem sido usado o MXPOST (Ratnaparkhi, 1996) como POS-tagger (ou tagger). O MXPOST é um tagger estatístico que usa um modelo de máxima entropia na identificação das etiquetas. Este tagger foi escolhido devido ao fato de que em estudos realizados por Aires (2000) para a língua portuguesa, a acurácia obtida sobre um conjunto de, aproximadamente, 100000 palavras e 27 tags possíveis, foi de 97\%. Para a correta execução do MXPOST é necessário um conjunto de treinamento e um tagset, que é o conjunto de etiquetas que representam as classes gramaticais e outras (como pontuação, números, entre outros). Os recursos usados neste projeto de mestrado estão disponíveis na página do projeto de taggers do NILC $^{28}$.

Dado que um objetivo deste projeto de mestrado é incorporar conhecimento da VerbNet.Br, e os verbos precisam de informações sintático-semântico uteis, duas ferramentas a utilizar, especificamente para a DLS dos verbos, são os parsers sintáticos e os anotadores de papéis semânticos.

Neste trabalho de mestrado, o parser PALAVRAS (Bick, 2000) foi usado para extrair as árvores sintáticas de cada sentença e assim, poder extrair as estruturas de subcategorização. $\mathrm{O}$ PALAVRAS é um parser sintático que usa uma léxico e um conjunto de regras gramaticais para fazer a análise, tanto morfológica quanto sintática. A razão pela qual este parser foi escolhido é que, segundo avaliações, possui um bom desempenho, sendo de $99 \%$ na análise morfológica e entre 97-98\% na análise sintática.

A anotação de papéis semânticos consiste em identificar os argumentos de um determinado verbo. (Gildea e Jurafsky, 2001, 2002).

\footnotetext{
${ }^{28}$ Disponível em http://www.nilc.icmc.usp.br/nilc/tools/nilctaggers.html
} 
Para o português brasileiro, têm sido desenvolvidos alguns sistemas de anotação de papéis semânticos, dos quais podemos mencionar o proposto por Alva-Manchego (2013), que usou um modelo de regressão logística para anotação automática de papéis semânticos. Fonseca (2013) propôs um sistema anotador de papéis semânticos usando um modelo neural, evitando assim a dependência de um parser sintático, contudo, os resultados obtidos não foram melhores do que os obtidos por Alva-Manchego. Em estudos recentes, Hartmann (2015) aprimorou o classificador proposto por Alva-Manchego (2013), acrescentando o córpus com mais instâncias para treino e teste, de maneira que se gere um modelo de aprendizado mais robusto que possa melhorar a tarefa de anotação. Salienta-se que todos os autores mencionados usaram o PropBank-Br como córpus de teste.

Neste trabalho de mestrado, optou-se por usar o anotador de papéis semânticos proposto por Alva-Manchego, usando o modelo treinado proposto por Hartmann (2015), pois este obteve os melhores resultados.

\subsection{Considerações Finais}

Neste capítulo foram apresentados conceitos, recursos e ferramentas relacionados ao presente trabalho de mestrado. No presente trabalho foram usados a WordNet-Pr, como repositório de sentidos; o MXPOST, como anotador morfossintático para o pré-processamento; o parser PALAVRAS para a extração de árvores sintáticas e estruturas de subcategorização; o anotador de papéis semânticos de Alva-Manchego (2013) com o modelo treinado de Hartmann (2015), e a VerbNet.Br, como léxico de verbos enriquecido com informações sintáticas. 


\section{Trabalhos Relacionados}

Neste capítulo, descreveremos alguns métodos relevantes na área de DLS encontrados na literatura. Na Seção 3.1, trataremos métodos baseados em conhecimento; na Seção 3.2, trataremos métodos baseados em córpus; e, finalmente, na Seção 3.3, apresentamos algumas considerações finais do capítulo.

Salienta-se que os trabalhos apresentados a seguir foram selecionados usando como critérios a difusão dos mesmos na literatura, a aplicabilidade em qualquer domínio e/ou idioma e a abordagem usada (sobreposição de palavras, buscas web, grafos, medidas de similaridade, entre outros), dando-se maior ênfase aos métodos baseados em conhecimento, dado que o presente trabalho se foca na investigação desta abordagem.

\subsection{Métodos baseados em Conhecimento}

\subsubsection{Trabalho de Lesk (1986)}

O método proposto por Lesk (1986) é um dos trabalhos mais utilizados em DLS. Tem sido muito utilizado tanto para realizar abordagens mais profundas quanto como baseline em diversos cenários. Lesk propôs um método de DLS que utiliza dicionários como repositório de sentidos. Este método parte do princípio de que o sentido de uma palavra é aquele que tem maior similaridade com o contexto. Para desambiguar uma palavra, obtêm-se os significados (sentidos) da palavra de um dicionário e também os significados das palavras de conteúdo que estão no contexto; depois, computa-se a quantidade se sobreposições entre a palavra alvo e cada palavra do contexto (considerando só as palavras de conteúdo); finalmente, o significado com maior número de sobreposições é o correto para a palavra alvo, e assim se faz para todas as palavras da sentença. 
Vamos mostrar como funciona o algoritmo do Lesk com o seguinte exemplo ${ }^{29}$ :

\section{Sentar no banco.}

Significado de "sentar":

1. Pôr (-se) num assento; apoiar as nádegas num assento.

2. Colocar ou colocar-se em determinado lugar.

Significado de "banco":

1. Assento estreito e comprido.

2. Pranchão elevado em que trabalham os carpinteiros, marceneiros, etc.

3. Balcão de comércio.

4. Grande cardume de peixe.

Como podemos ver, o primeiro significado de "sentar" apresenta uma palavra em comum com o primeiro significado do "banco" (que é a palavra em negrito, "assento"), e os outros significados não apresentam nenhuma sobreposição. Com este dado, o algoritmo daria como resposta que os sentidos de sentar e de banco seriam o número 1 de cada um.

Sobre este trabalho, salienta-se a importância do tamanho do dicionário para a desambiguação correta das palavras, já que dicionários pobres ocasionariam problemas na desambiguação de muitas palavras.

No trabalho do Lesk, não foi apresentada uma avaliação sistemática, porém se apresentaram os resultados de alguns testes com exemplos curtos de Pride and Prejudice ${ }^{30}$ e artigos selecionados da Associated Press ${ }^{31}$, conseguindo acurácia entre $50 \%$ e $70 \%$, segundo as palavras a serem desambiguadas. Salienta-se que no trabalho do Lesk não foram mencionadas as classes gramaticais às quais pertenciam as palavras a serem desambiguadas.

As vantagens deste método são a independência da língua, já que basta possuir um dicionário da língua em questão para aplicar este método; e a abrangência que possui, já que poderia desambiguar qualquer palavra contida num dicionário.

\footnotetext{
${ }^{29}$ Só foram considerados alguns significados das palavras "sentar" e "banco" advindos do dicionário online PRIBERAM (http://www.priberam.pt/dlpo/Default.aspx)

${ }^{30}$ Pride and Prejudice é um romance da escritora britânica Jane Austen.

${ }^{31}$ Disponível em http://www.ap.org/
} 
Dentre algumas desvantagens encontradas este trabalho pode-se citar a alta complexidade computacional, já que se tem que fazer comparações entre todos os significados das palavras que estejam incluídas na desambiguação. Outra desvantagem foi que algumas definições (glosas) oferecidas pelos dicionários podem ser muito curtas; desta forma dá-se maior importância às definições mais longas, podendo introduzir erros e também que os sentidos das palavras que já foram desambiguadas não são considerados para desambiguar as palavras que estão depois delas, ocasionando uma alta complexidade computacional e possivelmente ruído na desambiguação das palavras posteriores.

\subsubsection{Trabalho de Yarowsky (1995)}

Yarowsky (1995) explorou heurísticas de desambiguação a fim de evitar o trabalho redundante. A redundância é ocasionada por contextos semelhantes, nos quais muitas vezes o sentido das palavras é o mesmo. Neste caso, o método de desambiguação teria que ser executado para cada contexto, aumentando a complexidade. $\mathrm{O}$ autor propôs um algoritmo não supervisionado que desambigua palavras em um grande córpus. Este algoritmo começa com um conjunto pequeno de colocações $^{32}$ para cada sentido de uma palavra e vão-se adicionando outras colocações pertencentes aos sentidos da palavra. Este algoritmo inclui a heurística de um sentido por colocação para a criação do conjunto pequeno de colocações por sentido, e a heurística de um sentido por discurso para filtrar e adicionar mais colocações no córpus. O autor fez avaliações comparando sua abordagem com o método proposto por Schütze (1992), que é um método que usa técnicas de clustering para diferenciar os sentidos das palavras em um contexto. Os valores de acurácia obtidos em um conjunto de quatro palavras foram $96.7 \%$ para o seu método e $92.2 \%$ para o método de Schütze. Também comparou seu método com um método supervisionado que usa listas de decisão (LD), obtendo que, quando as duas técnicas usam o mesmo conjunto de treinamento (na qual a heurística de um sentido por colocação foi utilizada), as acurácias foram de $95.5 \%$ para o algoritmo proposto e $96.1 \%$ para a LD. Quando se adicionou a heurística de um sentido por discurso, as acurácias obtidas foram $96.5 \%$ e $96.1 \%$. Com estes resultados, conclui-se que as heurísticas exploradas contribuem para a criação de métodos com uma alta acurácia, sem um custo de anotação tão alto quanto precisariam os métodos supervisionados.

\subsubsection{Trabalho de Killgarriff et al. (2000)}

No relatório do Senseval-1, Kilgarriff et al. (2000) apresentaram 2 modificações sobre o método de Lesk: a primeira, uma versão simplificada do método proposto por Lesk, e a segunda, uma variação da primeira para um cenário de comparação com métodos supervisionados. Estes métodos foram usados como baselines nesse relatório. O método simplificado (Simple Lesk)

\footnotetext{
${ }^{32}$ Uma colocação é uma combinação frequente ou preferencial de palavras
} 
escolhe o sentido de uma palavra alvo cuja definição e exemplo possuem a maior quantidade de palavras em comum com as palavras do contexto da mesma, não considerando os significados destas. A variação deste método simplificado foi realizada usando ocorrência das palavras de contexto em um córpus fornecido no teste. Os autores não mostraram os resultados do método simplificado de Lesk, mas mencionaram que este algoritmo não foi superado por uma grande quantidade de métodos. Uma melhora nesta versão do algoritmo de Lesk foi a menor complexidade computacional ao calcular a sobreposição só com as palavras do contexto.

\subsubsection{Trabalho de Banerjee e Pedersen (2002)}

Banerjee e Pedersen (2002) propuseram uma adaptação do algoritmo de Lesk, visando o uso da WordNet-Pr (Fellbaum, 1998) como repositório de sentidos para a tarefa de Lexical sample do Senseval-2.

O algoritmo é executado da seguinte maneira:

- obtém-se as glosas dos synsets das palavras incluídas na janela de contexto;

- depois compara as glosas desses synsets entre cada par de palavras da janela de contexto e obtém o grau de similaridade;

- e, os synsets com maior grau de similaridades serão os sentidos selecionados.

Para comparar as glosas e obter o grau de similaridade, definiu-se uma sobreposição entre elas como a sequência mais extensa de uma ou mais palavras consecutivas que ocorrem nas duas glosas. Cada sobreposição adicionou uma pontuação igual ao quadrado do número de palavras na sobreposição. Para o cálculo da similaridade, consideraram-se as sobreposições das expressões que continham palavras de conteúdo e palavras vazias (stopwords), mas não as que continham só stopwords.

Outro ponto importante ao comparar as glosas dos synsets nos experimentos foi que não se considerou somente as glosas dos synsets das palavras incluídas na janela de contexto, mas também as glosas de outros synsets advindos de outras relações, tais como hiperonímia, hiponímia, holonímia, meronímia, troponímia e os atributos de cada palavra do par comparado.

Os valores das acurácias obtidas para as classes gramaticais substantivos, verbos e adjetivos foram $32.2 \%$, 24.9\% e $46.9 \%$, respectivamente, alcançando uma acurácia global de $31.7 \%$. Segundo a análise que fizeram, pode-se salientar a importância de considerar janelas de contexto curtas de até \pm 2 palavras e incluir stopwords no cômputo de similaridade, principalmente para os verbos e os adjetivos, pois a não inclusão destes produziu uma alta queda na acurácia, obtendo $7 \%$ e $11 \%$ de acurácia, respectivamente. 


\subsubsection{Mihalcea e Moldovan (1999)}

Mihalcea e Moldovan (1999) apresentaram dois métodos visando à desambiguação de substantivos, verbos, advérbios e adjetivos em um texto. Os métodos apresentados aproveitam o contexto da sentença. As palavras são agrupadas em pares e tenta-se desambiguar uma palavra dentro do contexto da outra palavra por meio de uma busca na web. Os autores salientaram que a abordagem usada é viável devido a web ter uma grande quantidade de dados que podem fornecer informações sobre como as palavras trabalham em conjunto. O primeiro algoritmo foi aplicado sobre as seguintes combinações: verbo-substantivo, adjetivo-substantivo e advérbioverbo, e é descrito a seguir:

- Para cada par de palavras, obtêm-se os sentidos advindos da WordNet-Pr para uma das palavras, deixando a outra palavra fixa.

- Com eles são formadas queries de busca (usando operadores OR e NEAR) mediante combinações dos sentidos de uma palavra (p1) e a outra palavra fixa (p2). Estes sentidos da WordNet-Pr são dados em um conjunto de sinônimos, portanto, as queries são das formas: ((Sentidop1Sinônimo1)-p2 OR ((Sentidop1Sinônimo2)-p2 OR ...) (((Sentidop1Sinônimo1) NEAR p2) OR (((Sentidop1Sinônimo2) NEAR p2) OR. . . ).

- Com as queries formadas, faz-se uma busca na $w e b^{33}$ e um ranque de resultados obtidos pelo buscador para cada par e, assim, seleciona-se o sentido do par com maior quantidade de resultados.

Como exemplo, para desambiguar o verbo "break" em um par de palavras "break" e "arm", sendo o primeiro um verbo e o segundo um substantivo, a execução das etapas seria a seguinte:

- deixamos a palavra "arm" fixa e obtemos os synsets da palavra "break", que são os seguintes (para esse exemplo, usaremos só os dois primeiros synsets para analisar as queries):

1. interrupt, break (terminate)

2. break, separate, split up, fall apart, come apart (become separated into pieces or fragments)

3. break (render inoperable or ineffective)

4. break, bust (ruin completely)

- depois, são formados pares entre "arm" e os synsets de "break", da seguinte maneira: ("arm", "interrupt") e ("arm", "break") do primeiro synset; e ("arm", "break"), (“arm",

\footnotetext{
${ }^{33} \mathrm{O}$ motor de busca Altavista foi usado nesta etapa.
} 
“separate"), ("arm", "Split up"), (“arm", "fall apart”) e ("arm", “come apart") do segundo synset;

- são então formadas as queries de busca da seguinte maneira: ("arm interrupt" OR "arm break") e ("arm break" OR “arm separate" OR "arm split up" OR "arm fall apart" OR "arm come apart");

- finalmente, são calculados os resultados para cada query no motor de busca.

Para este algoritmo, testaram-se 384 pares: 200 pares do tipo verbo-substantivo, 127 adjetivosubstantivo e 57 advérbio-verbo, extraídos do córpus SemCor 1.6 (Mihalcea, 1998). Os resultados obtidos mostraram que os piores resultados em taxa de acertos quando se selecionou o primeiro sentido do ranque foram encontrados para os verbos (60\%) e substantivos (76\%), sendo que os melhores foram para os adjetivos (79.8\%) e advérbios (87\%). Já quando se selecionaram os quatro primeiros sentidos do ranque para os substantivos e verbos, conseguiuse uma melhora significativa (98\% e $87 \%$, respectivamente). Salienta-se que, para os experimentos, só se usaram queries que continham o operador OR; os autores mencionaram que, para o operador NEAR, os resultados obtidos foram similares.

O segundo algoritmo adicionou ao primeiro algoritmo o conceito de Densidade Semântica, obtida pelo número de palavras em comum que estão dentro da distância semântica de duas ou mais palavras. Este algoritmo foi testado só para pares verbo-substantivo devido a estes possuírem uma estrutura hierárquica na WordNet, diferentemente dos adjetivos e advérbios, que são agrupados em clusters. A descrição do mesmo é feita a seguir:

- dado um par verbo-substantivo, obtém-se os sentidos dos dois elementos usando a WordNet-Pr;

- usando o primeiro algoritmo, obtém-se um ranque de sentidos dos substantivos, selecionando-se os mais bem posicionados (quantidade definida pelos pesquisadores e não explicitada);

- para cada possível par de sentidos verbo-substantivo (considerando os resultados obtidos no passo anterior), computa-se a densidade semântica;

- finalmente, cria-se um ranque com os resultados obtidos da densidade semântica, selecionando-se o melhor posicionado.

Um ponto a ressaltar é o cômputo da densidade semântica, a qual é calculada da seguinte forma (sendo $v_{i}$ o verbo e $n_{j}$ o substantivo):

- extraem-se todas as glosas da hierarquia incluindo $v_{i}$; 
- determinam-se os substantivos das glosas, constituindo o contexto de substantivos do verbo. Cada substantivo é guardado junto com um peso que indica o nível na hierarquia do verbo em cuja glosa o substantivo foi encontrado;

- determinam-se os substantivos da hierarquia de substantivos, incluindo $n_{j}$;

- finalmente, determina-se a densidade conceitual $C_{i j}$ dos conceitos comuns entre os substantivos em (2) e (3) usando a seguinte fórmula:

$$
C_{i j}=\frac{\sum_{k}^{\left|c d_{i j}\right|} w_{k}}{\log \left(\text { descendents }_{j}\right.}
$$

sendo $\left|c d_{i j}\right|$ o número de conceitos comuns entre as hierarquias de $v_{i}$ e $n_{j}$; $w_{k}$ são os níveis dos substantivos na hierarquia do $v_{i}$; e descendents $s_{j}$ o número total de palavras na hierarquia do $n_{j}$.

A hierarquia do verbo $v_{i}$ é dada pelos synsets desde o hiperônimo de mais alto nível até o verbo $v_{i}$, incluindo também os hipônimos diretos. A hierarquia do substantivo $n_{j}$ inclui todos os substantivos na classe de $n_{j}$, mas os autores não mostram como é obtida essa hierarquia.

Os resultados deste segundo algoritmo foram que a taxa de acertos dos substantivos e verbos melhorou em relação ao algoritmo anterior (86.5\% e 67\%, respectivamente). Os autores apresentaram duas limitações encontradas no desenvolvimento do método: a primeira foi a falta de etiquetagem morfossintática nas glosas, já que o método faz uma contagem de substantivos e precisa de um bom etiquetador morfossintático para melhorar o desempenho; a segunda foi a falta de contexto para a desambiguação de palavras, já que só se considerou uma palavra como contexto.

\subsubsection{Trabalho de Sinha e Mihalcea (2007)}

Sinha e Mihalcea (2007) propuseram um algoritmo de Desambiguação Lexical de Sentido não supervisionado baseado em grafos, usando várias medidas de similaridade semântica baseadas na WordNet-Pr (6 no total, disponíveis no pacote WordNet::Similarity (Patwardhan et al., 2003)) e algoritmos de centralidade de grafo.

O algoritmo tem a seguinte forma: dada uma sequência de palavras com suas possíveis etiquetas (que representam os sentidos), aplicam-se os seguintes passos:

- construção de grafo de dependência de etiquetas;

- pontuação de cada etiqueta usando algoritmos de centralidade baseados em grafos;

- e, escolha de etiqueta. 
A construção do grafo de dependências foi feita adicionando um vértice para cada etiqueta possível e uma aresta para cada par de etiquetas para o qual a dependência foi identificada. A dependência entre etiquetas (sentidos) é determinada mediante uma função de dependência, que mede a relação entre os dois sentidos. Para esta etapa, usaram-se seis medidas de similaridade semântica como funções de dependência entre dois sentidos, sendo estas: lch (Leacock e Chodorow, 1998); lesk (Lesk, 1986); wup (Wu e Palmer, 1994); res (Resnik, 1995); lin (Lin, 1998); e jnc (Jiang e Conrath, 1997). No caso em que o valor de uma dependência foi menor ou igual zero, a aresta correspondente a essa dependência foi retirada do grafo.

Para a pontuação, usaram-se algoritmos de centralidade de grafos, já que estes medem a importância de um vértice considerando a relação do mesmo com outros vértices do grafo. Usaram-se quatro algoritmos de centralidade: (1) o indegree, que calcula a quantidade de arestas que incidem sobre um vértice; (2) o closeness, que calcula o grau de proximidade, que corresponde à soma de todos os menores caminhos de um vértice a todos os demais no grafo; (3) o betweenness ou grau de intermediação, que calcula a quantidade de vezes que um vértice está presente em um menor caminho entre outros vértices do grafo; e (4) o PageRank (Brin e Page, 1998), que considera o vértice mais relevante (este algoritmo será mais detalhado na Subseção 3.1.12). Finalmente, escolheu-se como sentido mais apropriado a etiqueta com maior pontuação obtida depois do cálculo da centralidade. Na Figura 3.1, apresenta-se o grafo gerado para a sentença "The fighter broke his arm" ("O lutador quebrou o braço"), na qual os nós representam os sentidos das palavras, os pesos das arestas mostram a similaridade semântica (para o exemplo, foi usada a medida lesk) entre dois sentidos, e os números colocados para cada nó representam a medida de centralidade obtida (para o exemplo, foi usada a indegree). No exemplo citado, os nós ressaltados em verde são os sentidos atribuídos pelo método proposto.

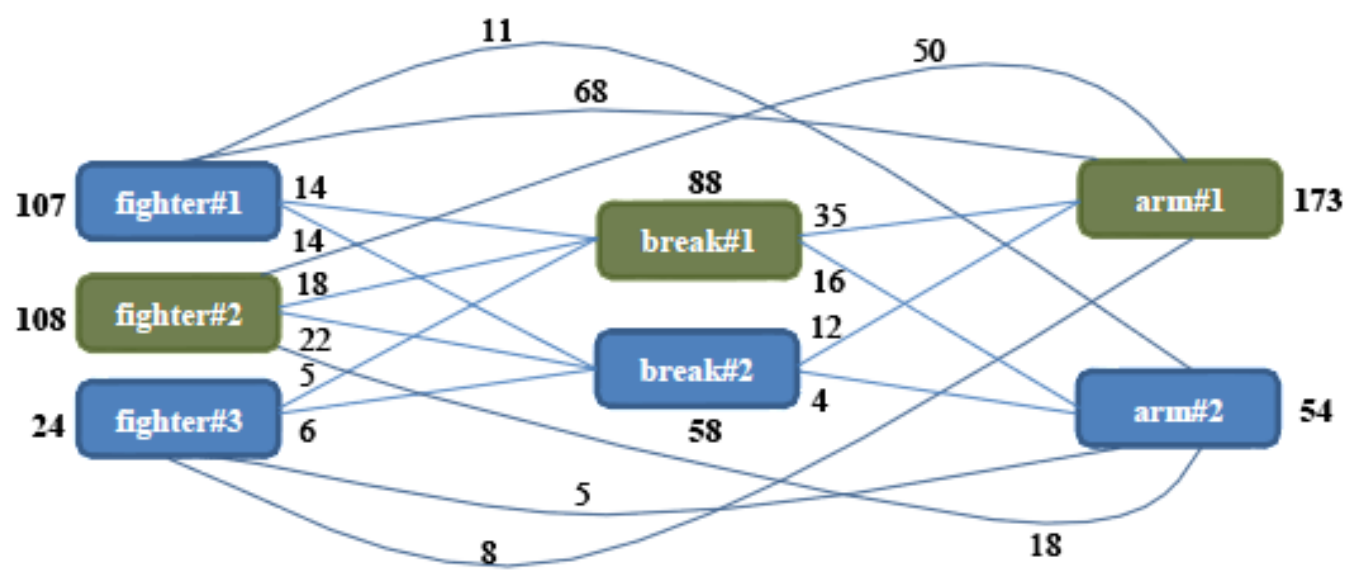

Figura 3.1: Grafo de relações gerado para a sentença "The fighter broke his arm" 
Para os experimentos realizados, usaram-se janelas de tamanho seis para cada palavra a ser desambiguada e os conjuntos de teste do Senseval-2 e Senseval-3. No primeiro experimento, foi usado um subconjunto do conjunto de dados do Senseval-3 e objetivou-se avaliar o desempenho das métricas de similaridade na desambiguação e, consequentemente, decidir a melhor combinação de medidas. Para isto, os autores fizeram os testes com o algoritmo indegree.

Os resultados obtidos foram focados nos verbos e nos substantivos (considerando que todas as métricas, com exceção de lesk, trabalham sobre estas classes gramaticais), mostrando que a medida jcn foi a melhor para os substantivos (85 verdadeiros positivos) e lch foi a melhor para os verbos (66 verdadeiros positivos). A métrica que obteve melhor cobertura foi lesk, que também é a única que trabalha sobre adjetivos e advérbios, além das outras classes gramaticais.

O segundo experimento foi a normalização das métricas $l c h, j c n$ e lesk, as quais apresentaram melhores resultados, com o fim de combinar as três no algoritmo de desambiguação. $O$ resultado desta normalização, ainda sem combinação, foi o crescimento em $10 \%$ na cobertura do algoritmo.

O terceiro experimento foi a combinação das medidas mencionadas no parágrafo anterior, sendo que a medida jcn focou na similaridade entre substantivos; a $l c h$, na similaridade entre verbos; e todas as demais (incluindo advérbios, adjetivos e relações entre classes gramaticais diferentes) foram tratadas com a medida lesk. Os resultados obtidos foram de 53.43\% para precisão e cobertura, superando os melhores resultados obtidos usando as métricas em separado (precisão: lesk (51.87\%); cobertura: lesk (44.97\%); e medida F: lesk (48.17)).

O quarto experimento focou na avaliação dos algoritmos de centralidade. Os autores usaram a combinação das métricas mencionadas nos parágrafos anteriores e avaliaram os quatro algoritmos de centralidade, sendo que os melhores resultados obtidos foram dos algoritmos indegree (precisão: 53.43\%; cobertura: 53.43\%) e PageRank (precisão: 52.82\%; cobertura: $52.30 \%$ ). Posteriormente, os autores propuseram um esquema de votação, o qual escolhe, para cada palavra a desambiguar, o sentido que possui maior quantidade de votações entre os quatro métodos avaliados. Este esquema apresentou melhores resultados (precisão: 54.86\%; cobertura: $52.40 \%)$.

Finalmente, foram feitos experimentos com os dados de teste do Senseval-2, resultando que o esquema de votação teve maior precisão (58.83\%) que os algoritmos de centralidade de forma isolada, entretanto, na cobertura, o algoritmo indegree, considerando a combinação de métricas de similaridade, obteve $56.54 \%$ frente aos $56.37 \%$ que obteve o esquema de votação. 
3.1.7 Trabalho de Roberts e Kordoni (2012)

Roberts e Kordoni (2012) apresentaram um modelo para predizer o sentido de um verbo usando informação de subcategorização e integrando-a no algoritmo SSI-Dijkstra. O SSI-Dijkstra (Cuadros e Rigau, 2008) é um algoritmo baseado em conhecimento que opera usando um grande grafo direcionado.

O grafo é construído usando a WordNet-Pr, nos quais os vértices são representados pelos synsets e as arestas representam as relações semânticas encontradas na WordNet-Pr. Os autores geram arestas inversas para garantir que as relações no grafo sejam simétricas. Depois, adicionam arestas representando relações semânticas advindas de outros recursos, tais como

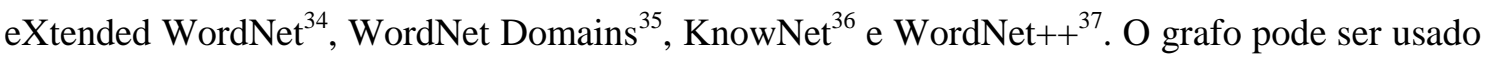
para dar uma medida de distância semântica, que é definida como o caminho mais curto no grafo entre dois synsets. Essa distância pode ser computada usando o algoritmo de Dijkstra.

O algoritmo SSI-Dijkstra é executado da seguinte maneira: começa com um contexto semântico (C), que contém um conjunto de sentidos da WordNet-Pr representando as palavras monossêmicas na atual sentença; palavras polissêmicas na sentença são colocadas em um conjunto chamado pending set $(P)$ para serem depois desambiguadas; em cada iteração, o algoritmo computa, para cada sentido " $s$ " de cada palavra a ser desambiguada, a distância semântica de todos os sentidos em $\mathrm{C}$ em relação ao sentido " $s$ "; o sentido que tem a menor distância até $C$ é escolhido e adicionado ao contexto; a palavra que foi desambiguada é removida de $P$. Um ponto importante é que devemos incluir no contexto $C$ todas as palavras que foram previamente desambiguadas, de maneira que a desambiguação da sentença seja uniforme.

A variação realizada no algoritmo SSI-Dijkstra foi a atribuição de pesos às arestas do grafo. Na variante, cada aresta que incide sobre um nó " $n$ " (representando o sentido " $s$ ") possui um peso dado por $1 / P(s)$, que é a inversa de probabilidade a priori de ver uma instância do synset "s" em um corpus balanceado. A estimação da distribuição de probabilidade dos synsets foi obtida contando os sentidos das palavras no SemCor (Miller et al., 1993) e suavizando as quantidades com Good-Turing estimation.

Usou-se essa mesma abordagem para integrar a informação sintática no algoritmo na forma de um modelo probabilístico de preferência de subcategorização. Segundo esse esquema, as arestas

\footnotetext{
${ }^{34}$ Disponível em http://xwn.hlt.utdallas.edu

${ }^{35}$ Disponível em http://wndomains.itc.it

${ }^{36}$ Disponível em http://adimen.si.ehu.es/web/KnowNet

${ }^{37}$ Disponível em http://lcl.uniroma1.it/wordnetplusplus
} 
que incidem no nó " $n$ " (representando o sentido do verbo "v" na atual sentença, com lema "l" e estrutura de subcategorização " $f$ ") têm um peso de $1 / P(v \mid l, f)$.

Para construir o modelo probabilístico, os autores usaram um conjunto de 12 estruturas de subcategorização dadas em (Andrew et al., 2004). Construiu-se o modelo usando o SemCor. O SemCor é um córpus que possui anotações de sentido, porém, não contém parse trees; portanto, teve-se que fazer um parsing do SemCor usando o Stanford Parser (Klein e Manning, 2003).

Depois desse processo de parsing, os autores tiveram que lidar com problemas de dados esparsos. Por exemplo, o verbo "appear" com o sentido de "give a certain impression" selecionou fortemente a estrutura de subcategorização $\mathrm{VPto}^{38}$ (frequência de 62), diferentemente das outras estruturas de subcategorização que apareceram com muito menor frequência, tais como VPing ${ }^{39}$, que apareceu só 1 vez.

Para corrigir esse problema de dados esparsos, construíram-se duas distribuições relacionadas: uma que contava as co-ocorrências da classe da VerbNet e a estrutura de subcategorização, e outra para a co-ocorrência do lema de verbo e a estrutura de subcategorização. Aplicou-se o método de suavização Good-Turing às 2 distribuições e, finalmente, as distribuições foram usadas em conjunto.

A avaliação foi realizada sobre o Senseval-2 na tarefa de All-words. Fizeram-se comparações com o método do sentido mais frequente (usado como baseline), resultando que o desempenho do método proposto superou o baseline (43.7\% e 39\% de cobertura, respectivamente). Os autores também fizeram comparações com o método de Agirre e Soroa (2009) ${ }^{40}(38.9 \%$ de cobertura), mostrando um melhor desempenho na DLS de verbos.

Com os resultados obtidos, os autores conseguiram demonstrar que adicionando modelos de subcategorização ao algoritmo SSI-Dijkstra, o desempenho dos algoritmos de DLS pode ser melhorado. Além disso, considerando que o método de Agirre e Soroa é um dos que obtém melhores resultados em desambiguação de verbos, podemos afirmar que o método proposto tem resultados que estão no estado da arte em DLS.

\subsubsection{Trabalho de Lu et al. (2012)}

Lu et al. (2012) apresentaram dois métodos de seleção de contexto usando um parser sintático, com o objetivo de demonstrar que uma correta seleção de palavras de contexto e uma correta

\footnotetext{
${ }^{38}$ VPto representa a estrutura de subcategorização na qual tem-se um verbo e depois a preposição "to".

${ }^{39}$ VPing representa a estrutura de subcategorização na qual tem-se um verbo na forma de gerúndio.

${ }^{40}$ Este método será apresentado na Subseção 3.1.12
} 
atribuição de pesos a essas palavras melhoram os resultados na desambiguação de palavras. Os autores argumentam que métodos de seleção de contexto baseados em janelas de palavras podem omitir palavras que sejam importantes e considerar palavras que possam ser ruído. Já no caso de métodos baseados em dependência, os autores argumentaram que um problema existente é que estes métodos selecionam apenas as palavras que estão ligadas diretamente à palavra a desambiguar (palavra alvo), não considerando a influência de outras palavras mais distantes.

O primeiro método usa a árvore de constituintes de uma sentença para obter as palavras de contexto e atribuir um determinado peso a cada palavra do contexto. Este peso representa a relevância de uma palavra no processo de desambiguação. Este método funciona da seguinte forma: (1) dada uma sentença, obtêm-se a árvore de constituintes; (2) para uma palavra alvo, procede-se a dar pesos às palavras do contexto (as outras palavras da sentença); e (3) se selecionam as $\mathrm{N}$ palavras do contexto com maior peso (sendo $\mathrm{N}$ definido nos experimentos). $\mathrm{O}$ peso atribuído para cada palavra de contexto é obtido considerando a distância entre a palavra do contexto e a palavra alvo na árvore e o nível do nó pai comum entre a palavra do contexto e a palavra alvo na árvore. A fórmula para obter o peso de cada palavra do contexto é apresentada a seguir:

$$
\operatorname{weight}\left(f_{i}\right)=\frac{1}{l^{\alpha}} \cdot \frac{1}{1+\beta \log _{10} d}
$$

onde $f_{i}$ representa a palavra de contexto na posição $i ; \quad l$, o nível do nó pai na árvore de constituintes; $d$, a distância entre a palavra de contexto e a palavra alvo; e $\alpha$ e $\beta$, os fatores de ajuste.

O segundo método usa a árvore de dependências de uma sentença para obter as palavras de contexto e atribuir um determinado peso a cada palavra do contexto. Este método funciona da mesma maneira que o anterior com a diferença que o peso atribuído para cada palavra de contexto é obtido considerando só a distância entre a palavra do contexto e a palavra alvo na árvore. A fórmula para obter o peso de cada palavra do contexto é apresentada a seguir:

$$
\operatorname{weight}\left(f_{i}\right)=\frac{1}{d^{\alpha}}
$$

onde $f_{i}$ representa a palavra de contexto na posição $i ; \quad d$, a distância entre a palavra de contexto e a palavra alvo; e $\alpha$, fator de ajuste.

Depois de obter as palavras de contexto e atribuir-lhes um peso com os métodos descritos anteriormente, procede-se a executar o método de desambiguação. Este método calcula a 
relação semântica entre cada sentido da palavra alvo e os sentidos das palavras do contexto, escolhendo o sentido que possua a relação semântica de maior valor. A fórmula que calcula a relação semântica para cada sentido é descrita a seguir:

$$
\operatorname{score}\left(w s_{i}\right)=\sum_{f_{j \in F_{w}}} \operatorname{weight}\left(f_{j}\right) \times \frac{\operatorname{wnss}\left(w s_{i,} f_{i}\right)}{\sum_{w s_{i^{\prime}} \in \operatorname{senses}(w)} w n s s\left(w s_{i^{\prime \prime}}, f_{i}\right)}
$$

onde:

$$
w n s s\left(w s_{i}, f_{j}\right)=\max _{f s_{x} \in \operatorname{senses}\left(f_{j}\right)}\left(w n s s\left(w s_{i}, f s_{x}\right)\right)
$$

e $w s_{i}$ representa o sentido de $w$ que ocupa a posição $i$; senses $(w)$, o conjunto de sentidos da $w ; f_{j}$, a palavra de contexto que ocupa a posição $j ; F_{w}$, o conjunto de palavras de contexto de $w$; e weight $\left(f_{j}\right)$, o peso atribuído à palavra de contexto $f_{j}$.

Os experimentos foram realizados sobre um conjunto de 41 palavras da tarefa Lexical sample, obtidos das seções de esportes e finanças do Reuter córpus e do British National Corpus (BNC). Os recursos usados nos experimentos foram os seguintes: o repositório de sentidos utilizado foi a WordNet-Pr, o parser sintático que usaram sobras as sentenças foi o Stanford Parser (Klein e Manning, 2003) e, para obter a medida de relação semântica, foi usado o método Context Vector do pacote WordNet::Similarity ${ }^{41}$.

Além desses dois métodos de seleção, os autores usaram um método baseado em janela de palavras (usando 16 palavras de contexto) e um método baseado em dependência para a seleção de palavras de contexto. Os resultados obtidos foram que o método de seleção baseado em árvores de constituintes obteve a melhor cobertura (39.86\%) e o método de seleção baseado em árvores de dependência obteve a segunda melhor cobertura (39.52\%), superando os métodos baseados em janelas de palavras e em dependências (34.55\% e $38.99 \%$, respectivamente). Os autores confirmaram sua hipótese de que uma melhor seleção de palavras de contexto e uma atribuição de pesos às mesmas melhora a desambiguação de palavras. Um ponto que os autores salientaram é que o resultado obtido pelo método baseado em árvore de constituintes se mostrou superior ao método baseado em árvore de dependências e argumentaram que este resultado é possível devido ao fato de que, no Stanford Parser, a árvore de dependências é gerada a partir da árvore de constituintes, portanto, a acurácia da árvore de dependência é menor.

\footnotetext{
${ }^{41}$ Disponível em http://wn-similarity.sourceforge.net
} 


\subsubsection{Trabalho de Nóbrega (2013)}

Nóbrega (2013) apresentou o primeiro trabalho de propósito geral para desambiguação lexical do sentido para o português brasileiro, sendo o foco do trabalho a desambiguação de substantivos. Neste trabalho, propuseram-se um estudo exploratório de métodos de DLS baseados em conhecimento para os substantivos e um método de DLS baseado em uma abordagem multidocumento. Foi usado o corpus CSTNews (Aleixo e Pardo, 2008) para a anotação manual de sentidos e assim avaliar os métodos desenvolvidos. O autor adota a heurística de um sentido por discurso, que parte da ideia de que palavras incluídas em textos que pertencem a um determinado tópico vão apresentar o mesmo sentido. Esta heurística foi adotada aproveitando também a estrutura de córpus CSTNews, que agrupa notícias em coleções. O repositório de sentidos utilizado foi a WordNet-Pr. Em consequência, dado que o foco da pesquisa era o português brasileiro, foi usado também um dicionário bilíngue (foi utilizado WordReference ${ }^{\circledR 2}{ }^{42}$ ) para poder fazer os mapeamentos para os synsets da WordNet-Pr.

Neste trabalho, Nóbrega explorou três métodos de DLS para comparar e propôs um método de DLS:

- O método heurístico, que retorna a tradução mais usual e o synset mais frequente como sentido escolhido;

- O método de Lesk, usando janelas de 5 palavras, considerando as adaptações de Banerjee e Pedersen (2002) e Kilgarriff et al. (2000), com as seguintes configurações: (G-T) compara a glosa do synset da palavra alvo com as possíveis traduções das palavras do contexto; (S-T) compara exemplos do synset da palavra alvo com as possíveis traduções das palavras do contexto; (GS-T) compara a glosa e os exemplos do synset com as possíveis traduções das palavras do contexto; (G-G) compara a glosa do synset da palavra alvo com as glosas dos synsets das palavras de contexto; (S-S) compara os exemplos do synset da palavra alvo com os exemplos do synset das palavras do contexto e (GS2) compara glosa e exemplos do synset da palavra alvo com os synsets das palavas do contexto;

- O método de Mihalcea e Moldovan (1999), usando apenas os pares de palavras formados por um substantivo e um verbo, já que os autores apresentam que esta combinação obteve o melhor desempenho.

- O método proposto, que cria um grafo de co-ocorrência multidocumento com informações de co-ocorrência entre a palavra alvo e outras palavras próximas dela, usando janelas de 3 e 5 palavras (G3 e G5 respectivamente), tudo isto dentro de uma coleção de textos do corpus.

\footnotetext{
${ }^{42}$ Disponível em http: //www.wordreference.com
} 
Vamos descrever o método proposto usando um exemplo: em uma coleção do CSTNews pretendemos desambiguar a palavra "avião". Para isto, obtemos janelas de 3 ou 5 palavras que contenham a palavra a ser desambiguada. Com isto, obtemos todas as palavras que coocorreram em uma mesma janela com a palavra "avião", e geramos um grafo com todas essas palavras, como se apresenta na Figura 3.2.

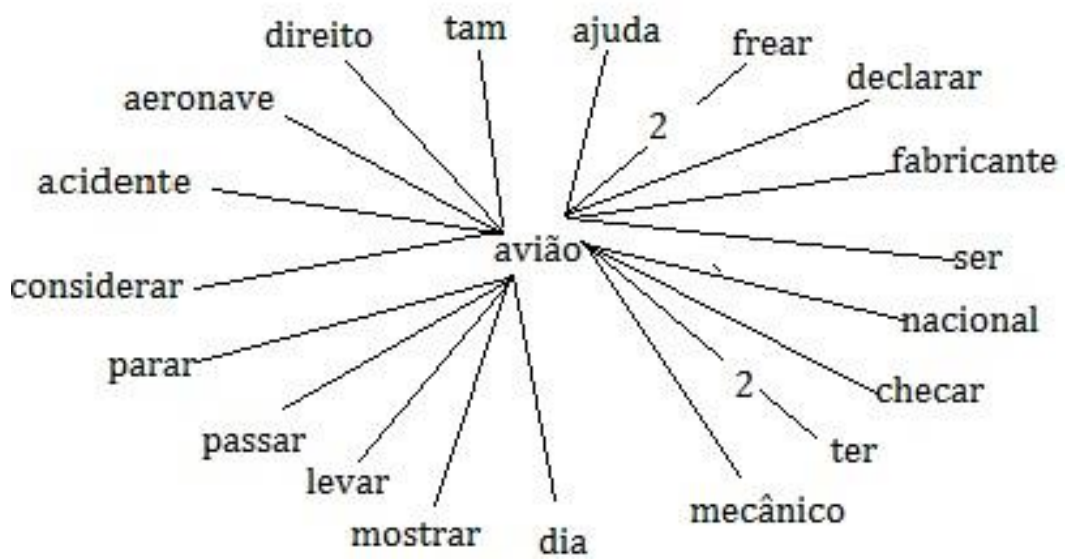

Figura 3.2: Grafo de co-ocorrência da palavra “avião”. Extraído de Nóbrega (2013)

Depois, com as palavras que mais co-ocorreram com a palavra alvo (quantidade determinada pela janela; se for G3, utiliza-se as 3 primeiras do ranque), cria-se uma lista de palavras do contexto. Para a Figura 3.2, as palavras de contexto escolhidas seriam "frear", "ter" e outra palavra selecionada aleatoriamente. Finalmente, aplica-se o algoritmo G-T para desambiguar o substantivo.

Houve três tipos de avaliações desenvolvidas neste trabalho: avaliar a tarefa All-words, a tarefa Lexical sample e avaliar a contribuição do cenário multidocumento na desambiguação. A tarefa All-words mostrou que os algoritmos G3 e G5 propostos obtiveram os melhores resultados em precisão, cobertura e acurácia $(49.56 \%, 43.90 \%, 43.90 \%$ e 46.87\%, 41.80\%, 41.80\%, respectivamente) em relação aos outros algoritmos utilizados, mas não foi superior aos resultados obtidos pelo método heurístico ( $51 \%$ em precisão, cobertura e acurácia). Para a tarefa de Lexical sample, selecionaram-se 20 palavras que apresentaram mais de dois sentidos anotados no córpus. Os resultados foram que a precisão do método proposto foi $19.10 \%$, sendo que a maior precisão foi obtida pelo método de Mihalcea (32.37\%). O melhor método de Lesk foi o S-T com $28.46 \%$ e o método heurístico obteve $27.88 \%$. O fato de que o método proposto apresente um menor desempenho nesta tarefa deve-se a este atribuir só um sentido por coleção de textos. Avaliando a contribuição do cenário multidocumento, obteve-se que os algoritmos G3 e G-T conseguiram desambiguar $43.90 \%$ e $41.20 \%$ das palavras (a diferença representa 61 palavras), respectivamente. Considerando que o algoritmo G3 faz uso do G-T no processo de 
desambiguação, concluiu-se que a utilização do cenário multidocumento tem uma contribuição positiva para a DLS.

\subsubsection{Trabalho de Travanca (2013)}

Travanca (2013) propôs duas abordagens para a Desambiguação Lexical de Sentido de verbos para o português europeu. A primeira, baseada em regras, faz uso das descrições lexicais, sintáticas e semânticas dos sentidos dos verbos presentes em um recurso lexical, chamado ViPEr (Baptista, 2012), para determinar o sentido de um verbo. A segunda usa aprendizado de máquina com um conjunto de atributos comumente usados em DLS para determinar o sentido correto de um verbo. As duas abordagens foram integradas no módulo XIP (parser) do STRING (Mamede et al., 2012), que é um sistema de PLN híbrido, estatístico e baseado em regras, desenvolvido no $\mathrm{L}^{2} \mathrm{~F}^{43}$.

ViPEr é um recurso lexical que descreve várias informações sintáticas e semânticas sobre os verbos do português europeu. Este recurso é dedicado aos verbos cujos sentidos permitem definir sua respectiva construção e as restrições seletivas nas posições dos argumentos (sujeito e complementos). Possui um total de 5037 lemas de verbos e um total de 6224 sentidos de verbos, considerando os que têm frequência 10 ou maior no córpus CETEMPúblico ${ }^{44}$ (Rocha e Santos, 2000).

Na primeira abordagem, objetivou-se a implementação de um sistema de geração de regras que forneça as regras e um léxico de verbos ao módulo XIP, como suporte à desambiguação de verbos. Antes de construir o sistema de geração de regras, foi necessário definir os atributos disponíveis no ViPEr que devem ser considerados no parsing e, consequentemente, usados na geração de regras. Os atributos escolhidos foram:

- restrições seletivas sobre os argumentos verbais (N0 até N3) e suas respectivas preposições;

- propriedade que denota construções reflexivas (por exemplo, queixar-se);

- propriedades de transformação, considerando os dois tipos de passivos mais comuns (com os auxiliares "ser" e "estar");

- propriedade que indica se o significado do verbo permite a construção do padrão verbum dicendi ${ }^{45}$

\footnotetext{
${ }^{43} \mathrm{~L}^{2} \mathrm{~F}$ é o Laboratório de sistemas de Língua Falada.

${ }^{44}$ Disponível em http://www.linguateca.pt/cetempublico/

${ }^{45}$ Chamamos verbum dicendi as formas verbais que designam ações de comunicação linguística (como "dizer" na sentença "Ele disse") ou que expressam crença, reflexão ou emoção (como "pensar" na sentença "Ele pensou"), que servem para introduzir a voz da personagem.
} 
- e, uma propriedade que indica a possibilidade de pronominalização do dativo em alguns argumentos verbais.

O sistema de geração de regras está composto por 4 módulos, mencionados a seguir:

- Parsing: o modulo de parsing começa processando o arquivo de ViPEr e construindo uma estrutura que represente cada verbo como um conjunto de significados. Por sua vez, cada significado é representado como uma coleção de atributos descritos em ViPEr e seus possíveis valores. Esse módulo também produz um léxico usado pela gramatica do XIP (XIP grammar). O léxico produzido contém informação sobre os lemas dos verbos e cada uma das possíveis classes as quais podem pertencer.

- Geração de diferenças, na qual cada verbo é percorrido, e as diferenças entre sentidos de um verbo são geradas. Estas são usadas para a criação das regras de desambiguação.

- Módulo de geração de regras. Nesse módulo, as diferenças encontradas no módulo anterior são transformadas em regras. Com cada diferença, normalmente se geram duas regras, uma para cada sentido contido na diferença.

- Prioridade de Regras. Nesse módulo, estabelece-se uma ordem na aplicação de regras. Essa ordem é obtida com base no impacto de cada uma das regras na determinação da classe correta.

Na segunda abordagem, foi usada a ferramenta MegaM (Daumé, 2004), que utiliza modelos de máxima entropia, para a geração do classificador. O classificador gerado foi integrado na ferramenta STRING. O classificador não foi testado sobre todos os verbos devido ao tempo de anotação manual de dados de treinamento. Os verbos utilizados para a avaliação do aprendizado de máquina foram: "explicar", "falar”, "ler", "pensar", "resolver”, "saber” e "ver". O que motivou os autores a usarem esses verbos foi que apresentaram um alto número de instâncias que não foram desambiguadas depois do teste da abordagem baseada em regras. Foram anotados, no total, 500 exemplos para cada lema.

Os atributos usados no método de classificação foram os seguintes:

- Atributos locais, obtidos em janelas de palavras, usando uma janela de tamanho 3. As informações coletadas sobre cada token foram a classe gramatical e o lema.

- Atributos sintáticos, considerando constituintes diretamente dependentes do verbo. As informações usadas foram a classe gramatical e o lema do núcleo de cada constituinte diretamente relacionado, junto com seu respectivo nome de dependência (SUBJ, CDIR e MOD foram considerados).

- Atributos semânticos, tais como as restrições seletivas dos argumentos do verbo. 
Para as avaliações, o baseline usado foi o método do sentido mais frequente. A técnica de avaliação foi a 10-fold cross validation, obtendo como resultado uma acurácia de $84 \%$ para o método baseline. Fazendo testes com o método baseado em regras, obteve-se $64.82 \%$ de acurácia. Já quando se usaram e a abordagem baseada em regras e o método baseline, a acurácia foi de $79.15 \%$. Finalmente, usando os dois métodos implementados (abordagem baseada em regras e aprendizado de máquina) e o baseline (usando o melhor método para cada verbo a desambiguar), obteve-se uma acurácia de $87.2 \%$.

\subsubsection{Trabalho de Gao et al. (2014)}

Gao et al. (2014) propuseram um método que explora o conhecimento semântico da WordNetPr. A ideia deles foi expandir o conhecimento para um sentido, usando os substantivos (já que eles são bons descritores das coisas) da glosa e os sentidos que advêm das relações semânticas na WordNet-Pr.

O método pode ser dividido em 3 passos: (1) selecionar as palavras de contexto, em que as palavras de contexto são selecionadas usando o método baseado em árvores de constituintes proposto por Lu et al. (2012); (2) extrair os substantivos das glosas de cada sentido da palavra a desambiguar (palavra alvo), chamado $G L$, e os sentidos correspondentes às relações semânticas na WordNet-Pr para cada sentido da palavra alvo (sinonímia, antonímia, meronímia, hiponímia, entre outros), chamado $S L$; e (3) selecionar o sentido correto para a palavra alvo. O sentido correto é aquele que possui a maior relevância semântica. A relevância semântica de um sentido é calculada como a soma da relevância semântica da palavra com seu contexto, a relevância semântica dos substantivos da glosa com seu contexto e os sentidos, extraídos das relações semânticas, com seu contexto.

Os autores definiram 5 tipos de relevância semântica que ajudariam no cálculo da relevância semântica geral para um sentido. A primeira delas foi a relevância semântica entre sentidos, chamada $r\left(S_{1}, S_{2}\right)$. Esta relevância é calculada com a seguinte fórmula:

$$
r\left(S_{1}, S_{2}\right)=\frac{\operatorname{dep}(S)}{\operatorname{dist}\left(S_{1}, S_{2}\right)+\operatorname{out}(S)+\varepsilon}
$$

onde dist $\left(S_{1}, S_{2}\right)$ representa a mínima distância entre o sentido $S_{1}$ e $S_{2}$ no grafo da WordNet-Pr; $S$, o mínimo pai comum entre $\mathrm{S}_{1}$ e $\mathrm{S}_{2} ; \quad \operatorname{dep}(S)$, a profundidade de $\mathrm{S}$ no grafo da WordNet-Pr; e out $(S)$, o grau de saída de S no grafo da WordNet-Pr.

A segunda relevância é dada entre um sentido e uma palavra, chamada $R(S, W)$. Esta relevância é calculada da seguinte maneira: 


$$
R(S, W)=\sum_{i=1}^{\left|W_{i}\right|} v_{i} \times r\left(S, W_{i}\right)
$$

onde $S$ representa o sentido; $W$, a palavra; $W_{i}$, o sentido $i$ da palavra $W ; r\left(S, W_{i}\right)$, a relevância semântica entre o sentido $S$ e o sentido $W_{i}$; e $v_{i}$, a frequência do sentido $W_{i}$.

A terceira relevância é dada entre um sentido e um conjunto de palavras, chamada $R(S, C)$. Esta relevância é calculada da seguinte maneira:

$$
R(S, C)=\sum_{i=1}^{|C|} V_{i} \times R\left(S, C_{i}\right)
$$

onde $S$ representa o sentido; $C$, o conjunto de palavras; $C_{i}$, a palavra $i$ do conjunto $C$; $\mathrm{R}\left(S, C_{i}\right)$, a relevância semântica entre o sentido $S$ e a palavra $C_{i}$; e $V_{i}$, o peso da palavra $C_{i}$, atribuído na seleção de palavras do contexto..

A quarta relevância é dada entre duas palavras e é calculada como o máximo valor de relevância semântica entre os sentidos das duas palavras.

Finalmente, a quinta relevância é dada entre dois conjuntos de palavras e é calculada como o máximo valor de relevância semântica obtido entre as palavras dos dois conjuntos.

Com estas definições feitas, os autores definiram a relevância semântica geral para um sentido de uma palavra alvo em um contexto como produto da somatória ponderada de R(S,C), $\mathrm{R}(\mathrm{GL}, \mathrm{C})$ e R(SL,C), com a frequência do sentido da palavra alvo.

Para os experimentos, os autores usaram o conjunto de dados da tarefa All-words do Senseval-3 e compararam os resultados obtidos pelo seu método com os obtido por uma adaptação do método de Lesk (1986). Os resultados obtidos foram que o método proposto foi superior nas classes gramaticais avaliadas (substantivo, verbo e adjetivo), obtendo uma precisão geral de $43.5 \%$, em relação a $33.4 \%$, obtido pela adaptação do Lesk.

3.1.12 Trabalho de Agirre et al. (2014) e Agirre e Soroa (2009)

Tanto em Agirre et al. (2014) quanto em Agirre e Soroa (2009), foi apresentado um método não supervisionado baseado em grafos que usa o conhecimento de uma base de conhecimento lexical (baseada na WordNet). O algoritmo usado em seu método foi o PageRank. Eles demonstraram que seu algoritmo usa o grafo completo da WordNet de maneira eficiente. Os autores mencionaram que seu método apresentou melhores resultados que abordagens prévias na tarefa de All-words para o inglês. Mostraram também que o método proposto pode ser 
adequado a outros idiomas, obtendo resultados bons, com a única condição de haver uma WordNet para o idioma em foco.

O algoritmo PageRank (Brin e Page, 1998) é um método para ranquear os vértices de um grafo de acordo com a sua estrutura de arestas. Esta abordagem pauta-se na hipótese de que o algoritmo PageRank irá apontar os sentidos mais relevantes dentro de um contexto. O ranque gerado pelo algoritmo consiste da soma de dois fatores: a quantidade de votos de um vértice e a probabilidade de alcançá-lo ao percorrer a estrutura do grafo. Os votos são atribuídos por meio das arestas, ou seja, se existe uma aresta $e_{i j}$ entre os vértices $v_{i}$ e $v_{j}$, um voto é atribuído à $v_{j}$ levando em consideração o grau de importância (ranque) de $v_{i}$. $\mathrm{O}$ valor da probabilidade de se alcançar um vértice é calculado por uma matriz $M$, construída a partir de um grafo $\mathrm{G}$ com $\mathrm{N}$ vértices. A matriz $M$ é constituída por $N$ linhas e $N$ colunas, onde cada célula $M_{j i}$ é preenchida com o valor $1 / d_{i}$ ou 0 , caso exista uma aresta entre os vértices $v_{i}$ e $v_{j}$ ou não, respectivamente. $\mathrm{O}$ valor $d_{i}$ representa a quantidade de arestas que saem do vértice $\mathrm{v}_{\mathrm{i}}$ (assim, $1 / d_{i}$ representa a probabilidade, sem adotar relevância, de sair de $v_{i}$ e chegar diretamente a $v_{j}$ ).

A fórmula a seguir calcula o valor do PageRank para cada vértice, onde $v$ representa um vetor contendo todas as probabilidades de se alcançar um vértice (este, na forma original, tem os mesmos valores para cada vértice, por exemplo, se fossem $N$ vértices, cada um deles teria probabilidade $1 / N$ ), a variável $M P r$ modela a quantidade de votos recebidos pelo vértice, e $c$ é um valor entre zero e um, denominado fator de relaxamento.

$$
\operatorname{Pr}=c M \operatorname{Pr}+(1-c) v
$$

Este algoritmo é calculado aplicando-o iterativamente até convergir a um threshold dado ou até um número de iterações executadas. Os autores desenvolveram 3 métodos: um usando o algoritmo PageRank original e outros dois com modificações no vetor v da formula mostrada.

O primeiro método é descrito a seguir:

- para cada palavra $W_{i}$ do contexto de entrada e cada sentido $\mathrm{v}_{\mathrm{i}}$ dessa palavra, faz-se uma busca em largura sobre um grafo de conhecimento (os grafos usados foram usados das bases de conhecimento lexical mencionadas no decorrer deste trabalho) começando no vértice $v_{i}$;

- em cada execução da busca em largura, computa-se o caminho mínimo entre um $\mathrm{v}_{\mathrm{i}}$ e todos os sentidos associados às palavras do contexto;

- depois destas execuções, obtém-se um conjunto de caminhos mínimos para cada sentido $\mathrm{v}_{\mathrm{i}}$, que se unem formando o grafo de desambiguação;

- finalmente, executamos o algoritmo PageRank original sobre o grafo de desambiguação; 
- Com os resultados obtidos depois da execução do algoritmo PageRank, escolhemos os sentidos mais bem ranqueados, sendo que, em caso de empate, escolhe-se um sentido aleatório dentre os empatados.

O segundo método implementado foi o Personalized PageRank (Ppr). Este método faz uso de todo o GKB. Neste método, inserem-se as palavras de contexto no grafo de conhecimento, que são relacionadas usando arestas direcionadas aos seus respectivos sentidos e, depois, executa-se o algoritmo de Ppr. A diferença entre o Ppr e o PageRank original é que, no primeiro, as probabilidades são concentradas nas palavras de contexto e, no segundo, todas as probabilidades do vetor $\mathrm{v}$ da equação têm o mesmo valor. Isto faz com que as palavras mais importantes insiram mais votos nos sentidos. Um problema encontrado neste algoritmo foi que, se algumas das palavras a serem desambiguadas tiverem dois sentidos que têm alguma relação semântica, esses sentidos podem se reforçar, tirando votos de outros sentidos.

Para solucionar este problema, apresentou-se um terceiro método, que usa o algoritmo Ppr_w2w, que é uma variação do Ppr, no qual é construído um grafo para cada palavra a ser desambiguada em um contexto. Entretanto, para cada palavra a ser desambiguada, concentra-se a probabilidade inicial só nos sentidos das palavras de contexto. Assim, são as palavras de contexto que incrementam a importância relativa dos sentidos da palavra alvo (palavra a ser desambiguada) e evita-se o problema encontrado no método anterior. Uma dificuldade encontrada foi que este método não desambigua todas as palavras em uma execução, mas apenas uma palavra para cada execução, fazendo com que seja menos eficiente.

Nos experimentos, usaram-se como bases de conhecimento lexicais o MCR16 (Multilingual Central Repository) (Atserias et al., 2004) mais o Xwn (eXtended WordNet relations) (Mihalcea e Moldovan, 2001), WordNet 1.7 mais o Xwn, e WordNet 3.0 mais a gloss $^{46}$; e para o algoritmo de PageRank, consideraram-se um máximo de 30 iterações para terminar a execução do algoritmo e um fator de relaxamento de 0.85 .

Para avaliar seus métodos, fizeram-se testes sobre o Senseval-2, o Senseval-3 e o Semeval-2007 na tarefa de All Words. No Senseval-2, obteve-se que o método Ppr_w2w apresentou o melhor resultado na avaliação geral, obtendo uma F1 de 59.7 (cobertura de 58.6\%). Também obteve o melhor resultado para as classes gramaticais verbo, adjetivo e advérbio (F1 de 40.3, 59.8 e 72.9, respectivamente; e cobertura de $38.9 \%, 58.3 \%$ e $70.1 \%$, respectivamente). No Senseval-3, o algoritmo Ppr_w2w apresentou também os melhores resultados na avaliação geral (F1 de 57.9), mas o método pPr obteve o melhor resultado para os verbos (F1 de 47.5). Já no Semeval-2007,

\footnotetext{
${ }^{46}$ A gloss inclui relações entre as palavras incluídas nas glosas dos synsets e os synsets da WordNet-Pr. Disponível em http://wordnet.princeton.edu/glosstag.shtml.
} 
o método tradicional de PageRank obteve os melhores resultados na avaliação geral (F1 de 43.0) e na avaliação por classe gramatical, no entanto, o método Ppr_w2w obteve o mesmo resultado para os verbos (F1 de 56.0).

\subsubsection{Trabalho de Chaplot et al. (2015)}

Chaplot et al. (2015) modelaram o problema de DLS como uma consulta de inferência Maximum A Posteriori (MAP) sobre um grafo não dirigido de Markov (em inglês, Markov Random Field ou MRF), construído usando a WordNet-Pr e parsers de dependência. O objetivo foi maximizar a probabilidade conjunta dos sentidos de todas as palavras em uma sentença, dadas as dependências de sentido geradas no grafo.

Este método foi construído tendo como premissa duas ideias básicas: (1) a dependência de sentido, que afirma que o sentido de uma palavra depende do sentido de outras palavras em uma sentença, e não das próprias palavras; e (2) a dependência seletiva, que afirma que o sentido de uma palavra depende do sentido de algumas palavras da sentença e não de todas.

A construção do grafo MRF foi realizada da seguinte maneira: para cada sentença, foram definidos nós para cada palavra de conteúdo (substantivos, verbos, adjetivos e advérbios) da mesma. O valor do nó pode ser representado pelos diferentes sentidos que pode apresentar a palavra. Foi também definido um valor de nó potencial que denota a distribuição de probabilidade de sentidos de uma palavra. Estes são determinados pela frequência do sentido na WordNet-Pr. A fórmula usada nesta distribuição foi a seguinte:

$$
\varphi\left(x_{i}=s_{i}^{a}\right) \sim \text { frequência }\left(s_{i}^{a}\right)+1 \text {; para todo a }
$$

onde: $x_{i}$ representa a palavra na posição $i ; \mathrm{s}_{i}{ }^{a}$, o sentido $a$ que assume a palavra $x_{i}$; e, frequência $\left(\mathrm{s}_{i}{ }^{a}\right)$, a frequência de ocorrência do sentido $\mathrm{s}_{i}^{a}$ na WordNet-Pr.

A respeito da criação de arestas: para cada sentença, as arestas foram construídas usando a estrutura de dependências de um parser de dependência (neste método, foram usados o Link Parser $^{47}$ e o Stanford Parser $^{48}$ ). O valor potencial de uma aresta foi definido usando a probabilidade de co-ocorrência de dois sentidos de duas palavras dependentes. Este valor foi obtido usando a medida de similaridade path do pacote WordNet::Similarity (Patwardhan et al., 2003). A fórmula usada para o valor potencial de uma aresta foi o seguinte:

$$
\varphi\left(x_{i}=s_{i}^{a}, x_{j}=s_{j}^{b}\right) \sim \operatorname{similaridade}\left(s_{i}^{a}, s_{j}^{b}\right) ; \text { para todo } a, b
$$

\footnotetext{
${ }^{47}$ Disponível em http://www.link.cs.cmu.edu/link/

${ }^{48}$ Disponível em http://nlp.stanford.edu/software/lex-parser.shtml
} 
onde $x_{i}$ representa a palavra na posição $i ; x_{j}$ representa a palavra na posição $j ; \mathrm{s}_{i}{ }^{a}$, o sentido $a$ que assume a palavra $x_{i} ; \mathrm{s}_{j}^{b}$, o sentido $b$ que assume a palavra $x_{j}$; e, similaridade $\left(\mathrm{s}_{i}{ }^{a}, \mathrm{~s}_{j}{ }^{b}\right)$, a medida de similaridade entre o sentido $\mathrm{s}_{i}^{a}$ e o sentido $\mathrm{s}_{j}^{b}$.

Com o MRF criado, o objetivo foi encontrar a combinação de sentidos que maximize a probabilidade conjunta, que vem dada pela seguinte fórmula:

$$
\varphi(X)=\varphi\left(x_{1}, x_{2}, x_{3}, \ldots x_{n}\right)=\prod_{x_{i} \in X} \varphi\left(x_{i}\right) \prod_{\left(x_{i}, x_{j}\right) \in E} \varphi\left(x_{i}, x_{j}\right)
$$

Com relação à avaliação, os autores realizaram experimentos sobre o conjunto de teste da tarefa de All-words do Senseval-2, do Senseval-3 e do Semeval-2007 e compararam os resultados com outros métodos baseados em grafos, tais como o método de Agirre et al. (2014) (melhor método baseado em grafos) e de Sinha e Mihalcea (2007). Nestes experimentos, foram usados a medida de similaridade path do pacote WordNet::Similarity, os parsers de dependência Link Parser e Stanford Parser, e o pacote UGM (Schmidt, 2007) do MatLab para executar a consulta de inferência MAP.

Dentre os resultados obtidos, salienta-se que, de maneira geral, o método proposto pelos autores superou todos os métodos comparados em todos os conjuntos de teste (uma medida F1 média de 56.57, quando usado o Link Parser, e 55.9 quando usado o Stanford Parser, em relação a 53.1 do método de Agirre e Soroa).

Analisando o desempenho dos métodos segundo a classe gramatical, obteve-se que o método proposto usando o Link Parser superou os demais em todas as classes gramaticais, com exceção dos substantivos no Senseval-2, no qual o método de Agirre e Soroa obteve 70.3 (em relação a 66.9 do método proposto) e dos adjetivos no Senseval-3, no qual o método de Agirre e Soroa obteve 63.6 (em relação a 59.9 do método proposto).

\subsection{Métodos baseados em Córpus}

\subsubsection{Trabalho de Audibert (2004)}

Audibert (2004) apresentou um estudo profundo de vários atributos para a desambiguação lexical do sentido. Ele usou um corpus para o francês, avaliando as 60 palavras mais ambíguas (20 substantivos, 20 adjetivos e 20 verbos, com médias de 14.2, 14.1 e 47.4 sentidos por palavra). As configurações de atributos avaliadas tiveram a forma seguinte: [par1, par2, par3, par4], onde (1) o par1 pode apresentar um dos valores de unigrama (1gr), bigrama (2gr) ou 
trigrama (3gr); (2) o par2 representa se vai ser usada a forma morfológica (o lema), a classe gramatical refinada (por exemplo, substantivo comum (NCOM) ou verbos em infinitivos (VINF)), ou a classe gramatical; (3) o par3 representa se será considerada a posição das palavras (position), distinção entre contexto esquerdo e direito (leftright) ou não considerará a ordem (unordered); e (4) o par4 representa se serão consideradas todas as palavras (all) ou só as palavras de conteúdo (content). O autor usou as técnicas de Naive Bayes e Listas de Decisão sobre os critérios utilizados para a desambiguação.

Com Naive Bayes, o autor mostrou os melhores resultados para as três classes gramaticais a serem desambiguadas, sendo que o melhor conjunto de atributos foi [2gr,lemma,leftright,all ], tendo uma precisão de $83.6 \%$ e tamanho da janela \pm 4 para os substantivos, $77.9 \%$ e \pm 3 para os adjetivos, e $74 \%$ e \pm 4 para os verbos.

As listas de decisão foram usadas para analisar classes gramaticais que têm maior importância na desambiguação e a distribuição espacial das mesmas. Concluiu-se que as palavras que estão ao lado direito do verbo (posições $+1,+2$ e +3 ) têm maior importância para a desambiguação de verbos, isto é, a informação que advém do objeto é mais importante para a desambiguação dos verbos do que a que advém do sujeito na ordenação sujeito-verbo-objeto.

Outra conclusão que se obteve foi a importância do uso de stopwords na desambiguação. Experimentos realizados mostraram que, quando se omitiu este tipo de palavras, a precisão do classificador por lista de decisão caiu em média $5.3 \%$ para os substantivos, $7.27 \%$ para os adjetivos, e o nível de queda mais alto foi para os verbos, com $13.53 \%$.

\subsubsection{Trabalho de Turney (2004)}

Turney (2004) fez um estudo na tarefa de Lexical sample do Senseval-3. Esta tarefa propôs a desambiguação de 57 palavras, com aproximadamente 140 exemplos de treinamento e 70 exemplos de teste para cada palavra. A forma de abordar a tarefa proposta foi tratando-a como um problema clássico de aprendizado de máquina supervisionado.

Cada exemplo é representado como um vetor variável de caraterísticas de tamanho grande (várias centenas), composto de características sintáticas e semânticas. Os atributos sintáticos são baseados em etiquetas morfossintáticas que são atribuídas por um etiquetador baseado em regras (Brill, 1994). Cada uma delas representa a existência de uma etiqueta morfossintática, exata ou não, em uma posição determinada ao redor da palavra alvo, sendo que os valores possíveis dessas características podem ser um ou zero (existência ou inexistência). As características semânticas são representadas pela posição mais próxima (seguinte ou anterior) das palavras do contexto com respeito à palavra alvo; os valores destas características são obtidos do cálculo da 
similaridade semântica entre a palavra alvo e uma palavra de contexto. A similaridade semântica é computada segundo o algoritmo PMI (Pointwise Mutual Information) usando recuperação de informação (Turney, 2001; Terra e Clarke, 2003). O cálculo das probabilidades da fórmula é feito usando o Waterloo Multitext System (Clarke et al., 1995) com um grande córpus coletado por um web crawler.

O software Weka foi usado para induzir o modelo dos dados de treinamento e predizer as classes de exemplos de teste. $\mathrm{Na}$ avaliação, o método proposto superou os resultados do baseline, atribuído pelo sentido mais frequente na WordNet-Pr. Contudo, o autor concluiu que o impacto no desempenho é relativamente pequeno, mas exaltou o uso das características semânticas e o cálculo da similaridade.

\subsubsection{Trabalho de Specia (2007)}

Specia (2007) apresentou um método de DLS para a tradução automática entre o inglês e o português. Focou na desambiguação de 10 verbos do inglês ("ask", "come", "get", "give”, "go", "live”, "look", “make”, "take” e "tell”) que foram considerados mais ambíguos. $\mathrm{O}$ método proposto usa formalismo baseados em lógica de primeira ordem, que permitem a representação de diversas fontes de conhecimento sobre os exemplos e as línguas fonte e alvo, e da técnica de Programação Lógica Indutiva (PLI) (Muggleton, 1991), que possibilita o aprendizado de modelos de desambiguação a partir dessa representação. Foi utilizado o sistema PLI Aleph (A Learning Engine for Proposing Hypotheses) (Srinivasan, 2000), que é um framework de PLI implementado em Prolog. Para explorar o potencial da PLI para a DLS, uma tarefa importante foi a identificação e aquisição de fontes de conhecimento relevantes para a DLS de verbos, as quais são mencionadas a seguir:

- Bag of words: cinco palavras à direita e à esquerda da palavra ambígua;

- Bigramas frequentes: pares de palavras adjacentes em uma sentença que ocorrem com uma frequência mínima no córpus (por exemplo, 10);

- POS: classes gramaticais das cinco palavras à direita e à esquerda da palavra ambígua;

- Contexto lematizado: lema das cinco palavras de conteúdo à direita e à esquerda da palavra ambígua;

- Colocações;

- Relações sintáticas;

- Relações sintáticas frequentes: pares de palavras sintaticamente relacionadas na sentença que ocorrem no córpus com uma frequência mínima (10 vezes); 
- Sobreposição de definições: o sentido (ou tradução) que apresenta a maior taxa de sobreposição entre as palavras na sua definição em um dicionário e as palavras vizinhas à palavra ambígua (excluindo stopwords);

- Restrições de seleção: restrições de seleção do verbo ambíguo, definidas em termos dos traços semânticos dos seus argumentos;

- Expressões verbais;

- Regras criadas depois de observações e experimentos no córpus paralelo usado.

Fizeram-se diversos experimentos, tanto avaliações intrínsecas (incluindo tarefas multilíngue e monolíngue) quanto extrínsecas com a abordagem de DLS proposta. Para tarefas multilíngues, o PLI superou os resultados de outros algoritmos de aprendizado de máquina com as mesmas fontes de conhecimento. Quando comparado a outras abordagens diferentes (algoritmos de aprendizado, fontes de conhecimento, etc.) para tarefas monolíngues as abordagens de PLI obtiveram resultados comparáveis aos melhores métodos utilizados no Senseval-3.

\subsubsection{Trabalho de Dligach e Palmer (2008)}

Dligach e Palmer (2008) apresentaram um método para extrair informação semântica dos argumentos dos verbos e aplicar estas informações na desambiguação dos mesmos.

Três tipos de atributos foram usados: lexicais, sintáticos e semânticos. Os atributos lexicais considerados foram: (1) todas as palavras pertencentes a classes gramaticais abertas, sendo estas extraídas da sentença onde se encontra o verbo a desambiguar e as duas sentenças adjacentes; e (2) duas palavras à direita e à esquerda do verbo a desambiguar, assim como suas respectivas classes gramaticais. Os atributos sintáticos foram extraídos do parser de constituintes; ao final foram considerados: existência de sujeito e/ou objeto no verbo e quais são os núcleos e as classes gramaticais deles, existência de uma sentença subordinada, existência de um adjunto, o caminho na árvore sintática, desde o verbo a ser desambiguado até os argumentos do verbo, e a estrutura de subcategorização. A informação semântica a ser obtida advém dos vizinhos de dependência dinâmica ou Dynamic Dependency Neighbors (DDNs). Os DDNs são um conjunto de verbos que podem usar um determinado substantivo como um objeto em uma sentença. Por exemplo, "breakfast" pode ser usado com os verbos "attended", "prepare", "give", "delivered", entre outros, ou seja, esses verbos formam o DDNs do substantivo "breakfast". Sabendo quais verbos podem acompanhar um substantivo, podemos conhecer as propriedades semânticas do mesmo.

Para obter a lista de DDNs, foi usado o córpus Gigaword (Graff, 2003). Este córpus contém 5.7M artigos de notícias. A forma de obtenção foi a seguinte: (1) o córpus teve que ser 
processado com o parser MaltParser (Nivre et al., 2007), (2) foram obtidos todos os pares de substantivos e verbos que participaram em uma relação objeto-verbo e (3) foram guardadas as frequências de ocorrência de cada par encontrado.

Para a extração os atributos semânticos, foi necessário fazer um processo com os DDNs. Esse processo foi realizado da seguinte maneira:

- encontrar o substantivo no objeto do verbo a desambiguar;

- extrair os DDNs para esse substantivo;

- ordenar os DDNs por frequência e obter os $50^{49}$ primeiros;

- finalmente, incluir esses DDNs em um vetor de atributos onde cada um dos verbos extraídos seja um atributo separado.

A avaliação foi feita usando um conjunto de verbos anotados no projeto OntoNotes (Hovy et al., 2006). Os dados de teste foram 46577 instâncias de 217 verbos. Foi usado para a classificação o libsvm ${ }^{50}$ e computou-se a acurácia usando 5-fold cross-validation.

$\mathrm{Na}$ avaliação, foram comparados dois modelos: o primeiro incluía todos os atributos (lexicais, sintáticos e DDNs), e o segundo incluía todos os atributos com exceção dos DDNs. Os resultados mostraram que a acurácia do primeiro modelo foi superior ao segundo $(82.88 \%$ e 82.38 , respectivamente).

Outra avaliação foi feita, com o fim de comparar o desempenho do classificador usando outros atributos semânticos (como a WordNet-Pr e um Reconhecedor de Entidades Nomeadas (REN)). Nesta avaliação, foram comparados 5 configurações:

1. incluindo atributos lexicais e sintáticos;

2. incluindo atributos lexicais, sintáticos e a WordNet-Pr;

3. incluindo atributos lexicais, sintáticos e o reconhecedor de entidades nomeadas;

4. incluindo atributos lexicais, sintáticos, a WordNet-Pr e o REN;

5. e, incluindo atributos lexicais, sintáticos e os DDNs.

O resultado apresentado foi que o quinto modelo (com uma acurácia de 82.97\%) superou a todos os outros, incluindo o quarto modelo (com uma acurácia de $82.38 \%$ ). Com isto, concluiuse que o uso de DDNs ajuda na desambiguação lexical de sentidos de verbos. Uma

\footnotetext{
${ }^{49}$ Essa quantidade vem da análise de que, conhecendo-se os 50 primeiros verbos dos DDNs, já poderíamos conhecer as propriedades semânticas de um substantivo.

${ }^{50}$ Método SVM da biblioteca Weka. Disponível em http://www.csie.ntu.edu.tw/ cjlin/libsvm
} 
desvantagem dessa técnica é a necessidade da presença do objeto na sentença para que os DDNs possam ser usados.

Outro detalhe que os autores salientaram é que os DDNs podem ser uma ferramenta importante na construção de um sistema de DLS de verbos robusto para um idioma ou um domínio com poucos recursos, dado que resultaram em uma alta acurácia nos experimentos.

\subsubsection{Trabalho de Che e Liu (2010)}

Che e Liu (2010) exploraram um conjunto de sistemas em pipeline, a fim de ver como a anotação de papéis semânticos (APS) ajuda a DLS. Além disso, propuseram um modelo baseado em modelo da lógica de Markov, que combina lógica de primeira ordem com redes de Markov, com o mesmo fim. O córpus onde se fizeram os experimentos foi o OntoNotes Release 3.0 (Hovy et al., 2006), usando 60\% do mesmo para treinamento, $20 \%$ para desenvolvimento e $20 \%$ para teste. Nestes experimentos, foram considerados apenas os substantivos e os verbos para a desambiguação, devido a estes cobrirem a maior quantidade de palavras com múltiplos sentidos. Fizeram-se comparações com métodos pipelines, nos quais, para resolver a DLS, primeiro encontram-se os papéis semânticos e vice-versa; o método baseline, que faz o tratamento da DLS e anotação de papéis semânticos como dois eventos independentes, e também com o método do sentido mais frequente usando a WordNet-Pr. Alguns dos resultados obtidos foram que o método proposto possui uma maior acurácia em comparação com os outros métodos desenvolvidos. Mesmo assim, o valor do incremento na acurácia foi estatisticamente insignificante.

Os autores salientaram que a anotação de papéis semânticos não só contribui para a desambiguação dos verbos em uma sentença, mas também a desambiguação dos argumentos envolvidos na sentença. Outro ponto importante é que a anotação de papéis semânticos e a DLS não podem ser consideradas como tarefas independentes, uma vez que cada uma delas contribui com a outra, e, portanto, devem ser tratadas em conjunto. Por exemplo, se sabemos que "cat" é um agente do predicado "hit" em uma sentença, pode-se imaginar que "dog" também poderia ser um agente de "hit", embora esse último não apareça nos dados de treinamento. Além disso, na sentença "the cat is hitting a ball.", se sabemos que "hit" tem um sentido relacionado a "jogar", pode-se imaginar que "ball" deve ter o sentido de "é um objeto usado para jogar"; da mesma maneira, o sentido correto de "ball" pode ajudar a desambiguação do sentido de "hit".

\subsubsection{Trabalho de Silva e Amancio (2012)}

Silva e Amancio realizaram um estudo sobre como as redes complexas podem ser uteis na DLS. Eles argumentam que métodos supervisionados atuais não capturam todas as informações 
necessárias no processo de desambiguação, portanto, eles propuseram um classificador que denominam de ordem alta.

Neste classificador, primeiro eles apresentaram uma técnica para que, por meio de redes complexas e um córpus de treinamento, possam se aprender padrões entre as palavras a ser desambiguadas e o seu contexto, de tal maneira que depois, possam ser usadas na desambiguação de palavras.

Com o grafo gerado (por meio das redes), criaram uma fórmula expressada como uma combinação linear de um classificador de baixa ordem (foram testados os algoritmos de C4.5, kNN, Naive Bayes) e o classificador de alta ordem (que veio dado de executar a instânia de teste sobre o grafo gerado na etapa anterior).

Os autores apresentaram resultados para a tarefa Lexical sample, analisando as palavras "save", "note", "march", "presente" e "jam". Salienta-se que em alguns casos o uso do classificador de alta ordem não contribuiu na melhora. Um ponto que ressaltaram os autores foi que se reforçou o fato de que as redes construídas usando as palavras não são totalmente desorganizadas. Em vez disso, cada conjunto de palavras tende a formar padrões que o descrevem de forma exclusiva.

\subsection{Considerações Finais}

Neste capítulo, mostraram-se métodos propostos baseados em conhecimento e também baseadas em córpus. Contudo, têm-se outros trabalhos que também podem ser estudados, já que, mesmo sendo mais antigos, ajudaram nos avanços da DLS pelas abordagens que tiveram. Alguns deles são o método de Sussna (1993), que apresentou pela primeira vez o uso da WordNet-Pr como repositório de sentidos, o método de Black (1988), que apresentou o uso de listas de decisão como método de DLS, e método de Veronis e Ide (1990), que apresentou o uso de redes neurais.

Como apresentado no fundamento teórico e reforçado nos trabalhos estudados, salienta-se que métodos baseados em conhecimento têm sido mais abrangentes. Isto se deve ao fato de terem recursos disponíveis de grande tamanho que oferecem muitas informações que podem ajudar na desambiguação. No caso dos métodos baseados em córpus, salientam-se os graus altos de acurácia que obtêm, já que usam uma grande quantidade de instâncias para um pequeno número de palavras a desambiguar, porém, métodos baseados nessa abordagem são menos abrangentes. Um detalhe importante é a seleção do repositório de sentidos, já que este precisa ser abrangente para poder capturar todos os possíveis sentidos das palavras. Nos últimos anos, e como visto nos trabalhos estudados, a WordNet-Pr tem sido muito usada para o desenvolvimento de métodos de DLS. 
Outro ponto a ser ressaltado é que a maioria de métodos estudados não possuem os mesmos níveis de acurácia em todas as classes gramaticais. Métodos baseados em conhecimento apresentam melhores resultados para classes gramaticais como substantivos ou adjetivos, porém, para os verbos, os resultados que apresentam são os piores.

A respeito dos verbos, podemos ver que o desempenho varia segundo a abordagem utilizada. Algoritmos que usam análise das palavras de contexto, como a variação do algoritmo de Lesk (1986) proposta por Banerjee e Pedersen (2002), apresentam valores de 24.9\% de acurácia; já métodos baseados em web (Mihalcea e Moldovan, 1998) obtêm melhores resultados, podendo apresentar até $67 \%$ de acurácia. Esses valores são atingidos devido ao fato da Web conter uma grande quantidade de informações. Os métodos baseados em grafos, por sua vez, apresentam uma medida F1 de 57.9 (Agirre et al., 2014).

Em todos os métodos mencionados no parágrafo anterior, não foram consideradas informações sintáticas nem semânticas. Por outro lado, pode-se ver que métodos que incluem informações sintáticas e semânticas possuem um melhor desempenho. Por exemplo, Roberts e Kordoni (2012), que apresentam um método baseado em grafos, incluindo informações sintáticas, conseguem atingir valores de $43.7 \%$ em cobertura (em relação a $38.9 \%$ de Agirre e outros). Isto reforça a hipótese de que o uso de repositórios que contenham essas informações ajudará a melhorar o desempenho dos métodos de DLS para os verbos. Pode-se ver também que, para o português, o estado da arte para métodos baseados em conhecimento encontra-se em $64.82 \%$ em acurácia (Travanca, 2013).

Na Tabela 3.1, apresenta-se um resumo dos métodos de DLS estudados, sendo a primeira coluna o método estudado, a segunda coluna a abordagem usada pelo método, a terceira coluna os recursos usados e a última coluna o idioma para o qual foi aplicado.

Na Figura 3.3, apresentam-se os principais trabalhos de DLS encontrados na literatura ordenados no tempo, mostrando-se os pontos mais relevantes de cada trabalho, pode-se, assim, notar a evolução da área no tempo. Salienta-se que na linha do tempo, os métodos situados acima da linha são baseados em córpus e os que estão embaixo dela, são métodos baseados em conhecimento. 


\begin{tabular}{|c|c|c|c|}
\hline Trabalho & Abordagem & Métodos e Recursos & Idioma \\
\hline Lesk (1986) & Conhecimento & Dicionários & Inglês \\
\hline $\begin{array}{l}\text { Yarowsky } \\
\text { (1995) }\end{array}$ & $\begin{array}{l}\text { Aprendizado de } \\
\text { Máquina }\end{array}$ & $\begin{array}{l}\text { Heurísticas de um } \\
\text { Sentido por Discurso } \\
\text { e um sentido por } \\
\text { colocação }\end{array}$ & Inglês \\
\hline $\begin{array}{l}\text { Mihalcea e } \\
\text { Moldovan } \\
\text { (1999) }\end{array}$ & Conhecimento & Buscadores Web & Inglês \\
\hline $\begin{array}{l}\text { Kilgarriff et al. } \\
\text { (2000) }\end{array}$ & Conhecimento & $\begin{array}{l}\text { Método de Lesk (1986) } \\
\text { simplificado }\end{array}$ & Inglês \\
\hline $\begin{array}{l}\text { Banerjee e } \\
\text { Pedersen } \\
(2002)\end{array}$ & Conhecimento & $\begin{array}{l}\text { Adaptação do método } \\
\text { de Lesk (1986) com a } \\
\text { WordNet-Pr }\end{array}$ & Inglês \\
\hline $\begin{array}{l}\text { Audibert } \\
\text { (2004) }\end{array}$ & Aprendizado de máquina & $\begin{array}{l}\text { Naive Bayes e Listas } \\
\text { de Decisão }\end{array}$ & Francês \\
\hline Turney (2004) & Aprendizado de máquina & Córpus Anotado & Inglês \\
\hline $\begin{array}{l}\text { Sinha e } \\
\text { Mihalcea } \\
\text { (2007) }\end{array}$ & Conhecimento & Grafo e medidas de similaridade & Inglês \\
\hline Specia (2007) & $\begin{array}{c}\text { Aprendizado de máquina } \\
\text { e Regras }\end{array}$ & Córpus paralelo & $\begin{array}{l}\text { Inglês- } \\
\text { Português }\end{array}$ \\
\hline $\begin{array}{c}\text { Dligach e } \\
\text { Palmer (2008) }\end{array}$ & Aprendizado de máquina & $\begin{array}{c}\text { Dynamic Dependency Neighbors } \\
\text { (DDN) }\end{array}$ & Inglês \\
\hline $\begin{array}{l}\text { Che e Liu } \\
(2010) \\
\text { Silva e }\end{array}$ & Aprendizado de máquina & Córpus & Inglês \\
\hline $\begin{array}{l}\text { Amancio } \\
(2012)\end{array}$ & Aprendizado de máquina & Redes complexas & Inglês \\
\hline $\begin{array}{l}\text { Roberts e } \\
\text { Kordoni } \\
(2012)\end{array}$ & Conhecimento & $\begin{array}{c}\text { SSI-Dijkstra, SemCor como córpus } \\
\text { com anotações de sentidos, estruturas } \\
\text { de subcategorização }\end{array}$ & Inglês \\
\hline $\begin{array}{l}\text { Lu et al. } \\
\text { (2012) }\end{array}$ & Conhecimento & $\begin{array}{c}\text { parser sintático e medidas de } \\
\text { similaridades }\end{array}$ & Inglès \\
\hline $\begin{array}{c}\text { Travanca } \\
(2013)\end{array}$ & $\begin{array}{l}\text { Aprendizado de máquina } \\
\text { e baseado em } \\
\text { conhecimento }\end{array}$ & $\begin{array}{c}\text { STRING, como sistema de PLN a } \\
\text { modificar; ViPEr, como repositório } \\
\text { de sentidos }\end{array}$ & Português \\
\hline $\begin{array}{l}\text { Nóbrega } \\
\text { (2013) }\end{array}$ & Conhecimento & $\begin{array}{c}\text { Grafo de co-ocorrência, algoritmo de } \\
\text { Lesk (1986) }\end{array}$ & Português \\
\hline $\begin{array}{l}\text { Gao et al. } \\
\text { (2014) }\end{array}$ & Conhecimento & $\begin{array}{c}\text { Parser sintático, relação semântica, } \\
\text { grafos }\end{array}$ & Inglês \\
\hline $\begin{array}{l}\text { Agirre et al. } \\
\text { (2014) }\end{array}$ & Conhecimento & Grafos PageRank & $\begin{array}{l}\text { Inglês e } \\
\text { Espanhol }\end{array}$ \\
\hline $\begin{array}{l}\text { Chaplot et al. } \\
\text { (2015) }\end{array}$ & Conhecimento & $\begin{array}{c}\text { Consulta de Inferência MAP, grafo de } \\
\text { dependência }\end{array}$ & Inglês \\
\hline
\end{tabular}

Tabela 3.1: Trabalhos de DLS estudados 
Abordagens baseadas em córpus

Audibert (2004)

Listas de decisão, Naive

Bayes, análise de

desambiguação

\section{Heurística}

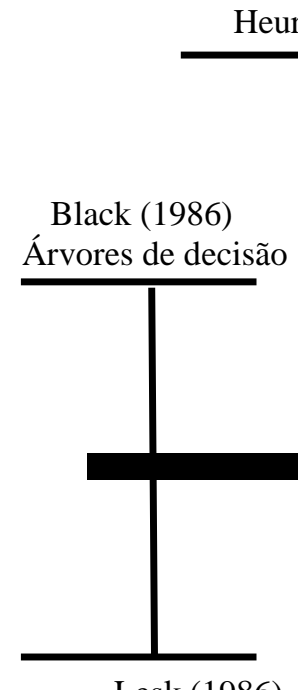

Lesk (1986)

Primeiro método de

DLS usando dicionários

Aprendizado de Máquina

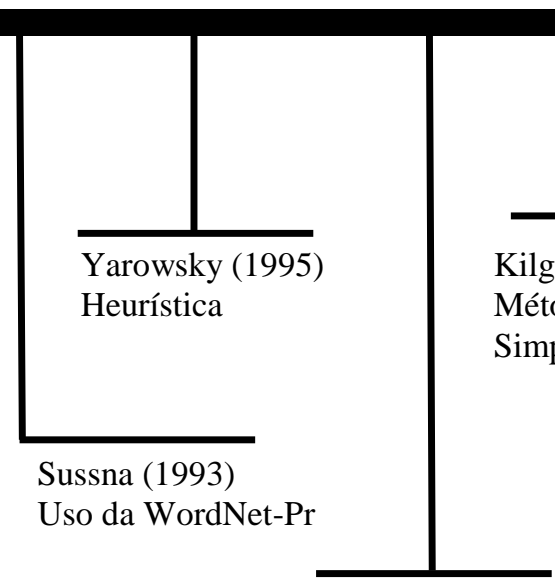

Mihalcea e Moldovan (1998)

Método baseado em Web contextos para a

Dligach e Palmer (2008)

Informação sintática dos

argumentos dos verbos

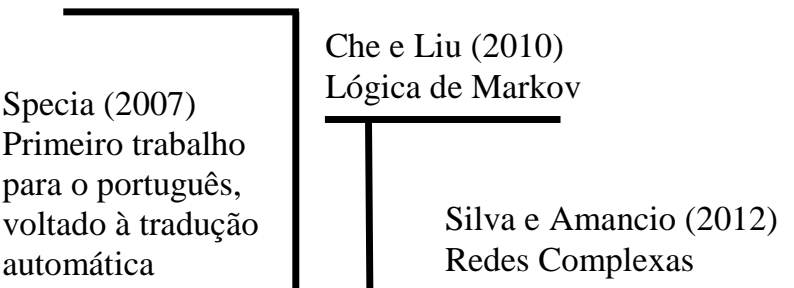

automática
Kilgarrif et al. (2000)

Método de Lesk

Simplificado

Banerjee e Pedersen (2002)

Método de Lesk usando

WordNet-Pr Grafos, SSI-Dijkstra, Estruturas de

Subcategorização

$$
\begin{array}{r}
\text { Lu et al. (2012) } \\
\text { Parser sintático e } \\
\text { medida de } \\
\text { similaridade }
\end{array}
$$

Redes Complexas

\section{Abordagens baseadas em conhecimento}

Figura 3.3: Linha do Tempo de Trabalhos Relacionados à Desambiguação Lexical de Sentido 


\title{
Capítulo
}

\author{
4
}

\section{Anotação de Córpus}

Uma etapa necessária do presente trabalho (que foi mencionado na Seção Objetivos do Capítulo 1) é a anotação de sentidos de verbos em um córpus. Com um córpus anotado com sentidos, poder-se-ão avaliar e comparar os métodos de Desambiguação Lexical de Sentido (DLS), além de fornecer um recurso útil para futuras pesquisas. Neste capítulo, apresenta-se o processo de anotação de córpus, as diretrizes que guiaram o processo, os resultados e a avaliação dos mesmos, descritos em Sobrevilla-Cabezudo et al. (2014). Desta forma, este capítulo tem a seguinte estrutura: na Seção 4.1, são apresentadas algumas considerações iniciais que servirão como guia para o processo de anotação; na Seção 4.2, é apresentada a metodologia de anotação usada; na Seção 4.3, é apresentada a ferramenta de auxílio à anotação; na Seção 4.4, são apresentados os resultados da anotação e a avaliação da mesma; e, finalmente, na Seção 4.5, são apresentadas as considerações finais.

\subsection{Considerações iniciais}

Nesta tarefa, teve-se por objetivo anotar o sentido das palavras da classe gramatical dos verbos. A escolha por esta classe pautou-se no fato de que os verbos, ao expressar um estado de coisas, são importantes na constituição dos enunciados (Fillmore, 1968). Além disso, dá-se continuidade ao trabalho realizado por Nóbrega (2013).

Para a execução desta tarefa, utilizou-se o CSTNews (Aleixo e Pardo, 2008; Cardoso et al., 2011), córpus multidocumento composto por 50 coleções ou grupos de textos, sendo que cada coleção aborda um mesmo tópico. No total, o CSTNews contém 72148 palavras, distribuídas em 140 textos. Os textos são do gênero "notícias jornalísticas". A escolha do CSTNews pautou-se nos seguintes fatores: (1) utilização prévia desse córpus no desenvolvimento de métodos de DLS para os substantivos comuns (Nóbrega, 2013) e (2) ampla abrangência de domínios ou categorias 
("política", "esporte", "mundo", entre outros.), fornecendo uma ampla quantidade de sentidos para o desenvolvimento de métodos de DLS robustos.

Especificamente, cada coleção do CSTNews contém: (1) 2 ou 3 textos sobre um mesmo assunto, extraídos de diferentes fontes jornalísticas; (2) sumários humanos (abstracts) mono e multidocumento; (3) sumários automáticos multidocumento; (4) extratos humanos multidocumento; (5) anotações semântico-discursivas; entre outras. As fontes jornalísticas das quais os textos foram extraídos correspondem a alguns dos principais jornais online do Brasil, tais como Folha de São Paulo, Estadão, Jornal do Brasil, O Globo e Gazeta do Povo. As coleções possuem em média 42 sentenças (de 10 a 89) e os sumários humanos multidocumento possuem em média 7 sentenças (de 3 a 14).

Como mencionado, os verbos ocupam lugar de centralidade nos enunciados. Isso pode ser constatado pela frequência de ocorrência dos mesmos no CSTNews. Na Figura 4.1, apresenta-se a distribuição da frequência de ocorrência das classes de palavras de conteúdo no CSTNews. Para o cálculo dessa distribuição, os textos do CSTNews passaram por um processo de etiquetação morfossintática automática, realizada pelo etiquetador ou tagger MXPOST (Ratnaparkhi, 1986), usando o modelo de treinamento para o português do Brasil obtido por Aires (2000) (que obteve 97\% de acurácia). Dessa etiquetação, verificou-se que a classe verbal é a segunda mais frequente (27.76\%). Os substantivos compõem a classe mais frequente, com $53.44 \%$ das palavras de conteúdo do córpus.

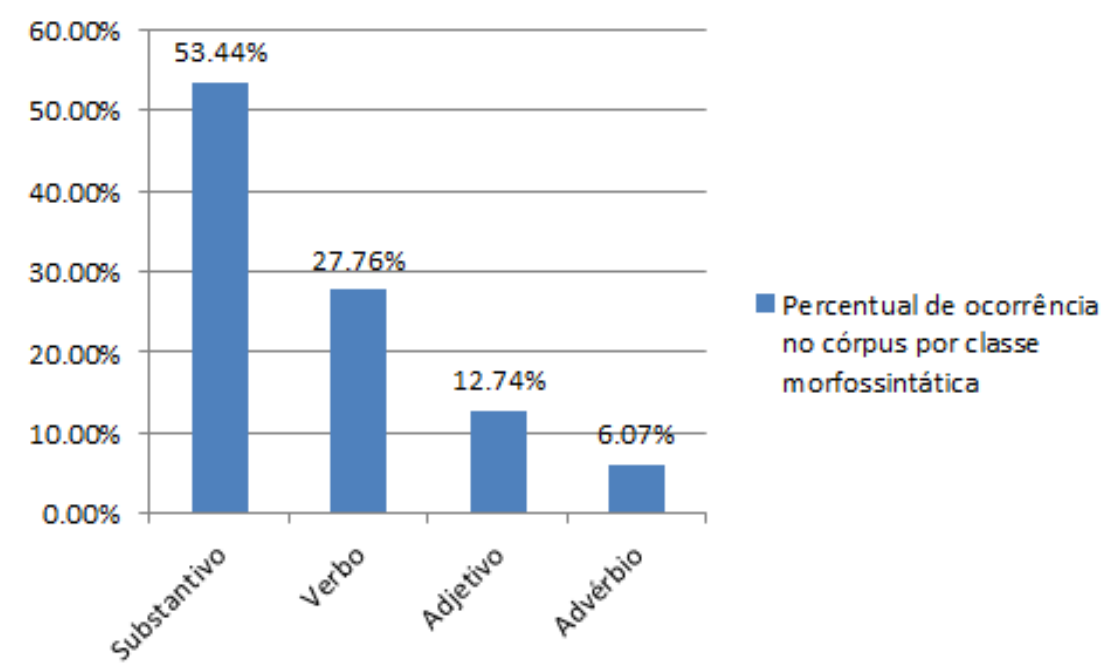

Figura 4.1: Percentual de ocorrência no córpus por classe morfossintática. Extraído de Nóbrega

Para a tarefa de anotação, alguns recursos lexicais desenvolvidos para o português, foram investigados, tais como o TeP 2.0 (Maziero et al., 2008), o Onto.PT (Gonçalo Oliveira et al., 2012) e a WordNet.Br (Dias da Silva, 2005). 
Apesar da existência desses recursos, optou-se por utilizar a WordNet.Pr, desenvolvida para o inglês, como repositório de sentidos. Mesmo tendo sido desenvolvida para o inglês, a WordNet.Pr foi escolhida porque, além de ser o recurso lexical mais utilizado nas pesquisas do PLN, apresenta (1) reconhecida adequação linguística e tecnológica, já que foi construída segundo princípios da ciência cognitiva e em um formato computacionalmente tratável, e (2) abrangência, já que a versão 3.0 possui mais de 155287 unidades lexicais do inglês e 117659 sentidos. Além disso, ressalta-se que a WordNet.Pr também foi o recurso utilizado por Nóbrega (2013) para o desenvolvimento de métodos de DLS para os substantivos do português.

\subsection{Metodologia de Anotação}

Para esta anotação, seguiu-se a mesma metodologia de Nóbrega (2013), que engloba critérios gerais e específicos.

Quanto aos critérios gerais, teve-se que, diante de uma coleção do CSTNews, os anotadores humanos tiveram que seguir 4 passos básicos: (1) escolher um dos textos da coleção para ser anotado; (2) anotar todas as palavras da classe dos verbos que ocorressem no texto escolhido em (1); (3) anotar o próximo texto da coleção após a anotação de todos os verbos do texto escolhido em (1) e assim sucessivamente, até que todos os textos da coleção tivessem sido anotados; (4) revisar a anotação de todos os textos da coleção e salvá-la no formato e endereço especificados.

Quanto aos critérios específicos, como a WordNet.Pr engloba os sentidos em inglês, delimitou-se um conjunto de 4 etapas para a anotação de cada verbo distinto:
A. selecionar um verbo " $x$ ” a ser anotado;
B. traduzir o verbo " $x$ ” para o inglês;
C. selecionar um synset da WordNet.Pr que representasse o sentido de " $x$ "; e,
D. anotar o verbo " $x$ " com o synset escolhido em (C).

Na Figura 4.2, a sequência metodológica composta pelas 4 etapas de anotação e os recursos linguísticos utilizados na tarefa é apresentada. As 4 etapas da Figura 4.2 auxiliaram a construção do editor NASP++, isto, é, uma ferramenta de auxílio à anotação de sentidos, a qual é descrita na próxima subseção.

Antes da descrição das funcionalidades da ferramenta NASP++, descreve-se cada uma das etapas metodológicas, enfatizando-se os critérios para a realização de cada uma delas. 


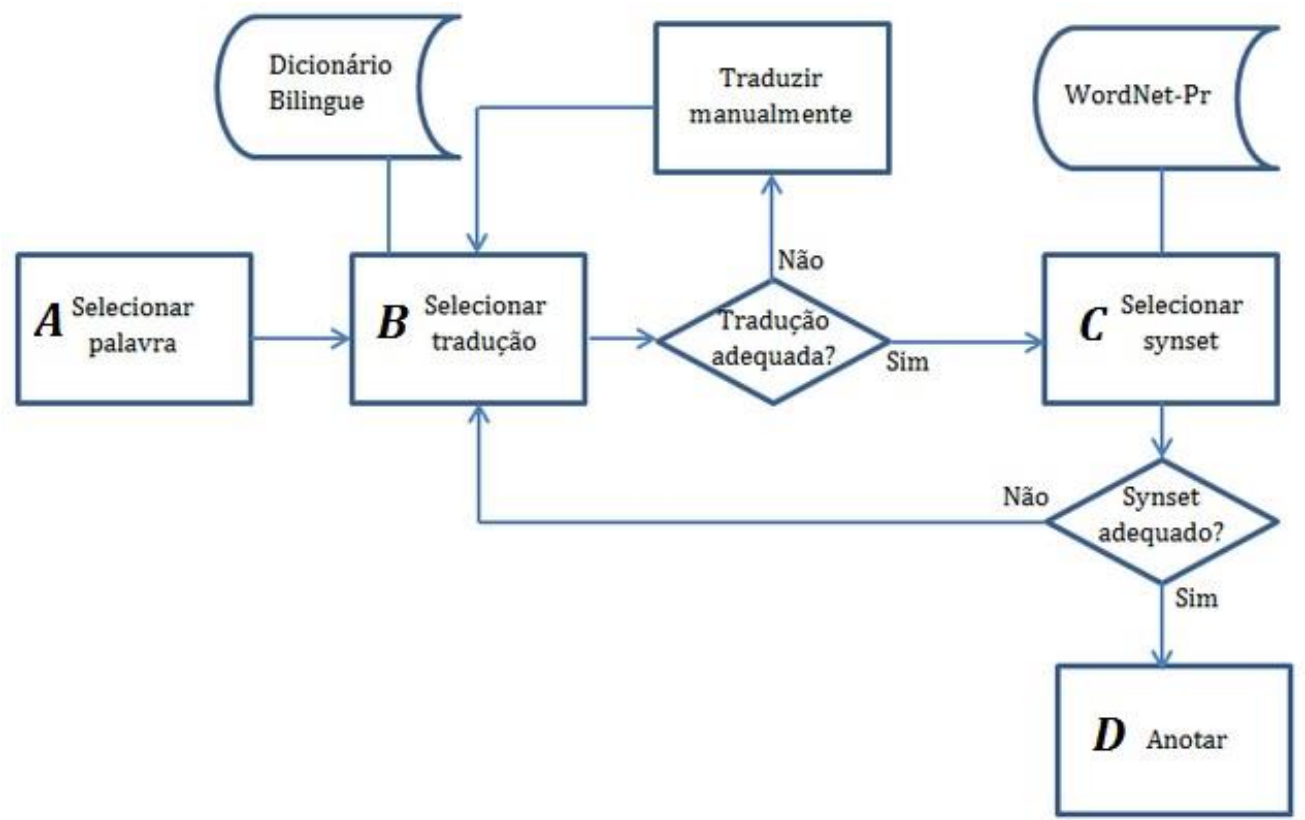

Figura 4.2: Metodologia de anotação

\subsubsection{Seleção dos verbos para anotação (Etapa A)}

Como mencionado, a anotação teve início com a seleção de um verbo que ocorre em um dos textos-fonte de uma coleção. Para a adequada identificação desses verbos, estabeleceram-se 5 regras específicas.

A primeira delas estabeleceu a revisão da identificação dos verbos no texto-fonte. Isso se deve ao fato de que optou-se por partir de textos-fonte anotados em nível morfossintático pelo tagger MXPOST (Rapnaparkhi, 1986). Apesar de bastante preciso, o tagger comete erros e, por isso, a etapa de seleção do verbo a ser anotado abarcou a tarefa de revisão da anotação morfossintática.

Assim, a cada palavra anotada como verbo, verificou-se se de fato a palavra era um verbo. Caso a anotação automática era correta, passava-se para a próxima etapa da anotação semântica. Caso a palavra não fosse um verbo, a palavra deveria ser anotada como "Erro de anotação". Por exemplo, na sentença "e o governo decretou toque de recolher", a palavra "recolher" faz parte do substantivo "toque de recolher" e, portanto, foi anotada como erro de anotação. Caso uma palavra fosse, de fato, um verbo e não tivesse sido identificado como verbo pelo tagger, o anotador anotava esta como se fosse um verbo (já que a ferramenta permite anotação morfossintática manual).

A segunda regra estabeleceu que os verbos auxiliares deveriam ser anotados como tal, adicionando o comentário "Verbo auxiliar" durante a anotação. Dessa forma, não se atribuiu 
sentidos/synsets a eles. Por exemplo, em "Ele havia saído de casa", "havia" é verbo auxiliar e "saído" (particípio) é o verbo principal ${ }^{51}$.

A terceira regra estabeleceu que, nas ocorrências formadas por um tempo composto seguido de infinitivo, o verbo principal (do composto) e o infinitivo deveriam ser anotados, posto que estes possuem conteúdo próprio. Por exemplo, em "Ele havia prometido retornar", o verbo "havia" é auxiliar, mas o verbo principal do composto ("prometido") e a forma no infinitivo que ocorre na sequência ("retornar") devem receber uma anotação de sentido por expressarem conteúdos bem definidos e independentes.

A quarta regra estabeleceu que, nos casos de predicados complexos (isto é, expressões que comumente possuem um equivalente semântico lexicalizado, por exemplo: "fazer uma queixa" $\rightarrow$ "queixar-se" e "tomar conta" $\rightarrow$ "cuidar"), devia-se: (1) associar ao verbo da expressão o comentário "predicado complexo" e (2) anotar o verbo com um synset da WordNet.Pr que representasse o significado global do predicado complexo. Assim, em "Ele dava crédito a ela", deve-se associar o comentário "predicado complexo" ao verbo "dava" e anotá-lo com um synset que represente o sentido do predicado complexo, que é "valorizar" / "confiar". Ressalta-se que a identificação dos predicados complexos foi automática, por meio da NASP++, com base na lista de predicados estabelecida por Duran et al. (2011). A confirmação (ou não) de que a expressão identificada pela ferramenta de anotação se tratava de fato de um predicado complexo era feita pelos anotadores. Alguns exemplos de predicados complexos encontrados foram:

- "Levantar o caneco", cuja tradução utilizada foi "win", no contexto de esporte.

- "Soltar uma bomba", cuja tradução foi "kick", também no mesmo contexto.

- "Dar sustentação", cuja tradução foi "support", no contexto de cotidiano.

A quinta regra de anotação estava relacionada à identificação dos verbos no particípio. Isso se deve ao fato de que a identificação das formas terminadas em "-ado (os/a/as)" ou "-ido (os/a/as)" como verbos no particípio ou adjetivos nem sempre é fácil. Assim, seguindo a definição de Azeredo (2010), essa regra estabeleceu que, se um verbo cumpre uma função de predicativo, então é identificado como um adjetivo. Por exemplo, na sentença "Este cão está perdido", o verbo no particípio "perdido" cumpre uma função de predicativo, mostrando o estado do substantivo "cão", portanto, é identificado como adjetivo.

\footnotetext{
${ }^{51}$ Os verbos principais carregam a carga semântica da forma verbal composta. Os verbos auxiliares são responsáveis por marcar o tempo, o aspecto, o modo, o número e a pessoa daquela forma verbal, normalmente.
} 


\subsubsection{Tradução dos verbos para o inglês (Etapa B)}

Como mencionado, a WordNet.Pr foi utilizada como repositório de sentidos para esta anotação. Como tais sentidos estão organizados em synsets escritos em inglês, os verbos em português a serem anotados precisaram ser traduzidos para o inglês.

A partir de um verbo em inglês " $x$ ”, a NASP++ recupera todos os synsets da WordNet.Pr associados a " $x$ " e os disponibiliza aos anotadores como possíveis sentidos a serem usados para a anotação do verbo em português, cabendo ao humano escolher o que mais adequadamente representa o sentido ou conceito subjacente ao verbo original em português.

Para traduzir os verbos para o inglês, a NASP++ acessa o dicionário bilíngue WordReference ${ }^{52}$. Depois disso, mostra aos anotadores as traduções possíveis em inglês da palavra original em português. Diante da tradução automática dos verbos, estabeleceram-se duas regras para a seleção da tradução equivalente.

A primeira delas estabeleceu que todas as traduções sugeridas pelo editor fossem analisadas antes da seleção da tradução equivalente. Essa regra foi estabelecida com o objetivo de se selecionar a tradução mais adequada em inglês. Essa análise pode incluir a consulta a recursos diversos, como o Google Tradutor ${ }^{53}$, o Linguee ${ }^{54}$ e outros dicionários bilíngues, com o objetivo de selecionar a palavra em inglês que expressasse o sentido do verbo em português de uma forma mais adequada.

A segunda regra estabeleceu que, caso o dicionário bilíngue não sugerisse uma tradução adequada, o anotador deveria inserir uma manualmente. Para sugerir uma tradução equivalente manualmente, sugeriu-se que os anotadores consultassem alguns recursos linguísticos, como o Michaelis Moderno Dicionário Inglês \& Português ${ }^{55}$ e os diferentes dicionários disponíveis no site Cambridge Dictionaries Online ${ }^{56}$ e os serviços online como o Google Tradutor e o Linguee.

\subsubsection{Seleção dos synsets (Etapa C)}

Quanto a essa etapa, ressalta-se que, assim que uma tradução é selecionada, deve se analisar os synsets compostos pela tradução para verificar se entre eles existe um que seja adequado.

\footnotetext{
${ }^{52}$ Disponível em http://www.wordreference.com

${ }^{53}$ Disponível em https://translate.google.com/

${ }^{54}$ Disponível em http://www.linguee.com.br/

${ }^{55}$ Disponível em http://michaelis.uol.com.br/

${ }^{56}$ Disponível em http://dictionary.cambridge.org/
} 
Frente a uma lacuna lexical ${ }^{57}$, foi estabelecido que um synset hiperônimo (ou seja, mais genérico) fosse selecionado. Por exemplo, o verbo "pedalar" na sentença "O Robinho pedalou..." não possui synset indexado na WordNet.Pr. Portanto, ter-se-ia que buscar uma generalização, que poderia ser "driblar".

\subsection{Ferramenta de Anotação}

A metodologia e os recursos ilustrados na Figura 4.2 auxiliaram o desenvolvimento da ferramenta NASP++, que pode ser definida como uma ferramenta de auxílio à anotação de sentidos. A NASP++ é uma versão atualizada da ferramenta NASP (Nóbrega, 2013), que originalmente foi desenvolvida para a anotação de sentidos dos nomes ou substantivos.

\subsubsection{As funcionalidades da NASP++}

A ferramenta fornece aos anotadores as seguintes funcionalidades:

- Anotação de sentidos para as palavras das classes dos substantivos e verbos que ocorrem em textos em português;

- Adição, às anotações, de um dos seguintes comentários:

- Sem comentários: observação por default; aplica-se quando não há observações sobre a anotação;

○ Não é verbo, erro de anotação: aplica-se quando a palavra a ser anotada foi erroneamente etiquetada como verbo pelo tagger;

- É predicado complexo: aplica-se quando o verbo a ser anotado pertence a um predicado complexo.

- É verbo auxiliar: aplica-se quando o verbo identificado pelo tagger é um verbo auxiliar.

- Outros: aplica-se quando existem outros tipos de observação sobre o processo de anotação de uma palavra, incluindo dificuldades de anotação.

- Delimitação da quantidade de palavras para anotação: ao contrário da NASP, que restringia a anotação dos substantivos a um conjunto dos $10 \%$ mais frequentes da coleção de textos-fonte, a ferramenta NASP++ não possui essa limitação, sendo que qualquer porcentagem dos verbos (e também substantivos) que ocorrem nos textos-fonte pode ser submetida ao processo de anotação;

- Geração de ontologia: por meio dessa funcionalidade, a NASP++ recupera da WordNet.Pr a hierarquia léxico-conceitual à qual cada synset utilizado na anotação pertence e unifica as

\footnotetext{
${ }^{57}$ Lacuna lexical é a inexistência de um synset que represente de forma mais apropriada o conceito específico subjacente a uma palavra
} 
hierarquias individuais de cada conceito em uma única estrutura hierárquica (que será detalhada na Seção 4.3.3).

\subsubsection{A interface gráfica}

Na Figura 4.3, apresenta-se a interface gráfica principal da NASP++, composta pelos seguintes campos: (A) visualizador dos textos-fonte para anotação; (B) painel para a visualização e seleção das traduções; (C) painel para a visualização e seleção dos synsets, e (D) painel para anotação dos comentários (D).

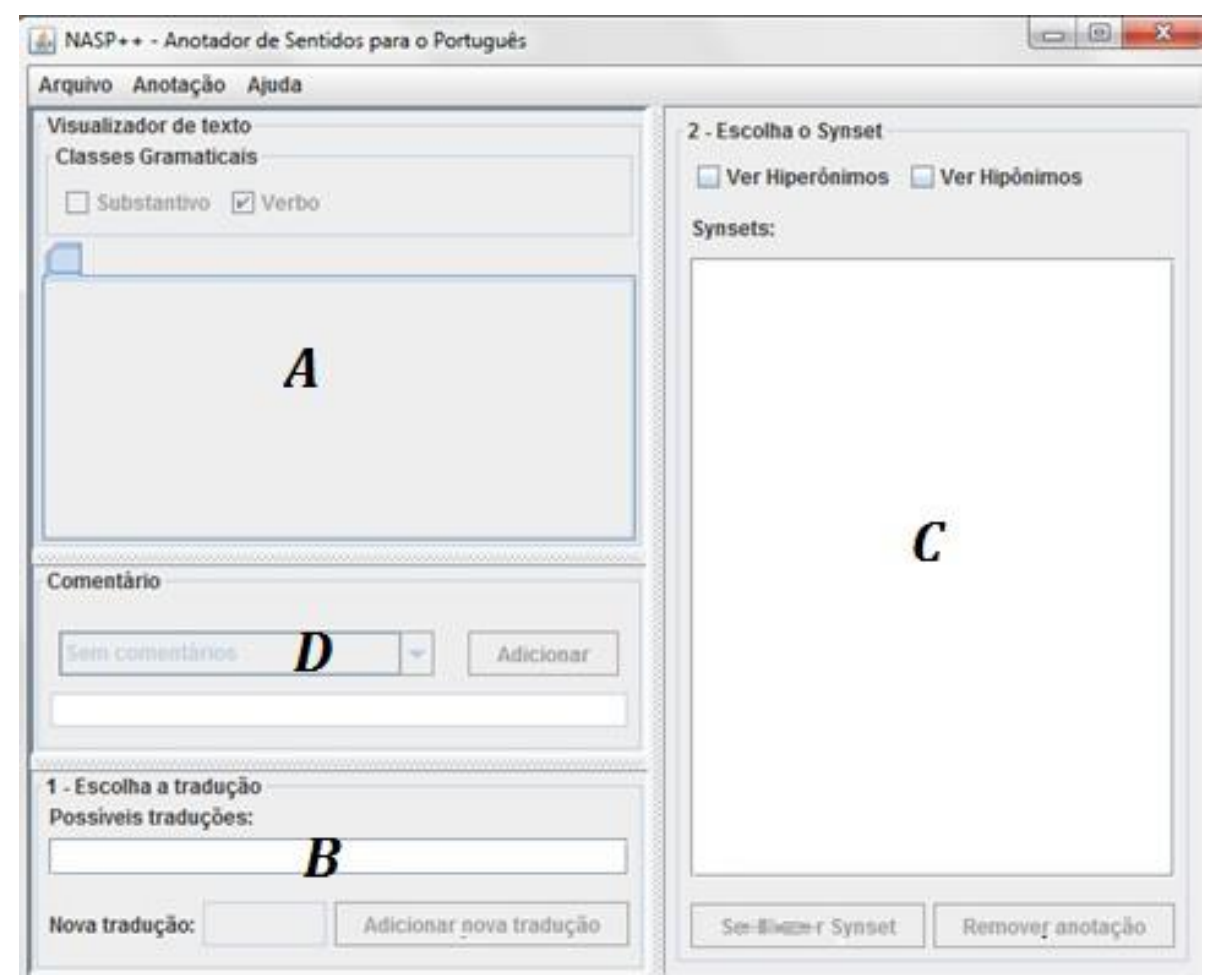

Figura 4.3: Tela principal da NASP++

Na sequência, na Figura 4.4, apresenta-se um exemplo de uso da NASP++ na anotação de verbo "morrer" da coleção 1 do córpus CSTNews.

O primeiro passo é o pré-processamento dos textos. Para isto, os textos de uma coleção a serem anotados são carregados e apresentados aos anotadores por meio do campo "Visualizador de textos-fonte" (Seção A na Figura 4.3). Este pré-processamento inclui a separação em tokens, lematização e identificação de "verbos" pelo etiquetador morfossintático MXPOST. Nos textosfonte, as palavras destacadas com um quadro (na ferramenta são mostradas em cor "vermelha") são aquelas que precisam ser anotadas. A partir das palavras em destaque, inicia-se o processo de anotação. Por exemplo, no caso do Texto 1 da figura a seguir, a anotação tem início com o primeiro verbo em destaque, no caso, "morreram". 


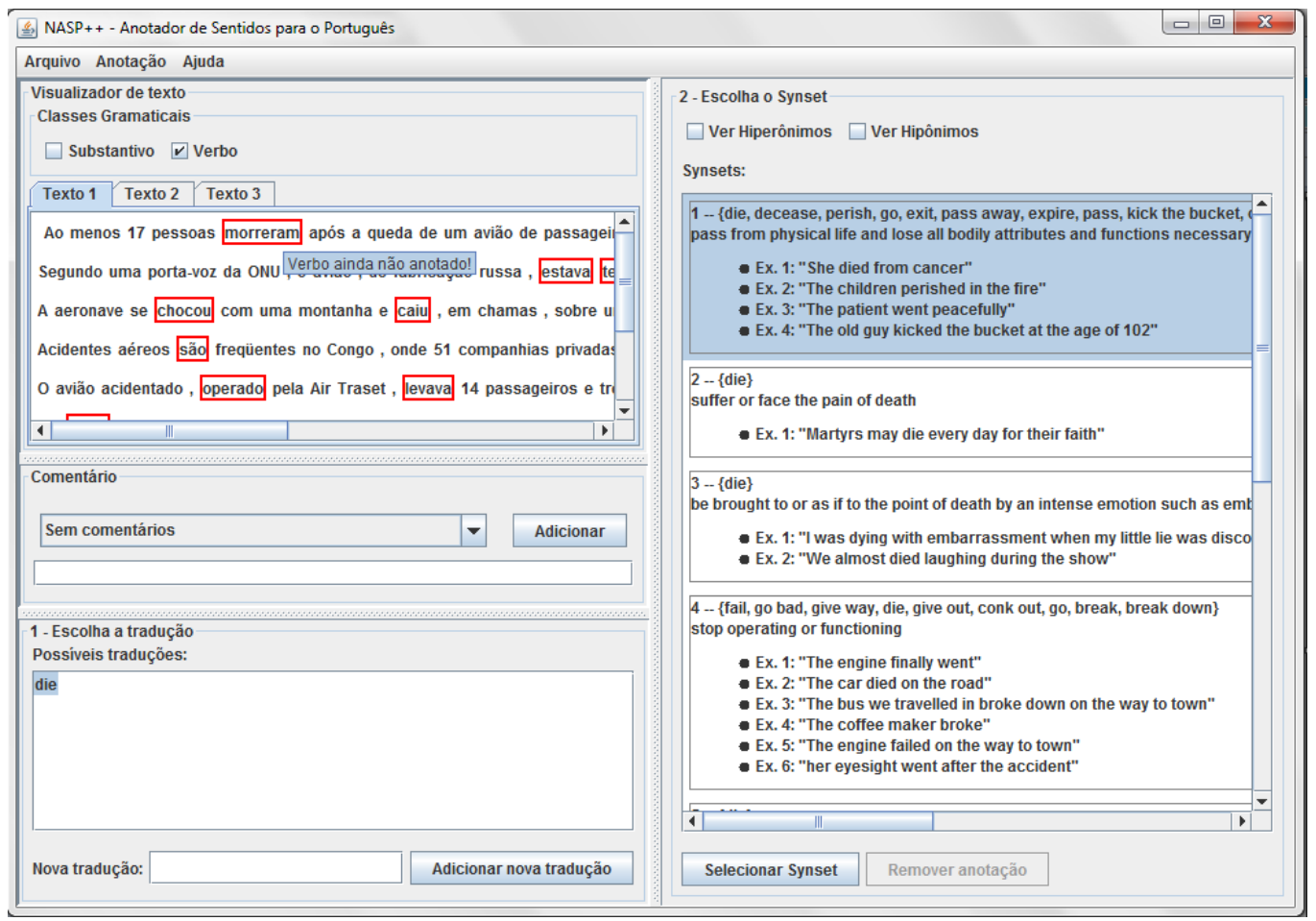

Figura 4.4: Exemplo de anotação do verbo "morrer" na NASP++

Após a seleção da palavra "morreram", automaticamente duas tarefas são realizadas pelo editor: (1) ativação do "Painel de comentários" (Seção D na Figura 4.3) e (2) recuperação, a partir do acesso ao dicionário WordReference ${ }^{\circledR}$, de todas as possíveis traduções em inglês para o verbo "morrer". As possíveis traduções são mostradas no "Painel para exibição e seleção das traduções" (Seção B na Figura 4.3). No caso de "morreram", a NASP++ recuperou somente uma tradução, "die".

Ao escolher a tradução "die", a NASP++ recupera automaticamente todos os synsets da WordNet.Pr associados a essa tradução. Ressalta-se que a NASP++ também recupera a glosa e os exemplos do synset. Dentre os synsets recuperados, cabe ao anotador selecionar o que mais adequadamente representa o sentido do verbo "morreram" no texto-fonte.

Caso os synsets (incluindo as glosas e exemplos) não sejam suficientes para se definir a representação mais adequada do sentido do verbo em português, o editor oferece a possibilidade de visualização dos hiperônimos e tropônimos dos synsets inicialmente recuperados.

Para selecionar um dos synsets recuperados, o qual será utilizado como sentido para a anotação da palavra em português, o usuário deve clicar no synset em questão, por exemplo, \{die, decease, perish, go, exit, pass away, expire, pass, kick the bucket, cash in one's chips, buy the farm, conk, give-up the ghost, drop dead, pop off, hoque, croak, snuff it\} e, na sequência, no botão "Selecionar synset", que consiste no passo "C" da metodologia de anotação. Uma vez selecionado 
um synset, a palavra anotada ("morreram") é destacada no campo "Visualizador de textos" em "verde". Esse destaque indica que à palavra em questão foi associado um sentido, no caso, um synset.

Partindo-se da suposição de que as diversas ocorrências de uma palavra em um texto (ou em textos que tratam do mesmo assunto) tendem a ter um mesmo sentido, ressalta-se que, uma vez que uma palavra " $x$ " tenha sido anotada com um sentido " $y$ ", todas as demais ocorrências de " $x$ " também são pré-anotados com “ $y$ ”. Na NASP++, as demais ocorrências de " $x$ ” pré-anotadas com “y” são destacadas em "amarelo", precisando da confirmação ou não dos anotadores. Na Figura 4.5, por exemplo, observa-se que outra ocorrência de "morreram" foi pré-anotada com o synset selecionado para a anotação da primeira ocorrência de "morreram".

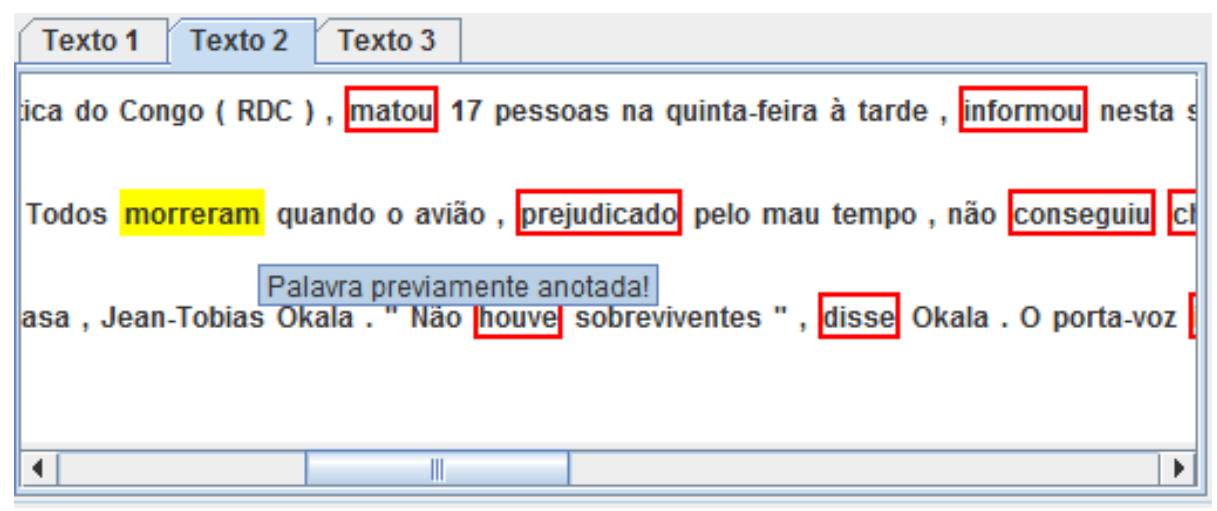

Figura 4.5: Visualizador de textos com o verbo "morrer" previamente anotado

Após a anotação de todos os verbos, a ferramenta permite salvar os textos-fonte anotados no formato de linguagem de marcação XML (do inglês, Extensible Markup Language), um dos mais utilizados para a tarefa de anotação de córpus. Na Figura 4.6, ilustra-se a anotação em um arquivo XML.

Nesse formato, a anotação é organizada em uma hierarquia de informações. No primeiro nível da hierarquia, tem-se 3 blocos que delimitam as informações relativas a: (1) os anotadores (indicados pela etiqueta "Anotadores"), (2) a classe da palavra que pode ser anotada (verbo e nome) e a porcentagem de palavras dessa classe (expressa em formato de 0 a 1) (indicada pela etiqueta "LimitesAnotacao") e o (3) arquivo do texto-fonte a ser anotado (indicado pela etiqueta “Arquivos"). 


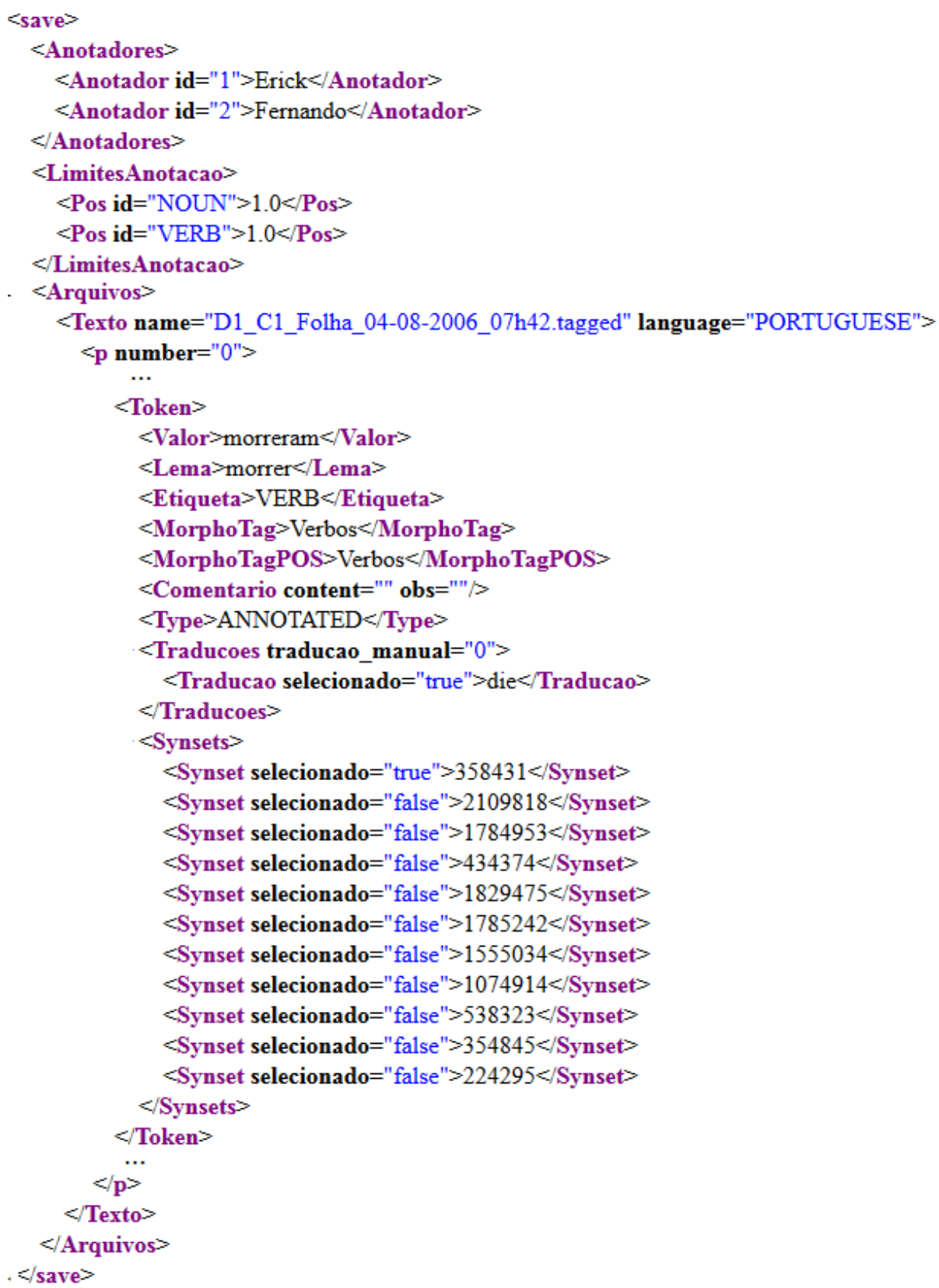

Figura 4.6: Arquivo de anotação em formato XML

O bloco de informações encapsuladas na etiqueta "Arquivos" engloba: (1) o arquivo referente ao texto-fonte a ser anotado (por exemplo, <Texto name="D1_C1_Folha_04-082006_07h42.tagged">) e a língua na qual está escrito (language="PORTUGUESE") e (2) a indicação de parágrafo $(<\mathrm{p}$ number="“0”). Além disso, o exemplo apresentado na Figura 4.6 registra ainda que os parágrafos são compostos por sentenças e que cada sentença é composta por palavras ou tokens (indicados pela etiqueta "Token"). Cada token que pode receber a anotação de sentidos possui uma lista de atributos, representados pelas seguintes etiquetas XML:

- Valor: contém a palavra em si.

- Tag: contém a anotação morfossintática advinda da ferramenta NASP++. 
- MorphoTagPOS: contém um mapeamento da anotação morfossintática feita pelo POSTagger, podendo ser: Verbos, Substantivos, Adjetivos, Advérbios e Outros.

- MorphoTag: por default, tem o mesmo valor que MorphoTagPOS, mas pode ser modificado pelo usuário quando existe um erro de anotação.

- Lema: descreve a forma canônica ou básica da palavra.

- Comentário: contém os comentários sobre a palavra anotada, os quais podem ser (1) "Sem comentários", (2) "Não é um verbo, erro de anotação", (3) "Verbo auxiliar", (4) "É predicado complexo" ou (5) "Outros" (as opções 2, 3 e 4 são específicas para os verbos), ou o usuário pode ainda adicionar observações distintas das previstas pela ferramenta, se assim achar pertinente.

- Type: contém o estado de anotação da palavra.

ANNOTATED: palavra anotada.

VERB_NO_ANNOTATED: verbo não anotado.

PREV_ANNOTATED: palavra previamente anotada.

NOUN_NO_ANNOTATED: substantivo não anotado.

NO_ANNOTATE: palavra não anotada (outras classes gramaticais).

- Traducoes: contém as traduções fornecidas pela ferramenta ou adicionadas pelo usuário; o atributo "selecionado" da tradução escolhida recebe o valor "true".

- Synsets: contém os synsets fornecidos pelas traduções propostas na NASP++; o atributo "selecionado" do synset escolhido recebe o valor "true". Cada valor do synset representa o identificador do synset na WordNet-Pr.

Uma vez que todos os verbos de uma coleção de textos-fonte tenham sido anotados segundo a metodologia, essa ferramenta de anotação tem a funcionalidade de gerar uma estrutura conceitual a partir dos synsets utilizados na anotação da coleção respectiva. A seguir, descreve-se como essa estrutura conceitual é gerada.

\subsubsection{Geração de Ontologias}

Uma hipótese que nasce da criação desta funcionalidade na NASP++ é a de que os sentidos subjacentes às palavras que ocorrem em um mesmo texto (ou coleção de textos que tratam de um mesmo tópico) tendem a ser próximos em uma estrutura conceitual. Para ilustrar essa hipótese, considera-se a anotação das palavras A e B nas coleções de textos C1 e C2. Em C1, tem-se que: (1) a palavra A ocorreu 3 vezes com o sentido A1 e (2) a palavra B foi anotada 3 vezes com o sentido B1. Em C2, a palavra A foi anotada com o sentido A2 e a palavra B não ocorreu.

Na Figura 4.7, ilustram-se as 2 hierarquias conceituais geradas a partir da anotação de A e B em C1 e em C2. Como ilustrada, a hipótese é a de que os sentidos A1 e B1 são próximos, pois 
ocorreram em um mesmo texto ou coleção, ao passo que A2 é distante de A1 e B1, por ocorrer em outra coleção. Com base nessa hipótese, pode-se inferir que em um novo texto no qual as palavras A e B tenham ocorrido, sendo a palavra B anotada com o conceito B1, há uma probabilidade mais alta de que o sentido subjacente à palavra $\mathrm{A}$ seja $\mathrm{A} 1 \mathrm{e}$ não $\mathrm{A} 2$, devido à menor distância na estrutura conceitual entre A1 e B1.

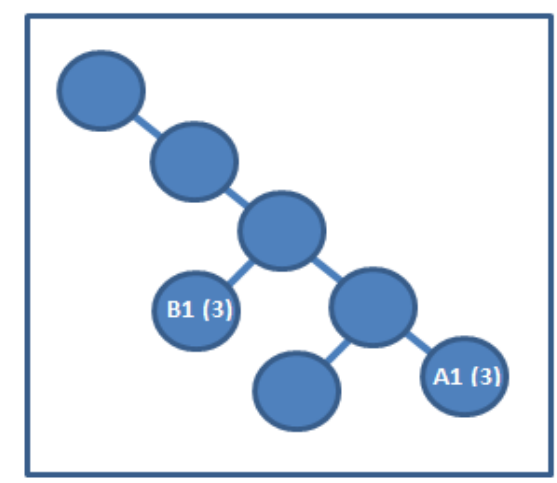

C1

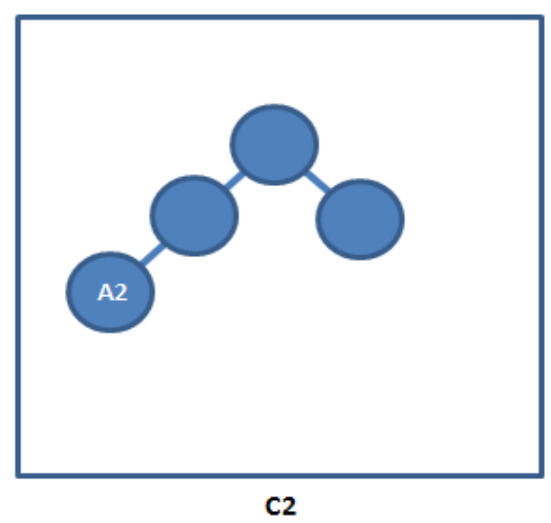

C2

Figura 4.7: Hierarquias conceituais das coleções $\mathrm{C} 1$ e C2

Tendo em vista que esse tipo de inferência pode ser futuramente relevante para a tarefa de DLS, desenvolveu-se no NASP++ a funcionalidade denominada "geração de ontologia".

A geração da estrutura conceitual é feita a partir dos synsets utilizados na anotação das palavras de dada coleção de textos. Especificamente, para cada synset " $x$ " selecionado para a anotação de uma palavra, a ferramenta automaticamente obtém: (1) os hipônimos imediatos de " $x$ ", (2) os cohipônimos de " $x$ ", (3) o hiperônimo imediato de " $x$ ", (4) os hiperônimos intermediários de " $x$ " e (5) o unique beginner de " $x$ ". Com este processo, a NASP++ obtém um grafo parcial para o synset " $x$ " selecionado.

Esse processo é repetido a cada synset selecionado para anotar uma palavra em português. Finalmente, os grafos parciais são unificados em uma hierarquia final, a qual representa todos os synsets utilizados na anotação dos textos-fonte de uma coleção. A seguir, são apresentadas as hierarquias geradas para os sentidos anotados de "morrer" e "matar" (Figura 4.8 e Figura 4.9) e a unificação das hierarquias parciais (Figura 4.10). 


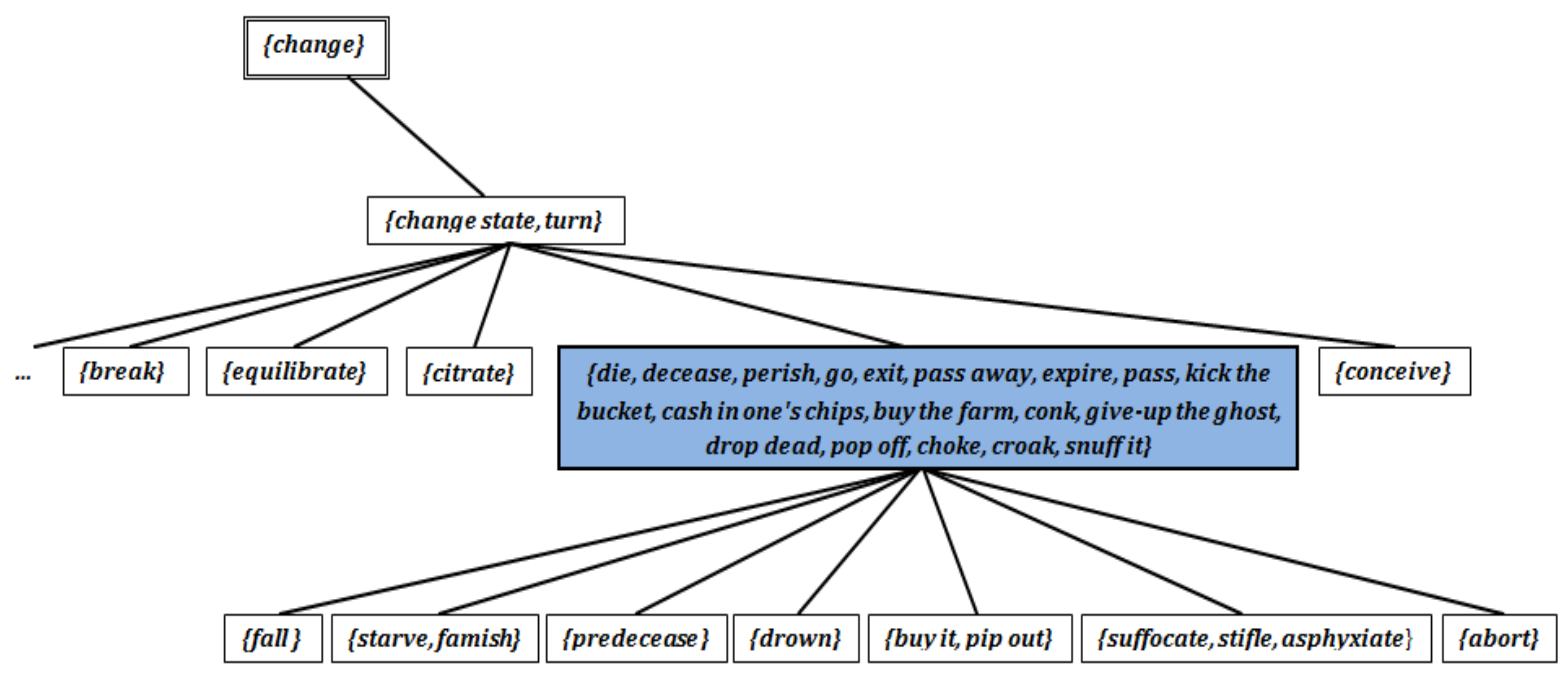

Figura 4.8: Hierarquia gerada para um synset do verbo "morrer"

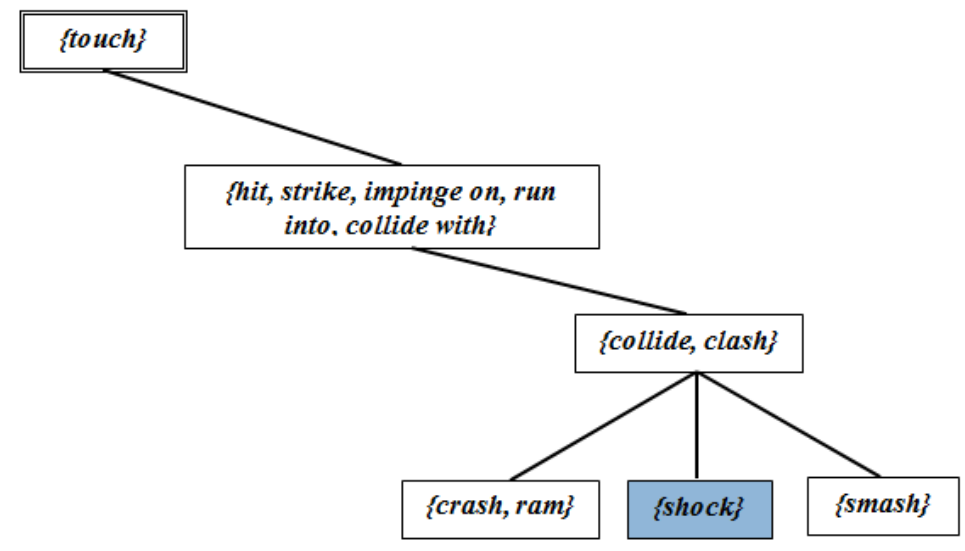

Figura 4.9: Hierarquia gerada para um synset do verbo "matar"

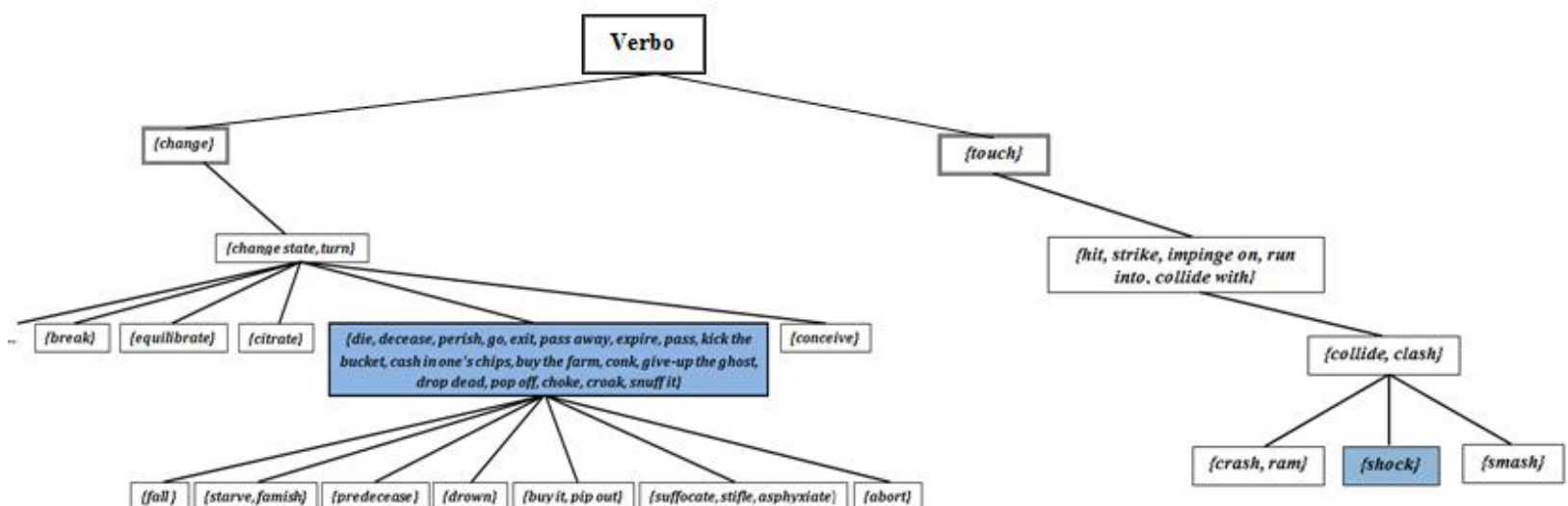

Figura 4.10: Exemplo de unificação de hierarquias parciais 


\subsection{Avaliação e Resultados}

\subsubsection{Visão Geral da Anotação}

A anotação foi realizada durante 7 semanas e meia, sendo que a primeira metade da primeira semana foi dedicada ao treinamento e teste da ferramenta NASP++ pelos anotadores. Cada sessão de anotação durou aproximadamente 1 hora.

Cada coleção do CSTNews foi anotada uma única vez por um único grupo de anotadores, com exceção de 3 coleções utilizadas para obter os valores de concordância, as quais foram anotadas por todos os grupos.

No total, participaram 10 anotadores distribuídos entre linguistas computacionais com graduação em Linguística/Letras ou Ciência da Computação. A cada sessão de anotação, os anotadores foram organizados em grupos de 2 ou 3 pessoas, sendo cada grupo responsável por uma coleção do córpus. Os grupos foram compostos por linguistas e cientistas da computação, de preferência, de tal forma que, em cada dia de anotação, houvesse configurações diferentes de linguistas e cientistas da computação em cada grupo, garantindo que a tarefa não se tornasse tendenciosa. Com isso, buscou-se também compartilhar o conhecimento dos anotadores, atingindo um padrão de anotação.

Na Tabela 4.1, apresenta-se a distribuição quantitativa da anotação dos verbos principais, verbos auxiliares, predicados complexos e dos erros de anotação.

\begin{tabular}{c|c|cccc}
\hline & Total & $\begin{array}{c}\text { Verbos } \\
\text { principais }\end{array}$ & $\begin{array}{c}\text { Predicados } \\
\text { complexos }\end{array}$ & $\begin{array}{c}\text { Verbos } \\
\text { auxiliares }\end{array}$ & $\begin{array}{c}\text { Erros de } \\
\text { anotação }\end{array}$ \\
\hline $\begin{array}{c}\text { \# instâncias } \\
\text { anotadas } \\
\text { porcentagem }\end{array}$ & 6494 & 5082 & 146 & 949 & 317 \\
\hline
\end{tabular}

Tabela 4.1: Estatísticas da anotação de verbos do córpus CSTNews

Quanto à anotação dos verbos principais, ressalta-se que foram anotadas 5082 instâncias. Das 5082 instâncias, há 844 verbos diferentes. Na anotação dos 844 verbos diferentes, foram selecionados 787 traduções e 1047 synsets diferentes.

Na Figura 4.11, apresenta-se a quantidade de synsets distintos selecionados para cada um dos verbos diferentes no córpus. No que se refere a isso, destaca-se que a quantidade de synsets distintos para a anotação de um verbo variou entre 1 e 18, a média de synsets por verbo diferente é 1.92 e o desvio padrão é 1.87. A respeito da quantidade de synsets distintos anotados para cada 
verbo diferente, podemos mencionar que na maioria dos casos um verbo foi anotado com apenas um synset, ou seja, na anotação de 508 verbos diferentes, apenas um synset foi selecionado pelos anotadores. Isto nos mostra que a maioria dos verbos tendem a expressar um único sentido em qualquer contexto.

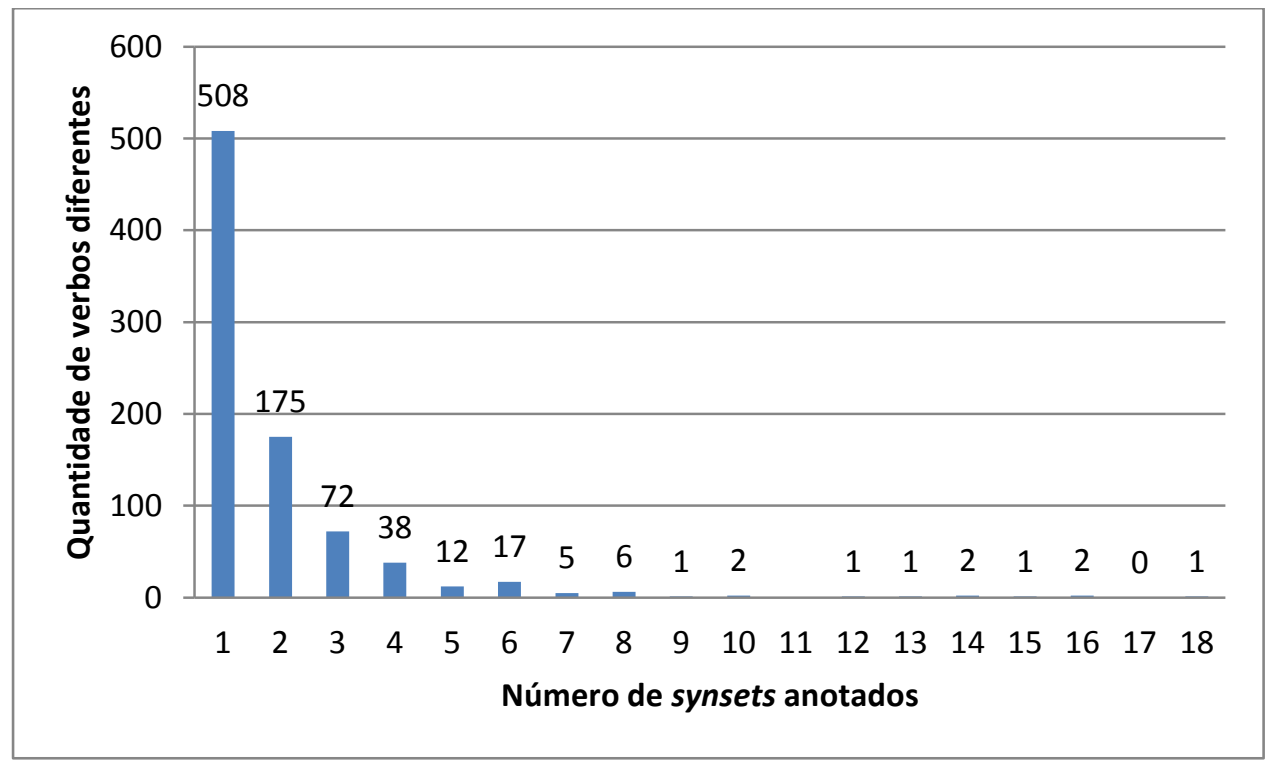

Figura 4.11: Distribuição de synsets por verbo diferente no córpus

Na Figura 4.12, apresenta-se a quantidade de synsets distintos selecionados para verbos diferentes nas coleções do córpus. Nesta figura, observa-se que os anotadores escolheram entre 1 e 4 synsets distintos para a anotação dos verbos diferentes de uma mesma coleção do córpus; os anotadores selecionaram apenas 1 synset para a maioria dos verbos diferentes (2671); e que média de synsets por verbo diferente é 1.07 e o desvio padrão é 0.30. Isto também ressalta que a maioria dos verbos tendem a expressar o mesmo sentido dentro de uma coleção de textos que falam do mesmo tema. 


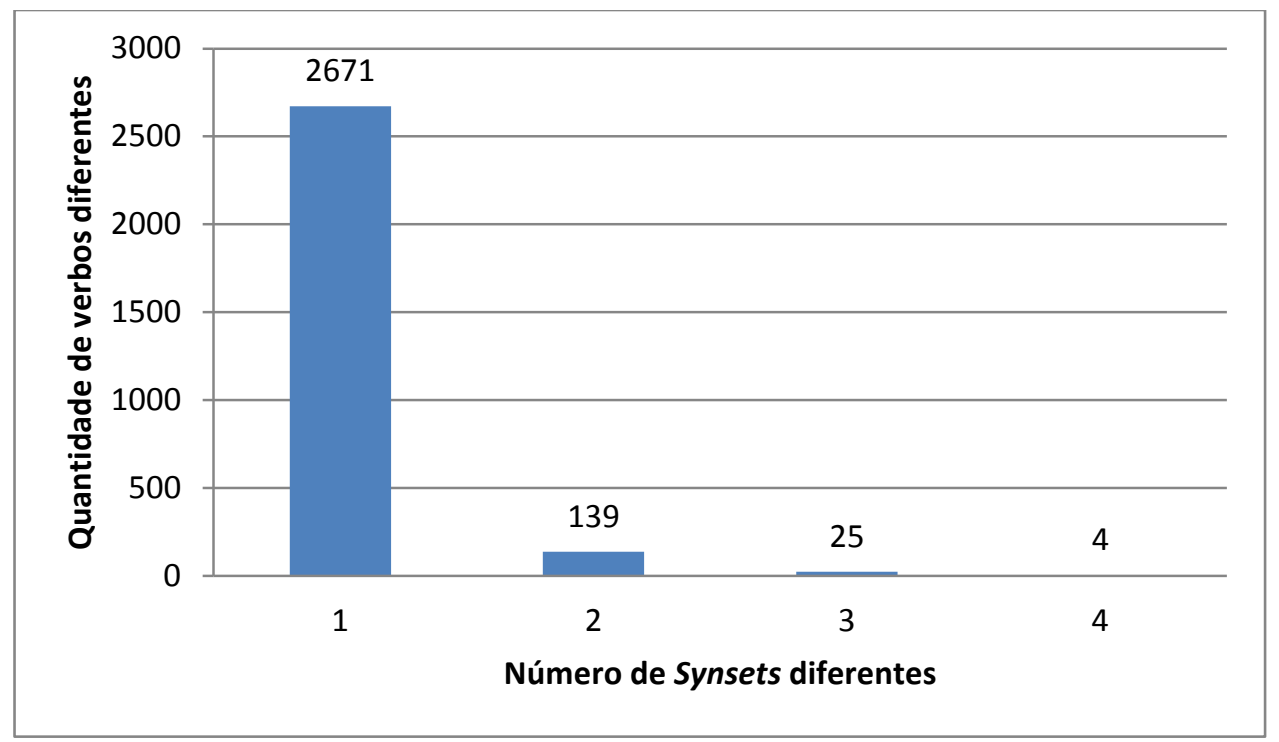

Figura 4.12: Distribuição de synsets por verbo diferente nas coleções do córpus

Na Tabela 4.2, apresentam-se as estatísticas referentes à anotação dos verbos e as obtidas por Nóbrega (2013) na anotação dos substantivos. Nessa tabela, ressalta-se que os verbos possuíram uma maior variação de sentidos, tanto no córpus, quanto em cada coleção. Isto reafirma o que é proposto na literatura (Miller et al., 1990) que os verbos são mais polissêmicos que os substantivos.

\begin{tabular}{c|cc}
\hline $\begin{array}{c}\text { Número máximo de synsets anotados por } \\
\text { palavra }\end{array}$ & $\begin{array}{c}\text { Substantivos } \\
\text { (Nóbrega, 2013) }\end{array}$ & Verbos \\
\hline No córpus & 5 & 18 \\
Em uma coleção & 3 & 4 \\
\hline
\end{tabular}

Tabela 4.2: Variação de número de synsets para substantivos e verbos

Partindo do princípio de que, quanto mais polissêmica for uma palavra, mais difícil é a tarefa de desambiguação, buscou-se calcular a dificuldade da tarefa de anotação pela quantidade de sentidos que as palavras anotadas podiam representar. Para calcular o grau de dificuldade da anotação de um verbo, considerou-se o número de synsets nos quais essa palavra ocorre na WordNet.Pr 3.0.

Na Figura 4.13, tem-se a distribuição dos verbos diferentes do córpus em função do número de synsets possíveis fornecidos pela WordNet.Pr. 


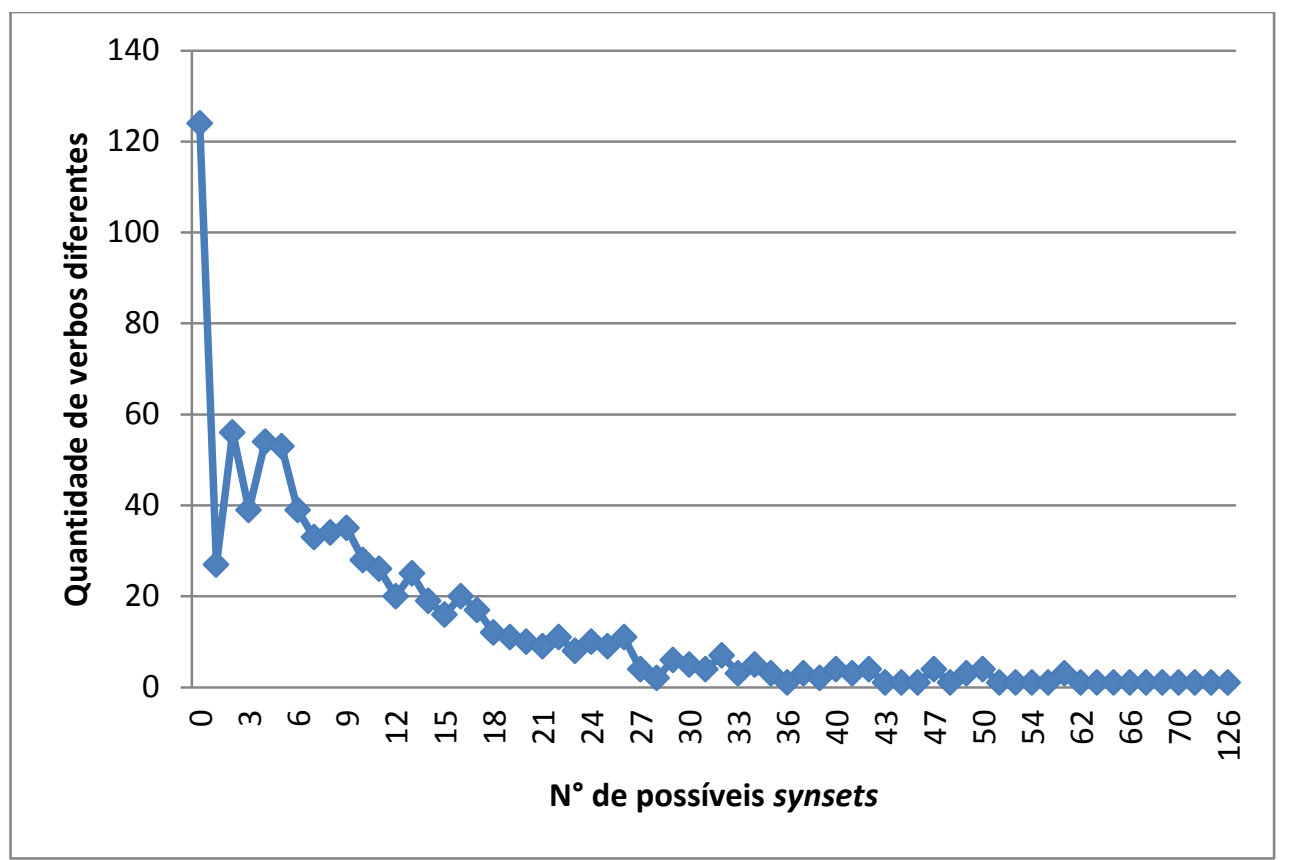

Figura 4.13: Distribuição do número de verbos diferentes por número de possíveis synsets

Analisando a distribuição da Figura 4.13, salienta-se que os verbos do córpus podem representar, em média, 12 sentidos distintos; 693 (82.11\%) dos 844 verbos distintos anotados podem representar 2 ou mais sentidos; e 276 verbos (32.7\%) dos mesmos superam a média de 12 synsets, os quais são considerados bastante polissêmicos.

Na Tabela 4.3, tem-se a comparação dos resultados obtidos com os de Nóbrega (2013) na anotação dos substantivos do CSTNews. Observa-se que a tarefa de anotação de sentidos dos verbos é mais difícil que a tarefa de anotação de sentidos dos substantivos, uma vez que os verbos são mais polissêmicos, podendo expressar mais conceitos que os substantivos (Miller et al., 1990). No CSTNews, os verbos possuem em média 12 sentidos na WordNet.Pr, enquanto que os substantivos, 6. Além disso, a quantidade de verbos do CSTNews com 2 ou mais synsets equivale a aproximadamente $82 \%$ do total de verbos distintos, enquanto que a quantidade de substantivos com 2 ou mais synsets equivale a 77\% dos substantivos distintos. Isso quer dizer que existem mais verbos ambíguos do que substantivos ambíguos no CSTNews. Por outro lado, existem mais substantivos altamente ambíguos (que têm mais synsets possíveis do que a média) do que verbos altamente ambíguos no córpus. 


\begin{tabular}{c|cc}
\cline { 2 - 3 } & $\begin{array}{c}\text { Substantivos } \\
\text { (Nóbrega, 2013) }\end{array}$ & Verbos \\
\hline Média do número de possíveis synsets por palavra & 6 & 12 \\
Porcentagem de palavras ambíguas & $77 \%$ & $82.11 \%$ \\
Porcentagem de palavras altamente ambíguas & $42 \%$ & $32.70 \%$ \\
\hline
\end{tabular}

Tabela 4.3: Comparação da distribuição de possíveis synsets por substantivos e verbos

Algumas das dificuldades encontradas na anotação são discutidas a seguir:

Apesar da lista de predicados complexos fornecida pela NASP++, a detecção dos mesmos foi uma tarefa difícil. Por exemplo, a ferramenta indicava como predicado complexo a expressão "ficaram feridas" e, portanto, dever-se-ia anotar o verbo "ficar" com o sentido da expressão. No entanto, durante a anotação, alguns anotadores anotaram a palavra "ficaram" como verbo auxiliar, gerando discordâncias.

Outra dificuldade da anotação foi a ausência de synsets que adequadamente representassem certos sentidos expressos pelos verbos em português. Esses casos são as chamadas lacunas lexicais. Por exemplo, o verbo "pedalar", com o sentido de "passar o pé por sobre a bola, em especial, por repetidas vezes, com o objetivo de enganar seu marcador.", como em "Robinho pedalou, driblou o zagueiro e chutou”, não é lexicalizado em inglês. Para esses casos, a regra de anotação é a de generalização, portanto, o verbo "pedalar" foi generalizado para "driblar" e foi selecionado o synset correspondente na WordNet.Pr $(\{$ dribble, carry $\})$.

Outro problema de falta de synsets foi para o verbo "poder". Não foram encontrados synsets adequados para nenhuma das traduções possíveis ("can", "may", "could" e "might"), pois o verbo é usado como modal na maioria dos casos.

Ressalta-se que os exemplos citados são de sentidos relacionados a domínios específicos e, nesses casos, o nível de expertise dos anotadores quanto aos domínios pode influenciar a anotação. Caso os anotadores fossem especialistas em determinados domínios, possivelmente a escolha da tradução e do synset tivesse sido diferente.

\subsubsection{Avaliação de Concordância}

Na avaliação da anotação, utilizou-se a medida Kappa (Carletta, 1996). Essa medida calcula o grau de concordância entre os anotadores em determinada tarefa, descontando-se a concordância ao acaso. Outras medidas de avaliação também foram usadas. Essas, mostradas abaixo, não descontam a concordância ao acaso, mas computam de forma direta o número de concordâncias entre os anotadores. 
- Concordância Total: número de vezes em que todos os anotadores concordaram em relação ao total de instâncias;

- Concordância Parcial: número de vezes em que a metade ou a maioria dos anotadores concordou em relação ao total de instâncias;

- Concordância Nula: número de vezes em que a maioria dos anotadores não concordou.

Especificamente, avaliou-se a concordância entre os anotadores com relação a 3 parâmetros: (1) seleção da tradução, (2) seleção do synset e (3) seleção da tradução e do synset. A avaliação desses 3 parâmetros foi feita a partir da anotação de 3 coleções do CSTNews, as mesmas utilizadas por Nóbrega (2013) para a avaliação da anotação de sentidos dos substantivos: C15, C29 e C50. Na avaliação, cada coleção foi anotada por 4 grupos diferentes de anotadores, obtendo-se os resultados apresentados nas Tabelas 4.4, 4.5 e 4.6 .

\begin{tabular}{c|cccc}
\hline Critério & Kappa & Total (\%) & Parcial (\%) & Nula (\%) \\
\hline Tradução & 0.591 & 42.11 & 52.63 & 5.26 \\
Synset & 0.483 & 35.53 & 56.58 & 7.89 \\
Tradução+synset & 0.421 & 28.95 & 63.16 & 7.89 \\
\hline
\end{tabular}

Tabela 4.4: Valores de concordância para a C15

\begin{tabular}{c|cccc}
\hline Critério & Kappa & Total (\%) & Parcial (\%) & Nula (\%) \\
\hline Tradução & 0.659 & 48.82 & 48.82 & 2.36 \\
Synset & 0.514 & 35.43 & 58.27 & 6.30 \\
Tradução+synset & 0.485 & 32.28 & 60.63 & 7.09 \\
\hline
\end{tabular}

Tabela 4.5: Valores de concordância para a C29

\begin{tabular}{c|cccc}
\hline Critério & Kappa & Total (\%) & Parcial (\%) & Nula (\%) \\
\hline Tradução & 0.695 & 55.50 & 44.04 & 0.46 \\
Synset & 0.529 & 34.40 & 60.55 & 5.05 \\
Tradução+synset & 0.516 & 33.95 & 60.09 & 5.96 \\
\hline
\end{tabular}

Tabela 4.6: Valores de concordância para a C50

Quanto à medida Kappa nas Tabelas 4.4, 4.5 e 4.6, observa-se que os valores obtidos para cada um dos 3 parâmetros aumentaram a cada experimento de avaliação, que seguiu a sequência C15, C29 e C50. Uma possível justificativa para esse aumento pode ser a experiência adquirida pelos anotadores durante o processo de anotação, isto é, quanto maior a familiaridade com as regras e a ferramenta de anotação, maior foi o nível de concordância. 
$\mathrm{Na}$ Tabela 4.7, apresentam-se os valores médios de concordância referentes às 3 coleções. Observa-se que o valor Kappa obtido para o parâmetro "synset" foi de 0.509, valor considerado aceitável no cenário da DLS. A concordância média do parâmetro "tradução" é superior à do parâmetro "synset". Isso era esperado, pois a tradução é uma tarefa mais usual e direta que a DLS. Finalmente, sobre o parâmetro "tradução + seleção do synset", vê-se que o valor médio da concordância é o menor. Isso se deve ao fato de que diferentes traduções podem fazer referência ao mesmo synset e diferentes synsets podem ser referenciados pela mesma tradução.

Quanto às outras medidas de concordância, salientam-se os valores altos obtidos para a "concordância parcial". Isso mostra que, mesmo com uma Kappa aceitável, os anotadores tiveram dúvidas na anotação. Algumas das causas podem ter sido a identificação de verbos no particípio e a identificação dos verbos auxiliares. Outros valores a destacar na Tabela 4.7 são os referentes à "concordância nula", que foram baixos.

\begin{tabular}{c|cccc}
\hline Critério & Kappa & Total (\%) & Parcial (\%) & Nula (\%) \\
\hline Tradução & 0.648 & 48.81 & 48.50 & 2.69 \\
Synset & 0.509 & 35.12 & 58.47 & 6.41 \\
Tradução+synset & 0.474 & 31.73 & 61.29 & 6.98 \\
\hline
\end{tabular}

Tabela 4.7: Valores de concordância gerais

Comparando com o trabalho de Nóbrega (2013), cujos resultados são apresentados na Tabela 4.8, vê-se que os valores de concordância para os substantivos são, na maioria, superiores aos dos verbos. Esse resultado também era esperado, já que os verbos são mais polissêmicos, o que dificulta a identificação do synset correspondente.

\begin{tabular}{c|cccc}
\hline Critério & Kappa & Total (\%) & Parcial (\%) & Nula (\%) \\
\hline Tradução & 0.853 & 82.87 & 11.08 & 6.05 \\
Synset & 0.729 & 62.22 & 22.42 & 14.36 \\
Tradução-Synset & 0.697 & 61.21 & 24.43 & 14.36 \\
\hline
\end{tabular}

Tabela 4.8: Valores de concordância da anotação feita por Nóbrega (2013)

Uma razão que influenciou nos valores de concordância obtidos para os verbos foi o nível de refinamento da WordNet-Pr. Isto faz com que os anotadores possam discordar com mais frequência já que a diferença entre cada sentido é muito pequena.

A seguir, apresentam-se algumas palavras nas quais os anotadores concordaram totalmente: 
"morreram", "reduzir", "hospitalizada, "investigar", "acabado", "considerou", "informou", "disseram", “anunciou”, “cometidos", "abusados", “convencer" e "começa"

Algumas das razões para a concordância total na anotação de tais palavras são:

- Os verbos em português expressam conceitos claros; por exemplo, na sentença "Nove pessoas morreram, três delas crianças, e...", pode-se facilmente identificar o sentido do verbo "morrer", que é "perder todos os atributos e funções corporais para manter a vida";

- O verbo em português possui uma tradução direta;

- Os vários sentidos que a tradução pode expressar são bem delimitados e distintos e estão definidos por synsets bem-formulados;

- Tais palavras em média expressam poucos sentidos distintos; por exemplo, o verbo "hospitalizada" expressa apenas um sentido e, por isso, é elemento constitutivo de apenas um synset (\{hospitalize, hospitalize $\}$ ) .

A seguir, mostra-se uma lista de palavras que obtiveram concordância nula:

"localizado", "levada", “aceitamos", "registrada", "conseguiram", "surgirem", "somariam", “deixou”, "entraram", “enfrentar", “entenderam”, “adiantaram”, “levar", “daria”, “assinalaram”

Alguns das razões pelas quais a concordância obtida pode ter sido nula são as seguintes:

- Os verbos em português expressam sentidos relativamente vagos; por exemplo, na sentença "As autoridades policiais de Moscou assinalaram que no recinto do mercado...", tem-se um exemplo de verbo "assinalar", cujo sentido é de difícil delimitação (foi anotado com os seguintes sentidos: \{inform\}: impart knowledge of some fact, state or affairs, or event to; \{state, say, tell\}: express in words; \{notice, mark, note\}: notice or perceive; e \{announce, declare\}: announce publicly or officially).

- A seleção de traduções equivalentes distintas pode ter levado os anotadores a selecionar synsets diferentes; por exemplo, para "localizada" foram usados "locate" e "localize";

- Os synsets selecionados, apesar de distintos, possuíam certa proximidade conceitual.

\subsection{Considerações Finais}

Neste capítulo, temos apresentado o processo de anotação de sentidos dos verbos do córpus CSTNews, as ferramentas usadas para a anotação, e a avaliação dos resultados da anotação realizada. Salienta-se que a escolha do CSTNews para esta pesquisa foi motivada pelas características do mesmo. Ao ser o CSTNews um córpus jornalístico, abrange vários diferentes domínios. Isto é favorável para este trabalho, dado que um dos nossos objetivos é explorar 
métodos de Desambiguação Lexical de Sentido baseados em conhecimento, isto é, que não sejam restritos a um domínio específico. O CSTNews será usado na avaliação dos métodos de Desambiguação Lexical de Sentido para os verbos, que serão descritos no seguinte capítulo. 


\section{Capítulo}

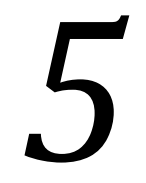

\section{Métodos de DLS Investigados}

Neste capítulo, serão abordados alguns métodos de DLS investigados neste trabalho e a avaliação dos mesmos na desambiguação de verbos. Na Seção 5.1, faremos algumas considerações iniciais, como a seleção dos métodos a investigar e o pré-processamento necessário para a adequação desses métodos ao português brasileiro; na Seção 5.2, serão descritos os métodos com os quais serão feitas as comparações; nas Seções 5.3, 5.4, 5.5 e 5.6 serão descritos os métodos de DLS investigados e suas adequações para a desambiguação de verbos; na Seção 5.7, será descrito o processo de incorporação de conhecimento profundo, advindo da VerbNet.Br, nos métodos investigados; e, finalmente, na Seção 5.8, serão descritas as considerações finais deste capítulo.

\subsection{Considerações Iniciais}

Um dos objetivos deste trabalho é explorar e adaptar métodos tradicionais da área de DLS e avaliá-los na desambiguação dos verbos do português do Brasil. Os métodos a serem explorados têm que cumprir com dois requisitos: ser irrestritos em relação com o domínio, para garantir a aplicabilidade dos métodos em qualquer cenário possível; e que possam ser flexíveis, pois desta maneira, podem ser integrados a outras aplicações, por exemplo, anotadores de papéis semânticos ou tradutores automáticos.

Como foram estudadas, abordagens de DLS baseadas em conhecimento têm uma maior abrangência, já que não dependem de córpus para treinamento e pelo suporte que têm de repositórios de sentidos. É por isso que se dará preferência à investigação de métodos desta abordagem.

Para o presente trabalho, foram escolhidos 4 métodos de DLS baseados em conhecimento, cada um seguindo uma técnica diferente. Os métodos são mencionados a seguir: método baseado em 
superposição de palavras, método baseado em Buscas Web, método baseado em Grafos e método focado no cenário multidocumento. Cada um desses métodos será adequado para a sua aplicabilidade na desambiguação de verbos.

Para a execução de cada método, é necessário um pré-processamento dos textos composto dos seguintes passos: (1) execução do anotador morfossintático MXPOST (Ratnaparkhi, 1996); (2) remoção das stopwords; (3) lematização das palavras de conteúdo; e (4) detecção das palavras alvo e representação do contexto.

Um ponto a ser considerado é a adaptação dos métodos investigados para o Português, especificamente, a obtenção dos synsets advindos da WordNet-Pr (devido ao fato da WordNet-Pr conter os synsets em inglês). A maneira como é feita a obtenção dos synsets em Inglês é a seguinte: para uma palavra em Português, obtêm-se todas as possíveis traduções em Inglês de um dicionário bilíngue (em nosso caso, foi usada o WordReference ${ }^{\circledR}$ ); depois, para cada tradução, obtém-se todos os possíveis synsets indexados na WordNet-Pr. Na Figura 5.1, pode ser visto como é realizada a tarefa de obter os synsets da WordNet-Pr para o verbo "reunir". Salienta-se que, para o exemplo, só os primeiros synsets são mostrados.

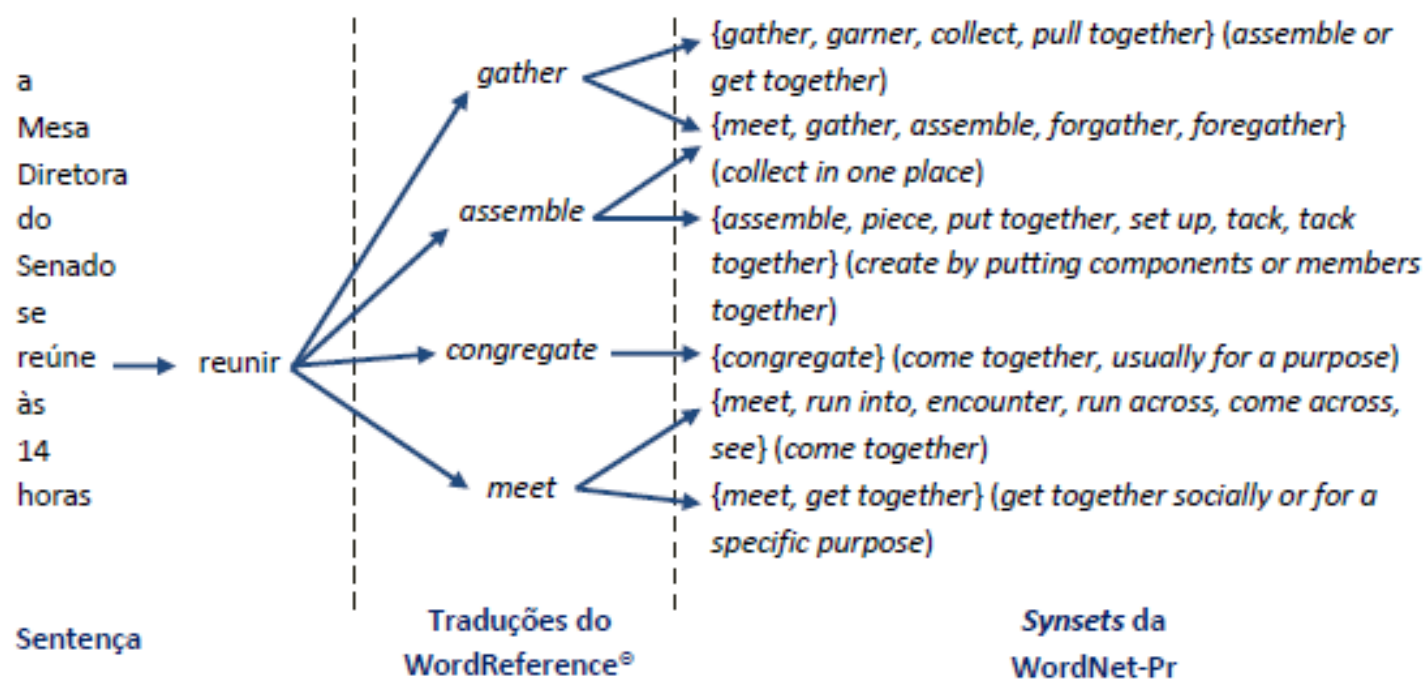

Figura 5.1: Método de obtenção dos synsets da WordNet-Pr para o verbo "reunir"

Para fins didáticos, usaremos a sentença "Na quinta-feira, a Mesa Diretora do Senado se reúne às 14 horas para decidir se aceita a quarta representação contra o presidente da Casa." da coleção número 44 do CSTNews, para mostrar como funcionam todos os métodos de DLS investigados. 


\subsection{Método Heurístico}

Neste trabalho, propõem-se dois métodos como baseline para comparar com os resultados obtidos pelos métodos de DLS investigados. O primeiro deles usa o sentido mais frequente de uma palavra. Este método é muito utilizado como baseline na literatura e, frequentemente, apresenta melhores resultados quando é comparado com métodos baseados em conhecimento. O método do sentido mais frequente (SMF) usa um repositório de sentidos no qual os sentidos indexados para uma palavra estão ordenados pela frequência e, assim, o método seleciona o primeiro sentido. A adequação feita para uma palavra em português brasileiro é a seguinte: (1) seleciona-se a primeira tradução mostrada pelo dicionário bilíngue WordReference ${ }^{\circledR}$ (devido aos resultados mostrados no WordReference ${ }^{\circledR}$ estarem ordenados pela frequência) e, (2) seleciona-se o primeiro sentido na lista de sentidos fornecidos pela WordNet-Pr para a tradução selecionada (devido aos sentidos da WordNet-Pr estarem ordenados pela frequência).

Por exemplo, na sentença proposta na Seção 5.1, a primeira tradução do verbo "reunir" é "gather", portanto, esta é selecionada. Finalmente, escolhe-se o primeiro synset da WordNet-Pr relacionado à tradução "gather", que corresponde a \{gather, garner, collect, pull together\} (assemble or get together), cuja tradução de glosa faz referência a "ficar juntos".

O segundo método é um método cego que consiste em (1) listar todos os synsets de todas as possíveis traduções para uma palavra em português brasileiro e (2) selecionar um sentido de maneira aleatória da lista de sentidos fornecidos pela WordNet-Pr.

Para o exemplo, o método selecionou o synset \{touch,adjoin,meet,contact\} (be in direct physical contact with; make contact) da tradução "meet", cuja glosa faz referência a "estar em contato físico com alguém".

\subsection{Método baseado em Sobreposição de Palavras}

O método investigado é o proposto por Lesk (1986). Este método desambigua uma palavra selecionando o sentido cujo rótulo (podendo ser representado pela definição do sentido) tenha o maior número de palavras em comum com os rótulos do seu contexto.

As adequações realizadas neste método foram as propostas por Nóbrega (2013). Estas adequações visaram à construção dos rótulos da palavra alvo e do seu contexto. A construção de um rótulo foi realizada usando o conjunto de palavras (na sua forma lematizada e excluindo as stopwords) das seguintes informações: (G) glosas dos synsets, (S) exemplos dos synsets e (T) possíveis traduções das palavras.

Considerando a forma de construir os rótulos de cada palavra, foram analisadas 6 tipos de 
configurações para comparar cada par de rótulos (onde o primeiro corresponde ao synset da palavra a ser desambiguada e o segundo a uma palavra de contexto):

- (G-T) compara a glosa do synset com as possíveis traduções da palavra de contexto;

- (S-T) compara os exemplos do synset com as possíveis traduções da palavra de contexto;

- (GS-T) compara a união da glosa e os exemplos do synset com as possíveis traduções da palavra de contexto;

- (G-G) compara a glosa do synset com a glosa de todos os synsets da palavra de contexto;

- (S-S) compara os exemplos do synset com os exemplos de todos os synsets da palavra de contexto;

- e, (GS2) compara a união da glosa e os exemplos do synset com a união da glosa e os exemplos de todos os synsets da palavra de contexto.

Considerando estas configurações, o método seleciona o synset da palavra alvo que contenha a maior quantidade de palavras em comum entre o rótulo do mesmo e os rótulos das palavras de contexto.

Além dessas configurações, neste trabalho foram realizadas outras variações, modificando o tamanho da janela de contexto e usando janelas de contexto não balanceadas. Estas variações foram feitas devido ao fato de que, segundo a literatura (Audibert, 2004), para a desambiguação de verbos é melhor usar janelas desbalanceadas, dando prioridade ao lado direito da janela, pois o objeto é mais importante do que o sujeito. Assim, foram usadas duas variações na janela de contexto: a primeira, usando uma palavra à esquerda e duas à direita; e a segunda, usando uma palavra à esquerda e três palavras à direita.

A seguir, apresenta-se um exemplo para a palavra alvo "reunir" usando uma janela desbalanceada, com uma palavra à esquerda e duas palavras à direita, e a configuração S-T. Na sentença, o contexto para a palavra "reunir" está formado pelas palavras "quinta-feira", "hora" e "decidir", portanto, tem-se que comparar cada rótulo dos synsets da palavra "reunir" (formado pelos exemplos) com os rótulos das traduções de "hora" ("hour"), "decidir" ("decide", "resolve" e " settle") e "quinta-feira" (que não possui traduções no WordReference $\left.{ }^{\circledR}\right)$. Após as comparações realizadas para cada synset, o método selecionou o synset \{gather,garner,collect,pull together\} (assemble or get together), cuja glosa faz referência a "ficar junto".

\subsection{Método baseado em Buscas Web}

O método investigado é o proposto por Mihalcea e Moldovan (1999) (para fins practicos, identificado pelo nome Mihalcea). Este método seleciona pares de palavras visando desambiguar uma delas usando como contexto a outra palavra. Neste método, constroem-se consultas formadas 
pelos synsets da palavra a desambiguar e a palavra de contexto. Posteriormente, estas consultas são postadas em um Motor de Busca, selecionando o synset que apresente a maior quantidade de resultados retornados pelo Motor de Busca.

As adequações feitas neste método foram as seguintes:

- Os pares de palavras escolhidos neste método são compostos por um verbo e um substantivo, considerando que o melhor contexto para a desambiguação de um verbo é definido pelo substantivo mais próximo na sentença. Ressalta-se que, em caso de empate entre dois substantivos com relação a um verbo, este método realiza uma seleção aleatória de um deles.

- Além dessa adequação, foi realizada uma variação do mesmo, considerando apenas a palavra mais próxima do lado direito (sabendo que na desambiguação de verbos o que está no objeto é mais importante do que no sujeito).

- Devido ao fato dos synsets serem escritos em Inglês, o método usa como contexto as traduções fornecidas pelo WordReference ${ }^{\circledR}$ do substantivo.

- As consultas são formadas pelos synsets do verbo a desambiguar e as traduções do substantivo mais próximo.

A seguir, apresenta-se um exemplo com a sentença proposta na Seção 5.1: para essa sentença, tem-se que o par escolhido para o verbo "reunir" é "hora". Com este par, são construídas as consultas formadas pelos synsets do verbo "reunir" e pelas traduções do substantivo "hora" ("hour"), como segue (para este exemplo, têm sido considerados apenas os dois synsets do verbo "reunir" com os melhores resultados):

- Synset: $\{$ touch, adjoin, meet, contact $\}$ - be in direct physical contact with; make contact

Consulta: "touch hour" OR "adjoin hour" OR "meet hour" OR "contact hour"

- Synset: \{meet, encounter, play, take on - contend against an opponent in a sport, game, or battle

Consulta: "meet hour" OR "encounter hour" OR "play hour" OR "take on hour"

Depois, essas consultas são postadas no buscador Bing ${ }^{\circledR}{ }^{58}$, computando-se os resultados para cada sentido e, finalmente, escolhendo-se o sentido que apresente a maior quantidade de resultados retornados. Para o exemplo, o método escolheu o synset \{touch, adjoin, meet, contact\}, que apresentou os melhores resultados (504000), em vez do synset \{meet, encounter, play, take on\} que obteve 329000 resultados.

\footnotetext{
${ }^{58} \mathrm{O}$ uso do motor de busca Bing ${ }^{\circledR}$ se deve ao fato de que quando foi desenvolvido este mestrado, a API era utilizável de maneira gratuita.
} 
O método investigado nesta abordagem é o proposto por Agirre et al. (2014). Os autores propuseram 3 métodos que usam o algoritmo de PageRank (Brin e Page, 1998) sobre um grafo de conhecimento extraído da WordNet-Pr:

- O primeiro deles cria um sub-grafo com as palavras incluídas em uma porção de texto (sentença, parágrafo ou texto) e executa o algoritmo PageRank sobre esse grafo, selecionando, para cada palavra, os synsets com maior valor de PageRank.

- O segundo método usa o grafo inteiro da WordNet-Pr e executa o algoritmo PageRank sobre o grafo inteiro, mas atribui prioridade só para nós pertencentes aos synsets das palavras da porção de texto.

- O terceiro método é similar ao segundo, mas com a diferença que este método desambigua uma palavra da porção de texto em cada execução, e a forma como funciona é atribuindo prioridade para os nós pertencentes aos synsets de todas as palavras da porção de texto, com exceção dos synsets da palavra a ser desambiguada. A suposição pela qual se dá prioridade para synsets das palavras incluídas no contexto é que o synset da palavra a ser desambiguada deve ser influenciado somente pelas palavras no contexto.

Desses 3 métodos mencionados, foi escolhido o terceiro, já que se teve como objetivo a desambiguação de palavras da classe gramatical "Verbo" e não todas as palavras de um texto. O algoritmo PageRank foi usado considerando um limite máximo de 30 iterações e um fator de relaxamento de 0.85 , seguindo o artigo mencionado. Salienta-se que, para este método, a desambiguação foi realizada por sentença e por parágrafo.

A seguir, apresenta-se o grafo gerado para a desambiguação da palavra "reunir" (só algumas palavras do contexto são apresentadas). 


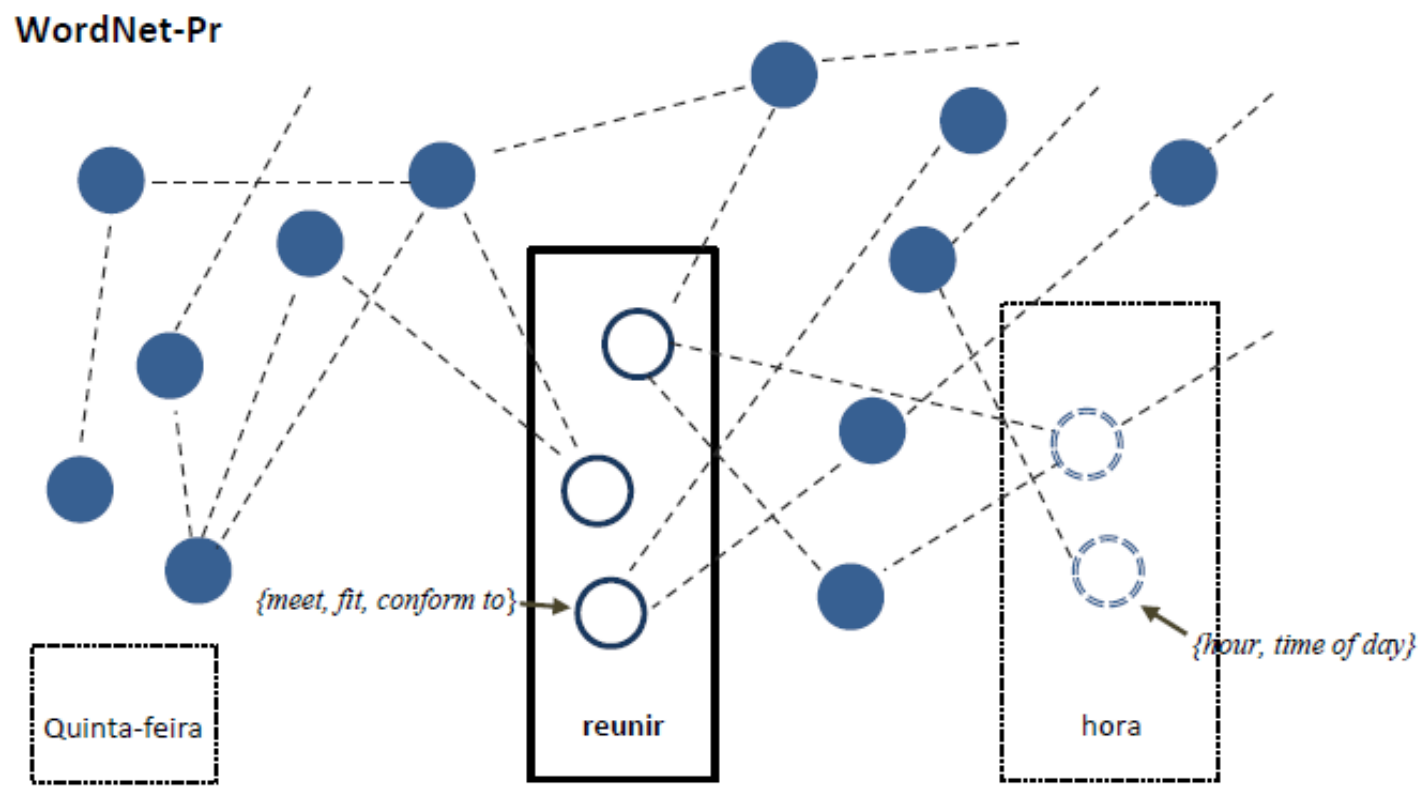

Figura 5.2: Representação de uma parte do parágrafo para a desambiguação da palavra "reunir"

Na Figura 5.2, apresenta-se a representação de uma porção do parágrafo descrito na Subseção 5.1 para o verbo "reunir". Os synsets da WordNet-Pr estão representados círculos (sejam pontilhados ou com linha compacta) e as arestas representadas por linhas pontilhadas. Nota-se que a palavra "quinta-feira" não possui nenhum synset, isto acontece porque não foi encontrada nenhuma tradução possível para essa palavra e, portanto, nenhum synset foi mostrado. Os quadros pontilhados incluem os synsets das palavras do contexto e a prioridade é atribuída nesses nós (limitados por círculos pontilhados). O quadro com linha compacta abrange os synsets da palavra alvo, neste caso, o verbo "reunir". Na Figura ressaltam-se alguns synsets para a palavra de contexto e a palavra a desambiguar. Para o exemplo apresentado, o método selecionou o synset \{meet,fit,conform to\} (satisfy a condition or restriction\}, cuja glosa faz referência a "satisfazer uma condição ou restrição".

\subsection{Método focado em Cenário Multidocumento}

O último método investigado é o proposto por Nóbrega e Pardo (2014) (identificado pelo nome Nobrega e Pardo). Este método usa como contexto uma representação multidocumento e assume que, para cada palavra, todas as ocorrências da mesma possuem o mesmo sentido dentro de uma coleção de textos. Durante a etapa de pré-processamento, este método cria um grafo de coocorrência com todas as palavras de conteúdo de uma coleção. A co-ocorrência é dada por janelas de palavras de tamanho 3 e 5 (a isto tem que se adicionar a palavra a analisar). Por exemplo, na sentença usada na Seção 5.1 tem-se a seguinte sequência, "quinta-feira", "reunir", "hora", "decidir" e "aceitar". Portanto, se usássemos uma janela de tamanho 3, formar-se-iam as seguintes janelas: "quinta-feira-reunir-hora-decidir", "reunir-hora-decidir-aceitar", "hora- 
decidir-aceitar- $x$ " e "decidir-aceitar- $x$ - $x$ ". Nota-se que os símbolos " $x$ " usados nas janelas formadas representam que não existem mais palavras nessa sequência.

Na Figura 5.3, apresenta-se o grafo gerado para a sequência utilizada. Para cada janela, criam-se arestas entre as palavras pertencentes à mesma. Caso exista uma aresta repetida, procede-se ao incremento do peso da aresta.

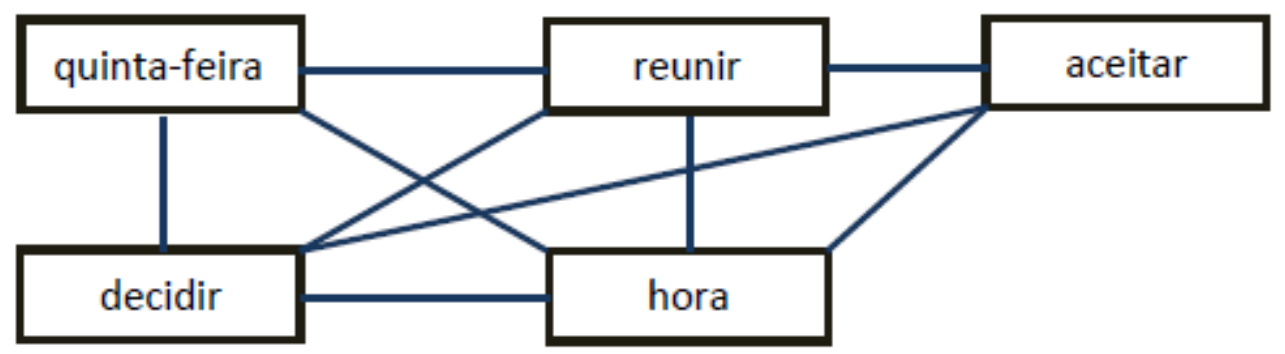

Figura 5.3: Grafo gerado a partir da sequência "quinta-feira", "reunir", "hora", "decidir", e "aceitar"

Uma vez gerado o grafo de co-ocorrência de uma coleção, faz-se o seguinte: para uma palavra alvo (em nosso caso, um verbo), selecionam-se as "n" palavras que mais co-ocorrem com ela no grafo (estas palavras são usadas como contexto da palavra alvo); depois, o algoritmo de Lesk, apresentado na Seção 5.3, é executado, selecionando o synset da palavra alvo que possua mais palavras em comum com o seu contexto.

Na Figura 5.4, apresenta-se a lista de palavras que co-ocorreram com o verbo "reunir". Nota-se que todas as palavras co-ocorreram uma vez com o verbo "reunir", portanto, suas arestas não possuem peso (sendo por padrão igual a 1). Com estas palavras, o método selecionou as 3 palavras que mais co-ocorreram com "reunir" (para este caso, selecionou aleatoriamente), que foram "processo", "conjunto" e "quinta-feira", e se aplicou o método de Lesk na configuração ST. Finalmente, o método selecionou o synset \{assemble, piece, put together, set up, tack, tack together\} (create by putting components or members together), cuja glosa faz referência a "criar colocando componentes ou membros juntos". 


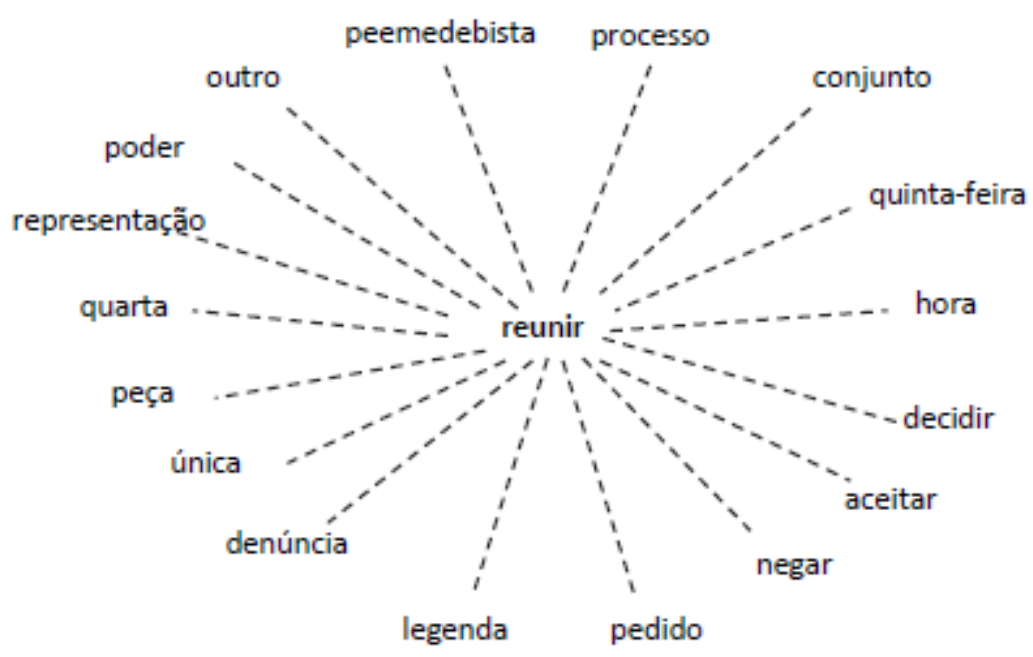

Figura 5.4: Grafo de co-ocorrência gerado para o verbo "reunir"

\subsection{Incorporação de Conhecimento da VerbNet.Br}

Como foi mencionado, a VerbNet é um recurso lexical que agrupa verbos segundo as classes de Levin (1986). As classes de Levin agrupam verbos segundo características sintáticas e semânticas similares. Levin partiu da suposição de que verbos com uma semântica próxima compartilham informações sintáticas (estrutura sintática), podendo-se agrupá-los em classes semânticas usando apenas em seu comportamento sintático.

A ideia na qual se baseia a incorporação do conhecimento da VerbNet.Br é que, dado que haja verbos, dentre um mesmo texto, que pertencem à mesma classe da VerbNet.Br, compartilhando características sintático-semânticas, os contextos dos verbos agrupados podem-se ajudar no processo de desambiguação. Assim, a incorporação do conhecimento da VerbNet.Br está dividida em duas etapas: (1) agrupamento dos verbos segundo as classes da VerbNet.Br (descrito nas Seções 5.7.1 e 5.7.2) e (2) enriquecimento do contexto dos verbos agrupados (descrito na Seção 5.7.3).

\subsubsection{Agrupamento de verbos segundo Classes da VerbNet.Br}

A ideia de agrupar verbos surgiu motivada pelo mencionado por Harris (1954), que disse que palavras que ocorrem em contextos similares, tendem a apresentar significados similares. Considerando que um texto determinado (no nosso caso, notícias jornalísticas) fala sobre um mesmo tema (contexto), pode-se sugerir que verbos dentro de um mesmo texto apresentam certa relação semântica (não necessariamente advinda da sinonímia), e essa relação pode ser obtida usando a VerbNet.Br. Por exemplo, se um texto de política diz "o candidato X subiu de 5\% para $15 \%$ " e também "o candidato Y caiu de 14\% para 3\%", pode-se ver que o verbo "subir" e o verbo "cair" possuem uma relação semântica (progredir ou regredir) e as duas pertencem a uma 
mesma classe da VerbNet.Br (escape-51.1), portanto, podem se ajudar no processo de desambiguação.

Considerando o mencionado no parágrafo anterior, fez-se um método de agrupamento que usou o critério chamado "dominância", isto é, quanto maior a quantidade de verbos que pertencem a uma mesma classe, mais provável é que estes apresentem alguma relação. Assim, para cada verbo incluído em um texto, obtiveram-se todas as possíveis classes às quais poderia pertencer (considerando só a forma lematizada). Depois, encontrou-se a classe que incluísse a maior quantidade de verbos no texto e se formou um conjunto com esses verbos (critério de dominância). Com os verbos restantes procedeu-se a fazer o mesmo procedimento, até não se encontrar nenhum conjunto possível de verbos.

Na Figura 5.5, apresenta-se um exemplo no qual pode se ver as diferentes classes às quais pertencem os verbos enumerados de 1 até 5. Usando o método de agrupamento, o primeiro conjunto a se formar seria o da classe $\mathrm{VNClass}_{1}$, que possui 3 verbos $\left(\mathrm{V}_{1}, \mathrm{~V}_{3}\right.$ e $\left.\mathrm{V}_{5}\right)$. Depois disso, forma-se o conjunto seguinte, mas, neste caso, não existem mais grupos a serem formados (todas as outras classes conteriam apenas um verbo cada uma).

\section{Verbos Classes da VerbNet.Br}

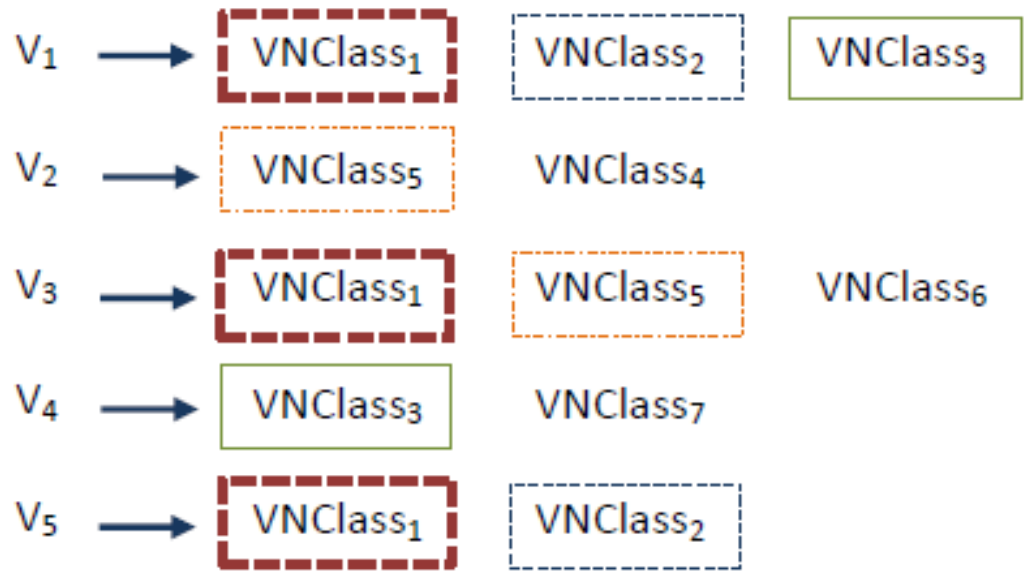

Figura 5.5: Classes da VerbNet.Br possíveis para cada verbo

\subsubsection{Refinamento do agrupamento de verbos usando informações sintáticas}

Uma dificuldade encontrada na etapa anterior foi que, para cada verbo, foram consideradas todas as classes da VerbNet.Br possíveis. Isto poderia fazer com que o método trouxesse classes que, na verdade, não deveriam ser trazidas, já que, para que um verbo pertença a uma classe da VerbNet.Br, tem que cumprir também as características sintáticas e semânticas, além do lema estar incluído na classe. 
Foi assim que se refinou a lista de classes da VerbNet.Br para cada verbo, usando um filtro segundo o frame sintático do mesmo, ou seja, para considerar uma classe da VerbNet.Br, a classe teria que conter o verbo em análise e o seu frame sintático. Para executar este filtro, considerou-se usar a estrutura sintática que resulta da execução do parser PALAVRAS, mas o problema foi que a estrutura sintática produzida pelo PALAVRAS não diferencia entre argumentos e adjuntos, e a VerbNet.Br considera apenas os argumentos de um verbo e não os adjuntos. A alternativa para esta distinção foi o uso de anotadores de papéis semânticos. Foi assim que se usou o anotador de papéis semânticos proposto por Alva-Manchego (2013), usando o modelo treinado de Hartmann (2015). O problema com esta ferramenta foi que, apesar de mostrar a estrutura argumental, ele não mostra diretamente a estrutura sintática do mesmo. Dado que as duas ferramentas são complementares, optou-se por usá-las em conjunto. Os passos para a análise de uma sentença e a obtenção do frame sinático foram os seguintes:

- executar o anotador de papéis semânticos e obter a estrutura argumental;

- extrair a estrutura sintática advinda do PALAVRAS;

- formatar a entrada para o uso na VerbNet.Br;

- e, finalmente, mapear as duas estruturas, considerando só os argumentos.

A seguir, usaremos como exemplo a sentença apresentada na Seção 5.1. Ao executar o anotador de papéis semânticos proposto por Alva-Manchego na sentença, obteve-se a estrutura argumental apresentada na Figura 5.6:

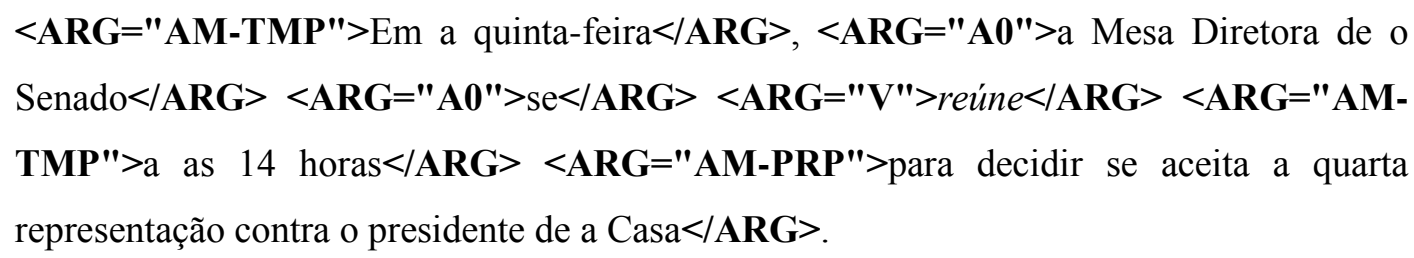

Figura 5.6: Estrutura Argumental da sentença de exemplo para o verbo "reunir"

Na Figura 5.6, extrai-se que a estrutura de argumentos do verbo "reunir" está composta por a seguinte sequência: AM-TMP_A0_A0_V_AM-TMP_AM-PRP, donde AM-TMP representa um adjunto temporal, A0 um Agente, e AM-PRP um adjunto de propósito. Contudo, para fazer o mapeamento com a VerbNet.Br, foi necessário considerar a estrutura argumental a partir do verbo, sendo V_AM-TMP_AM-PRP.

Da mesma forma, o parser PALAVRAS foi executado sobre a mesma sentença para encontrar a estrutura sintática do verbo "reunir", obtendo-se a seguinte estrutura: PP[em]_NP_NP_V_PP[a]_PP[para]. Finalmente, para fazer o mapeamento com a VerbNet.Br, a estrutura sintática foi considerada a partir do verbo, resultando em V_PP[a]_PP[para]. 
Finalmente, fez-se um mapeamento entre a saída do anotador de papéis semânticos e a saída do PALAVRAS, com o fim de encontrar o frame sintático do verbo "reunir". Na Figura 5.7, apresenta-se o mapeamento realizado entre o anotador de papéis semânticos e a saída do PALAVRAS.

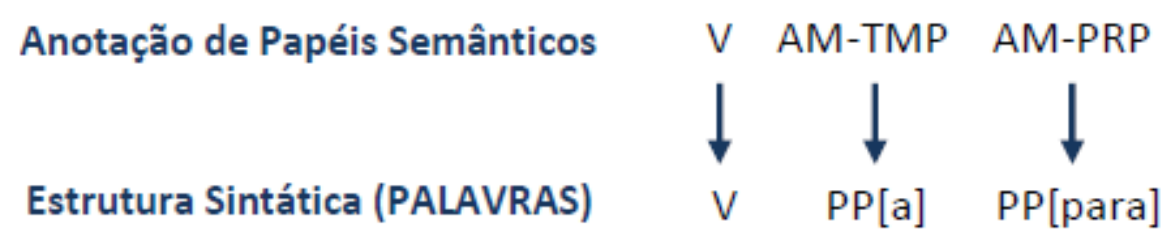

Figura 5.7: Mapeamento entre a saída do anotador de papéis semânticos e a estrutura sintática apresentada no parser PALAVRAS

Do mapeamento apresentado na Figura 5.7 e considerando que na VerbNet.Br são necessários apenas os argumentos e não os adjuntos, obteve-se que o frame sintático do verbo "reunir" foi representado por $\mathrm{V}$ somente, já que os sintagmas preposicionais foram identificados como adjuntos de tempo e de propósito e, portanto, não foram considerados..

\subsubsection{Enriquecimento de Contextos nos métodos de DLS explorados}

Depois de executar o agrupamento de verbos segundo as Classes da VerbNet.Br, procedeu-se a enriquecer o contexto dos verbos que tinham sido agrupados. Este enriquecimento de contextos foi aplicado ao método de Lesk e ao método de Nóbrega e Pardo, já que eles apresentaram os melhores resultados. O primeiro usa uma abordagem monodocumento, e, o outro, multidocumento.

No caso do método de Lesk, usou-se o agrupamento considerando o filtro por estrutura de subcategorização. A maneira como se enriqueceram os contextos no método de Lesk foi a seguinte: dados os contextos de cada verbo incluído em um mesmo conjunto, uniram-se todos para formar um único contexto, do qual foram selecionados as " $n$ " palavras mais frequentes como contexto final. Finalmente, para cada verbo do conjunto, o algoritmo de Lesk foi executado usando a configuração S-T e as palavras do contexto final. Salienta-se que os verbos que não pertencem a nenhum conjunto são desambiguados da forma usual.

Por exemplo, na sentença da Seção 5.1, para o verbo "reunir", tem-se como o contexto as palavras "quinta-feira", "hora" e "decidir". Este verbo foi agrupado com outros 3 verbos: (1) "juntar", com o contexto formado por "líder", "só" e "representação"; (2) "ocorrer", com o contexto formado por "exemplo", "representação" e "ideal"; e (3) "coordenar", com o contexto formado por "denúncia", "esquema" e "arrecadar". Portanto, o contexto formado é composto pelas palavras "representação (2)", "líder", "só”, "quinta-feira", "hora”, "decidir", "exemplo", "ideal", 
"denúncia", "esquema" e "arrecadar". Deste contexto, foram usados apenas as 3 palavras mais frequentes como contexto final, isto é, as palavras "representação", "lider" e "só",59.

Finalmente, o algoritmo de Lesk foi executado usando este contexto final para cada verbo do conjunto, selecionando o synset \{gather, garner, collect, pull together\} (assemble or get together), cuja glosa faz referência a "ficar junto", para o verbo "reunir".

No caso do método de Nóbrega e Pardo, usou-se o agrupamento sem considerar o filtro por estrutura de subcategorização. Isso se deve ao fato de que este método usa a heurística de um sentido por discurso, ou seja, cada ocorrência de um verbo possui o mesmo sentido, independentemente da estrutura de subcategorização que possua.

A maneira como se enriqueceram os contextos no método de Nóbrega e Pardo foi similar à usada no método de Lesk, isto é, juntando todos os contextos. Salienta-se que os verbos que não pertencem a nenhum conjunto são desambiguados da forma usual.

Por exemplo, na coleção à qual pertence a sentença da Seção 5.1, o verbo "reunir" foi agrupado com "incluir", "entrar", "tratar", "ocorrer", "juntar", "coordenar" e "vir" na mesma classe da VerbNet.Br. Portanto, formou-se um grafo geral, unindo todas as palavras de contexto de cada verbo contido no conjunto. O grafo gerado é apresentado na Figura 5.8, onde o centro "verbos" representa todos os verbos incluídos no conjunto formado e o peso das arestas representa o número de co-ocorrências com qualquer verbo incluído no conjunto formado.

Do grafo gerado apresentado na Figura 5.8, o método escolheu como contexto as 3 palavras que mais co-ocorreram com todos os verbos incluídos no conjunto formado, ou seja, as palavras "denúncia", "representação" e "pedido"60. Finalmente, o algoritmo de Lesk foi executado usando este contexto para cada verbo do conjunto, e assim, selecionou o synset \{gather, garner, collect, pull together\} (assemble or get together), cuja glosa faz referência a "ficar junto", para o verbo "reunir".

\footnotetext{
59 Para o exemplo, as palavras "líder", "só", "quinta-feira", "hora", "decidir", "exemplo", "ideal", "denúncia", "esquema" e "arrecadar" poderiam ter sido incluídos nas 2 palavras de contexto faltantes, já que possuíam a mesma quantidade de co-ocorrências com "reunir". Neste caso, o método selecionou aleatoriamente duas palavras da lista.

${ }^{60}$ Para o exemplo, as palavras "pedido", "proceso" e "semana" poderiam ter sido incluídos na palavra de contexto faltante, já que possuíam a mesma quantidade de co-ocorrências. Neste caso, o método selecionou a palavra "pedido" de maneira aleatória.
} 


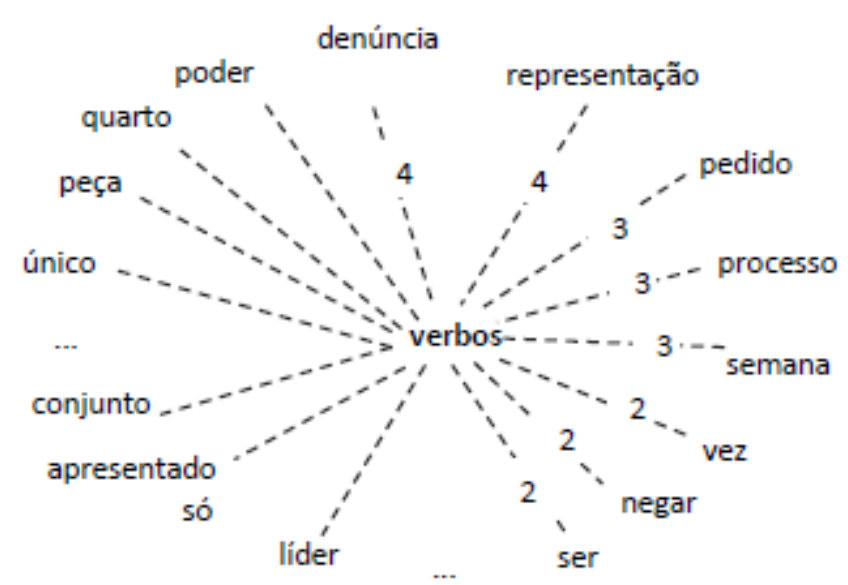

Figura 5.8: Grafo de co-ocorrência gerado juntando todos os verbos incluídos em uma mesma classe da VerbNet.Br

\subsection{Considerações Finais}

Neste capítulo, foram apresentados os métodos explorados neste trabalho de mestrado e a maneira como se usou o conhecimento da VerbNet.Br para enriquecer o contexto dos métodos de Lesk e de Nóbrega. Contudo, esta não é a única maneira na qual poderia ter sido usado o conhecimento da VerbNet.Br, podendo ter sido usadas as restrições de seleção dos argumentos para melhorar o método de desambiguação e as relações existentes entre os sentidos dos verbos na VerbNet.Br e os papéis semânticos da mesma, entre outras. No capítulo seguinte, serão apresentados os resultados obtidos e uma avaliação dos mesmos. 


\section{Experimentos e Resultados}

Neste capítulo é apresentada a avaliação dos métodos explorados no capítulo anterior no córpus CSTNews. Assim, este capítulo é divido em 3 seções. Na Seção 6.1, são apresentadas as considerações iniciais desta avaliação, isto é, as medidas usadas e as tarefas avaliadas. Na Seção 6.2, são apresentados os resultados obtidos pelos métodos explorados no capítulo anterior. Finalmente, na Seção 6.3, são apresentados os resultados obtidos pelos métodos explorados quando se faz a incorporação do conhecimento da VerbNet.Br e uma comparação com os métodos originais.

\subsection{Considerações Iniciais}

As avaliações foram realizadas sobre a anotação de sentidos de verbos no córpus CSTNews. Neste trabalho, foram usados dois métodos como baseline: o método do sentido mais frequente (SMF), que, como foi descrito, é um método muito utilizado na literatura e é difícil de ser superado por métodos baseados em conhecimento; e um método cego, que é um método mais simples que escolhe aleatoriamente os sentidos para cada verbo. O topline usado foi o desempenho humano na tarefa de anotação e foi calculado usando as coleções usadas na obtenção dos valores de concordância.

Respeito das tarefas a avaliar, foram consideradas para a avaliação dos métodos tradicionais a tarefa All-words, na qual objetivou-se desambiguar todas as palavras do córpus, e a tarefa Lexical sample, na qual, foram selecionados os 20 verbos mais polissêmicos no córpus, sobre as quais se avaliaram os métodos explorados.

As medidas utilizadas para avaliar os métodos explorados foram as descritas na Seção 2.4, isto é, precisão (P), cobertura (C), abrangência (A) e acurácia (Ac). 
6.2 Avaliação de métodos explorados

No capítulo anterior, descreveram-se os métodos a serem explorados e as variações realizadas para a adequação no contexto dos verbos. A seguir, detalham-se os resultados obtidos para cada método e suas variações na tarefa All-words, para finalmente, consolidar os melhores resultados em uma Tabela geral (Tabela 6.5). Ressalta-se que os valores destacados em negrito são os melhores.

A respeito do método de Lesk, foram avaliadas todas as configurações de rótulos apresentadas na Seção 5.3 e as variações usando janelas desbalanceadas. Na Tabela 6.1, apresentam-se os resultados obtidos para cada variação de janela e suas respectivas configurações. Ressalta-se que a notação usada para as variações do método de Lesk seguem a forma Lesk$<$ número_palavras_esquerda>-<número_palavras_direita>. Assim, Lesk-2-2 S-T faz referência ao método de Lesk usando como janela 2 palavras à esquerda e 2 palavras à direita, junto com a configuração de S-T (sobreposição de palavras entre os exemplos dos synsets da palavra a desambiguar e as traduções do contexto).

\begin{tabular}{|c|c|c|c|c|c|}
\hline \multicolumn{2}{|c|}{ Variação } & $\mathbf{P}(\%)$ & $\mathrm{C}(\%)$ & $A(\%)$ & Ac (\%) \\
\hline \multirow{6}{*}{ Lesk-2-2 } & G-T & 37.24 & 35.06 & 94.14 & 35.06 \\
\hline & S-T & 38.41 & 36.16 & 94.14 & 36.16 \\
\hline & GS-T & 33.87 & 31.89 & 94.14 & 31.89 \\
\hline & S-S & 14.54 & 13.56 & 93.27 & 13.95 \\
\hline & G-G & 21.64 & 20.35 & 94.02 & 20.39 \\
\hline & GS2 & 18.08 & 17.00 & 94.02 & 17.04 \\
\hline \multirow{6}{*}{ Lesk-1-2 } & G-T & 38.84 & 36.50 & 93.98 & 36.58 \\
\hline & $\mathrm{S}-\mathrm{T}$ & 40.10 & 37.69 & 93.98 & 37.77 \\
\hline & GS-T & 36.18 & 34.01 & 93.98 & 34.09 \\
\hline & S-S & 15.58 & 14.33 & 91.98 & 15.30 \\
\hline & G-G & 22.32 & 20.90 & 93.65 & 21.14 \\
\hline & GS2 & 18.62 & 17.44 & 93.65 & 17.68 \\
\hline \multirow{6}{*}{ Lesk-1-3 } & G-T & 37.14 & 34.96 & 94.12 & 35.00 \\
\hline & $\mathrm{S}-\mathrm{T}$ & 37.71 & 35.49 & 94.12 & 35.53 \\
\hline & GS-T & 33.48 & 31.51 & 94.12 & 31.55 \\
\hline & $\mathrm{S}-\mathrm{S}$ & 14.92 & 13.94 & 93.43 & 14.23 \\
\hline & G-G & 21.36 & 20.09 & 94.06 & 20.13 \\
\hline & GS2 & 17.70 & 16.65 & 94.06 & 16.69 \\
\hline
\end{tabular}

Tabela 6.1: Avaliação do método de Lesk 
Na Tabela 6.1, mostra-se que a melhor variação do método de Lesk foi a que usou uma janela composta de 1 palavra à esquerda e 2 à direita (variação 1-2), e a configuração S-T para a criação de rótulos (40.10\% em precisão e $37.69 \%$ em cobertura). Salienta-se que, como dito na literatura (Audibert, 2004), o uso de janelas desbalanceadas traz benefícios na DLS de verbos. Contudo, embora o desbalanceamento trouxe uma melhoria no método, quando este foi maior (como visto na variação de 1 palavra à esquerda e 3 à direita ou variação 1-3), trouxe informações que continham ruído, o que diminuiu o desempenho do mesmo.

Outro ponto a salientar é que, quando avaliada a abrangência, o método que usou a variação com uma janela balanceada com 2 palavras nos dois lados (variação 2-2), obteve os melhores resultados, seguido por a variação 1-3, e finalmente a variação 1-2. A razão para isto é que esta última variação usa uma janela de contexto menor às outras, assim, algumas dessas palavras poderiam não possuir tradução no dicionário bilíngue ou synsets na WordNet-Pr, o que ocasionaria a não desambiguação de alguns verbos.

Em relação às configurações usadas, a melhor configuração foi usando os exemplos dos synsets da palavra a desambiguar com as traduções das palavras do contexto. Salienta-se que ao usar rótulos mais elaborados, por exemplo, a combinação de glosa e exemplo de um synset, o desempenho tende a cair. Além disso, quando comparados glosas e/ou exemplos de synsets tanto das palavras a desambiguar quanto das palavras de contexto, o desempenho foi caindo mais, o que diz que rótulos mais simples contribuem positivamente no método de Lesk.

A respeito do método de Mihalcea, foram avaliadas a variação que usa como contexto a palavra mais próxima, considerando as palavras à esquerda e à direita (variação Esq-Dir), e a variação que usa a palavra mais próxima, considerando só as palavras à direita (variação Dir). Na Tabela 6.2, apresentam-se os resultados obtidos para cada variação.

\begin{tabular}{c|cccc}
\hline Variação & P (\%) & C (\%) & A (\%) & Ac (\%) \\
\hline Esq-Dir & $\mathbf{1 7 . 2 1}$ & $\mathbf{1 4 . 4 3}$ & $\mathbf{8 3 . 8 7}$ & $\mathbf{1 9 . 4 4}$ \\
Dir & 14.96 & 12.51 & 83.65 & 17.14 \\
\hline
\end{tabular}

Tabela 6.2: Avaliação do método de Mihalcea

Em relação aos resultados apresentados na Tabela 6.2, obteve-se que o método que usou a variação Esq-Dir mostrou os melhores resultados. Estes resultados foram contra a hipótese que o lado direito (objeto) é mais importante do que o lado esquerdo (sujeito). Contudo, salienta-se um erro que poderia ter acontecido na variação Dir é que, apesar de escolher como contexto o substantivo mais próximo pelo lado direito (o que está no objeto), muitas vezes a distância entre o substantivo mais próximo e o verbo a desambiguar foi muito grande, pudendo pertencer a outra 
sentença, e desta forma induzir um erro no método.

A respeito do método de Agirre e Soroa, foram avaliadas as variações usando como contexto o parágrafo no qual está presente o verbo e a sentença na qual está presente o verbo. Na Tabela 6.3, apresentam-se os resultados obtidos para cada variação.

\begin{tabular}{c|cccc}
\hline Variação & P (\%) & C (\%) & A (\%) & Ac (\%) \\
\hline Parágrafo & $\mathbf{2 8 . 4 5}$ & $\mathbf{2 6 . 8 0}$ & $\mathbf{9 4 . 2 0}$ & $\mathbf{2 6 . 8 0}$ \\
Sentença & 26.03 & 24.52 & 94.20 & 24.52 \\
\hline
\end{tabular}

Tabela 6.3: Avaliação do método de Agirre e Soroa

$\mathrm{Na}$ Tabela 6.3, nota-se que os melhores resultados corresponderam à variação que usou o parágrafo como contexto. Isto, devido ao fato de esse método usar um maior número de palavras para influenciar o contexto. Além disso, dado que por definição, todas as sentenças dentro de um mesmo paragrafo falam coisas relacionadas, era esperado que este método atingisse os melhores resultados.

A respeito do método de Nóbrega e Pardo, foram avaliadas as duas configurações de rótulos que melhor desempenho tiveram no método de Lesk, isto é G-T e S-T-, e as variações usando janelas de contexto que contenham 3 e 5 palavras. . Ressalta-se que a notação usada para as variações do método de Nóbrega seguem a forma Nóbrega e Pardo-<número_palavras $>$. Assim, Nóbrega e Pardo-3 S-T faz referência ao método de Nóbrega usando uma janela de contexto de 3 palavras e a configuração S-T (comparação entre os exemplos dos synsets da palavra a desambiguar e as traduções do contexto). Na Tabela 6.4, apresentam-se os resultados obtidos para cada variação de janela e suas respectivas configurações.

\begin{tabular}{c|c|cccc}
\hline \multicolumn{2}{c|}{ Variação } & P (\%) & C (\%) & A (\%) & Ac (\%) \\
\hline Nóbrega e & G-T & 37.83 & 35.61 & 94.14 & 35.65 \\
Pardo-3 & S-T & $\mathbf{4 0 . 3 3}$ & $\mathbf{3 7 . 9 7}$ & 94.14 & $\mathbf{3 8 . 0 0}$ \\
\hline Nóbrega e & G-T & 33.54 & 31.59 & $\mathbf{9 4 . 2 0}$ & 31.59 \\
Pardo-5 & S-T & 36.67 & 34.54 & $\mathbf{9 4 . 2 0}$ & 34.54 \\
\hline
\end{tabular}

Tabela 6.4: Avaliação do método de Nóbrega

Como pode ser visto na Tabela 6.4, a variação que usa janelas de tamanho 3 e a configuração S-T obteve os melhores resultados. Contudo, salienta-se que ao avaliar a abrangência, a variação que usa janelas de tamanho 5 obteve o melhor resultado. Isto era esperado, porque ao ter uma maior quantidade de palavras no contexto, é maior a probabilidade de desambiguar um verbo. Dentro das configurações utilizadas e de maneira similar ao método de Lesk, a configuração S-T apresentou os melhores resultados nas 2 variações. 
Finalmente, na Tabela 6.5, apresentam-se os melhores resultados para cada método na tarefa Allwords (incluindo-se os métodos baseline: SMF e Cego). Ressalta-se que nesta tabela são destacados em negrito os melhores resultados e o melhor método dentre os explorados.

\begin{tabular}{c|cccc}
\hline Método & P(\%) & C (\%) & A (\%) & Ac (\%) \\
\hline Topline & 61.11 & 57.85 & 94.71 & - \\
\hline SMF & $\mathbf{4 9 . 9 1}$ & $\mathbf{4 7 . 0 1}$ & $\mathbf{9 4 . 2 0}$ & - \\
Cego & 10.04 & 9.46 & $\mathbf{9 4 . 2 0}$ & 9.46 \\
Lesk & 40.10 & 37.69 & 93.98 & 37.77 \\
Mihalcea & 17.21 & 14.43 & 83.87 & 19.44 \\
AgirreSoroa & 28.45 & 26.80 & $\mathbf{9 4 . 2 0}$ & 26.80 \\
Nóbrega e Pardo & $\mathbf{4 0 . 3 3}$ & $\mathbf{3 7 . 9 7}$ & 94.14 & $\mathbf{3 8 . 0 0}$ \\
\hline
\end{tabular}

Tabela 6.5: Resultados gerais para a tarefa All-words

Da Tabela 6.5, nota-se que nenhum método conseguiu superar o método do sentido mais frequente (com uma diferença mínima de 9.58\% entre o método SMF e o método de Nóbrega e Pardo), porém, todos os métodos superaram o método cego, o que era esperado. Os métodos obtidos ordenados em relação a seu desempenho, não considerando os métodos usados como baseline, foram os seguintes: (1) Nóbrega e Pardo, (2) Lesk, (3) AgirreSoroa e (4) Mihalcea.

O método de Nóbrega e Pardo apresentou os melhores resultados quando avaliada a precisão, cobertura e acurácia. A razão para este resultado está explicada ao ver a pouca variação de sentidos que existe no córpus, isto é, os verbos tenderam a possuir o mesmo sentido dentro de uma coleção de textos, o que favoreceu o método de Nóbrega, que atribui um único sentido para cada palavra em uma coleção. No caso da abrangência, o método de Agirre e Soroa obteve os melhores resultados porque, como foi descrito, o contexto contém mais palavras que contribuem na desambiguação dos verbos. Nesta medida, outro detalhe a destacar é que os valores de abrangência não foram muito distantes da abrangência do topline. A respeito da acurácia dos métodos, salienta-se que o método do sentido mais frequente (que foi descrito na seção 2.4) produziu uma melhor mínima em todos os métodos investigados.

A tarefa Lexical sample foi realizada avaliando as 20 palavras mais polissêmicas no córpus. Com a finalidade de analisar o percentual de acerto dos métodos sobre os verbos selecionados, foi considerado apenas o valor de precisão $(\mathrm{P})$ para cada método.

Na Tabela 6.6, apresentam-se os resultados obtidos na tarefa Lexical sample para todos os métodos explorados. Nesta tabela, as colunas descrevem o verbo avaliado (Verbo), a frequência de ocorrência no córpus (F), a número de synsets usados na anotação manual do córpus (S), o 
método do sentido mais frequente (SMF), o método cego (C), a melhor variação do método de Lesk (L), a melhor variação do método de Mihalcea (M), a melhor variação do método de Agirre e Soroa (AS) e a melhor variação do método de Nóbrega e Pardo (N). Salientam-se em negrito os valores maiores ou iguais ao método SMF.

Como pode ser visto, nenhum método conseguiu superar o método do sentido mais frequente, contudo. Também, todos os métodos conseguiram superar o método cego. O método de Lesk obteve os melhores resultados sobre o conjunto de teste. O método de Nóbrega e Pardo obteve o segundo lugar em desempenho e por pouca diferencia com o método de Lesk. Um ponto a salientar que produziu estes resultados foi a pouca variabilidade de sentidos (apesar de ter usado os verbos mais polissémicos) no córpus.

Em relação aos métodos de Mihalcea e de Agirre e Soroa, pode se salientar que os métodos foram consistentes com os resultados obtidos na tarefa All-words. Contudo, o método de Mihalcea obteve os piores resultados. Isto aconteceu porque, embora o método de Mihalcea use como contexto o substantivo mais próximo, em muitos casos, os substantivos mais próximos pertenceram a outra sentença, portanto, ao invés de ajudar na desambiguação, introduziu ruído na mesma.

Um detalhe a considerar é o fato de que a maior quantidade de synsets anotados manualmente, mais difícil foi desambiguar para os métodos explorados, em relação aos baselines.

Com a finalidade de comparar os resultados obtidos na DLS dos verbos com os obtidos para os substantivos, apresentam-se os resultados obtidos no trabalho de Nóbrega e Pardo (2014) na tarefa All-words para os substantivos. Os resultados obtidos são apresentados na Tabela 6.7.

Nesta tabela, nota-se que os valores obtidos foram melhores, em comparação com os obtidos para verbos. Isto é consistente com o que diz a literatura. Miller et al. (1990) mencionou que os verbos são a classe gramatical mais difícil de desambiguar e que os sentidos dos verbos possuem uma maior variabilidade em presença de diferentes substantivos, diferentemente dos substantivos, que tendem a possuir uma estabilidade no sentido em presença de diferentes verbos.

Outro ponto a salientar é que, na anotação de sentidos de substantivos no córpus CSTNews, os valores de concordância obtidos foram maiores do que os obtidos nos verbos e apresentou-se que os substantivos possuíram pouca variabilidade de sentidos no córpus, portanto, isto contribuiu a obter melhores resultados. 


\begin{tabular}{|c|c|c|c|c|c|c|c|c|}
\hline Verbo & $\mathbf{F}$ & $\mathbf{S}$ & SMF & $\mathrm{C}$ & $\mathbf{L}$ & $\mathbf{M}$ & $\mathbf{A S}$ & $\mathbf{N}$ \\
\hline tratar & 9 & 7 & 11.11 & 11.11 & 22.22 & 11.11 & 22.22 & 0.00 \\
\hline estabelecer & 12 & 7 & 8.33 & 8.33 & 16.67 & 9.09 & 16.67 & 8.33 \\
\hline marcar & 17 & 7 & 0.00 & 0.00 & 9.09 & 10.00 & 36.36 & 0.00 \\
\hline vir & 18 & 8 & 30.00 & 5.00 & 30.00 & 0.00 & 0.00 & 15.00 \\
\hline colocar & 20 & 8 & 63.16 & 5.26 & 31.58 & 6.25 & 52.63 & 21.05 \\
\hline fechar & 21 & 8 & 36.84 & 0.00 & 5.26 & 23.08 & 0.00 & 21.05 \\
\hline dar & 22 & 14 & 13.21 & 3.77 & 9.43 & 4.00 & 0.00 & 7.55 \\
\hline cair & 24 & 8 & 17.39 & 0.00 & 17.39 & 0.00 & 0.00 & 17.39 \\
\hline encontrar & 24 & 10 & 12.50 & 4.17 & 4.17 & 4.17 & 4.17 & 0.00 \\
\hline registrar & 27 & 8 & 3.85 & 3.85 & 7.69 & 20.00 & 15.38 & 3.85 \\
\hline levar & 31 & 13 & 9.09 & 0.00 & 3.03 & 0.00 & 6.06 & 0.00 \\
\hline receber & 36 & 9 & 61.11 & 0.00 & 42.86 & 9.38 & 11.11 & 58.33 \\
\hline apresentar & 38 & 8 & 50.00 & 0.00 & 36.11 & 20.00 & 0.00 & 47.22 \\
\hline passar & 44 & 15 & 38.30 & 2.13 & 23.40 & 2.56 & 8.51 & 29.79 \\
\hline deixar & 49 & 16 & 19.61 & 1.96 & 13.73 & 2.00 & 7.84 & 19.61 \\
\hline chegar & 55 & 12 & 29.09 & 3.64 & 23.64 & 20.41 & 27.27 & 23.64 \\
\hline ficar & 58 & 16 & 11.27 & 1.41 & 8.45 & 3.13 & 8.45 & 8.45 \\
\hline fazer & 93 & 18 & 31.62 & 0.85 & 11.11 & 0.00 & 1.71 & 14.53 \\
\hline ter & 143 & 10 & 75.82 & 5.88 & 62.75 & 5.44 & 5.23 & 67.97 \\
\hline ser & 450 & 14 & 88.11 & 8.59 & 69.32 & 27.40 & 58.37 & 72.69 \\
\hline Precisão média & - & - & 30.52 & 3.30 & 22.39 & 8.90 & 14.10 & 21.82 \\
\hline
\end{tabular}

Tabela 6.6: Avaliação da tarefa Lexical sample

\begin{tabular}{c|cccc}
\hline Método & P (\%) & C (\%) & A (\%) & Ac (\%) \\
\hline SMF & 51.00 & 51.00 & 100.00 & - \\
Lesk & 42.20 & 41.20 & 91.10 & 41.20 \\
Mihalcea & 39.71 & 39.47 & 99.41 & 39.59 \\
Nóbrega & 49.56 & 43.90 & 88.59 & 43.90 \\
\hline
\end{tabular}

Tabela 6.7: Resultados da tarefa All-words para os substantivos. Nóbrega e Pardo (2014) 
6.3 Avaliação de incorporação de conhecimento da VerbNet.Br

A última etapa consistiu em avaliar a variação do desempenho dos métodos quando são usadas as informações da VerbNet.Br escolhidas no capítulo anterior.

Nesta etapa, foi utilizado o Teste de Wilcoxon para os testes de significância estatística entre os métodos originais e os métodos com incorporação de conhecimento da VerbNet.Br. Neste teste foi usado um valor de corte de 0,05 , o que representa um $95 \%$ de confiabilidade nos resultados, que é o valor mais utilizado na literatura. A escolha do teste de Wilcoxon se deve ao fato de que, na área de PLN, os valores das métricas para comparar métodos não seguem uma distribuição normal (Søgaard et al., 2014).

Durante a execução dos experimentos, tiveram-se algumas considerações relacionadas às classes da VerbNet.Br e aos verbos que poderiam ser analisados em cada conjunto formado durante o agrupamente. As considerações empregadas são descritas a seguir:

- A classe other-cos-53.2 da VerbNet.Br. Na VerbNet.Br, esta classe foi usada caso não se conseguisse definir uma classe para um verbo especifico, portanto, contém muitos verbos que poderiam introduzir ruído no processo de desambiguação. Por esta razão, optou-se por não considera-la na etapa de agrupamento dos verbos.

- Verbos altamente ambíguos. Dentre todos os verbos, existem alguns que são considerados "light verbs" ou verbos suporte. Estes verbos são considerados altamente polissêmicos, já mudam de sentido segundo o substantivo com o qual são combinados. Por exemplo, na expressão "fazer questão", o verbo "fazer" assume o sentido de "insistir". Já na expressão "fazer contas", o verbo "fazer" assume o sentido "contar". A lista de verbos altamente ambíguos foi fornecida pela Dra. Magali Duran, e inclui os verbos "dar", "fazer", "levar", "passar", "pôr", "ter" e "tomar" 61.

- Verbos de cópula. Os verbos de cópula ou de ligação, não possuem uma semântica própria. Eles servem para "ligar" um tópico a um comentário, indicando um estado, uma mudança de estado ou uma permanência de estado. A lista de verbos que podem cumprir a função de cópula inclui os verbos "ser", "estar", "continuar", "permanecer", "parecer", "tornar", "virar", "andar", "ficar". Salienta-se que, na VerbNet.Br, não são considerados os verbos de cópula no agrupamento de classes, pelo que, em ocasiões, poderia introduzir ruído na desambiguação.

\footnotetext{
${ }^{61}$ A lista apresentada contém apenas os verbos mais ambíguos. Existem casos que outros verbos também podem cumprir uma função de suporte.
} 
- Número mínimo de verbos por conjunto. A razão para considerar o número mínimo de verbos para formar um conjunto é que, ao usar o critério de "dominância", visou saber quanto era o número mínimo de verbos que poderiam formar realmente um conjunto a desambiguar.

Com as considerações estabelecidas, fizeram-se testes com diferentes variações, considerando (1) a inclusão ou não dos verbos altamente ambíguos, (2) a inclusão ou não de verbos de cópula, e (3) o número mínimo de verbos para formar um conjunto.

Os resultados das diferentes variações do método de Lesk usando o conhecimento da VerbNet.Br são apresentados na Tabela 6.8. Na tabela, mostra-se que a notação usada possui a forma Lesk$<$ inclui_altamente_ambiguos $>-<$ inclui_copula $>-<$ mínimo_verbos $>$, onde os tags $<$ inclui_altamente_ambiguos $>$ e $<$ inclui_copula $>$ assumem valores de 1 , se são incluídos, e 0 , se não são incluídos. Por exemplo, a variação Lesk-0-0-2 faz referência ao método de Lesk que não considera os verbos altamente ambíguos e os verbos de cópula para o agrupamento, e, além disso, o número mínimo de verbos para formar um conjunto é 2 .

\begin{tabular}{c|cccc}
\hline Variação & P(\%) & C (\%) & A (\%) & Ac (\%) \\
\hline Lesk & 40.10 & 37.69 & 93.98 & 37.77 \\
\hline Lesk-0-0-2 & 39.97 & 37.57 & $\mathbf{9 4 . 0 0}$ & 37.65 \\
Lesk-0-0-3 & 39.92 & 37.53 & $\mathbf{9 4 . 0 0}$ & 37.61 \\
Lesk-0-0-4 & 39.88 & 37.49 & $\mathbf{9 4 . 0 0}$ & 37.57 \\
\hline Lesk-0-1-2 & 39.78 & 37.39 & $\mathbf{9 4 . 0 0}$ & 37.47 \\
Lesk-0-1-3 & 39.73 & 37.35 & $\mathbf{9 4 . 0 0}$ & 37.43 \\
Lesk-0-1-4 & 39.90 & 37.51 & $\mathbf{9 4 . 0 0}$ & 37.59 \\
\hline Lesk-1-0-2 & 40.26 & 37.85 & $\mathbf{9 4 . 0 0}$ & 37.93 \\
Lesk-1-0-3 & 40.22 & 37.81 & $\mathbf{9 4 . 0 0}$ & 37.89 \\
Lesk-1-0-4 & 40.22 & 37.81 & $\mathbf{9 4 . 0 0}$ & 37.89 \\
\hline Lesk-1-1-2 & 40.13 & 37.73 & $\mathbf{9 4 . 0 0}$ & 37.81 \\
Lesk-1-1-3 & 40.07 & 37.67 & $\mathbf{9 4 . 0 0}$ & 37.75 \\
Lesk-1-1-4 & $\mathbf{4 0 . 2 8}$ & $\mathbf{3 7 . 8 7}$ & $\mathbf{9 4 . 0 0}$ & $\mathbf{3 7 . 9 5}$ \\
\hline
\end{tabular}

Tabela 6.8: Resultados obtidos nas variações do método de Lesk

Da Tabela 6.8, destaca-se que a variação que obteve os melhores resultados foi a que considerou uma agrupamento mínimo de 4 verbos, e os verbos de cópula e os verbos altamente ambíguos no agrupamento (Lesk-1-1-4).

Comparando com os resultados obtidos pelo método original de Lesk, salienta-se que a variação Lesk-1-1-4 obteve melhores resultados em todas as medidas de avaliação. Contudo, aplicando o 
teste de Wilcoxon usando um nível de confiança de 95\%, obteve-se que esta variação não apresentou diferença estatística.

Os resultados das diferentes variações do método de Nóbrega e Pardo (representado por NP) usando o conhecimento da VerbNet.Br são apresentados na Tabela 6.9. Destaca-se que a notação usada na tabela possui a forma NP-<inclui_altamente_ambiguos $>-<$ inclui_copula $>$ $<$ mínimo_verbos>, da mesma forma que as variações do método de Lesk. Por exemplo, a variação NP-0-0-6 faz referência ao método de Nóbrega e Pardo que não considera os verbos altamente ambíguos e os verbos de cópula para o agrupamento, e, além disso, o número mínimo de verbos para formar um conjunto é 6 .

\begin{tabular}{c|cccc}
\hline Variação & P(\%) & C (\%) & A (\%) & Ac (\%) \\
\hline NP & 40.33 & 37.97 & 94.14 & 38.00 \\
\hline NP-0-0-6 & 40.21 & 37.87 & $\mathbf{9 4 . 1 6}$ & 37.91 \\
NP-0-0-7 & 40.58 & 38.20 & 94.14 & 38.24 \\
NP -0-0-8 & 40.39 & 37.89 & 93.80 & 37.92 \\
NP -0-0-9 & 40.41 & 37.91 & 93.80 & 37.95 \\
\hline NP -0-1-6 & 40.40 & 38.04 & $\mathbf{9 4 . 1 6}$ & 38.08 \\
NP -0-1-7 & $\mathbf{4 1 . 0 2}$ & $\mathbf{3 8 . 4 8}$ & 93.80 & $\mathbf{3 8 . 5 2}$ \\
NP -0-1-8 & 40.22 & 37.87 & 94.14 & 37.91 \\
NP -0-1-9 & 40.26 & 37.91 & 94.14 & 37.95 \\
\hline NP -1-0-6 & 40.51 & 38.14 & $\mathbf{9 4 . 1 6}$ & 38.18 \\
NP -1-0-7 & 40.66 & 38.14 & 93.80 & 38.18 \\
NP -1-0-8 & 40.24 & 37.89 & 94.14 & 37.93 \\
NP -1-0-9 & 39.80 & 37.47 & 94.14 & 37.51 \\
\hline NP -1-1-6 & 40.17 & 37.83 & 94.06 & 37.87 \\
NP -1-1-7 & 40.16 & 37.81 & 94.14 & 37.85 \\
NP -1-1-8 & 40.26 & 37.91 & 94.14 & 37.95 \\
NP -1-1-9 & 39.97 & 37.63 & 94.14 & 37.67 \\
\hline
\end{tabular}

Tabela 6.9: Resultados obtidos nas variações do método de Nóbrega

Da Tabela 6.9, salienta-se que, de maneira geral, os melhores resultados foram obtidos usando um mínimo de 7 verbos para cada conjunto, formado. Isto mostra que o número mínimo de verbos que devem usar-se em este tipo de agrupamento para ter maior segurança é 7. Contudo, é necessária uma avaliação mais profunda do agrupamento.

A variação que obteve os melhores resultados foi a que considerou uma agrupamento mínimo de 7 verbos, os verbos de cópula no agrupamento e excluiu os verbos altamente ambíguos. 
Comparando com os resultados obtidos pelo método original de Nóbrega, salienta-se que a melhor variação (Nóbrega-0-1-7) obteve melhores resultados em todas as medidas de avaliação, excetuando a abrangência. Apesar desses resultados, aplicando o teste de Wilcoxon usando um nível de confiança de 95\%, obteve-se que não apresentou diferença estatística.

Com as avaliações dos métodos investigados, realizadas neste capítulo, pode-se concluir que:

O uso do dicionário bilíngue WordReference ${ }^{\circledR}$ na desambiguação de verbos não prejudicou o desempenho dos métodos de DLS. Isto é percebido quando são comparados os valores de abrangência obtidos pelos métodos desenvolvidos e o topline.

Foi possível desenvolver métodos de DLS para verbos, usando a WordNet-Pr, que apresentem resultados superiores ao método baseline cego. Contudo, estes métodos não conseguiram superar o baseline do sentido mais frequente. A razão para isto é que a maioria dos verbos no córpus foram anotados apenas com um sentido, e na maioria das vezes foi escolhido o primeiro, o que é favorável ao método do sentido mais frequente.

Ao comparar os resultados obtidos pelos métodos de DLS de substantivos e de verbos, verificouse que a DLS de verbos possui uma maior complexidade do que a DLS de substantivos e isso se ve refletido no desempenho dos métodos.

O uso da VerbNet.Br contribuiu nos métodos de DLS de verbos, mas esta contribuição não foi estatisticamente significativa. Duas razões que poderiam ter atingido o desempenho da incorporação da VerbNet.Br foram encontradas na etapa de agrupamento de verbos. A primeira delas parte da criação da VerbNet.Br. Este recurso foi criado semiautomaticamente, e nessa primeira versão, os frames sintáticos identificados foram obtidos traduzindo-os do inglês, portanto, existe uma grande quantidade de frames sintáticos que não foram considerados (por serem próprios do português ou por falta de exemplos que contenham essos frames), assim, muitos verbos que poderiam ter sido incluídos no agrupamento, não foram considerados. A segunda razão foi a existência de classes verbais que aceitavam verbos sem considerar os frames sintáticos que apresentavam, isto fez com que não exista um filtro de verbos por classes, prejudicando o agrupamento. A respeito destas razões, salienta-se que não foi realizada uma avaliação linguística para este recurso, portanto, acredita-se que, após uma validação linguística, o desempenho do método proposto melhorará. 


\section{Capítulo}

\section{Conclusões}

Neste capítulo são apresentadas as conclusões, limitações, contribuições e trabalhos futuros deste projeto de mestrado. Assim, o capítulo está divido em 3 seções; na Seção 7.1, apresentam-se as conclusões do trabalho e as limitações encontradas no percurso no desenvolvimento deste mestrado, na Seção 7.2, apresentam-se as contribuições realizadas neste mestrado e, finalmente, na Seção 7.3, são apresentados sugestões de trabalhos futuros.

\subsection{Conclusões}

Os objetivos centrais de esta pesquisa foram a investigação e desenvolvimento de métodos tradicionais de DLS para os verbos e a incorporação de conhecimento proveniente da VerbNet.Br nesses métodos para avaliar a variação no desempenho dos mesmos.

Uma necessidade inerente que surgiu dos objetivos supracitados foi a anotação de sentidos em um córpus. O córpus selecionado para esta pesquisa foi o CSTNews (Aleixo e Pardo, 2008). Este córpus contém um conjunto de 140 textos agrupados em coleções de 2 o 3 textos cada uma. A ração para a escolha de este córpus foi que um córpus jornalístico e abrange vários domínios (esportes, política, cotidiano, entre outros), o que contribui para o foco de esta pesquisa que é explorar métodos de DLS que sejam independentes do domínio.

O córpus CSTNews foi anotado usando a WordNet-Pr como repositório de sentidos e o WordReference ${ }^{\circledR}$ como dicionário bilíngue para fazer os mapeamentos entre as palavras do português brasileiro e os sentidos da WordNet-Pr em inglês. Para isto, foi desenvolvida a NASP++, uma ferramenta que dá suporte à anotação de sentidos de verbos e que é uma nova versão da NASP (Nóbrega, 2013), que dava suporte para a anotação de substantivos. 
Dentre os resultados obtidos na anotação, destaca-se a grande variação de sentidos anotados, tanto por coleção quanto por córpus, porém, apesar desta grande variação, a quantidade de palavras anotadas com apenas um sentido foi predominante.

O valor de concordancia obtido, segundo a medida Kappa, foi 0.509. Este valor é moderado, mas sugere que a tarefa pode ser automatizada. Em relação com os valores obtidos para os substantivos (Nóbrega, 2013), ressalta-se que a tarefa de anotação de sentidos de verbos foi mais dificil (sendo que o valor de Kappa para os substantivos foi de 0.729), o que se reflete na quantidade de sentidos anotados no córpus e a quantidade de sentidos possíveis que um verbo pode apresentar.

Dado o aumento da necessidade de métodos que possam ser integrados em outras aplicações, ou seja, métodos que sejam independentes do domínio, optou-se por explorar métodos de DLS baseados em conhecimento. Assim, foram escolhidos 4 métodos, cada um seguindo uma técnica diferente. Os métodos propostos foram um método baseado em sobreposição de palavras, um método baseado em buscas web, método baseado em grafos e um método focado no cenário multidocumento. Estes métodos foram selecionados por serem muito citados na literatura e/ou por obterem bons resultados dentre os métodos da literatura.

O segundo objetivo foi incorporar conhecimento linguístico da VerbNet.Br nos métodos de DLS desenvolvidos. Para isto, foi usado o conceito sobre o qual está criada a VerbNet.Br, que é agrupar os verbos que compartilham características sintáticas e semânticas. A hipótese que surgiu foi que em um texto jornalístico podem ser encontrados verbos que pertençam à mesma classe da VerbNet.Br e, portanto, os contextos podem ser enriquecidos juntando os contextos no processo de desambiguação.

Para a avaliação dos métodos investigados e a incorporação do conhecimento da VerbNet.Br foram usados dois métodos como baseline: um método que atribui o sentido mais frequente dentre um repositório para uma palavra e um método cego que seleciona aleatoriamente o sentido para uma palavra.

O processo de avaliação consistiu em 3 etapas. A primeira delas foi avaliar o desempenho geral (de todos os verbos do córpus) dos métodos tradicionais investigados em relação aos baselines, e, adicionalmente, compará-los com o desempenho obtido na DLS de substantivos (Nóbrega, 2013). A respeito de esta etapa, obteve-se que o método que usou o sentido mais frequente não foi superado por nenhum método tradicional. Já o método cego foi superado por todos os demais métodos. Considerando só os métodos estudados, o método focado no cenário multidocumento foi o que obteve melhores resultados. Isto aconteceu devido a que ao analisar o córpus, encontrou-se 
que as palavras são anotadas com o mesmo sentido dentro de uma coleção de textos. Com relação à comparação com o desempenho nos substantivos, confirmou-se o que menciona a literatura, isto é, o desempenho dos métodos de DLS para os verbos se mostrou inferior quando comparado com o desempenho dos substantivos.

A segunda etapa visou avaliar o desempenho dos métodos desenvolvidos em uma pequena amostra com verbos ambíguos encontrados no córpus. O resultado desta avaliação mostrou também que o baseline do sentido mais frequente não foi superado por nenhum método e o método cego foi superado por todos. Nesta avaliação obteve-se que o método que apresentou melhores resultados foi o método de Lesk.

A terceira etapa consistiu em avaliar a variação do desempenho dos métodos tradicionais de DLS quando se incorpora conhecimento linguístico da VerbNet.Br. Os resultados obtidos mostraram que o agrupamento de verbos na VerbNet.Br mostrou melhores resultados quando a quantidade de verbos agrupados foi maior, porém, a diferença encontrada entre os métodos tradicionais antes e depois da incorporação do conhecimento linguístico não é estatisticamente significante. Uma razão que explicou este resultado foi que a VerbNet.Br possui uma boa precisão mas não uma boa cobertura, já que ao só conter os frames sintáticos traduzidos do inglês, não possui um bom conjunto de frames sintáticos que definam uma classe específica para o português, e desta forma, muitos verbos não são considerados no agrupamento. Outra razão é a existência de classes verbais que não possuem um filtro de frame sintático, isto ocasiona que muitos verbos que não guardem alguma semelhança sintática e semântica sejam agrupados.

Outros resultados e validações de hipóteses que podemos citar estão em relação ao uso da WordNet-Pr como repositório de sentidos e o WordReference ${ }^{\circledR}$ como dicionário bilíngue. A respeito do uso da WordNet-Pr como repositório de sentidos, pode-se afirmar que apesar de ter sido desenvolvida para inglês, não ocasionou um prejuízo na tarefa de DLS para os verbos. Isto se vê refletido nos valores de abrangência (número de verbos desambiguados, correta ou incorretamente, pelos métodos em relação ao total de verbos a desambiguar), já que se obtiveram valores de aproximadamente $94 \%$ para todos os métodos desenvolvidos.

Algumas dificuldades encontradas no uso da WordNet-Pr foram as lacunas lexicais. Um exemplo deste tipo de lacuna apresenta-se no verbo "pedalar" da sentença "O Robinho pedalou", o qual é "um tipo específico de drible" e não possui correspondência direta na WordNet-Pr. No caso da anotação manual do córpus, a solução para este tipo de dificuldades foi encontrar a generalização do verbo em questão (que neste caso seria "driblar"), e depois anotar o sentido correto proveniente da WordNet-Pr. Já no caso da execução dos métodos de DLS, seria necessária a implementação de mecanismos de generalização para obter o verbo "driblar". 
A respeito do uso do dicionário bilíngue WordReference® para encontrar o mapeamento dos sentidos da WordNet-Pr para cada verbo no português brasileiro, pode-se notar a utilidade do recurso, ao não prejudicar os valores de abrangência. Um problema encontrado neste recurso foi a quantidade de possíveis traduções oferecidas na execução dos métodos de DLS, que poderia afetar os valores de precisão e cobertura. No caso da anotação manual de córpus, se o dicionário bilíngue não oferecesse uma tradução adequada para o verbo em português brasileiro, se podia adicionar manualmente a tradução mais adequada, e assim continuar com o processo de anotação. Já no caso da execução dos métodos de DLS, não aconteceu da mesma forma, o que poderia ter prejudicado o desempenho da tarefa.

\subsection{Contribuições}

As contribuições realizadas neste trabalho de mestrado são descritas a seguir:

- Um córpus anotado manualmente com sentidos de verbos usando a WordNet-Pr como repositório de sentidos. Este recurso pode servir para futuras pesquisas nesta área.

- Atualização da ferramenta de auxilio à anotação de sentidos original (NASP), para a anotação de sentidos de verbos e a criação de ontologias.

- Adaptação e desenvolvimento de métodos de DLS para o tratamento de verbos seguindo critérios úteis usados na literatura.

- Implementação e avaliação de uma proposta nova de incorporação do conhecimento da VerbNet.Br sobre um método monodocumento baseado em sobreposição de palavras (Lesk) e um método multidocumento (Nóbrega e Pardo).

- Disponibilização de demonstrações online dos métodos implementados neste trabalho. As demonstrações estão localizadas na página do projeto PROS@ ${ }^{62}$, pois este trabalho de mestrado é parte do projeto PROS@ - "Processamento Semântico de Textos em Português Brasileiro", que surgiu do convênio entre o ICMC-USP e a empresa SAMSUNG Eletrônica da Amazônia.

- Por fim, como resultado deste trabalho de mestrado tem sido aceitos, até o momento, 2 artigos em eventos da área de Linguística Computacional como primeiro autor (Sobrevilla-Cabezudo et al. (2014) e Sobrevilla-Cabezudo e Pardo (2015)).

\subsection{Trabalhos Futuros}

Alguns trabalhos futuros, produto deste mestrado, são mencionados a seguir:

\footnotetext{
${ }^{62}$ Disponível em http://nilc.icmc.usp.br/semanticnlp/index.php?id=principal\&dir=includes\&lang=pt-br
} 
- Em relação ao córpus, pretende-se aumentar a quantidade de instâncias de alguns verbos do córpus, com o fim de poder desenvolver métodos de Aprendizado de Máquina sobre os mesmos. Uma opção a ser desenvolvida é o uso de algoritmos semi-supervisionados para obter uma maior quantidade de instâncias.

- Em relação aos métodos investigados, propõe-se investigar outras ferramentas que possam ser incorporadas nos métodos de DLS, tais como dicionários bilíngues especializados (por exemplo, de "esportes") ou o Reconhecedor de Entidades Nomeadas, com o fim de melhorar o desempenho dos mesmos.

- Em relação à incorporação de conhecimento da VerbNet.Br, pretende-se estudar outras maneiras de incorporar o conhecimento da VerbNet.Br nos métodos de DLS, por exemplo, usar as relações entre os verbos e os argumentos, assim como o mapeamento que existe com a WordNet-Pr, para enriquecer o grafo de conhecimento e, assim, melhorar o método de Agirre e Soroa. Outro ponto a investigar é o refinamento do método de agrupamento de verbos proposto neste mestrado. Neste trabalho, tem-se utilizado informações sintáticas e uma heurística de ocorrência de verbos, porém, informações de natureza semântica (restrições seletivas sobre os argumentos) poderiam trazer melhoras no agrupamento.

- Em relação à avaliação dos métodos de DLS, um estudo interessante seria realizar uma avaliação extrínseca, isto é, avaliar a variação no desempenho de outras ferramentas quando um método de DLS é usado e quando não é usado. 


\section{Referências Bibliográficas}

Abney, S. (2002). Bootstrapping, in Proceedings of the 40th Annual Meeting of the Association for Computational Linguistics, Philadelphia, pp.360-367.

Afonso, S.; Bick, E.; Haber, R.; Santos, D. (2002). "Floresta sintá(c)tica: a treebank for Portuguese", in Proceedings of the Third International Conference on Language Resources and Evaluation, Las Palmas de Gran Canaria, Espanha, pp. 1698-1703.

Agirre, E. e Edmonds, P. (2006). "Introduction", in Word Sense Disambiguation: Algorithms and Applications, pp. 1-28. Springer.

Agirre, E.; Soroa, A. (2009). Personalizing pagerank for word sense disambiguation, in Proceedings of the 12th Conference of the European Chapter of the Association for Computational Linguistics, Atenas, Grécia, pp. 33-41. Association for Computational Linguistics.

Agirre, E.; de Lacalle, O. L.; Soroa, A. (2014). Random walks for knowledge-based word sense disambiguation. Computational Linguistics, pp. 57-84. MIT Press

Agostini, V.; Camargo, R. T.; Di Felippo, A.; Pardo, T. A. S. (2012). Alinhamento manual dos sumários humanos e dos textos-fonte do córpus multidocumento CSTNews. Série de Relatórios Técnicos do Instituto de Ciências Matemáticas e de Computação, Universidade de São Paulo, no. 380. NILC-TR-01-12. São Carlos-SP, Junho, 20p.

Aires, R. V. X. (2000). Implementação, adaptação, combinação e avaliação de etiquetadores para o português do Brasil. Dissertação de Mestrado, Instituto de Ciências Matemáticas e de Computação, Universidade de São Paulo, Brasil. 166p.

Akkaya, C.; Wiebe, J.; Mihalcea, R. (2009). Subjectivity Word Sense Disambiguation, in Proceedings of the 2009 Conference on Empirical Methods in Natural Language Processing, Singapore, pp. 190-199. Association for Computational Linguistics. 
Aleixo, P.; Pardo, T. A. S. (2008). CSTNews: um córpus de textos jornalísticos anotados segundo a teoria discursiva multidocumento CST (Cross-document Structure Theory). Série de Relatórios Técnicos do Instituto de Ciências Matemáticas e de Computação, Universidade de São Paulo, no. 326. São Carlos-SP, Maio, 12p.

Alva-Manchego, F. (2013). Anotação Automática Semissupervisionada de Papéis Semânticos para o Português do Brasil. Dissertação, Instituto de Ciências Matemáticas e de Computação, Universidade de São Paulo.

Andrew, G.; Grenager, T.; Manning, C. D. (2004). Verb sense and subcategorization: Using joint inference to improve performance on complementary tasks, in Proceedings of the 2004 Conference on Empirical Methods in Natural Language Processing, Barcelona, Espanha, pp. 150-157. Association for Computational Linguistics.

Atserias, J.; Villarejo L.; Rigau, G.; Agirre, E.; Carroll, J.; Magnini, B.; Vossen, P.(2004). The meaning multilingual central repository, in Proceedings of the Second International WordNet Conference, Brno, República Checa, pp. 80-210.

Audibert, L. (2004). Word sense disambiguation criteria: a systematic study, in Proceedings of the 20th international conference on Computational Linguistics, Geneva, Suíça, pp. 910-916. Association for Computational Linguistics.

Azeredo, J. C. (2000). Fundamentos de Gramática do Português. Jorge Zahar Editor. 283p.

Baker, C. F.; Fillmore C. J.; Lowe J. B. (1998). The Berkeley Framenet project, in Proceedings of 17th International Conference on Computational Linguistics, Morristown, NJ, USA, pp. 86-90. Association for Computational Linguistics.

Baptista J. (2012). ViPEr: A Lexicon-Grammar of European Portuguese Verbs, in Proceedings of the 31st International Conference on Lexis and Grammar, Nové Hrady, República Checa, pp. 1016.

Banerjee, S.; Pedersen, T. (2002). An adapted lesk algorithm for word sense disambiguation using wordnet, in Proceedings of the Third International Conference on Computational Linguistics and Intelligent Text Processing, Londres, Reino Unido, pp. 136-145. Springer-Verlag.

Bertoldi A. e Chishman, R. L. de O. (2009). Desafios para a Criação de um Léxico baseado em Frames para o Português: um estudo dos frames Judgment e Assessing. In Proceedings of the The 7th Brazilian Symposium in Information and Human Language Technology, São Carlos, Brasil, pp. 1-8. 
Bick, E. (2000). The Parsing System PALAVRAS: Automatic Grammatical Analysis of Portuguese in a Constraint Grammar Framework. PhD thesis. Arhus University.

Black, E. W. (1988). An experiment in computational discrimination of English word senses, in IBM Journal of Research and Development, Riverton, NJ, USA, pp. 185-194. IBM Corporation.

Brill, E. (1994). Some advances in transformation-based part of speech tagging, in Proceedings of the Twelfth National Conference on Artificial Intelligence, Menlo Park, CA, USA, pp. 722-727. American Association for Artificial Intelligence.

Brin, S.; Page, L. (1998). The anatomy of a large-scale hypertextual web search engine, in Proceedings of the Seventh International Conference on World Wide Web, Amsterdam, Países Baixos, pp. 107-117. Elsevier Science Publishers B. V.

Cardoso, P.C.F.; Maziero, E.G.; Jorge, M.L.C.; Seno, E.M.R.; Di Felippo, A.; Rino, L.H.M.; Nunes, M.G.V.; Pardo, T.A.S. (2011). CSTNews - a discourse-annotated corpus for single and multi-document summarization of news texts in brazilian Portuguese, in Proceedings of the 3rd RST Brazilian Meeting, Cuiabá, MT, Brasil, pp. 88-105. Sociedade Brasileira de Computação.

Carletta, J. (1996). Assessing agreement on classification tasks: The kappa statistic. Computational Linguistics 22, Cambridge, MA, USA, pp. 249-254. MIT Press.

Chaplot, D. S.; Bhattacharyya, P.; Paranjape, A. (2015). Unsupervised Word Sense Disambiguation Using Markov Random Field and Dependency Parser, in Proceedings of the Twenty-Ninth AAAI Conference on Artificial Intelligence, pp. 2217-2223

Che, W. e Liu, T. (2010). Jointly modeling WSD and SRL with Markov logic, in Proceedings of the 23rd International Conference on Computational Linguistics, Beijing, China, pp. 161-169. Association of Computational Linguistics.

Clarke, C. L. A.; Cormack, G. V.; Burkowski, F. J. (1995). An Algebra for Structured Text Search and a Framework for its Implementation. The Computer Journal 38, pp. 43-56. Oxford University Press.

Cuadros, M.; Rigau, G. (2008). KnowNet: Building a Large Net of Knowledge from the Web, in Proceedings of the 22nd International Conference on Computational Linguistics, Manchester, Reino Unido, pp. 161-168. Association for Computational Linguistics. 
Dang, H. T.; Palmer, M. (2005). The role of semantic roles in disambiguating verb senses, in Proceedings of the 43rd Annual Meeting on Association for Computational Linguistics, Ann Arbor, Michigan, USA, pp. 42-49. Association for Computational Linguistics.

Daumé, H. (2004). Notes on CG and LM-BFGS Optimization of Logistic Regression. Paper available in http://pub.hal3.name\#daume04cg-bfgs, implementation available in http://hal3.name/megam/

De Paiva, V.; Rademaker, A.; De Melo, G. (2012). OpenWordNet-PT: An Open Brazilian Wordnet for Reasoning, in Proceedings of COLING 2012: Demonstration Papers, Mumbai, India, pp. 353-360. The COLING 2012 Organizing Committee.

Dias Da Silva, B. C. (2005). A construção da base da wordnet.br: Conquistas e desafios, in Proceedings of the Third Workshop in Information and Human Language Technology (TIL 2005), in conjunction with XXV Congresso da Sociedade Brasileira de Computação. São Leopoldo, RS, Brasil, pp. 2238-2247. Sociedade Brasileira de Computação.

Dias Da Silva, B. C.; Di Felippo, A.; Nunes, M. G. V. (2008). The automatic mapping of princeton wordnet lexical-conceptual relations onto the brazilian Portuguese wordnet database, in Proceedings of the Sixth International Conference on Language Resources and Evaluation, Marrakech, Marrocos, pp. 1535-1541. European Language Resources Association.

Dligach, D. e Palmer, M. (2008). Novel Semantic Features for Verb Sense Disambiguation, in Proceedings of the 46th Annual Meeting of the Association for Computational Linguistics on Human Language Technologies: Short Papers, Columbus, Ohio, USA, pp. 29-32. Association for Computational Linguistics.

Duran, M. S.; Ramisch, C.; Aluísio, S. M.; Villavicencio, A. (2011). Identifying and Analyzing Brazilian Portuguese Complex Predicates, in Proceedings of the Workshop on Multiword Expressions: from Parsing and Generation to the Real World, Portland, OR, USA. pp. 74-82.

Duran, M. S.; Aluísio, S. M. (2012). Propbank-br: a brazilian treebank annotated with semantic role labels, in Proceedings of the Eight International Conference on Language Resources and Evaluation, Istambul, Turquia, pp. 1862-1867. European Language Resources Association.

Duran, M. S.; Martins, J. P.; Aluísio, S. M. (2013a). Um repositório de verbos para a anotação de papéis semânticos disponível na web, in Proceedings of the $9^{\text {th }}$ Brazilian Symposium in Information and Human Language Technology, Fortaleza CE, Brasil, pp. 168-172. Sociedade Brasileira de Computação. 
Duran, M. S.; Aluísio, S. M. (2015). Automatic Generation of a Lexical Resource to support Semantic Role Labeling in Portuguesem in Proceedings of SEM 2015: The Fourth Joint Conference on Lexical and Computational Semantics, p. 216-221.

Edmonds, P. (2002). Senseval: The evaluation of word sense disambiguation systems, in Proceedings of ELRA Newsletter 7.

Fellbaum, C. (1998). WordNet: An Electronic Lexical Database. Cambridge. MIT Press.

Fillmore, C. J. (1968). The Case for Case, in Universals in Linguistic Theory, Holt, Rinehart and Winston, New York, pp. 1-89.

Fonseca, E. R. (2013). Uma Abordagem Conexionista para Anotação de Papéis Semânticos. Dissertação, Instituto de Ciências Matemáticas e de Computação, Universidade de São Paulo.

Gao, N.; Zuo, W.; Dai, Y.; Lv, W. (2014). Word sense disambiguation; Syntactic parsing; Semantic relevancy, in Knowledge Engineering and Management, pp. 147-156. Springer Berlin Heidelberg.

Gildea, D. and D. Jurafsky (2001). Identifying Semantic Roles in Text, in 17th International Joint Conference on Artificial Intelligence (IJCAI-01), Seattle, Washington.

Gildea, D. and D. Jurafsky (2002). Automatic labeling of semantic roles. Computational Linguistics. 28(3), pp. 245-288.

Graff, D. (2003). English Gigaword. Philadelphia, Linguistic Data Consortium.

Gonçalo Oliveira, H.; Antón Pérez, L.; Gomes, P. (2012). Integrating lexical-semantic knowledge to build a public lexical ontology for Portuguese, in Proceedings of the $17^{\text {th }}$ international conference on Applications of Natural Language Processing and Information Systems, Berlin, Alemanha, pp. 210-215. Springer-Verlag.

Hanks, P. (1996). Contextual Dependencies and Lexical Sets, in International Journal of Corpus Linguistics, pp. 75-98.

Harris, Z. (1954). Distributional structure. Word. vol. 10. Pp. 146-162.

Hartmann, N. (2015). Anotação Automática de Papéis Semânticos de Textos Jornalísticos e de Opinião sobre Árvores Sintáticas não Revisadas. Dissertação, Instituto de Ciências Matemáticas e de Computação, Universidade de São Paulo. 
Hovy, E.; Marcus, M.; Palmer, M.; Ramshaw, L.; Weischedel, R. (2006). Ontonotes: the $90^{\circ}$ solution, in Proceedings of the Human Language Technology Conference of the North American Chapter of the ACL, New York, USA, pp. 57-60. Association for Computational Linguistics.

Ide, N.; Véronis, J. (1998). Introduction to the special issue on word sense disambiguation: the state of the art, in Computational Linguistics, Cambridge, MA, USA, pp. 2-40. MIT Press.

Jiang, J.; Conrath, D. (1997). Semantic similarity based on corpus statistics and lexical taxonomy, in Proceedings of International Conference Research on Computational Linguistics, Taipei, Taiwan, pp. 19-33. Association for Computational Linguistics.

Jurafsky, D.; Martin, J. H. (2009). Speech and Language Processing: an Introduction to Natural Language Processing, Computational Linguistics, and Speech Recognition (2nd Ed.). Prentice Hall. Pearson. 988p.

Kilgarriff, A.; England, B.; Rosenzweig J. (2000). English senseval: Report and results, in Proceedings of the 2nd International Conference on Language Resources and Evaluation, Atenas, Grécia, pp. 1239-1244. European Language Resources Association.

Kilgarriff, A.; Yallop, C. (2000). What's in a Thesaurus?, in Proceedings of the 2nd Conference on Language Resources and Evaluation, Atenas, Grécia. pp. 1371-1379. European Language Resources Association.

Kipper, K. (2005). Verbnet: A broad coverage, comprehensive verb lexicon. Ph.D. Thesis (Philosophy). University of Pennsylvania, USA.

Klein, D.; Manning, C. D. (2003). Accurate Unlexicalized Parsing, in Proceedings of the 41st Meeting of the Association for Computational Linguistics, Stroudsburg, PA, USA, pages 423430. Associtation for Computational Linguistics.

Kucera, H. e Francis, W. N. (1967). Computational analysis of present-day American English (2 ${ }^{\text {nd }}$ Edition), Providence, RI . 424p. Brown University Press.

Leacock, C.; Chodorow, M. (1998). Combining local context and wordnet similarity for word sense identification, in WordNet: An Electronic Lexical Database (Language, Speech, and Communication), Cambridge, Massachusetts, USA, pp. 265-283. MIT Press.

Lesk, M. (1986). Automatic sense disambiguation using machine readable dictionaries: how to tell a pine cone from an ice cream cone, in Proceedings of the 5th annual international 
conference on Systems documentation, New York, USA, pp. 24-26. Association for Computing Machinery.

Levin, B. (1993). English Verb Classes and Alternation, A Preliminary Investigation. The University of Chicago Press. 366p.

Lin, D. (1998). An information-theoretic definition of similarity, in Proceedings of the Fifteenth International Conference on Machine Learning, San Francisco, CA, USA, pp. 296-304. Morgan Kaufmann Publishers Inc.

Loper, E., Yi, S.; Palmer, M. (2007). Combining lexical resources: Mapping between PropBank and VerbNet, in Proceedings of the 7th International Workshop on Computational Linguistics, Tilburg, Países Baixos. pp. 1-12.

Lu, W.; Huang, H.; Zhu, C. (2012). Feature Words Selection for Knowledge-based Word Sense Disambiguation with Syntactic Parsing, Przeglad Elektrotechniczny, pp. 82-87.

Machado, I. M.; de Alencar, R. O.; de Oliveira C. J. R. e Davis, C. A. (2011). An ontological gazetteer and its application for place name disambiguation in text, in Journal Brazilian Computional Society, pp. 267-279. Springer-Verlag.

Mamede N. J.; Baptista, J.; Diniz, C.; Cabarrão, V. (2012). STRING: An Hybrid Statistical and Rule-Based Natural Language Processing Chain for Portuguese, in Proceedings of 10th International Conference on Computational Processing of Portuguese, demo session, Coimbra, Portugal.

Mann, W. C.; Thompson, S. A. (1987). Rhetorical structure theory: A theory of text organization. Relatório técnico. Information Sciences Institute. Univesity of Southern California.

Marcus, M. P.; Marcinkiewicz M. A.; Santorini B. (1993). Building a large annotated corpus of english: the penn treebank. In Computional Linguistics, Cambridge, MA, USA, pp. 313-330. MIT Press.

Maziero, E. G.; Pardo, T. A. S. ; Di Felippo, A.; Dias da Silva, B. C. (2008). A base de dados lexical e a interface web do Tep 2.0 - thesaurus electrônico para o português do brasil. In Anais do VI Workshop em Tecnologia da Informação e da Linguagem Humana (TIL), Vila Velha, Espírito Santo, pp. 390-392.

Melli's, G. (2011). Semcor corpus. Online. Disponível em: http://www.gabormelli.com/RKB/SemCor_Corpus. 
Mihalcea, R. (1998). Semcor semantically tagger corpus. Unpublished Manuscript.

Mihalcea, R. (2006). Knowledge-Based Methods for WSD, in Word Sense Disambiguation: Algorithms and Applications, pp. 107-132. Springer.

Mihalcea, R.; Moldovan, D. I. (1999). A method for word sense disambiguation of unrestricted text, in Proceedings of the 37th annual meeting of the Association for Computational Linguistics on Computational Linguistics, College Park, Maryland, USA, pp. 152-158. Association for Computational Linguistics.

Mihalcea, R.; Moldovan, D. I. (2001). extended wordnet: progress report, in Proceedings of NAACL Workshop on WordNet and Other Lexical Resources, Pittsburgh, PA, USA, pp. 95-100.

Miller, G. A.; Beckwith, R.; Fellbaum, C.; Gross, D.; Miller, K. (1990). Introduction to Wordnet: An on-line lexical database, in International Journal of Lexicography, pp. 235-244. Oxford University Press

Miller, G. A.; Leacock, C.; Tengi, R. \& Bunker, R. T. (1993). A semantic concordance, in Proceedings of the workshop on Human Language Technology, Stroudsburg, PA, USA, pp. 303308. Association for Computational Linguistics.

Muggleton, S. (1991). Inductive Logic Programming. New Generation Computing, pp. 295-318. Springer.

Navigli, R. (2009). Word Sense Disambiguation: A Survey. ACM Computing Surveys, New York, NY, USA, pp. 10:1-10:69. ACM.

Nivre, J.; Hall, J.; Nilsson, J.; Chanev, A.; Eryigit, G.; Kübler, S.; Marinov, S.; Marsi, E. (2007). MaltParser: A language-independent system for data-driven dependency parsing. Natural Language Engineering, pp. 95-135. Cambridge University Press.

Nóbrega, F. A. A. (2013). Desambiguação Lexical de sentidos para o português por meio de uma abordagem multilíngue mono e multidocumento. Dissertação de Mestrado, Instituto de Ciências Matemáticas e de Computação - Universidade de São Paulo, Brasil.

Nóbrega, F. A. A.; Pardo, T. A. S. (2013). Desambiguação lexical de sentido com uso de informação multidocumento por meio de redes de co-ocorrência, in Proceedings of the 9th Brazilian Symposium in Information and Human Language Techonology, Fortaleza, CE, Brasil, pp. 138-147. Association for Computational Linguistics. 
Nóbrega, F.A.A.; Pardo, T.A.S. (2014). General Purpose Word Sense Disambiguation Methods for Nouns in Portuguese, in Proceedings of the PROPOR 2014 PhD and MSc/MA Dissertation Contest / 11st International Conference on Computational Processing of Portuguese - PROPOR (LNAI 8775), São Carlos-SP/Brazil, pp. 94-101. Springer.

Palmer, M.; Gildea, D.; Kingsbury, P. (2005). The proposition bank: An annotated corpus of semantic roles. Computional Linguistics 31, Cambridge, MA, USA, pp. 71-106. MIT Press.

Palmer, M.; Gildea, D.; Xue, N. (2010). Semantic Role Labeling. Synthesis Lectures on Human Language Technology Series. 104p. Mogan \& Claypoole Publishers

Patwardhan, S.; Banerjee, S.; Pedersen, T. (2003). Using measures of semantic relatedness for word sense disambiguation, in Proceedings of the 4th International Conference on Computational Linguistics and Intelligent Text Processing, Berlin, Heidelberg, pp. 241-257. Springer-Verlag.

Piruzelli, M. P. F.; Dias da Silva B. C. (2010). Estudo exploratório de informações lexicais relevantes para a resolução de ambiguidades lexical e estrutural, em Anais do IX Encontro do Círculo de Estudos Linguísticos do Sul, Universidade do Sul de Santa Catarina. Palhoça, SC. pp. $1-14$.

Plaza, L.; Diaz, A. (2011) Using semantic graphs and word sense disambiguation techniques to improve text summarization, in XXVII Congreso de la Sociedad Española para el Procesamiento del Lenguaje Natural, Huelva, Espanha, pp. 97-105.

Radev, D. R. (2000). A common theory of information fusion from multiple text sources step one: Cross-Document Structure, in Proceedings of the 1st SIGDIAL Workshop on Discourse and Dialogue, Stroudsburg, PA, USA, pp. 74-83. Association for Computational Linguistics.

Ratnaparkhi, A. (1996). A Maximum Entropy Par t-Of-Speech Tagger, in Proceedings of the Empirical Methods in Natural Language Processing Conference, Pennsylvania, USA, pp. 133142.

Resnik, P. (1995). Using information content to evaluate semantic similarity in a taxonomy, in Proceedings of the 14th International Joint Conference on Artificial Intelligence, San Francisco, CA, USA, pp. 48-453. Morgan Kaufmann Publishers Inc.

Roberts, W.; Kordoni, V. (2012). Using Verb Subcategorization for Word Sense Disambiguation, in Proceedings of the Eight International Conference on Language Resources and Evaluation, Istambul, Turquia, pp. 829-832. European Language Resources Association. 
Rocha, P. A.; Santos, D. (2000). CETEMPúblico: Um corpus de grandes dimensões de linguagem jornalística portuguesa. In Maria das Graças Volpe Nunes (ed.), V Encontro para o processamento computacional da língua portuguesa escrita e falada, Atibaia, São Paulo, ICMC/USP, pp. 131-140.

Roget, P. M. (1911). Roget's International Thesaurus, 1st ed. Cromwell, New York, NY.

Salomão, Maria M. M. (2009). FrameNet Brasil: Um trabalho em progresso. Revista Calidoscópio, v. 7, n. 3, pp. 171-182.

Sanchez, A. (1995). Definición e historia de los corpus. CUMBRE - Corpus Linguístico de Español Contemporáneo, Madrid, SGEL, pp. 7-24.

Scarton, C. E.; Aluísio, S. M. (2009). Herança automática das relações de hiperonímia para a wordnet.br. Série de Relatórios Técnicos do Instituto de Ciências Matemáticas e de Computação, Universidade de São Paulo, São Carlos-SP, 48p.

Scarton, C. E. (2011). Verbnet.br: construção semiautomática de um léxico computacional de verbos para o português do Brasil, in Proceedings of the 8th Brazilian Symposium in Information and Human Language Technology, Cuiabá, MT, Brasil, pp. 20-29. Sociedade Brasileira de Computação.

Scarton, C. E. (2013). VerbNet.Br: construção semiautomática de um léxico verbal online e independente de domínio para o português do Brasil. Dissertação de Mestrado, Instituto de Ciências Matemáticas e de Computação - Universidade de São Paulo, Brasil.

Schmidt, M. (2007). UGM: Matlab code for undirected graphical models. Disponível em http://www.cs.ubc.ca/schmidtm/Software/UGM.html

Schütze, H. (1992). Dimensions of meaning, in Proceedings of the 1992 ACM/IEEE conference on Supercomputing, Supercomputing, Los Alamitos, CA, USA, pp. 787-796. IEEE Computer Society Press.

Silva, T. C.; Amancio, D. R. (2012). Word sense disambiguation via high order of learning in complex networks. EPL (Europhysics Letters). Vol. 98 N.5, pp. 58001.

Sinha, R.; Mihalcea, R. (2007). Unsupervised graph-based word sense disambiguation using measures of word semantic similarity, in Proceedings of the International Conference on Semantic Computing, Washington, DC, USA, pp. 363-369. IEEE Computer Society. 
Søgaard, A.; Johannsen, A.; Plank, B.; Hovy, D.; Martinez, H. (2014). What's in a p-value in nlp?, in Proceedings of the 18th Conference on Computational Natural Language Learning (CONLL2014), pp. 1-10.

Sobrevilla-Cabezudo, M. A.; Maziero, E. G.; Souza, J. W. C.; Dias, M. S.; Cardoso, P. C. F.; Balage Filho, P. P.; Agostini, V.; Nóbrega, F. A. A.; de Barros, C. D.; Di Felippo, A.; Pardo, T. A. S. (2014). Anotação de Sentidos de Verbos em Notícias Jornalísticos em Português do Brasil. Série de Relatórios Técnicos do Instituto de Ciências Matemáticas e de Computação, Universidade de São Paulo. NILC - TR - 14 - 05. São Carlos, SP.

Specia, L. (2007). Uma Abordagem Híbrida Relacional para a Desambiguação Lexical de Sentido na Tradução Automática. Tese de Doutorado, Instituto de Ciências Matemáticas e de Computação - Universidade de São Paulo, Brasil.

Srinivasan, A. (2000). The Aleph Manual. Technical Report, Computing Laboratory, Oxford University.

Sussna, M. (1993). Word sense disambiguation for free-text indexing using a massive semantic network, in Proceedings of the second international conference on Information and knowledge management (CIKM '93), New York, NY, USA, 67-74. ACM.

Terra, E.; Clarke, C. L. A. (2003). Frequency estimates for statistical word similarity measures, in Proceedings of the 2003 Conference of the North American Chapter of the Association for Computational Linguistics on Human Language Technology, Morristown, NJ, USA, pp. 165172. Association for Computational Linguistics.

Travanca, T. (2013). Verb Sense Disambiguation. Dissertação de Mestrado, Instituto Técnico Superior, Universidade Técnica de Lisboa, Lisboa, Portugal.

Turney, P. (2001), Mining the Web for Synonyms: PMI-IR versus LSA on TOEFL, in Proceedings of the 12th European Conference on Machine Learning, Londres, Reino Unido, pp. 491-502. Springer-Verlag.

Turney, P. (2004). Word sense disambiguation by web mining for word co-occurrence probabilities, in Senseval-3: Third International Workshop on the Evaluation of Systems for the Semantic Analysis of Text, Barcelona, Espanha, pp. 239-242. Association for Computational Linguistics

Turney, V.; Gantz, J.; Reinsel, D.; Minton, S. (2014). The Digital Universe of Opportunities: Rich Data and the Increasing Value of the Internet of Things. International Data Corporation. 
Veronis, J.; Ide, N. (1990). Word sense disambiguation with very large neural networks extracted from machine readable dictionaries, in Proceedings of COLING-90, Helsinki, Finland, pp. 389394. Association for Computational Linguistics.

Wilks, Y.; Fass, D.; Guo, C.; McDonald, J. E.; Plate, T.; Slator, B. M. (1988). Machine tractable dictionaries as tools and resources for natural language processing, in Proceedings of the 12th conference on Computational linguistics, Budapest, Hungary, pp. 750-755. Association for Computational Linguistics.

Wu Z.; M. Palmer. (1994). Verb semantics and lexical selection, in Proceedings of the 32nd Annual Meeting of the Association for Computational Linguistics, Las Cruces, New Mexico, pp. 133-138. Association for Computational Linguistics.

XTAG Research Group. (2001). A lexicalized tree adjoining grammar for english. Technical Report IRCS-01-03, IRCS, University of Pennsylvania.

Yarowsky, D. (1995). Unsupervised word sense disambiguation rivaling supervised methods, in Proceedings of the 33rd Annual Meeting on Association for Computational Linguistics, Stroudsburg, PA, USA, pp. 189-196. Association for Computational Linguistics.

Yi, S.; Palmer, M. (2004). Pushing the boundaries of Semantic Role Labeling with SVM, in Proceedings of the 3rd International Conference on Natural Language Processing, Hyderabad, India. 